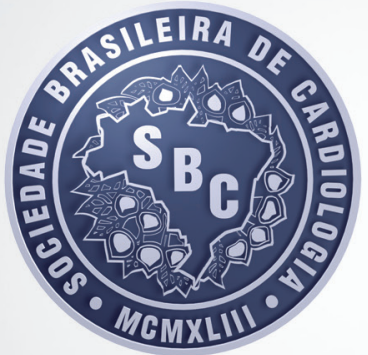

www.cardiol.br

Arquivos Brasileiros de

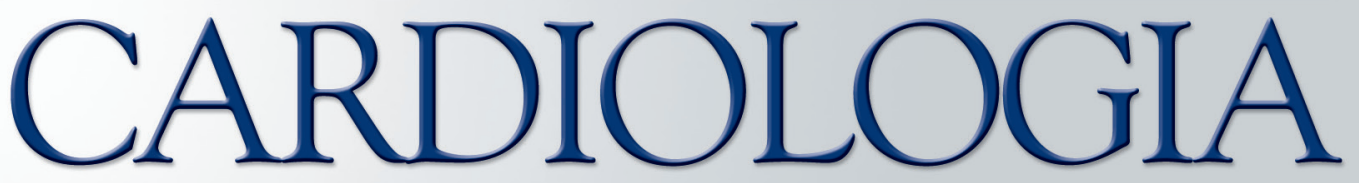

SOCIEDADE BRASILEIRA DE CARDIOLOGIA ISSN-0066-782X Volume 97, № 5, Supl.1, Novembro 2011

\title{
DIRETRIZ BRASILEIRA DE VALVOPATIAS - SBC 2011 I DIRETRIZ INTERAMERICANA DE VALVOPATIAS - SIAC 2011
}




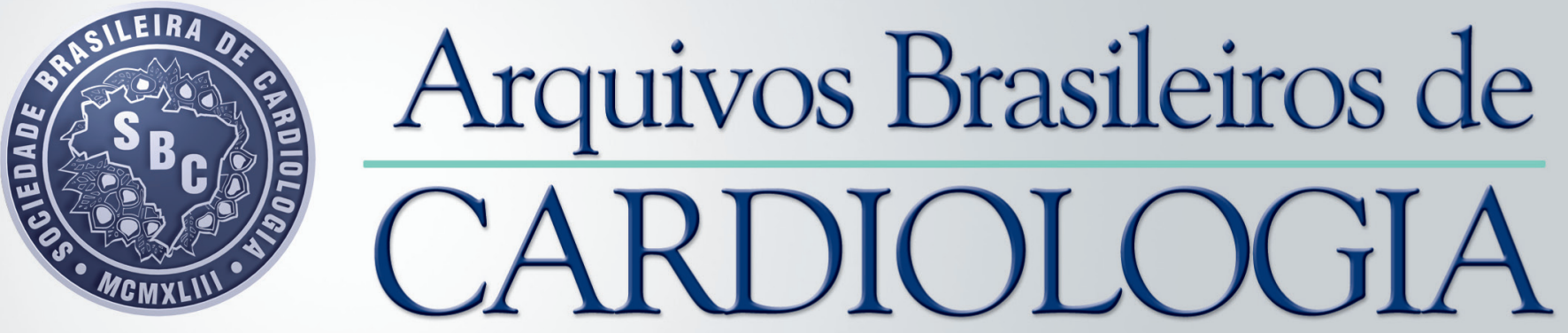

\section{DIRETRIZ BRASILEIRA DE VALVOPATIAS - SBC 2011 I DIRETRIZ INTERAMERICANA DE VALVOPATIAS - SIAC 2011}

\section{Esta diretriz deverá ser citada como:}

Tarasoutchi F, Montera MW, Grinberg M, Barbosa MR, Piñeiro DJ, Sánchez CRM, Barbosa MM et al. Diretriz Brasileira de Valvopatias - SBC 2011 / I Diretriz Interamericana de Valvopatias - SIAC 2011. Arq Bras Cardiol 2011; 97(5 supl. 1): 1-67 



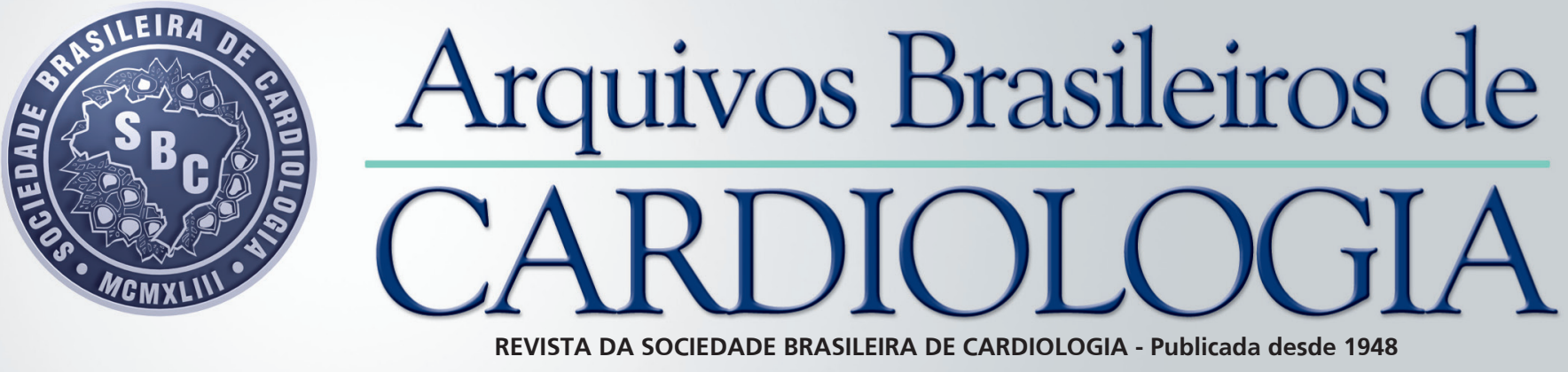

Diretor de Comunicação Miguel Antônio Moretti

Editor-Chefe

Luiz Felipe P. Moreira

Editores Associados

Cardiologia Clínica

José Augusto Barreto-Filho

Cardiologia Cirúrgica

Paulo Roberto B. Evora
Cardiologia Intervencionista

Pedro A. Lemos

Cardiologia Pediátrica/Congênitas

Antonio Augusto Lopes

Arritmias/Marcapasso

Mauricio Scanavacca

Métodos Diagnósticos Não-Invasivos

Carlos E. Rochitte

Pesquisa Básica ou Experimental

Leonardo A. M. Zornoff
Epidemiologia/Estatística

Lucia Campos Pellanda

Hipertensão Arterial

Paulo Cesar B. V. Jardim

Ergometria, Exercício e

Reabilitação Cardíaca

Dr. Ricardo Stein

Primeiro Editor (1948-1953)

† Jairo Ramos

\section{CONSELHO EDITORIAL}

\section{Brasil}

Adib D. Jatene (SP)

Alexandre A. C. Abizaid (SP)

Alfredo José Mansur (SP)

Álvaro Avezum (SP)

Amanda G. M. R. Sousa (SP)

André Labrunie (PR)

Andrei Sposito (DF)

Angelo A. V. de Paola (SP)

Antonio Augusto Barbosa Lopes (SP)

Antonio Carlos C. Carvalho (SP)

Antônio Carlos Palandri Chagas (SP)

Antonio Carlos Pereira Barretto (SP)

Antonio Cláudio L. Nóbrega (RJ)

Antonio de Padua Mansur (SP)

Ari Timerman (SP)

Armênio Costa Guimarães (BA)

Ayrton Klier Péres (DF)

Ayrton Pires Brandão (RJ)

Barbara M. lanni (SP)

Beatriz Matsubara (SP)

Braulio Luna Filho (SP)

Brivaldo Markman Filho (PE)

Bruce B. Duncan (RS)

Bruno Caramelli (SP)

Carisi A. Polanczyk (RS)

Carlos Alberto Pastore (SP)

Carlos Eduardo Negrão (SP)

Carlos Eduardo Rochitte (SP)

Carlos Eduardo Suaide Silva (SP)

Carlos Vicente Serrano Júnior (SP)

Celso Amodeo (SP)

Charles Mady (SP)

Claudio Gil Soares de Araujo (RJ)

Cleonice Carvalho C. Mota (MG)

Dalton Valentim Vassallo (ES)

Décio Mion Jr (SP)

Denilson Campos de Albuquerque (RJ)

Dikran Armaganijan (SP)

Djair Brindeiro Filho (PE)

Domingo M. Braile (SP)

Edmar Atik (SP)

Edson Stefanini (SP)

Elias Knobel (SP)

Eliudem Galvão Lima (ES)

Emilio Hideyuki Moriguchi (RS)

Enio Buffolo (SP)
Eulógio E. Martinez Fo (SP)

Evandro Tinoco Mesquita (RJ)

Expedito E. Ribeiro da Silva (SP)

Fábio Sândoli de Brito Jr. (SP)

Fábio Vilas-Boas (BA)

Fernando A. P. Morcerf (RJ)

Fernando Bacal (SP)

Flávio D. Fuchs (RS)

Francisco Antonio Helfenstein Fonseca (SP)

Francisco Laurindo (SP)

Francisco Manes Albanesi Fo (RJ)

Gilmar Reis (MG)

Gilson Soares Feitosa (BA)

Ínes Lessa (BA)

Iran Castro (RS)

Ivan G. Maia (RJ)

Ivo Nesralla (RS)

Jarbas Jakson Dinkhuysen (SP)

João Pimenta (SP)

Jorge Ilha Guimarães (RS

Jorge Pinto Ribeiro (RS)

José A. Marin-Neto (SP)

José Antonio Franchini Ramires (SP)

José Augusto Soares Barreto Filho (SE)

José Carlos Nicolau (SP)

José Geraldo de Castro Amino (RJ)

José Lázaro de Andrade (SP)

José Péricles Esteves (BA)

José Teles Mendonça (SE)

Leopoldo Soares Piegas (SP)

Luís Eduardo Rohde (RS)

Luiz A. Machado César (SP)

Luiz Alberto Piva e Mattos (SP)

Lurildo Saraiva (PE)

Marcelo C. Bertolami (SP)

Marcia Melo Barbosa (MG)

Marco Antônio Mota Gomes (AL)

Marcus V. Bolívar Malachias (MG)

Maria Cecilia Solimene (SP)

Mario S. S. de Azeredo Coutinho (SC)

Maurício I. Scanavacca (SP)

Mauricio Wajngarten (SP)

Max Grinberg (SP)

Michel Batlouni (SP)

Nabil Ghorayeb (SP)

Nadine O. Clausell (RS)

Nelson Souza e Silva (RJ)
Orlando Campos Filho (SP)

Otávio Rizzi Coelho (SP)

Otoni Moreira Gomes (MG)

Paulo A. Lotufo (SP)

Paulo Cesar B. V. Jardim (GO)

Paulo J. F. Tucci (SP)

Paulo J. Moffa (SP)

Paulo R. A. Caramori (RS)

Paulo R. F. Rossi (PR)

Paulo Roberto S. Brofman (PR)

Paulo Zielinsky (RS)

Protásio Lemos da Luz (SP)

Renato A. K. Kalil (RS)

Roberto A. Franken (SP)

Roberto Bassan (RJ)

Ronaldo da Rocha Loures Bueno (PR)

Sandra da Silva Mattos (PE)

Sergio Almeida de Oliveira (SP)

Sérgio Emanuel Kaiser (RJ)

Sergio G. Rassi (GO)

Sérgio Salles Xavier (RJ)

Sergio Timerman (SP)

Silvia H. G. Lage (SP)

Valmir Fontes (SP)

Vera D. Aiello (SP)

Walkiria S. Avila (SP)

William Azem Chalela (SP)

Wilson A. Oliveira Jr (PE)

Wilson Mathias Jr (SP)

\section{Exterior}

Adelino F. Leite-Moreira (Portugal)

Alan Maisel (Estados Unidos)

Aldo P. Maggioni (Itália)

Cândida Fonseca (Portugal)

Fausto Pinto (Portugal)

Hugo Grancelli (Argentina)

James de Lemos (Estados Unidos)

João A. Lima (Estados Unidos)

John G. F. Cleland (Inglaterra)

Maria Pilar Tornos (Espanha)

Pedro Brugada (Bélgica)

Peter A. McCullough (Estados Unidos)

Peter Libby (Estados Unidos)

Piero Anversa (Itália) 


\section{SOCIEDADE BRASILEIRA DE CARDIOLOGIA}

Presidente

Jorge Ilha Guimarães

Vice-Presidente

Márcia de Melo Barbosa

Presidente-Eleito

Jadelson Pinheiro de Andrade

Diretor Administrativo

Carlos Cleverson Lopes Pereira

Diretora Financeira

Andréa Araujo Brandão

Diretor de Relações Governamentais José Wanderley Neto

Diretor de Comunicação

Miguel Antonio Moretti

Diretor de Qualidade Assistencial

José Carlos Raimundo Brito

Diretor Científico

Ângelo Amato Vincenzo de Paola

Diretor de Promoção de Saúde

Cardiovascular - SBC/Funcor

Dikran Armaganijan

Diretor de Relações Estaduais e Regionais Reinaldo Mattos Hadlich
Diretor de Departamentos Especializados

Djair Brindeiro Filho

Diretor de Tecnologia da Informação Fernando Augusto Alves da Costa

Diretor de Pesquisa

Renato A. K. Kalil

Editor-Chefe Arquivos Brasileiros de Cardiologia

Luiz Felipe P. Moreira

Editor do Jornal SBC

Ibraim Masciarelli

Coordenador de Registros

Luiz Alberto Piva e Mattos

Coordenador de Projetos

Fábio Sândoli de Brito

Coordenador de Normatizações e

Diretrizes

Iran Castro

Coordenador de Educação Continuada Evandro Tinoco Mesquita

Planejamento Estratégico da SBC

Enio Leite Casagrande e Paulo Ernesto Leães
Presidentes das Soc. Estaduais e Regionais Ivan Romero Rivera (AL)

Marlucia do Nascimento Nobre (AM)

Lucelia Batista N. Cunha Magalhaes (BA)

José Sebastião de Abreu (CE)

Luiz Roberto Leite da Silva (DF)

Ricardo Ryoshim Kuniyoshi (ES)

Weimar Kunz Sebba Barroso de Souza (GO)

José Nicodemo Barbosa (MA)

José Maria Peixoto (MG)

Frederico Somaio Neto (MS)

Débora Andrea Castiglioni Alves (MT)

Kleber Renato Ponzi Pereira (PA)

Ana Claudia Andrade Lucena (PB)

Carlos Roberto Melo da Silva (PE)

Mauricio Batista Paes Landim (PI)

Manoel Fernandes Canesin (PR)

Roberto Esporcatte (RJ)

Itamar Ribeiro de Oliveira (RN)

Gilberto Lahorgue Nunes (RS)

Ilnei Pereira Filho (SC)

Rika Kakuda da Costa (SE)

Luiz Antonio Machado Cesar (SP)

Ibsen Suetônio Trindade (TO)

Lazaro Fernandes de Miranda (Centro-Oeste)

José Xavier de Melo Filho (Norte-Nordeste)

\section{DEPARTAMENTOS E GRUPOS DE ESTUDOS}

SBC/DA - Departamento de Aterosclerose Raul Dias dos Santos Filho

SBC/DECAGE - Departamento de Cardiogeriatria

Roberto Dischinger Miranda

SBC/DCC - Departamento de Cardiologia Clínica

Marcelo Westerlund Montera

SBC/DCM - Departamento de Cardiologia da

Mulher

Regina Coeli Marques de Carvalho

SBC/DCP - Departamento de Cardiologia

Pediátrica

leda Biscegli Jatene

SBC/DIC - Departamento de Imagem

Cardiovascular

José Luiz Barros Pena

SBC/DERC - Departamento de Ergometria e Reabilitação Cardiovascular

William Azem Chalela

SBC/DFCVR - Departamento de Fisiologia Cardiovascular Respiratória e Cardiologia

Experimental

Frederico Somaio Neto
SBC/DHA - Departamento de Hipertensão Arterial

Marcus Vinícius Bolivar Malachias

SOBRAC - Sociedade Brasileira de Arritmias Cardíacas

Guilherme Fenelon

SBCCV - Sociedade Brasileira de Cirurgia Cardiovascular

Gilberto Venossi Barbosa

SBHCI - Sociedade Brasileira de

Hemodinâmica e Cardiologia

Intervencionista

Mauricio de Rezende Barbosa

SBC/DERC/GECESP - Grupo de Estudos de Cardiologia do Esporte

Nabil Ghorayeb

SBC/DCC/GAPO - Grupo de Estudos de Avaliação Perioperatória

Bruno Caramelli

SBC/DCC/GECETI - Grupo de estudos em Coronariopatias, Emergências e Terapia Intensiva

Oscar Pereira Dutra
SBC/DCC/GEEL - Grupo de Estudo de Eletrocardiografia

Carlos Alberto Pastore

SBC/DCC/GEECABE - Grupo de Estudos de Epidemiologia e Cardiologia Baseada em Evidências

Alvaro Avezum Júnior

SBC/DEIC - Departamento de Insuficiência Cardíaca

Fernando Bacal

SBC/DCC/GEVAL - Grupo de Estudos de Valvopatia

Flávio Tarasoutchi

SBC/DCP/GECIP - Grupo de Estudos de Circulação Pulmonar

Maria Virginia Tavares Santana

SBC/DIC/GECN - Grupo de Estudos em Cardiologia Nuclear

Gabriel Leo Blacher Grossman

SBC/DCC/GERT - Grupo de Estudos de Ressonância e Tomografia Cardiovascular Paulo Roberto Schvartman 


\section{ARQUIVOS BRASILEIROS DE CARDIOLOGIA}

Volume 97, № 5, Suplemento 1, Novembro 2011

Indexação: ISI (Thomson Scientific), Cumulated Index Medicus (NLM), SCOPUS, MEDLINE, EMBASE, LILACS, SciELO, PubMed

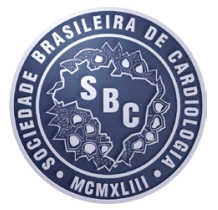

Av. Marechal Câmara, 160 - 3o andar - Sala 330

20020-907 • Centro • Rio de Janeiro, RJ • Brasil

Tel.: (21) 3478-2700

E-mail: arquivos@cardiol.br

www.arquivosonline.com.br

SCIELO: www.scielo.br

\section{Departamento Comercial}

Telefone: (11) 3411-5500

e-mail: comercialsp@cardiol.br

Produção Editorial

SBC - Núcleo Interno de Publicações
Produção Gráfica e Diagramação SBC - Núcleo Interno de Design

Impressão

Prol Editora Gráfica

Tiragem

11.000 exemplares
Os anúncios veiculados nesta edição são de exclusiva responsabilidade dos anunciantes, assim como os conceitos emitidos em artigos assinados são de exclusiva responsabilidade de seus autores, não refletindo necessariamente a opinião da SBC.
Todos os direitos reservados e protegidos pela lei 9.610 de 19/02/98. Nenhuma parte desta publicação poderá ser reproduzida sem autorização prévia por escrito dos Editores, sejam quais forem os meio empregados: eletrônico, mecânico, fotográfico, gravação ou quaisquer outros.
Material de distribuição exclusiva à classe médica. Os Arquivos Brasileiros de Cardiologia não se responsabilizam pelo acesso indevido a seu conteúdo e que contrarie a determinação em atendimento à Resolução da Diretoria Colegiada (RDC) no 96/08 da Agência Nacional de Vigilância Sanitária (Anvisa), que atualiza o regulamento técnico sobre Propaganda, Publicidade, Promoção e informação de Medicamentos. Segundo o artigo 27 da insígnia, "a propaganda ou publicidade de medicamentos de venda sob prescrição deve ser restrita, única e exclusivamente, aos profissionais de saúde habilitados a prescrever ou dispensar tais produtos (...)".

Garantindo o acesso universal, o conteúdo científico do periódico continua disponível para acesso gratuito e integral a todos os interessados no endereço: www.arquivosonline.com.br.

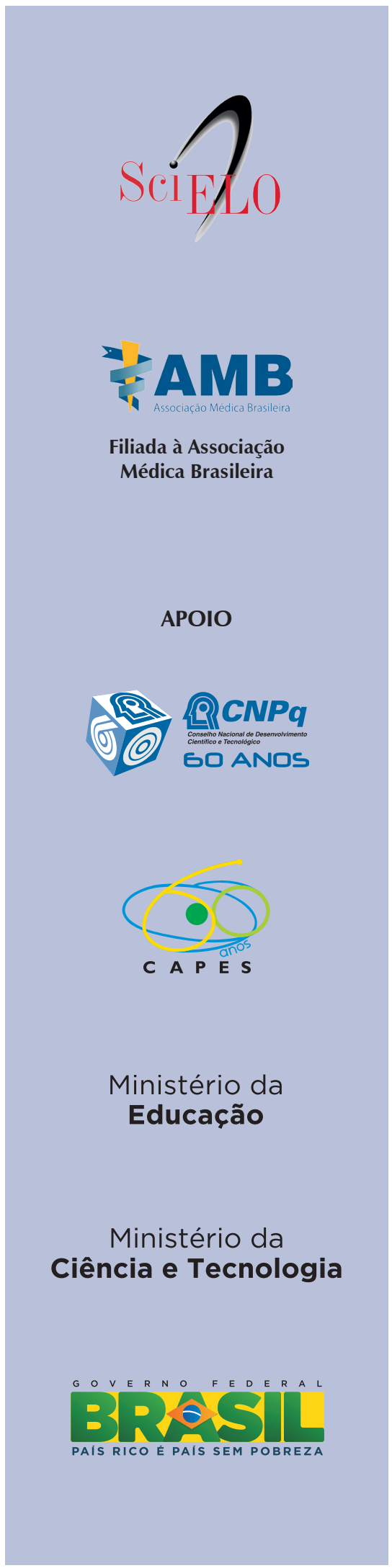




\section{SUMÁRIO}

5.1. Introdução.

6.3.2.1. Tipos de procedimentos

6.3.2.2. Indicações de tratamento cirúrgico

6.3.2.3. Insuficiência mitral isquêmica

6.3.3. Procedimentos percutâneos na insuficiência mitral

6.3.3.1. Anuloplastia

6.3.3.2. Clipe mitral página 1

6.4. Insuficiência mitral aguda 
7.2.1.1. Estenose aórtica com baixo gradiente e função ventricular reduzida.

página 18

7.2.1.2. Estenose aórtica "importante" na presença de baixo gradiente e fração de ejeção normal página 18

7.2.1.3. Ecocardiografia transesofágica na estenose aórtica página 19

7.2.1.4. Ecocardiografia 3D na valvopatia aórtica...... página 19

7.2.2. Cateterismo cardíaco na estenose aórtica página 19

7.2.2.1. Cateterismo cardíaco na estenose aórtica com baixo fluxo / baixo gradiente. página 19

7.2.3. Tomografia computadorizada página 20

7.2.4. Ressonância magnética cardiovascular página 20

7.3. Tratamento página 20

7.3.1. Tratamento farmacológico página 20

7.3.2. Tratamento cirúrgico da estenose aórtica página 21

7.3.2.1. Pacientes sintomáticos página 21

7.3.2.2. Pacientes assintomáticos. página 21

7.3.2.3. Aspectos relacionados à idade página 22

7.3.3. Tratamento percutâneo da estenose valvar aórtica: valvuloplastia por cateter-balão e implante de bioprótese por cateter .

página 23

7.3.3.1. Seleção dos pacientes para implante de bioprótese por cateter

página 24

7.3.3.2. Implante de bioprótese por cateter: procedimento e dispositivos

página 24

7.3.3.3. Resultados do implante de biopróteses aórticas por cateter.... página 25

7.3.3.4. Implante de bioprótese por cateter em pacientes com disfunção de prótese biológica

página 26

7.3.4. Valvuloplastia aórtica com cateter-balão página 26

7.3.4.1. Valvuloplastia aórtica em estenose aórtica congênita em recém-nascidos e crianças página 26

7.4. Insuficiência cardíaca aguda no paciente com estenose aórtica

página 27

\section{Insuficiência aórtica}

página 27

8.1. Introdução página 27

8.1.1. Fatores prognósticos página 27

8.2. Diagnóstico página 28

8.2.1. Ecocardiografia

8.2.2. Cateterismo cardíaco na insuficiência aórtica página 28

8.2.3. Tomografia computadorizada e ressonância magnética cardiovascular página 28

8.3. Tratamento página 29

8.3.1. Tratamento farmacológico página 29

8.3.1.1. Vasodilatadores página 29

8.3.2. Tratamento cirúrgico página 29

8.4. Situações clínicas especiais página 30

8.4.1. Ectasia anuloaórtica página 30

8.4.2. Dissecção aguda da aorta página 30

8.5. Insuficiência aórtica aguda página 30

8.5.1. Introdução. página 32

8.5.2. Tratamento página 32

8.5.2.1. Tratamento farmacológico página 32

8.5.2.2. Tratamento cirúrgico página 32

8.5.2.3. Endocardite infecciosa página 32

8.5.2.4. Dissecção aórtica página 32

8.5.2.5. Trauma página 32 página 32 


\section{Diretrizes}

9. Doenças da valva tricúspide

. página 32

9.1. Estenose tricúspide página 32

9.2. Insuficiência tricúspide página 33

10. Doenças da valva pulmonar página 34

10.1. Estenose pulmonar página 34 página 34

10.1.1. Valvuloplastia pulmonar em estenose pulmonar congênita página 35

10.2. Insuficiência pulmonar página 35

11. Próteses mecânicas e biológicas página 35

11.1. Próteses mecânicas mitrais página 36

11.2. Próteses biológicas ou biopróteses mitrais página 36

11.3. Procedimentos da valva aórtica

página 37

11.3.1. Próteses mecânicas aórticas. página 38

11.3.2. Próteses biológicas aórticas página 38 página 38 página 39

11.3.4. Próteses sem suporte (stentless) página 39

11.4. Situações clínicas especiais

página 40 página 40 página 40

11.4.2. Reoperação para substituir uma prótese valvar. página 40

12. Anticoagulação em pacientes portadores de valvopatias.

página 40 página 40

12.1.1. Varfarina página 41 página 41

12.2.1. Dose inicial e de manutenção do anticoagulante oral . página 41

12.3. Anticoagulação na doença valvar com valva nativa página 41

12.4. Anticoagulação em portadores de prótese mecânica página 42

12.5. Anticoagulação em portadores de prótese biológica página 42

12.6. Superdosagem página 43

12.7. Ponte de heparina

. página 44

13. Hipertensão pulmonar página 44

13.1. Definição. página 44

13.2. Fisiopatologia página 44 página 44 página 44 página 45 página 45

13.4. Hipertensão pulmonar nas valvopatias página 45

13.5. Cuidados no período pós-operatório 
14.1. Probabilidade de doença arterial coronariana em pacientes com valvopatias página 46

14.2. Diagnóstico da doença arterial coronariana em portadores de valvopatias página 47

14.3. Tratamento da doença arterial coronariana no momento da cirurgia valvar página 47

15. Profilaxia da febre reumática página 48

15.1. Profilaxia primária da febre reumática página 48

15.2. Profilaxia secundária. página 48

15.3. Perspectivas página 50

16. Profilaxia da endocardite infecciosa página 50

17. Profilaxia da endocardite infecciosa para procedimentos dentários página 51

18. Profilaxia da endocardite infecciosa para procedimentos no trato respiratório página 51

19. Profilaxia da endocardite infecciosa para procedimentos nos tratos genitourinário e gastrointestinal (Tabela 54). página 51

20. Acompanhamento no pós-operatório de cirurgia valvar página 53

21. Valvopatia e gravidez. página 53

21.1. Prognóstico e complicações das valvopatias na gravidez

página 53

21.1.1. Estenose mitral página 53

21.1.2. Insuficiência mitral página 54

21.1.3. Prolapso da valva mitral página 54

21.1.4. Estenose aórtica página 54

21.1.5. Insuficiência aórtica página 54

21.1.6. Lesão tricúspide página 54

21.1.7. Prótese biológica página 54

21.1.8. Prótese mecânica página 54

21.2. Manejo das complicações das valvopatias na gravidez página 54

21.2.1. Recomendações gerais página 54

21.2.2. Tratamento farmacológico página 54

21.2.2.1 Tratamento da congestão pulmonar na estenose mitral página 55

21.2.2.2. Tratamento da estenose aórtica grave página 55

21.2.2.3. Tratamento da insuficiência cardíaca na valvopatia mitral e aórtica página 55

21.2.2.4. Cirurgia cardíaca durante a gravidez página 55

21.2.2.5. Tratamento das arritmias cardíacas página 56

21.3. Prevenção do tromboembolismo página 56

21.4. Profilaxia da endocardite infecciosa durante a gravidez e o parto página 56

21.5. Assistência obstétrica página 56 


\title{
Diretriz Brasileira de Valvopatias - SBC 2011 I Diretriz Interamericana de Valvopatias - SIAC 2011
}

\author{
ReAlizaç̃o
}

Sociedade Brasileira de Cardiologia

Coordenador de Normatizações e Diretrizes da SBC

Iran Castro

\section{Coordenadores da Diretriz}

Flávio Tarasoutchi, Marcelo Westerlund Montera, Max Grinberg, Daniel J. Piñeiro, Carlos R. Martinez Sánchez

\section{Comissão de Redação e Planejamento}

Antonio Carlos Bacelar, Antonio Sérgio de Santis Andrade Lopes, João Ricardo Cordeiro Fernandes, Lucas José Tachotti Pires, Ricardo Casalino Sanches de Moraes, Tarso Augusto Duenhas Accorsi

\section{Autores}

Alexandre Siciliano Colafranceschi, Alberto Takeshi Kiyose, Alfredo Inácio Fiorelli, Antonio Carlos Bacelar, Antonio Sérgio de Santis Andrade Lopes, Auristela Isabel de Oliveira Ramos, Bertha Napchan Boer, Camilo Abdulmassih Neto, Carlos R. Martínez Sánchez** , Cesar Augusto Esteves, Clara Weksler, Daniel J. Piñeiro**, Dany David Kruczan, Eduardo Giusti Rossi, Evandro Tinoco Mesquita, Fabio Sândoli de Brito Junior, Fernando Bacal, Fernando Bosh**, Fernando Florenzano Urzua**, Fernando Moraes, Flávio Tarasoutchi*, Francisco Diniz Affonso da Costa, Gilberto Venossi Barbosa*, Guilherme Sobreira Spina, Henrique Murad, Humberto Martínez Hernández** , João Ricardo Cordeiro Fernandes, José Armando Mangione, José Carlos Raimundo Brito, José Roberto Maldonado Murillo**, Juan Carlos Plana**, Juan José Paganini**,Juan Krauss**, Lídia Ana Zytynski Moura, Lucas José Tachotti Pires, Luiz Antonio Ferreira Carvalho, Luiz Francisco Cardoso, Marcelo Katz, Marcelo Luiz Campos Vieira, Marcelo Westerlund Montera*, Márcia de Melo Barbosa*, Mauricio de Rezende Barbosa*, Max Grinberg*, Omar Alonzo Villagrán**, Pablo Maria A. Pomerantzeff, Paulo de Lara Lavitola, Ricardo Casalino Sanches de Moraes, Rogério Eduardo Gomes Sarmento Leite, Roney Orismar Sampaio, Sérgio Franco**, Silvia Marinho Martins, Solange Bordignon, Tarso Augusto Duenhas Accorsi, Tirone E. David**, Víctor Rojas Duré**, Victor Rossei **, Walkiria Samuel Ávila

\section{REVISORES}

Adalberto Menezes Lorga, Álvaro Vieira Moura, Antonio Carlos Sobral Sousa, Iran Castro

* Coordenadores de subgrupos da diretriz brasileira de valvopatias - SBC 2011

** Autores membros da SIAC

\section{Correspondência:}

Flavio Tarasoutchi - Av. Dr. Enéas de Carvalho Aguiar, 44 - InCor HCFMUSP - Andar AB - Unidade Clínica de Valvopatias CEP 05403-000. E-mail: tarasout@uol.com.br 


\section{Declaração obrigatória de conflito de interesses}

Nos últimos 3 anos, o autor/colaborador da Diretriz:

\begin{tabular}{|c|c|c|c|c|c|c|c|}
\hline Nome do médico & $\begin{array}{c}\text { Participou } \\
\text { de estudos } \\
\text { clínicos e/ou } \\
\text { experimentais } \\
\text { subvencionados } \\
\text { pela indústria } \\
\text { farmacêutica ou } \\
\text { de equipamentos } \\
\text { relacionados } \\
\text { à diretriz em } \\
\text { questão }\end{array}$ & $\begin{array}{l}\text { Foi palestrante } \\
\text { em eventos } \\
\text { ou atividades } \\
\text { patrocinadas } \\
\text { pela indústria } \\
\text { relacionados } \\
\text { à diretriz em } \\
\text { questão }\end{array}$ & $\begin{array}{l}\text { Foi (é) membro } \\
\text { do conselho } \\
\text { consultivo } \\
\text { ou diretivo } \\
\text { da indústria } \\
\text { farmacêutica } \\
\text { ou de } \\
\text { equipamentos }\end{array}$ & $\begin{array}{l}\text { Participou } \\
\text { de comitês } \\
\text { normativos } \\
\text { de estudos } \\
\text { científicos } \\
\text { patrocinados } \\
\text { pela indústria }\end{array}$ & $\begin{array}{c}\text { Recebeu } \\
\text { auxílio pessoal } \\
\text { ou institucional } \\
\text { da indústria }\end{array}$ & $\begin{array}{c}\text { Elaborou } \\
\text { textos } \\
\text { científicos em } \\
\text { periódicos } \\
\text { patrocinados } \\
\text { pela indústria }\end{array}$ & $\begin{array}{l}\text { Tem ações da } \\
\text { indústria }\end{array}$ \\
\hline Adalberto Menezes Lorga & Não & Não & Não & Não & Não & Não & Não \\
\hline Alberto Takeshi Kiyose & Não & Não & Não & Não & Não & Não & Não \\
\hline $\begin{array}{l}\text { Alexandre Siciliano } \\
\text { Colafranceschi }\end{array}$ & Não & Não & Não & Não & Não & Não & Não \\
\hline Alfredo Inácio Fiorelli & Não & Não & Não & Não & Não & Não & Não \\
\hline Alvaro Viera Moura & Não & Não & Não & Não & Não & Não & Não \\
\hline Antonio Carlos Bacelar & Não & Não & Não & Não & Não & Não & Não \\
\hline Antonio Carlos Sobral Sousa & Não & Não & Não & Não & Não & Não & Não \\
\hline $\begin{array}{l}\text { Antonio Sérgio de Santis } \\
\text { Andrade Lopes }\end{array}$ & Novartis & Não & Não & Não & Não & Não & Não \\
\hline $\begin{array}{l}\text { Auristela Isabel de Oliveira } \\
\text { Ramos }\end{array}$ & Não & Não & Não & Não & Não & Não & Não \\
\hline Bertha Paula Napchan Boer & Não & Não & Não & Não & Não & Não & Não \\
\hline Camilo Abdulmassih Neto & Não & Não & Não & Não & Não & Não & Não \\
\hline Carlos R. Martínez Sánchez & Não & Não & Não & Não & Não & Não & Não \\
\hline Cesar Augusto Esteves & Não & Não & Não & Não & Não & Não & Não \\
\hline Clara Weksler & Não & Não & Não & Não & Não & Não & Não \\
\hline Daniel J. Piñeiro & Não & Não & Não & Não & Não & Não & Não \\
\hline Dany David Kruczan & Não & Não & Não & Não & Não & Não & Não \\
\hline Eduardo Giusti Rossi & Não & Não & Não & Não & Não & Não & Não \\
\hline Evandro Tinoco Mesquita & Não & Não & Não & Não & Não & Não & Não \\
\hline Fabio Sândoli de Brito Junior & Não & Medtronic & Não & Não & Não & Não & Não \\
\hline Fernando Bacal & Não & Não & Não & Não & Novartis & Não & Não \\
\hline Fernando Bosch & Ample Medical & Não & Não & Não & Não & Não & Não \\
\hline Fernando Florenzano Urzua & Não & Não & Não & Não & Não & Não & Não \\
\hline Fernando Moraes & Não & Não & Não & Não & Não & Não & Não \\
\hline Flávio Tarasoutchi & Não & Não & Não & Não & $\begin{array}{l}\text { Boehring } \\
\text { Ingelheim }\end{array}$ & $\begin{array}{l}\text { Boehring } \\
\text { Ingelheim }\end{array}$ & Não \\
\hline $\begin{array}{c}\text { Francisco Diniz Affonso da } \\
\text { Costa } \\
\end{array}$ & Não & Tissue Regenix & Tissue Regenix & Não & Não & Não & Não \\
\hline Gilberto Venossi Barbosa & Não & Não & Não & Não & Não & Não & Não \\
\hline Guilherme Sobreira Spina & Não & Não & Não & Não & Não & Não & Não \\
\hline Henrique Murad & Não & Não & Não & Não & Não & Não & Não \\
\hline $\begin{array}{l}\text { Humberto Martínez } \\
\text { Hernández }\end{array}$ & Não & Não & Não & Não & Não & Não & Não \\
\hline
\end{tabular}




\begin{tabular}{|c|c|c|c|c|c|c|c|}
\hline Nome do médico & $\begin{array}{c}\text { Participou } \\
\text { de estudos } \\
\text { clínicos e/ou } \\
\text { experimentais } \\
\text { subvencionados } \\
\text { pela indústria } \\
\text { farmacêutica ou } \\
\text { de equipamentos } \\
\text { relacionados } \\
\text { à diretriz em } \\
\text { questão }\end{array}$ & $\begin{array}{l}\text { Foi palestrante } \\
\text { em eventos } \\
\text { ou atividades } \\
\text { patrocinadas } \\
\text { pela indústria } \\
\text { relacionados } \\
\text { à diretriz em } \\
\text { questão }\end{array}$ & $\begin{array}{l}\text { Foi (é) membro } \\
\text { do conselho } \\
\text { consultivo } \\
\text { ou diretivo } \\
\text { da indústria } \\
\text { farmacêutica } \\
\text { ou de } \\
\text { equipamentos }\end{array}$ & $\begin{array}{l}\text { Participou } \\
\text { de comitês } \\
\text { normativos } \\
\text { de estudos } \\
\text { científicos } \\
\text { patrocinados } \\
\text { pela indústria }\end{array}$ & $\begin{array}{c}\text { Recebeu } \\
\text { auxílio pessoal } \\
\text { ou institucional } \\
\text { da indústria }\end{array}$ & $\begin{array}{c}\text { Elaborou } \\
\text { textos } \\
\text { científicos em } \\
\text { periódicos } \\
\text { patrocinados } \\
\text { pela indústria }\end{array}$ & $\begin{array}{l}\text { Tem ações da } \\
\text { indústria }\end{array}$ \\
\hline Iran Castro & Não & Não & Não & Não & Não & Não & Não \\
\hline $\begin{array}{l}\text { João Ricardo Cordeiro } \\
\text { Fernandes }\end{array}$ & Não & Não & Não & Não & Não & Não & Não \\
\hline José Armando Mangione & Não & Não & Não & Não & Não & Não & Não \\
\hline José Carlos Raimundo Brito & Não & Não & Não & Não & Não & Não & Não \\
\hline $\begin{array}{l}\text { José Roberto Maldonado } \\
\text { Murillo }\end{array}$ & Não & Não & Não & Não & Não & Não & Não \\
\hline Juan Carlos Plana & Não & Não & Não & Não & General Eletric & Não & Não \\
\hline Juan José Paganini & Não & Não & Não & Não & Não & Não & Não \\
\hline Juan Krauss & Não & Não & Não & Não & Não & Não & Não \\
\hline Lídia Ana Zytynski Moura & Não & Não & Não & Não & Não & Não & Não \\
\hline Lucas José Tachotti Pires & Não & Não & Não & Não & Não & Não & Não \\
\hline $\begin{array}{l}\text { Luiz Antonio Ferreira } \\
\text { Carvalho }\end{array}$ & Não & Medtronic & Não & Não & Não & Não & Não \\
\hline Luiz Francisco Cardoso & Não & Não & Não & Não & Não & Não & Não \\
\hline Marcelo Katz & Não & Não & Não & Não & Não & Não & Não \\
\hline Marcelo Luiz Campos Vieira & Não & Não & Não & Não & Não & Não & Não \\
\hline Marcelo Westerlund Montera & Não & Não & Não & Não & $\begin{array}{l}\text { Servier, Merck e } \\
\text { Abbott }\end{array}$ & Não & Não \\
\hline Márcia de Melo Barbosa & Não & Não & Não & Não & Não & Não & Não \\
\hline Mauricio de Rezende Barbosa & Não & Não & Não & Não & Não & Não & Não \\
\hline Max Grinberg & Não & Não & Não & Não & Não & Não & Não \\
\hline Omar Alonzo Villagrán & Não & Não & Não & Não & Não & Não & Não \\
\hline $\begin{array}{l}\text { Pablo Maria A. } \\
\text { Pomerantzeff }\end{array}$ & Não & Não & Não & Não & Não & Não & Não \\
\hline Paulo de Lara Lavitola & Não & Não & Não & Não & Não & Não & Não \\
\hline $\begin{array}{c}\text { Ricardo Casalino Sanches } \\
\text { de Moraes }\end{array}$ & Não & Não & Não & Não & Não & Não & Não \\
\hline $\begin{array}{l}\text { Rogério Eduardo Gomes } \\
\text { Sarmento Leite }\end{array}$ & Não & Medtronic & Não & Não & Não & Não & Não \\
\hline Roney Orismar Sampaio & $\begin{array}{l}\text { Daiichi Sankyo e } \\
\text { Novartis }\end{array}$ & Roche & Não & Não & $\begin{array}{l}\text { Daiichi Sankyo, } \\
\text { Novartis e Roche }\end{array}$ & Não & Não \\
\hline Sérgio Franco & Não & Não & Não & Não & $\begin{array}{l}\text { ST Jude Medical } \\
\text { e Medtronic }\end{array}$ & Não & Não \\
\hline Silvia Marinho Martins & Novartis, Amgen & Sanofi & Não & Não & Não & Não & Não \\
\hline Solange Bordignon & Não & Não & Não & Não & Não & Não & Não \\
\hline $\begin{array}{c}\text { Tarso Augusto Duenhas } \\
\text { Accorsi }\end{array}$ & Não & Não & Não & Não & Não & Não & Não \\
\hline Tirone E. David & Não & Não & Não & Não & Não & Não & Não \\
\hline Víctor Rojas Duré & Não & Não & Não & Não & Não & Não & Não \\
\hline Victor Rossel & Não & Não & Não & Não & Não & Não & Não \\
\hline Walkiria Samuel Ávila & Não & Não & Não & Não & Não & Não & Não \\
\hline
\end{tabular}




\section{Objetivo da diretriz}

A América Latina forma um continente multicultural e etnicamente diversificado, com múltiplas disparidades regionais. Por exemplo, no Brasil, o país evolui com melhores índices sociais, maior urbanização e envelhecimento progressivo da população, porém apresenta Índice de Desenvolvimento Humano (IDH) médio de 0,699, mortalidade infantil média de 19,3/mil nascidos vivos e expectativa de vida de 72,4 anos, o que o classifica no ranking mundial, respectivamente, na $73^{\underline{a}}$, $106^{\underline{a}}$ e $92^{\underline{a}}$ posições ${ }^{1-3}$. Esses dados evidenciam a pouca estrutura que o país oferece para o suporte de vida da maioria dos seus habitantes, situação também encontrada nos demais países latino-americanos. No Brasil, existem áreas com IDH de até 0,824 , comparáveis a países desenvolvidos- Essas características alteram o perfil das doenças cardiovasculares ao longo do país, com destaque para as valvopatias. Tais contrastes sociais fazem que poucos países experimentem a realidade brasileira e latino-americana: manutenção da sequela valvar reumatismal incidindo em jovens, incremento progressivo de valvopatias degenerativas nos mais idosos e falta de recursos elementares ao lado de ilhas de excelência em saúde. Apesar da melhora do poder aquisitivo, cerca de três quartos da população ainda dependem exclusivamente do Sistema Único de Saúde (SUS- )ํㅗ com previsão de dificuldades para suprir a demanda dos portadores de doença valvar. É imperiosa a necessidade de correto diagnóstico e acompanhamento, uso adequado de recursos e tratamento intervencionista no momento certo da história natural da valvopatia, para que se tenha uma menor morbimortalidade associada a essa doença.

São poucos os trabalhos randomizados, controlados e com grande número de pacientes para guiar de forma definitiva o tratamento da doença valvar. A maioria das evidências das diretrizes internacionais é de nível C, ou seja, embasada em trabalhos de menor impacto e/ou na opinião de especialistas daqueles países. Há divergência para diagnóstico e conduta das valvopatias entre as diretrizes internacionais e há baixa aplicação de muitas dessas recomendações na prática médica diária. A experiência dos múltiplos centros brasileiros na condução de pacientes portadores de valvopatias é única no cenário mundial e são várias as publicações em revistas de bom impacto. No panorama nacional destaca-se a experiência com Febre Reumática (FR), conhecimento da história natural das valvopatias, desenvolvimento de técnicas cirúrgicas e próteses, experiência com bioprótese, manejo de anticoagulação, entre outros. Além disso, vários avanços recentes relatados em múltiplas publicações, principalmente em relação ao tratamento intervencionista por cateterismo, ainda não foram contemplados em diretrizes.

Foi por essas razões que a Sociedade Brasileira de Cardiologia e a Sociedade Interamericana de Cardiologia (SIAC) empenharam-se em organizar a Diretriz Brasileira de Valvopatias - SBC 2011 / I Diretriz Interamericana de Valvopatias - SIAC 2011, com visão holística do problema e apoio de vários grupos e departamentos, contemplando as várias realidades possíveis dos países latino-americanos.
Esta Diretriz é a compilação de múltiplas evidências nacionais e internacionais e opiniões de especialistas brasileiros e latino-americanos com intuito de auxiliar médicos na tomada de decisão ante um paciente portador de valvopatia.

\section{Metodologia e evidências}

Os membros selecionados para escrever estas recomendações são médicos com reconhecida experiência na área, envolvidos no tratamento das valvopatias, atuantes em instituições reconhecidas e com grande volume de pacientes acompanhados e operados e com publicações de artigos pertinentes, em conjunto com médicos jovens que desde a graduação e a residência médica estão envolvidos com pacientes portadores de valvopatias.

Foram levados em consideração os estudos relevantes publicados até 2011, obedecendo à hierarquia da pirâmide de evidências e ao enquadramento nos graus de recomendações (Classes I, Ila, IIb, III - tabela 1) e o impacto dos níveis de evidência $(A, B, C)$.

Tabela 1 - Classificação das indicações e definição das classes

\begin{tabular}{|c|c|}
\hline Classe I & $\begin{array}{l}\text { Consenso de que o procedimento / tratamento é útil e } \\
\text { eficaz. }\end{array}$ \\
\hline Classe II & $\begin{array}{l}\text { Condições para as quais não há consenso acerca da } \\
\text { utilidade e eficácia do procedimento/tratamento. }\end{array}$ \\
\hline Classe Ila & $\begin{array}{l}\text { A opinião favorece a indicação do procedimento/ } \\
\text { tratamento. }\end{array}$ \\
\hline Classe Illb & $\begin{array}{l}\text { A opinião não favorece claramente a indicação do } \\
\text { procedimento/tratamento. }\end{array}$ \\
\hline Classe III & $\begin{array}{c}\text { Consenso de que o procedimento/tratamento não é útil e } \\
\text { em alguns casos pode gerar risco. }\end{array}$ \\
\hline
\end{tabular}

\subsection{Níveis de Evidência}

A - Dados obtidos a partir de estudos randomizados, de boa qualidade, que seguem as orientações do CONSORT (Consolidated Standards of Reporting Trials) ou meta-análises de grandes estudos randomizados que seguem as orientações do CONSORT;

B - Dados obtidos de um único ensaio clínico randomizado de boa qualidade que segue a orientação do CONSORT ou vários estudos nãorandomizados;

C - Dados obtidos de estudos que incluíram séries de casos e/ou dados de consenso e/ou opinião de especialistas.

\section{Epidemiologia}

No Brasil, a doença valvar representa uma significativa parcela das internações por doença cardiovascular. Diferentemente de países mais desenvolvidos, a FR é a principal etiologia das valvopatias no território brasileiro, responsável por até $70 \%$ dos casos. Esta informação deve ser valorizada ao aplicar dados de estudos internacionais nessa população, tendo em vista que os doentes reumáticos apresentam média etária menor, assim como imunologia e evolução exclusivas dessa doença. 


\section{Diretrizes}

Os dados brasileiros sobre FR são obtidos por meio de pesquisa feita no sistema Datasus, que se referem basicamente ao número de internações hospitalares e de intervenções valvares, subestimando o número real de casos de $F R$, uma vez que não inclui os pacientes que têm $F R$ diagnosticada ambulatorialmente e que não necessitaram de internação ${ }^{5}$. Estudos realizados na população de escolares em algumas capitais brasileiras estimaram a prevalência de cardite reumática entre 1 e 7 casos/1.000, enquanto nos Estados Unidos a prevalência está entre 0,1 e 0,4 casos/1.000 escolares ${ }^{6,7}$.

A valvopatia mitral reumática mais comum é a dupla disfunção não balanceada (insuficiência e estenose em diferentes estágios de evolução) manifestada entre a $2 \stackrel{\text { a }}{\text { e }}$ a $5^{\text {a }}$ décadas de vida. Caracteristicamente, a Insuficiência Mitral (IM) corresponde à lesão aguda, enquanto a estenose, às lesões crônicas; entretanto, é possível que pacientes apresentem graus variados de estenose e insuficiência mitral. O Prolapso da Valva Mitral (PVM), no Brasil, é a segunda causa de IM, cuja evolução é dependente da intensidade do prolapso e tem idade média de apresentação em torno de 50 anos $^{8}$.

A valvopatia aórtica tem apresentação bimodal, e nos indivíduos jovens destacam-se a etiologia reumática e a doença congênita bicúspide, enquanto nos idosos prevalece a doença aórtica senil calcífica, que está associada aos fatores de risco tradicionais para aterosclerose (dislipidemia, tabagismo e hipertensão arterial) ${ }^{9}$.

Alguns dados epidemiológicos emergentes vêm mudando a forma de apresentação de pacientes com doenças valvares. A população geriátrica, cada vez mais frequente nas unidades de internação e consultórios, apresenta índices elevados de calcificação e disfunção valvar. Em geral, os idosos realizam poucas atividades físicas ou são sedentários, sendo comuns achados sugestivos de lesões valvares importantes em indivíduos assintomáticos ou oligossintomáticos, frequentemente com Estenose Aórtica (EAo). Atualmente, há aumento de pacientes portadores de miocardiopatias (isquêmica, hipertensiva, alcoólica, por drogas etc.) nos quais há IM secundária, mas não menos importante. Também há aumento de pacientes portadores de valvopatias com comorbidades graves, com limitação para avaliação e indicação de tratamento intervencionista, como os portadores de neoplasia em radioterapia e/ou quimioterapia, entre outros.

Nessa última década ocorreu um incremento de novos procedimentos executados com auxílio de técnicas videoassistidas e do uso da robótica, através de pequenas incisões de acesso no tórax e no coração, conhecidos como procedimentos minimamente invasivos, e muito embora já existam relatos de séries de casos com milhares de pacientes operados com resultados animadores, manda a cautela que seja aguardada a avaliação de sua eficácia e a manutenção dos bons resultados em longo prazo em estudos em andamento.

A Endocardite Infecciosa (EI) incide cada vez mais em indivíduos idosos e hospitalizados, frequentemente associada a próteses, cateteres, fios de marca-passo e outros dispositivos invasivos, com maior participação de estafilococos e outros germes agressivos (bacilos gram negativos). Grande parte da população brasileira, contudo, apresenta má saúde bucal e baixo acesso a tratamento odontológico, com manutenção de alta incidência de endocardite estreptocócica em valva nativa e próteses.

O manejo clínico da valvopatia continua dependente da escolha ideal para o momento do tratamento intervencionista, uma vez que esse constitui a única opção capaz de alterar a evolução natural da doença valvar. As medicações são utilizadas para tratar comorbidades e aliviar sintomas; além disso, medidas profiláticas são eficazes na prevenção da endocardite e surtos de atividade reumática. A história e o exame clínico continuam servindo como divisor de águas na tomada de decisão na doença valvar.

Para o tratamento do portador de valvopatias, é fundamental reflexão sobre três fundamentos para condução à terapêutica: capacidade médica, evidências da ciência e relação médico-paciente. Após análise do benefício conceitual pelo conhecimento científico, deve-se analisar a segurança para o paciente e respeitar a sua autonomia, ponderar sobre a autonomia da equipe de saúde e instituição e, por fim, evitar negligência e imprudência. Essa estratégia foi denominada RESOLVA (Roteiro para Resolução de Valvopatia), elaborada por Grinberg e cols. e já aprovada para publicação.

\section{Tabela 2 - Recomendações para o diagnóstico das valvopatias}

\begin{tabular}{lcc}
\hline $\begin{array}{l}\text { Classe de } \\
\text { recomendação }\end{array}$ & Indicação & $\begin{array}{c}\text { Nível de } \\
\text { evidência }\end{array}$ \\
\hline Classe I & $\begin{array}{c}\text { Exame físico direcionado ao } \\
\text { diagnóstico de valvopatia em todos os } \\
\text { pacientes com insuficiência cardiaca } \\
\text { ou suspeita clínica de valvopatia ou } \\
\text { cardiopatia estrutural. }\end{array}$ & C \\
\hline Classe I & $\begin{array}{c}\text { Eletrocardiograma em todos os } \\
\text { pacientes com suspeita clínica de } \\
\text { valvopatia. }\end{array}$ & C \\
\hline Classe I & $\begin{array}{c}\text { Radiografia de tórax em todos os } \\
\text { pacientes com suspeita clínica de } \\
\text { valvopatia. }\end{array}$ & C \\
\hline Classe I & $\begin{array}{c}\text { Ecocardiografia em pacientes } \\
\text { assintomáticos com sopros indicativos } \\
\text { de alta probabilidade de doença } \\
\text { cardíaca. }\end{array}$ & C \\
\hline
\end{tabular}

\section{Diagnóstico das valvopatias}

Um preciso diagnóstico anatômico e funcional é fundamental para o correto manejo das valvopatias ${ }^{10}$. O ponto de partida é a realização de anamnese e exame físico completos, com destaque para a ausculta cardíaca. 
O exame físico permite uma avaliação confiável, com alta especificidade para o diagnóstico das valvopatias, e o conhecimento prévio de dados da história pode guiar melhor o médico durante a realização do exame físico ${ }^{11,12}$. As múltiplas opções de métodos complementares de investigação não substituem e nem tornaram obsoleta a propedêutica cardiovascular. Não há exame complementar com sensibilidade e especificidade máximas para o diagnóstico anatômico, etiológico e funcional das valvopatias, fazendo que a impressão clínica inicial seja imprescindível para definição e interpretação da avaliação subsidiária, até mesmo maximizando a relação custo-benefício da saúde ${ }^{13}$. Destaca-se também a frequente dissociação entre achados clínicos e de exames complementares, e a progressão da avaliação complementar - principalmente com exames invasivos - só deve ser feita após alta suspeita clínica de valvopatia $^{14}$. Aliás, sempre que possível, o profissional que vai executar o exame complementar deve também conhecer bem a anamnese e o exame físico, facilitando assim a compreensão e a correlação com os dados encontrados. Na Tabela 2, encontram-se as principais recomendações para o correto diagnóstico das valvopatias.

Palpitações são queixas frequentes dos portadores de valvopatia mitral, enquanto dor torácica anginosa ao esforço e síncope ao esforço são mais frequentes em pacientes com valvopatia aórtica. Rouquidão (síndrome de Ortner) pode ser manifestação de $\mathrm{EM}^{16}$. Todas as valvopatias podem evoluir com sintomas de Insuficiência Cardíaca (IC) como dispneia aos esforços, ortopneia, dispneia paroxística noturna, tosse, chiado, hemoptise, edema periférico e fadiga $^{16}$. A anamnese deve avaliar sintomas no passado e no presente, resposta a medicações, além da presença de comorbidades e se houve profilaxia para surto reumático e endocardite infecciosa. É fundamental procurar dados que indiquem se o paciente apresenta limitação de provável causa cardíaca para as atividades habituais. Nesse aspecto, o desafio é maior em pacientes idosos e com comorbidades. A presença de sintomas, especialmente dispneia aos esforços, é o principal indicador de tratamento intervencionista de uma valvopatia anatomicamente importante. Portanto, todo paciente com síndrome de intolerância ao esforço e síndrome de retenção hídrica deve ser considerado como potencial portador de valvopatia ${ }^{17,18}$.

O exame físico segue a anamnese e é importante mesmo em assintomáticos, permitindo avaliar a presença e estimar a gravidade da valvopatia, o que terá implicações prognósticas e terapêuticas ${ }^{19}$.

Antes da ausculta cardíaca, o exame físico geral pode fazer suspeitar da presença e repercussão das valvopatias. A facies mitralis ${ }^{16}$ é caracterizada pela hiperemia crônica dos maxilares, com ou sem teleangiectasias, justificada pela hipertensão venosa cefálica, geralmente consequente à EM moderada a importante. Estase jugular, hepatomegalia, esplenomegalia, ascite, edema sacral e edema de membros inferiores são marcadores de IC direita habitualmente por Hipertensão Pulmonar (HP) secundária à valvopatia mitral importante (mais frequentemente com estenose), apesar de ocorrer em qualquer valvopatia em estado avançado de evolução. O aumento da onda "a" do pulso venoso jugular (idealmente avaliado na jugular interna) pode ser por Estenose Tricúspide (ET) ou HP grave, enquanto o aumento da onda " $v$ " é manifestação de insuficiência Tricúspide Importante (IT). Cianose de extremidades não é comum, porém pode ocorrer em baixo débito consequente a valvopatia importante (especialmente aórtica). Pectus excavatum aumenta a probabilidade de PVM. A presença de sinais compatíveis com síndrome de Marfan deve ser pesquisada, tendo em vista maior prevalência de prolapso com IM e aneurisma de aorta torácica com Insuficiência Aórtica (IAo) nesses pacientes ${ }^{20}$.

O ictus cordis não se altera de forma significativa na EM, porém pode ser desviado para a esquerda permanecendo no quarto espaço intercostal - quando há disfunção do ventrículo direito. A EAo pode repercutir com ictus sustentado (muscular) com fases inicial e final mais demoradas, além de aumento da área de palpação (maior número de polpas digitais). As lesões regurgitativas importantes, especialmente IAo, cursam com ictus hiperdinâmico, com início e fim rápidos, habitualmente desviados para baixo e para a esquerda, com aumento da amplitude palpada. O pulso com ascenso lento e baixa amplitude, chamado parvus et tardus, é característico de EAo importante, porém nem sempre presente nos idosos. O pulso com ascenso rápido e alta amplitude, conhecido como martelo d'água ou Corrigan (palpado na carótida), é habitual manifestação da IAo importante, assim como a maior divergência entre os valores da pressão sistólica e diastólica, isto é, aumento da pressão de pulso (com pressão diastólica baixa). Múltiplos sinais propedêuticos são causados pelo alto volume sistólico ejetado na IAo importante, por exemplo: movimentação frontal da cabeça (de Musset), expansão da íris (Becker), pulsação carotídea ampla (dança das artérias), impulsões da úvula (Müller), pulso capilar ungueal (Quincke), impulsão do fígado (Rosenback), impulsão do baço (Gerhard), sopro nas artérias femorais (Traube), intensificação do sopro femoral com compressão da artéria (Duroziez), queda de $15 \mathrm{mmHg}$ da pressão diastólica com elevação do braço (Mayne) e diferença da pressão sistólica poplítea e braquial maior que $60 \mathrm{mmHg}$ (Hill). A palpação de pulso com frequência persistentemente irregular aumenta a probabilidade de Fibrilação Atrial (FA) ou outra taquicardia atrial - mais frequentes em valvopatia mitral -, podendo cursar com dissociação da frequência percebida pelo pulso e da frequência cardíaca auscultada no tórax. A análise do pulso carotídeo ou femoral permite melhor percepção da amplitude e frequência ${ }^{20,21}$.

Há aparecimento de sopro cardíaco por uma ou mais das situações a seguir: aumento do fluxo sanguíneo em valvas normais ou anormais; obstrução ao fluxo anterógrado - lesões estenóticas; fluxo regurgitante por valvas incompetentes - insuficiências valvares ${ }^{21,22}$. Os sopros podem representar estados de alto fluxo, sem relevância fisiopatológica, ou serem consequentes a valvopatias e doenças congênitas. Portanto, é fundamental associar achados auscultatórios com dados da anamnese e informações obtidas pelo exame físico geral. Sopros têm grande valor quando se alteram em avaliações sequenciais, 
seja em valva nativa, seja em prótese, representando piora anatômica ${ }^{19}$. A percepção tátil do sopro (frêmito), apesar de pouco comum, é muito específica de valvopatia importante.

É importante uma caracterização adequada do sopro para que se infira de forma fidedigna qual é a valvopatia subjacente. Todo sopro deve ser avaliado quanto a cronologia (sistólico ou diastólico), foco da ausculta (local mais audível), frequência (alta, melhor audível com o diafragma do estetoscópio, ou baixa, melhor audível com a campânula), configuração (platô, diamante, decrescendo, decrescendo-crescendo), duração (proto, meso, telessistólico ou diastólico), timbre (característica do som) e irradiação. Em geral, quanto maior a intensidade do sopro, maior a gravidade anatômica da valvopatia. Classifica-se a intensidade de 1 a 6: 1 - audível somente com manobras; 2 - facilmente audível, porém sem irradiação significativa; 3 - moderadamente alto e com irradiação ampla; 4 - alto e com frêmito; 5 - ausculta possível com parte do estetoscópio sobre a pele; 6 - ausculta com estetoscópio próximo à pele, sem contato. A ausculta deve ser realizada concomitantemente à palpação do pulso. Os sopros auscultados na base cardíaca habitualmente irradiam para fúrcula e carótidas e são amplificados com o tórax inclinado para a frente e com pausa expiratória. Os sopros auscultados no ápice cardíaco habitualmente irradiam para axila e são amplificados com ausculta em decúbito lateral esquerdo. Os sopros de câmaras direitas são mais bem auscultados com manobra de inspiração profunda, sem fechamento da glote, idealmente com paciente na posição sentada ou em pé ${ }^{22}$.

De forma geral, existem quatro sopros principais:

- Sopro sistólico em focos da base - alta frequência, configuração em diamante, rude: caracteriza ejeção pelas valvas semilunares com obstrução, portanto EAo e Estenose Pulmonar (EP). Quanto mais tardio o pico do sopro, maior a gravidade da valvopatia. Paciente com EAo importante e calcificação da aorta pode apresentar irradiação do sopro para o foco mitral, com timbre piante (fenômeno de Gallavardin).

- Sopro diastólico em focos da base - alta frequência, configuração em decrescendo, aspirativo: resultado de regurgitação pelas valvas semilunares incompetentes, isto é, IAo e Insuficiência Pulmonar (IP). Quanto mais o sopro ocupar a diástole, maior a gravidade, sendo sopro holodiastólico marcador de regurgitação importante. Em casos de IAo importante podem ocorrer sopro mesossistólico aórtico por hiperfluxo e sopro mesodiastólico mitral por fluxo direcionado para valva mitral deixando-a semifechada durante a diástole ventricular (sopro de Austin-Flint).

- Sopro sistólico em focos do ápice - alta frequência, configuração em platô, em jato de vapor: caracteriza regurgitação pelas valvas atrioventriculares incompetentes, isto é, IM e IT. Sopros rudes e com duração mesotelessistólica representam regurgitação consequente a PVM e, com manobra de Valsalva, tornam-se holossistólicos. Sopros piantes podem ocorrer por ruptura de cordoalha ou de prótese mitral.

- Sopro diastólico em focos do ápice - baixa frequência, configuração em decrescendocrescendo se ritmo sinusal, ou apenas decrescendo se Fibrilação Atrial (FA), ruflar: resultado de obstrução pelas valvas atrioventriculares, característica da EM e ET. O sopro da estenose mitral frequentemente tem pouca intensidade e é precedido de estalido de abertura da valva (sinal patognomônico de sequela reumatismal). Quanto mais precoce o estalido e o início do sopro, mais importante a estenose ${ }^{20,21}$.

Os sopros de câmaras esquerdas são mais prevalentes, mas é frequente o achado de IT, habitualmente secundária. A diferenciação do sopro de câmara esquerda para o da valva correspondente à direita é feita pelo foco, manobras de amplificação e alterações de pulso e pressão arterial $^{20}$.

Os sopros ejetivos nas valvas semilunares podem ocorrer mesmo na presença de aparato valvar normal, sendo chamados de sopros inocentes, que caracteristicamente aparecem em crianças e adultos jovens. Hiperfluxo por essas valvas que ocorre, por exemplo, no hipertiroidismo, na gestação, na anemia, nas fístulas arteriovenosas e na ejeção em artéria dilatada também é causa de sopro ejetivo. Outros diagnósticos diferenciais para esse sopro são a estenose subvalvar e supravalvar ${ }^{11}$.

O sopro sistólico regurgitativo mitral funcional habitualmente é mesossistólico e de baixa intensidade e o da IM aguda é pouco audível, habitualmente protossistólico. IM importante pode cursar com sopro mesodiastólico mitral por hiperfluxo. O diagnóstico diferencial dos sopros regurgitantes pelas valvas atrioventriculares é o sopro da comunicação interventricular.

A análise das bulhas e de outros sons cardíacos também é importante para o diagnóstico auscultatório das valvopatias. A primeira bulha é hiperfonética na EM e habitualmente hipofonética nas outras valvopatias, quando existe calcificação ou disfunção ventricular grave. A segunda bulha é hiperfonética quando há HP, porém fica hipofonética nas valvopatias aórticas. Na EAo importante, a segunda bulha pode ser única ou apresentar desdobramento paradoxal. Clique protossistólico aórtico é marcador de valva aórtica bicúspide. Clique mesotelessistólico mitral é característico de PVM.

Apesar da complexidade e múltiplas informações necessárias para a realização de um exame físico adequado, o treinamento de estudantes e profissionais para esse fim aumenta a sensibilidade e a especificidade desse método, com reprodutibilidade intergrupos ${ }^{12}$.

De forma geral, após a avaliação clínica, Eletrocardiograma de 12 dDerivações (ECG) e radiografia de tórax completam a avaliação à beira-leito ${ }^{16}$. Em geral, apresentam bom valor preditivo negativo para afastar valvopatia com repercussão. Por sua vez, se houve pouca suspeita clínica, porém com alterações eletrocardiográficas como arritmias supraventriculares, sobrecargas atriais e ventriculares e/ou radiografia de tórax anormal com aumento do 
índice cardiotorácico, alterações da silhueta cardíaca esquerda e direita, do tronco da artéria pulmonar e da aorta, há necessidade de prosseguir investigação com ecocardiografia ${ }^{11,19}$.

A ecocardiografia domina o diagnóstico complementar das valvopatias. Pode confirmar a presença de valvopatia, avaliar gravidade e sugerir etiologia e prognóstico. É exame não invasivo, sem radiação, acessível, reprodutível e de custo relativamente baixo. Deve ser realizado em todos os pacientes com suspeita de valvopatia, exceto em assintomáticos com sopro de intensidade 1 , preferencialmente sem alterações significativas eletrocardiográficas e radiográficas ${ }^{23-25}$.

Outros métodos diagnósticos podem ser utilizados: fluoroscopia, ventriculografia com radionuclídeos, teste de 6 minutos, teste ergométrico, teste ergoespirométrico, tomografia computadorizada, ressonância magnética, cateterismo e biomarcadores ${ }^{18,19,26-29}$.

De forma geral, quando há dúvidas na real Classe Funcional (CF) do paciente apenas pela anamnese e ausência de complicadores que já indiquem tratamento intervencionista indicam-se exames como biomarcadores e provas funcionais (teste de 6 minutos, teste ergométrico, teste ergoespirométrico) para melhor definição da repercussão da valvopatia.

Quando há dúvidas em relação à Fração de Ejeção (FE) ventricular obtida pela ecocardiografia podem-se utilizar a ventriculografia por radionuclídeos e a ressonância magnética para obtenção de informação mais fidedigna. A ressonância também é um excelente método para avaliação quantitativa da regurgitação, porém menos útil para quantificação e planimetria de estenoses, além de não estar validada para a avaliação de próteses valvares, morfologia valvar, valva aórtica bicúspide, demais valvas e vegetações ${ }^{30}$.

A tomografia computadorizada pode auxiliar na compreensão de comorbidades e melhor caracterização das valvopatias, mas ainda não constitui um método que substitui os métodos tradicionais para o diagnóstico das valvopatias. Recentemente, demonstrou-se que a angiotomografia de coronárias apresenta bom valor preditivo negativo para afastar aterosclerose obstrutiva em pacientes com baixa a moderada probabilidade pré-teste de Doença Arterial Coronariana (DAC), de forma que esse exame pode ser uma alternativa ao cateterismo com cineangiocoronariografia em pacientes com esse perfil ${ }^{31}$.

Tanto a ressonância magnética quanto a tomografia computadorizada podem ser úteis para avaliação da aorta (intensidade de calcificação e grau de dilatação), auxiliando na indicação de tratamento cirúrgico do paciente ${ }^{30,31}$.

O cateterismo cardíaco diagnostica lesões estenóticas por meio da manometria de câmaras e lesões regurgitantes por meio de ventriculografia ou aortografia; é o método padrão de referência para o diagnóstico das valvopatias. No entanto, a maioria dos pacientes não necessita dessa avaliação invasiva, que é reservada a casos de discordância entre achados clínicos, eletrocardiográficos, radiográficos e ecocardiográficos ${ }^{11}$.

\section{Estenose mitral}

\subsection{Introdução}

A estenose mitral (EM) caracteriza-se pela resistência ao fluxo sanguíneo transmitral em razão do espessamento e da imobilidade dos folhetos valvares, decorrendo fundamentalmente de sequela reumática ${ }^{11}$. Dentre outras possíveis causas, destacamse a congênita, as doenças infiltrativas (mucopolissacaridoses), El, lúpus eritematoso sistêmico, artrite reumatoide e estados serotoninérgicos (síndrome carcinoide) ${ }^{11,32}$.

Os principais achados anatomopatológicos da EM consistem no espessamento dos folhetos valvares, áreas de calcificação, fusão comissural e encurtamento de cordoalhas ${ }^{33}$. Fisiopatologicamente, a obstrução ao deflúvio atrial gera um gradiente pressórico entre o átrio e o ventrículo esquerdos. A elevação da pressão atrial esquerda transmite-se de maneira retrógrada ao leito vascular pulmonar, determinando congestão passiva local, edema intersticial, HP e desenvolvimento progressivo de sintomas ${ }^{32}$.

Os principais marcadores de mau prognóstico são o desenvolvimento de sintomas, a presença de FA e a evolução para $\mathrm{HP}^{11,19}$.Uma vez atingidos níveis muito elevados de Pressão Sistólica de Artéria Pulmonar (PSAP - acima de $80 \mathrm{mmHg}$ ), a sobrevida média reduz-se para 2,4 anos ${ }^{34}$.

\subsection{Diagnóstico}

Na avaliação diagnóstica da EM, o ECGpoderá mostrar sobrecarga atrial esquerda nos casos com lesão moderada a importante. Em presença de HP, poderá haver desvio do eixo elétrico cardíaco para a direita e sinais de aumento das câmaras direitas. Nesta última situação, é frequente a presença de FA. A radiografia de tórax mostra aumento do átrio esquerdo. A dilatação da artéria pulmonar e das cavidades direitas, assim como no ECG, é indicativa de HP associada. Pode haver graus variáveis de congestão pulmonar, sendo as linhas B de Kerley particularmente visíveis nos pacientes com EM importante de longa evolução. O teste ergométrico pode ser útil na avaliação da capacidade funcional em indivíduos com poucos sintomas, porém que limitaram sua atividade física de forma significativa.

\subsubsection{Ecocardiografia}

A ecocardiografia com Doppler colorido é um exame complementar importante para o diagnóstico e avaliação da gravidade anatômica e funcional da EM. Além de possibilitar o acompanhamento de gestantes e pós-intervenção, esse método também influencia na decisão terapêutica. Comumente a via de acesso é a transtorácica - Ecocardiografia Transtorácica (ETT) -, mas há situações específicas em que é necessária a realização da Ecocardiografia Transesofágica (ETE).

O exame fornece informações fundamentais para o manuseio adequado da doença. Dentre os dados mais relevantes destacamos a área valvar mitral, aferida pela planimetria, pelo Pressure Half-Time (PHT), o gradiente diastólico transvalvar, o escore valvar de Wilkins, a PSAP, trombos atriais esquerdos e a presença de $\mathrm{IT}^{11,19}$. Utilizando os valores de área valvar e gradiente pressórico médio é possível graduar a EM em discreta, moderada e importante (tabela 3). 
Tabela 3 - Graduação da estenose mitral

\begin{tabular}{lcc}
\hline Lesão (grau) & Área $(\mathbf{c m} 2)$ & Gradiente \\
\hline Discreta & $>1,5$ & $<5$ \\
\hline Moderada & 1,0 a 1,5 & 5 a 10 \\
\hline Importante & $<1,0$ & $>10$ \\
\hline
\end{tabular}

* Gradiente médio em repouso $(\mathrm{mmHg})$

O escore de Wilkins, descrito em 1988, consiste na avaliação ecocardiográfica da valva mitral com ênfase na descrição dos aspectos estruturais ${ }^{35}$. Quatro parâmetros são considerados: mobilidade dos folhetos, espessamento valvar, grau de calcificação e acometimento do aparato subvalvar. Uma graduação de um a quatro pontos para cada item resulta num escore que pode variar de 4 a 16 pontos. Pacientes com escore de Wilkins inferior ou igual a 8 são candidatos a valvuloplastia mitral percutânea, na ausência de outras contraindicações. A tabela 4 descreve, em detalhes, os parâmetros avaliados.

A acurácia do ETE para identificação de trombos no átrio esquerdo é muito superior à do ETT, especialmente no apêndice atrial. Principalmente nos pacientes em FA, mas também naqueles em ritmo sinusal, a identificação de trombos atriais deve ser realizada pelo ETE. Nos pacientes com antecedente de fenômeno embólico ou naqueles com indicação de valvuloplastia percutânea e suspeita de trombo atrial o ETE está indicado.

As recomendações para realização de ETT e ETE encontram-se na tabela 5.

\section{Tabela 4 - Escore ecocardiográfico de Wilkins}

\section{Mobilidade dos folhetos:}

1 - Mobilidade elevada da valva com apenas restrição nas extremidades dos folhetos

2 - Regiões medial e basal apresentam mobilidade normal

3 - A valva continua se movendo adiante na diástole, principalmente na base

4 - Nenhum ou mínimo movimento dos folhetos em diástole

Acometimento subvalvar:

1 - Mínimo espessamento subvalvar exatamente abaixo dos folhetos mitrais

2 - Espessamento de cordas estendendo-se por mais de um terço do

comprimento

3 - Espessamento expandindo-se para o terço distal das cordas

4 - Espessamento extenso e encurtamento de todas as estruturas das cordas expandindo-se para os músculos papilares

Espessura dos folhetos:

1 - Espessamento dos folhetos com espessura próxima do normal (4-5mm)

2 - Camadas médias normais, espessamento considerável de margens

(5-8mm)

3 - Espessamento expandindo através de toda a camada $(5-8 \mathrm{~mm})$

4 - Espessamento considerável de toda a camada do tecido (>8-10 mm)

\section{Calcificação valvar:}

1 - Uma área única da ecoluminosidade aumentada

2 - Mínimas áreas de luminosidade confinadas às margens do folheto

3 - Luminosidade expandindo-se dentro da porção média dos folhetos

4 - Luminosidade extensa, além dos limites dos folhetos
Tabela 5 - Recomendações da ecocardiografia na estenose mitral

\begin{tabular}{lcc}
\hline $\begin{array}{c}\text { Classe de } \\
\text { recomendação }\end{array}$ & Indicação & $\begin{array}{c}\text { Nível de } \\
\text { evidência }\end{array}$ \\
\hline Classe I & $\begin{array}{c}\text { ETT no diagnóstico e avaliação da } \\
\text { morfologia e gravidade da estenose } \\
\text { mitral, possiveis alterações estruturais } \\
\text { e possiveis lesões associadas. }\end{array}$ & B \\
\hline Classe I & $\begin{array}{c}\text { ETT na reavaliação de pacientes com } \\
\text { mudanças de sinais e sintomas. }\end{array}$ & B \\
\hline
\end{tabular}

ETT para realização de escore ecocardiográfico em pacientes

Classe I com EM moderada ou importante para determinar a possibilidade de tratamento percutâneo.

ETT após intervenção percutânea ou
Clasúrgica da valva mitral, como nova
avaliação de base.

\begin{tabular}{ccc}
\hline Classe I & $\begin{array}{c}\text { ETT para avaliação das alterações } \\
\text { hemodinâmicas e adaptação } \\
\text { ventricular durante a gravidez. }\end{array}$ & C \\
\hline Classe I & $\begin{array}{c}\text { Ecocardiografia sob estresse para } \\
\text { avaliação do gradiente médio e pressão } \\
\text { arterial pulmonar quando há discrepância } \\
\text { entre os sintomas e a gravidade da } \\
\text { estenose mitral em repouso. }\end{array}$ & C \\
\hline
\end{tabular}

ETE na identificação de trombo atrial
e avaliação do grau de insuficiência
mitral associada em pacientes
$\begin{gathered}\text { candidatos a valvuloplastia percutânea } \\ \text { com suspeita de trombo atrial. }\end{gathered}$

\begin{tabular}{ccc}
\hline ETT na avaliação de pacientes & & \\
Classe Ila & $\begin{array}{c}\text { clinicamente estáveis com EM importante } \\
\text { a cada ano, EM moderada a cada dois } \\
\text { anos e EM discreta a cada três anos. }\end{array}$ & C \\
\hline Classe Ila & $\begin{array}{c}\text { ETE durante procedimento } \\
\text { intervencionista para valvuloplastia } \\
\text { percutânea. }\end{array}$ & C \\
\hline Classe III & $\begin{array}{c}\text { ETE na avaliação morfológica e } \\
\text { hemodinâmica quando os dados } \\
\text { obtidos pela ETT são satisfatórios. }\end{array}$ \\
\hline
\end{tabular}

ETT: Ecocardiografia transtorácica; ETE: Ecocardiografia transesofágica; EM: Estenose mitral

\subsubsection{Cateterismo cardíaco}

As medidas hemodinâmicas no cateterismo cardíaco podem ser utilizadas para determinar a gravidade da EM. As pressões verificadas no átrio e no ventrículo esquerdos determinam o gradiente diastólico através da valva mitral, que consiste na expressão fundamental da gravidade da $\mathrm{EM}^{36}$. Pressões 
pulmonares e resistência vascular pulmonar também podem ser aferidas, contribuindo para avaliação da repercussão da valvopatia na circulação pulmonar.

Com o advento da ecocardiografia com Doppler, em geral não há mais necessidade de cateterismo na maioria dos pacientes com EM. Frequentemente, a área valvar medida pelo gradiente mitral ao Doppler e a pressão na artéria pulmonar têm boa correlação entre si. O cateterismo está indicado quando existe discrepância entres as medidas ecocardiográficas e a situação clínica do paciente sintomático. A manometria dos átrios esquerdo e direito deve ser obtida no estudo hemodinâmico quando houver elevação desproporcional da PSAP em relação ao gradiente pressórico transvalvar e à área mitral ${ }^{11,19}$.

A ventriculografia é recomendada para os casos de dupla lesão mitral que apresentem dificuldades na determinação clínicoecocardiográfica do grau de regurgitação valvar. Caso a CF de sintomas seja desproporcional à avaliação hemodinâmica não invasiva em repouso, pode ser necessária a realização de cateterismo esquerdo e direito com esforço físico ou mediante prova de volume associada à infusão de atropina. A cineangiocoronariografia é reservada a pacientes com suspeita de DAC associada ou na presença de fatores de risco: homens com mais de 40 anos de idade, mulheres após a menopausa ou que tenham mais de um fator de risco coronariano. Em pacientes com perfil de menor risco, a cineangiocoronariografia pode ser substituída pela angiotomografia de coronárias.

A Tabela 6 sumariza as principais recomendações de cateterismo cardíaco na EM.

\section{Tabela 6 - Recomendações de cateterismo cardíaco na estenose mitral}

\begin{tabular}{lcc}
\hline $\begin{array}{l}\text { Classe de } \\
\text { recomendação }\end{array}$ & Indicação & $\begin{array}{c}\text { Nível de } \\
\text { evidência }\end{array}$ \\
\hline Classe I & $\begin{array}{c}\text { Para avaliação da gravidade da EM } \\
\text { quando os testes não invasivos são } \\
\text { inconclusivos. }\end{array}$ & C \\
\hline Classe I & $\begin{array}{c}\text { Cineangiocoronariografia antes do } \\
\text { tratamento cirúrgico da valva mitral em } \\
\text { pacientes com fatores de risco para DAC. }\end{array}$ & C \\
\hline Classe Ila & $\begin{array}{c}\text { Para avaliação da resposta } \\
\text { hemodinâmica da pressão da artéria } \\
\text { pulmonar e pressões do átrio esquerdo } \\
\text { ao teste de sobrecarga, quando os } \\
\text { sintomas e estudo hemodinâmico em } \\
\text { repouso são discordantes. }\end{array}$ & $\mathrm{C}$ \\
\hline Classe III & $\begin{array}{c}\text { Para avaliação da gravidade da EM } \\
\text { quando os dados do ecocardiograma } \\
\text { forem concordantes com os achados } \\
\text { clínicos. }\end{array}$ & $\mathrm{C}$ \\
\hline
\end{tabular}

$E M$ - Estenose mitral; DAC - Doença arterial coronariana.

\subsection{Tratamento}

\subsubsection{Tratamento farmacológico}

A terapia medicamentosa poderá apenas aliviar os sintomas, sem efeitos diretos sobre a obstrução fixa ${ }^{11}$. Nos casos de EM discreta, estando o paciente assintomático e em ritmo sinusal, não há necessidade de intervenção farmacológica específica. Nos pacientes com EM moderada a importante, poderá ser indicada enquanto o paciente aguarda procedimento intervencionista, visando à melhora dos sintomas, ou no controle de complicações (por exemplo, FA).

O uso de diuréticos (especialmente os de alça) associado à restrição hidrossalina é recomendado quando manifestações de congestão pulmonar estiverem presentes (dispneia aos esforços, ortopneia e/ou dispneia paroxística noturna) ${ }^{37}$. Nos estágios evolutivos finais da EM surgem sinais de IC direita (edema periférico, hepatomegalia, ascite), determinando hipovolemia relativa devido ao sequestro hídrico pelo terceiro espaço. Essas alterações hemodinâmicas promovem ativação do sistema renina-angiotensina-aldosterona, resultando em hiperaldosteronismo secundário. Nessas situações, os antagonistas da aldosterona, como a espironolactona, podem ser valiosos adjuvantes à terapia diurética habitual. Os sintomas de IC esquerda devem-se às altas pressões encontradas no átrio esquerdo e no leito capilar pulmonar, consequentes à obstrução mecânica ao fluxo transmitral. Como tal perturbação hemodinâmica encontra-se à montante do Ventrículo Esquerdo (VE), esse apresenta sua função contrátil íntegra. Sendo assim, o uso de digitálicos não é justificado nos pacientes com função contrátil normal e em ritmo sinusal. Entretanto, nas situações em que a EM associa-se à FA, os digitálicos representam uma alternativa complementar para controle da frequência ventricular.

O controle da Frequência Cardíaca (FC) constitui um dos pilares do tratamento clínico da EM. As taquicardias geralmente são mal toleradas, na medida em que reduzem o tempo de enchimento diastólico ventricular. Caso esse tempo seja diminuído pela metade, o gradiente pressórico transmitral irá quadruplicar, acarretando elevação da pressão venosa pulmonar. Os betabloqueadores, ao controlar a FC em repouso, são capazes de reduzir os gradientes e as pressões desenvolvidas pelo átrio esquerdo ${ }^{37,38}$.Adicionalmente, essa classe de agentes também possui a propriedade de estabilizar a FC durante a atividade física, atenuando o incremento fisiológico no gradiente pressórico mitral nessas circunstâncias ${ }^{39}$.

Eventos embólicos sistêmicos representam uma grave complicação da EM, ocorrendo em 13\% a 26\% dos pacientes e fortemente associados à idade e à presença de $\mathrm{FA}^{40}$. A anticoagulação oral plena [com INR-alvo (INR - International Normalized Ratio) entre 2,0 e 3,0] é recomendada na EM associada a evento embólico prévio, trombo atrial esquerdo ou $\mathrm{FA}^{11}$.O acréscimo de aspirina em baixas doses (50 a $100 \mathrm{mg} / \mathrm{dia}$ ) é sugerido quando houver ocorrência de evento embólico ou documentação de trombo atrial esquerdo em pacientes adequadamente anticoagulados ${ }^{41}$.

As recomendações de tratamento farmacológico na EM estão na tabela 7 . 
Tabela 7 - Recomendações para tratamento farmacológico na estenose mitral

\begin{tabular}{|c|c|c|}
\hline $\begin{array}{l}\text { Classe de } \\
\text { recomendação }\end{array}$ & Indicação & $\begin{array}{l}\text { Nível de } \\
\text { evidência }\end{array}$ \\
\hline Classe I & $\begin{array}{l}\text { Betabloqueadores na EM moderada a } \\
\text { importante, sintomática, na ausência de } \\
\text { contraindicações. }\end{array}$ & C \\
\hline Classe I & $\begin{array}{c}\text { Betabloqueadores na EM moderada a } \\
\text { importante, assintomática, na presença } \\
\text { de fibrilação atrial e na ausência de } \\
\text { contraindicações. }\end{array}$ & C \\
\hline Classe I & $\begin{array}{l}\text { Diuréticos na EM moderada a } \\
\text { importante sintomática. }\end{array}$ & C \\
\hline Classe I & $\begin{array}{c}\text { Anticoagulação oral plena na EM associada } \\
\text { a evento embólico prévio, trombo atrial } \\
\text { esquerdo ou fibrilação atrial. }\end{array}$ & B \\
\hline Classe lla & $\begin{array}{l}\text { Digitálicos como terapia adjuvante no controle } \\
\text { da frequência ventricular na EM moderada a } \\
\text { importante na presença de fibrilação atrial. }\end{array}$ & C \\
\hline Classe lla & $\begin{array}{l}\text { Bloqueadores de canais de cálcio } \\
\text { não diidropiridínicos na EM moderada } \\
\text { a importante com necessidade de } \\
\text { controle de frequência ventricular, na } \\
\text { presença de contraindicações ao uso de } \\
\text { betabloqueadores. }\end{array}$ & C \\
\hline Classe lla & $\begin{array}{l}\text { Anticoagulação oral plena na EM com } \\
\text { átrio esquerdo > 55mm e evidência de } \\
\text { contraste atrial espontâneo. }\end{array}$ & C \\
\hline Classe lla & $\begin{array}{l}\text { Associação de aspirina em baixas doses } \\
\text { (50 a 100mg) à anticoagulação oral plena } \\
\text { após ocorrência de evento embólico ou } \\
\text { trombo atrial esquerdo em pacientes } \\
\text { adequadamente anticoagulados. }\end{array}$ & C \\
\hline Classe III & $\begin{array}{l}\text { Tratamento farmacológico da } \\
\text { estenose mitral discreta em pacientes } \\
\text { assintomáticos e em ritmo sinusal. }\end{array}$ & C \\
\hline
\end{tabular}

EM - Estenose mitral.

\subsubsection{Tratamento intervencionista}

Há duas modalidades aceitas para o tratamento intervencionista da EM: a Valvuloplastia Mitral Percutânea por Cateter-Balão (VMCB) e a cirurgia (comissurotomia ou troca valvar). A escolha da melhor intervenção baseia-se em características clínicas (status funcional e preditores de risco operatório), anatomia valvar e na experiência da equipe cirúrgica (tabelas 8 e 9).

5.3.2.1. Valvuloplastia mitral percutânea por cateterBalão (VMCB)

A taxa de sucesso com esse tipo de terapia é alta, oscilando entre $80 \%$ e $95 \%$. No entanto, a obtenção desses resultados exige uma equipe de hemodinâmica treinada e experiente. São considerados parâmetros de sucesso: redução de 50\% a 60\% no gradiente transmitral, área valvar mitral final acima de $1,5 \mathrm{~cm}^{2}$ e decréscimo da pressão capilar pulmonar para níveis abaixo de $18 \mathrm{mmHg}$. Atualmente, em razão do maior treinamento dos diferentes centros de hemodinâmica, observamos menor incidência de complicações, sendo as principais os acidentes vasculares encefálicos (0,5\% a $1 \%)$, o tamponamento cardíaco $(0,7 \%$ a $1 \%)$ e a insuficiência mitral importante $(0,9 \%$ a $2 \%)$. A mortalidade é baixa, usualmente inferior a $0,5 \%{ }^{42}$.
O principal critério de elegibilidade para a VMCB é a análise morfológica da valva mitral através da ETT. A ETE, no entanto, pode apresentar vantagens adicionais, comparada à ETT, já que avalia com maior precisão a presença de trombos no átrio esquerdo e o grau de insuficiência mitral.

O paciente ideal apresenta os folhetos valvares flexíveis, não calcificados e pouco acometimento subvalvar. O critério ecocardiográfico mais utilizado na avaliação da morfologia do aparelho valvar é o escore descrito por Wilkins e cols. ${ }^{35}$, já citado anteriormente. Os pacientes ideais são aqueles que possuem escore $\leq 8$ pontos, devido aos excelentes resultados imediatos e no seguimento clínico. Escores elevados ( $\geq 12$ pontos) indicam valvas com deformidade acentuada e, nessa situação, a VMCB possui papel limitado, não sendo normalmente indicada. Aqueles que se situam entre 9 e 11 pontos necessitam avaliação individualizada, com ponderação de comorbidades e do risco cirúrgico para a escolha da melhor modalidade de tratamento ${ }^{43-46}$.

As principais contraindicações à VMCB são a existência prévia de insuficiência mitral moderada a importante, trombo atrial esquerdo, escore ecocardiográfico de Wilkins desfavorável (acima de 8 pontos), presença de outras valvopatias concomitantes que requeiram tratamento cirúrgico e DAC com indicação de revascularização cirúrgica associada ${ }^{11}$. A avaliação de trombos atriais por meio do ETE é recomendada para pacientes com histórico de FA ou eventos embólicos prévios ${ }^{47}$.

\section{Tabela 8 - Recomendações para valvuloplastia por cateter-balão na} estenose mitral

\begin{tabular}{|c|c|c|}
\hline $\begin{array}{l}\text { Classe de } \\
\text { recomendação }\end{array}$ & Indicação & $\begin{array}{c}\text { Nível de } \\
\text { evidência }\end{array}$ \\
\hline Classe I & $\begin{array}{l}\text { Pacientes com EM moderada a } \\
\text { importante, sintomáticos (CF II, III ou } \\
\text { IV), com anatomia valvar favorável, na } \\
\text { ausência de trombo atrial esquerdo ou } \\
\text { insuficiência mitral moderada a importante. }\end{array}$ & A \\
\hline Classe I & $\begin{array}{l}\text { Pacientes com EM moderada a } \\
\text { importante, assintomáticos, com anatomia } \\
\text { valvar favorável à intervenção percutânea } \\
\text { e HP (PSAP > 50mmHg em repouso } \\
\text { ou > 60mmHg com atividade física), na } \\
\text { ausência de trombo atrial esquerdo ou } \\
\text { insuficiência mitral moderada a importante. }\end{array}$ & C \\
\hline Classe Ila & $\begin{array}{c}\text { Pacientes com EM moderada a } \\
\text { importante, sintomáticos (CF III ou IV), } \\
\text { com morfologia não ideal à VMCB e } \\
\text { de alto risco ou com contraindicação à } \\
\text { intervenção cirúrgica. }\end{array}$ & C \\
\hline Classe Ilb & $\begin{array}{l}\text { Pacientes com EM moderada a } \\
\text { importante, assintomáticos, com anatomia } \\
\text { valvar favorável à intervenção percutânea } \\
\text { e fibrilação atrial de início recente, na } \\
\text { ausência de trombo atrial esquerdo ou } \\
\text { insuficiência mitral moderada a importante. }\end{array}$ & C \\
\hline Classe III & Pacientes com EM discreta. & C \\
\hline Classe III & $\begin{array}{c}\text { Pacientes com EM moderada a } \\
\text { importante na vigência de trombo } \\
\text { atrial esquerdo ou insuficiência mitral } \\
\text { moderada a importante. }\end{array}$ & C \\
\hline
\end{tabular}

EM - Estenose mitral; CF - Classe funcional; HP - Hipertensão pulmonar; PSAP Pressão sistólica da artéria pulmonar; VMCB - Valvuloplastia mitral por cateter-balão 


\subsubsection{Tratamento cirúrgico}

A utilização de procedimentos terapêuticos invasivos para correção das lesões valvares provocadas por doenças estruturais do coração é muitas vezes necessária como a única opção capaz de restaurar a função dessas valvas, propiciando o remodelamento reverso das cavidades cardíacas, a recuperação da função ventricular e a remissão dos sintomas. O restabelecimento da função valvar é realizado por técnicas reconstrutivas denominadas plástica valvar ou, na impossibilidade dessa, por meio da substituição da valva lesada por substitutos valvares (próteses mecânicas ou biológicas), ou ainda utilizando-se homoenxertos heterólogos ou enxertos autólogos.

Quanto à indicação, essa modalidade de intervenção reserva-se para pacientes sintomáticos (CF III-IV) com alguma das seguintes contraindicações à VMCB: anatomia valvar desfavorável (escore de Wilkins superior a 8 associado a calcificação e comprometimento do aparelho subvalvar); presença de dupla lesão mitral com insuficiência moderada a importante; concomitância de valvopatia tricúspide ou aórtica significativa e trombo atrial esquerdo persistente (sem resolução após tempo adequado de anticoagulação oral) ${ }^{11}$.Vários centros cardiológicos mundiais reportam bons resultados com a comissurotomia aberta. A sobrevida média em 15 anos é próxima a 96\%, com sobrevida livre de complicações valvares em torno de $92 \%{ }^{48}$. Também é possível benefício da cirurgia em pacientes com EM moderada a importante em pacientes com eventos embólicos apesar de anticoagulação adequada e naqueles com CF I a II, com HP grave, sem anatomia favorável à VMCB. Pacientes portadores de FA que irão se submeter a cirurgia valvar podem se beneficiar do tratamento cirúrgico concomitante da FA (como cirurgia de Maze ou ablação por radiofrequência).

A preservação da valva mitral por meio da comissurotomia cirúrgica, apesar de desejável, nem sempre é exequível ${ }^{11}$.A mortalidade relacionada à troca valvar oscila entre $3 \%$ e $10 \%$, sendo influenciada por idade, classe funcional, HP e presença de doença arterial coronariana concomitante ${ }^{48}$.

Tabela 9 - Recomendações para tratamento cirúrgico na estenose mitral

\begin{tabular}{|c|c|c|}
\hline $\begin{array}{l}\text { Classe de } \\
\text { recomendação }\end{array}$ & Indicação & $\begin{array}{c}\text { Nível de } \\
\text { evidência }\end{array}$ \\
\hline Classe I & $\begin{array}{l}\text { Pacientes com EM moderada a } \\
\text { importante, sintomáticos (CF III ou IV), } \\
\text { com contraindicações à VMCB. }\end{array}$ & B \\
\hline Classe I & $\begin{array}{c}\text { Pacientes com EM moderada a } \\
\text { importante, sintomáticos (CF III ou IV), } \\
\text { em centros sem equipe treinada para } \\
\text { realização de VMCB. }\end{array}$ & B \\
\hline Classe Ila & $\begin{array}{l}\text { Pacientes com EM moderada a } \\
\text { importante associada a eventos } \\
\text { embólicos recorrentes, apesar de } \\
\text { adequada anticoagulação. }\end{array}$ & C \\
\hline Classe lla & $\begin{array}{l}\text { Tratamento cirúrgico combinado da } \\
\text { fibrilação atrial em pacientes com EM } \\
\text { moderada a importante, sintomática } \\
\text { (CF III ou IV), quando indicado } \\
\text { tratamento cirúrgico da EM. }\end{array}$ & C \\
\hline Classe Ila & $\begin{array}{l}\text { Pacientes com EM importante, } \\
\text { assintomáticos (CF I ou II), com } \\
\text { HP grave (PSAP } \geq 80 \mathrm{mmHg} \text { ), não } \\
\text { candidatos à VMCB. }\end{array}$ & C \\
\hline Classe III & Pacientes com EM discreta. & C \\
\hline
\end{tabular}

O fluxograma abaixo resume as estratégias de tratamento intervencionista na EM moderada e importante.

\section{Fluxograma das estratégias de tratamento intervencionista na estenose mitral moderada e importante}

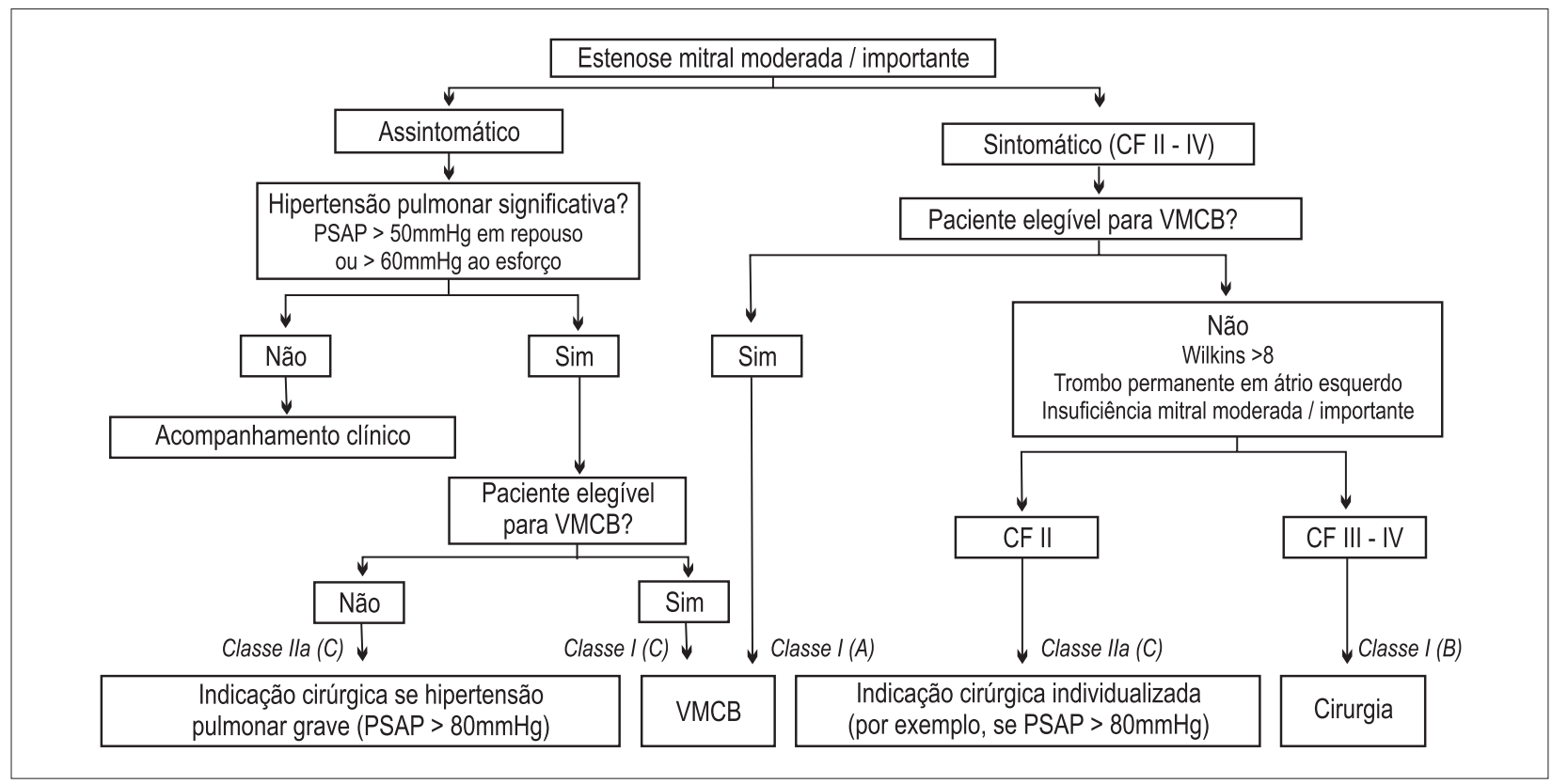

CF-Classe funcional; VMCB - Valvuloplastia mitral por cateter-balão; PSAP-Pressão sistólica da artéria pulmonar. 


\section{Diretrizes}

\section{Insuficiência mitral}

\subsection{Introdução}

A Insuficiência Mitral (IM) é caracterizada pela regurgitação sanguínea para o átrio esquerdo durante a sístole ventricular. Pode ser decorrente de anormalidades em diferentes locais do aparato valvar, tais como folhetos, ânulo, cordas tendíneas e músculos papilares. Etiologicamente, a insuficiência mitral pode ser classificada em primária (resultante de deformidade estrutural valvar) ou secundária, quando relacionada a outra doença cardíaca. Dentre as causas primárias, destacam-se o prolapso valvar mitral, a endocardite infecciosa, a Febre Feumática (FR), traumas e as deformidades congênitas. As etiologias secundárias estão relacionadas à isquemia miocárdica, cardiomiopatia hipertrófica e disfunção ventricular esquerda do tipo sistólica.

A prevalência do Prolapso da Valva Mitral (PVM) na população geral varia de $1 \%$ a $2,5 \%{ }^{49}$. PVM pode ocorrer de forma familiar ou não, sendo transmitido como traço autossômico ${ }^{50,51}$. A história natural da evolução dos pacientes portadores de prolapso da valva mitral é variável, e a evolução é muito favorável na grande maioria dos $\operatorname{casos}^{52,53}$.

A primeira avaliação para o diagnóstico de PVM deve ser o exame físico ${ }^{54,55}$.A ausculta cardíaca pode ser normal, ou ainda podem ser evidenciados múltipos clicks variáveis durante a sístole e a presença de sopro sistólico tardio ou holossistólico decorrente de insuficiência mitral.

\subsection{Diagnóstico}

O ECG do paciente com IM crônica pode apresentar sobrecarga de câmaras esquerdas, assim como sinais de sobrecarga de câmaras direitas nos casos com HP. Pode haver área inativa ou bloqueio de ramo relacionados ao comprometimento ventricular. Na radiografia de tórax podem estar presentes o aumento das câmaras esquerdas e sinais de congestão pulmonar.

\subsubsection{Ecocardiografia}

A quantificação ecocardiográfica da insuficiência valvar mitral pode ser realizada com o emprego das seguintes aferições: 1 área do jato regurgitante com Doppler colorido; 2 largura da vena contracta; 3 volume regurgitante; 4 fração regurgitante; 5 área do orifício regurgitante; além da aferição das dimensões das câmaras cardíacas, como mostra a tabela 10 .

O diagnóstico atualmente definido para PVM leva em consideração a evidência do deslocamento $\geq 2 \mathrm{~mm}$ acima do ânulo mitral das cúspides da valva para dentro do átrio esquerdo em observação no plano paraesternal de câmaras esquerdas e em outros planos ${ }^{56}$. Não há concordância na literatura com relação ao diagnóstico quando o deslocamento das cúspides é observado somente na projeção apical 4 ou 5 câmaras ${ }^{57,58}$. O PVM pode ocorrer associado ou não ao espessamento das cúspides $(5 \mathrm{~mm}$, observado durante a diástase), acompanhado ou não de insuficiência valvar. Espessamento valvar $\geq 5 \mathrm{~mm}$ reforça a possibilidade do diagnóstico.

A ecocardiografia permite o diagnóstico morfológico da valva e do mecanismo de regurgitação (inferindo etiologia) e a avaliação quantitativa (gravidade da regurgitação). É útil também na programação do tratamento cirúrgico (predição da probabilidade de plástica valvar).

As recomendações para o uso da ecocardiografia na IM estão evidenciadas na tabela 11 .

\subsubsection{Eco 3D em insuficiência mitral}

A ecocardiografia tridimensional possibilita a análise acurada de todo o conjunto de estruturas que compõe o aparato valvar e subvalvar mitral. Proporciona uma melhor possibilidade de detalhamento para a determinação da estratégia cirúrgica, assim como pode vir a ter impacto na determinação do momento cirúrgico para o tratamento da valvopatia mitral. A rotação tridimensional permite a visualização da valva mitral a partir do átrio esquerdo (plano de observação próximo da visão do cirurgião na sala operatória), o que traz maior realidade à identificação estrutural cardíaca.

Tabela 10 - Insuficiência valvar mitral: quantificação ecocardiográfica

\begin{tabular}{|c|c|c|c|}
\hline & & \multicolumn{2}{|c|}{ Insuficiência valvar mitral } \\
\hline \multicolumn{2}{|c|}{ Quantificação ecocardiográfica discreta } & Moderada & Importante \\
\hline $\begin{array}{l}\text { Área do jato regurgitante com } \\
\text { Doppler colorido }(\mathrm{cm} 2)\end{array}$ & $\begin{array}{c}\text { Área pequena, jato central } \\
(<4 \mathrm{~cm} 2 \text { ou }<20 \% \text { da área do átrio esquerdo })\end{array}$ & $\begin{array}{c}20 \% \text { a } 40 \% \text { da área do átrio } \\
\text { esquerdo }\end{array}$ & $>40 \%$ da área do átrio esquerdo \\
\hline Vena contracta $(\mathrm{cm})$ & $<0,3$ & $0,3-0,69$ & $\geq 0,7$ \\
\hline Volume regurgitante (mL/batimento) & $<30$ & $30-59$ & $\geq 60$ \\
\hline Fração regurgitante (\%) & $<30$ & $30-49$ & $\geq 50$ \\
\hline Área do orifício regurgitante (cm2) & $<0,2$ & $0,2-0,39$ & $\geq 0,4$ \\
\hline \multicolumn{4}{|l|}{ Parâmetros adicionais } \\
\hline Dimensão do átrio esquerdo & - & - & Aumentada \\
\hline Dimensão do ventrículo esquerdo & - & - & Aumentada \\
\hline
\end{tabular}


Tabela 11 - Recomendações da ecocardiografia na insuficiência mitral

\begin{tabular}{|c|c|c|}
\hline $\begin{array}{l}\text { Classe de } \\
\text { recomendação }\end{array}$ & Indicação & $\begin{array}{c}\text { Nível de } \\
\text { evidência }\end{array}$ \\
\hline Classe I & $\begin{array}{l}\text { ETT no diagnóstico e na avaliação } \\
\text { da morfologia e gravidade da IM, } \\
\text { seu mecanismo etiológico e suas } \\
\text { repercussões hemodinâmicas. }\end{array}$ & B \\
\hline Classe I & $\begin{array}{l}\text { ETT na avaliação periódica semestral } \\
\text { ou anual da função ventricular esquerda } \\
\text { em pacientes com IM moderada ou } \\
\text { importante, assintomáticos. }\end{array}$ & C \\
\hline Classe I & $\begin{array}{l}\text { ETT na reavaliação de pacientes com } \\
\text { mudanças de sinais e sintomas. }\end{array}$ & C \\
\hline Classe I & $\begin{array}{l}\text { ETT após intervenção cirúrgica da valva } \\
\text { mitral, como nova avaliação de base. }\end{array}$ & C \\
\hline Classe I & $\begin{array}{c}\text { ETT na avaliação das alterações } \\
\text { hemodinâmicas e adaptação ventricular } \\
\text { durante a gravidez. }\end{array}$ & C \\
\hline Classe I & $\begin{array}{c}\text { ETE perioperatório ou intraoperatório em } \\
\text { pacientes com indicação de correção } \\
\text { cirúrgica da IM. }\end{array}$ & B \\
\hline Classe I & $\begin{array}{l}\text { ETE na avaliação de pacientes com IM } \\
\text { nos quais o ETT seja inconclusivo. }\end{array}$ & B \\
\hline Classe I & $\begin{array}{l}\text { Ecocardiografia sob estresse em } \\
\text { pacientes com IM importante, } \\
\text { assintomáticos, para avaliação da } \\
\text { tolerância ao esforço e efeitos na } \\
\text { pressão pulmonar. }\end{array}$ & C \\
\hline Classe Ila & $\begin{array}{l}\text { ETE em pacientes com IM importante, } \\
\text { assintomáticos, sob análise para } \\
\text { correção cirúrgica conservadora. }\end{array}$ & C \\
\hline Classe III & $\begin{array}{l}\text { ETT na avaliação periódica de rotina } \\
\text { em pacientes com IM discreta, } \\
\text { assintomáticos, com dimensões } \\
\text { e função sistólica do ventrículo } \\
\text { esquerdo normais. }\end{array}$ & C \\
\hline Classe III & $\begin{array}{c}\text { ETE na avaliação periódica de rotina ou } \\
\text { para investigação em pacientes com IM } \\
\text { de valva nativa assintomáticos. }\end{array}$ & C \\
\hline
\end{tabular}

ETT - Ecocardiografia transtorácica; ETE - Ecocardiografia transesofágica; IM - Insuficiência mitral.

Especialmente para a análise dos pacientes portadores de PVM, o emprego da ecocardiografia tridimensional (transtorácica e principalmente transesofágica) permite a identificação mais detalhada dos escalopes valvares (A1, A2, A3, P1, P2, P3), a aferição da área valvar, dos diâmetros intercomissurais, dos diâmetros ântero-posterior e médiolateral do átrio esquerdo e da altura do anel valvar. Permite também a determinação da angulação espacial entre as valvas mitral e aórtica. Para a quantificação da insuficiência valvar mitral, permite a aferição da vena contracta tridimensional e do volume regurgitante sem a necessidade da aplicação de inferências matemáticas e geométricas. Para a observação da calcificação valvar mitral, a ecocardiografia tridimensional ainda não tem sido utilizada de forma consistente.
Outra grande possibilidade de aplicação da ecocardiografia tridimensional relacionada ao PVM acompanhada de insuficiência valvar é a observação da anatomia e função do átrio esquerdo. O exame permite a aferição da fração de esvaziamento do átrio esquerdo, da análise da contração atrial e do remodelamento atrial relacionado à evolução da insuficiência valvar mitral. Dessa forma, é fundamental empregar método que possibilite a observação global do átrio esquerdo em seus diversos planos de apresentação espacial. Essa análise mais detalhada leva a um maior entendimento da fisiologia atrial na evolução do seu remodelamento temporal. Atualmente, a comparação da análise ecocardiográfica tridimensional do átrio esquerdo com a análise com a ressonância magnética demonstra correlação adequada entre os métodos, apresentando aplicabilidade na prática clínica diária ${ }^{59}$.

Do ponto de vista teórico, esses métodos ecocardiográficos tridimensionais representam grande avanço para a investigação da valvopatia mitral, necessitando, no entanto, de maior validação com estudos populacionais para a determinação do seu real impacto clínico.

\subsubsection{Cateterismo cardíaco}

O cateterismo cardíaco, com ou sem estresse, é necessário quando há discrepância entre a clínica e os achados não invasivos ${ }^{60}$. O cateterismo também deve ser realizado quando a cirurgia é contemplada em casos em que há dúvidas sobre a gravidade da IM após testes não invasivos, discrepância da pressão de artéria pulmonar ou quando há necessidade de avaliar presença, extensão e gravidade de DAC (idade avançada, hipercolesterolemia, ou hipertensão), ou ainda quando há suspeita de que a IM tenha etiologia isquêmica (quer seja por infarto do miocárdio conhecido, quer por suspeita de isquemia), devendo a cineangiocoronariografia ser realizada antes da cirurgia (vide tabela 12). Estudo hemodinâmico com esforço pode fornecer informações adicionais para a tomada de decisões ${ }^{61}$.

\section{Tabela 12 - Recomendações para cateterismo cardíaco na insuficiência mitral}

\begin{tabular}{lcc}
\hline $\begin{array}{l}\text { Classe de } \\
\text { recomendação }\end{array}$ & Indicação & $\begin{array}{c}\text { Nível de } \\
\text { evidência }\end{array}$ \\
\hline Classe I & $\begin{array}{c}\text { Ventriculografia esquerda e medidas } \\
\text { hemodinâmicas quando os testes não } \\
\text { invasivos são inconclusivos em relação } \\
\text { à gravidade da IM, função do VE ou } \\
\text { necessidade de cirurgia. }\end{array}$ & C \\
\hline Classe I & $\begin{array}{c}\text { Estudo hemodinâmico quando a pressão } \\
\text { da artéria pulmonar é desproporcional à } \\
\text { gravidade do refluxo mitral na avaliação } \\
\text { por testes não invasivos. }\end{array}$ & C \\
\hline Classe I & $\begin{array}{c}\text { Cineangiocoronariografia antes do } \\
\text { tratamento cirúrgico da valva mitral em } \\
\text { pacientes com fatores de risco para DAC. }\end{array}$ & C \\
\hline Classe III & $\begin{array}{c}\text { Ventriculografia esquerda e medidas } \\
\text { hemodinâmicas em pacientes com IM } \\
\text { nos quais a cirurgia não é contemplada. }\end{array}$ & C \\
\hline
\end{tabular}

IM - Insuficiência mitral; VE - Ventrículo esquerdo; DAC - Doença arterial coronariana. 


\section{Diretrizes}

\subsection{Tratamento}

\subsubsection{Tratamento farmacológico}

Na insuficiência mitral aguda com repercussão clínica e hemodinâmica recomenda-se o uso de vasodilatadores e diuréticos preferencialmente por via intravenosa, objetivando redução das pressões de enchimento ventricular. Dentre os vasodilatadores, destacam-se os nitratos, especialmente o nitroprussiato de sódio, em razão da capacidade de redução de pós-carga e da fração regurgitante. Agentes inotrópicos, como a dobutamina, são indicados nos cenários mais críticos, em que a regurgitação valvar associada à disfunção ventricular determina baixo débito cardíaco e hipotensão arterial sistêmica ${ }^{62}$.

Não há tratamento farmacológico definido para a insuficiência mitral crônica assintomática. Embora exista racional fisiopatológico para o uso de vasodilatadores, a evidência científica atual não demonstra benefícios clínicos ${ }^{63}$. Pequenos estudos não comprovaram melhora significativa dos volumes ventriculares e do grau de regurgitação mitral com o uso de Inibidores da Enzima de Conversão da Angiotensina (leca) ${ }^{64}$. Além disso, essa terapia pode mascarar a evolução clínica desses pacientes por abrandar o surgimento de sintomas, acarretando atraso na indicação do tratamento cirúrgico. Em contrapartida, na insuficiência mitral secundária resultante de miocardiopatia dilatada com disfunção ventricular sistólica, o uso de leca e de betabloqueadores, como verificado por diversos estudos, pode melhorar tanto o grau de regurgitação mitral quanto a classe funcional ${ }^{62}$.

O uso de vasodilatadores e diuréticos é recomendado na insuficiência mitral crônica sintomática objetivando exclusivamente a melhora de classe funcional, enquanto o paciente aguarda o procedimento cirúrgico, sem demonstração de benefícios na mortalidade. A terapia anticoagulante é indicada na insuficiência mitral associada à fibrilação atrial permanente ou paroxística, com INR-alvo entre 2,0 e 3,0. A frequência cardíaca, nesses casos, deve ser controlada com bloqueadores de canais de cálcio do tipo nãodiidropiridínicos (diltiazem, verapamil), digoxina, amiodarona ou betabloqueadores.

As recomendações acima encontram-se esquematizadas na tabela 13 .

\subsubsection{Tratamento cirúrgico}

\subsubsection{Tipos de procedimentos}

Atualmente, a correção da IM é realizada por: 1 reconstrução por plástica; 2 substituição da valva por prótese com preservação parcial ou total das estruturas subvalvares; 3 substituição por prótese com remoção do aparelho valvar. Esses procedimentos têm indicações específicas, bem como riscos e benefícios (tabela 14).

A plástica valvar preserva as estruturas da valva nativa, que fazem parte da estrutura morfológica e funcional do VE e são responsáveis pela manutenção da forma e volume dessa câmera e pela preservação da função ventricular no pós-operatório, com maiores taxas de sobrevivência imediata e tardia. Por essas razões, é o procedimento de escolha para a maioria dos pacientes. Esses benefícios são mantidos tanto nos pacientes assintomáticos com IM importante e com função do VE preservada quanto nos muito sintomáticos e com Fração de Ejeção do Ventrículo Esquerdo (FEVE) gravemente comprometida ${ }^{65}$.

Os procedimentos reconstrutivos da valva mitral dependem das características morfológicas das lesões, como a quantidade de tecido flexível das cúspides, a presença e extensão de calcificação e o envolvimento de uma ou de ambas as cúspides, e da experiência do cirurgião. O ato operatório demanda mais tempo de Circulação Extracorpórea (CEC) nas reconstruções mais complexas comparado à substituição valvar e menor tempo nas correções de menor complexidade.

Os índices de reoperação são similares aos da substituição valvar e cursam entre $7 \%$ e $10 \%$ em 10 anos em casos de IM recorrente importante, geralmente devidos ao procedimento inicial em aproximadamente $70 \%$ dos pacientes, e pela progressão da doença valvar em $30 \%$ deles. Os índices de sucesso são maiores e com baixas taxas de reoperações nos procedimentos sobre a cúspide posterior quando comparados com os procedimentos envolvendo a cúspide anterior ou ambas as cúspides. A falha técnica na reconstrução da função valvar implica substituição da valva, expondo o paciente aos riscos relacionados à prótese. Assim, a indicação em pacientes assintomáticos e com FEVE normal requer alto grau de certeza de sucesso operatório da plástica ${ }^{66}$.

Tabela 13 - Recomendações para tratamento farmacológico na insuficiência mitral

\begin{tabular}{|c|c|c|}
\hline $\begin{array}{l}\text { Classe de } \\
\text { recomendação }\end{array}$ & Indicação & $\begin{array}{l}\text { Nível de } \\
\text { evidência }\end{array}$ \\
\hline Classe I & Vasodilatadores intravenosos na IM aguda, importante e sintomática, enquanto aguarda definição cirúrgica. & B \\
\hline Classe I & Diuréticos na IM crônica importante, sintomática e com sinais de congestão, enquanto aguarda definição cirúrgica. & C \\
\hline Classe I & Vasodilatadores orais na IM crônica importante, sintomática, enquanto aguarda definição cirúrgica. & B \\
\hline Classe Ila & Digitálicos no controle de frequência ventricular na FA de alta reposta associada à IM crônica importante. & C \\
\hline Classe Ilb & Betabloqueadores para controle de frequência ventricular na FA de alta reposta associada à IM crônica importante. & C \\
\hline Classe Ilb & $\begin{array}{l}\text { Bloqueadores de canais de cálcio não diidropiridínicos para controle de frequência ventricular na FA de alta reposta associada } \\
\text { à IM crônica importante. }\end{array}$ & C \\
\hline Classe III & Vasodilatadores na IM crônica assintomática com função ventricular normal e na ausência de hipertensão arterial sistêmica. & C \\
\hline
\end{tabular}

IM - Insuficiência mitral; FA - Fibrilação atrial. 


\subsubsection{Indicações de tratamento cirúrgico}

O tratamento cirúrgico está indicado nos casos de insuficiência mitral importante e sintomática (CF II, III ou IV).

Vários estudos retrospectivos mostraram que a plástica mitral correlaciona-se a maiores índices de sobrevida e menor mortalidade operatória comparativamente à substituição valvar $^{67}$. Em 2003, uma grande análise prospectiva comparou os desfechos relacionados às duas técnicas cirúrgicas. A sobrevida em cinco anos para o grupo de pacientes submetidos aplástica mitral foi de $82 \%$, diferindo significativamente da verificada no grupo em que a troca valvar foi realizada $(72 \%)^{68}$. Adicionalmente, a plástica mitral, ao preservar o aparato valvar original do paciente, evita os riscos da anticoagulação crônica exigida para as próteses mecânicas, além de determinar menores taxas de reoperação que a substituição por biopróteses ${ }^{11,69,70}$.

Enriquez-Sarano e cols. observaram que o tratamento cirúrgico por meio de plástica mitral foi exequível em $90 \%$ dos pacientes portadores de PVM, com mortalidade operatória de 1,7\%. Nos casos de etiologia reumatismal ou secundários à endocardite infecciosa, a plástica mitral restringiu-se a $63 \%$ dos pacientes, com maior mortalidade operatória $(5,7 \%)^{71}$. Especificamente para o PVM, diversos estudos demonstram melhores resultados cirúrgicos nos casos de insuficiência por acometimento do folheto posterior, com menor incidência de regurgitação residual e necessidade de reoperação ${ }^{66,72-74}$. O maior desses estudos foi conduzido pela equipe da clínica Mayo e analisou os desfechos clínicos em 1.411 pacientes tratados cirurgicamente. Foi realizada plástica valvar em cerca de $83 \%$ desses indivíduos.

$\mathrm{Na}$ ocorrência de insuficiência mitral discreta a moderada associada a sintomatologia exuberante, faz-se necessária a consideração de outros possíveis diagnósticos, além de uma reavaliação da gravidade anatômica mediante diferentes métodos como a ETE, a Ressonância Nuclear Magnética Cardíaca (RNMC) e a ventriculografia convencional ou por radioisótopos.

Para os pacientes assintomáticos, o momento ideal para a intervenção cirúrgica ainda é controverso. De modo geral, recomenda-se cirurgia quando surgirem sinais ecocardiográficos de disfunção ventricular (FE menor que $60 \%$ ou diâmetro sistólico final do VE - DsVE - acima de 40mm ${ }^{11}$. A evidência para indicação de tratamento cirúrgico em pacientes portadores de disfunção ventricular sistólica provém de um estudo retrospectivo norte-americano que analisou os preditores de sobrevida em 409 indivíduos operados por insuficiência mitral importante ${ }^{75}$. Os pacientes foram alocados em três grupos de acordo com a função ventricular: FE $\geq 60 \%$, FE entre $50 \%$ e $59 \%$ e FE menor do que $50 \%$. Os valores de sobrevida para os diferentes grupos foram de $72 \%$, 53\% e $32 \%$, respectivamente. No subgrupo com FE maior ou igual a $60 \%$, os pacientes oligossintomáticos (CF I/ II) apresentaram maior sobrevida do que os demais (CF III/IV). Utilizando essas evidências, a diretriz norte-americana adota medidas de DsVE acima de 40mm como ponto de corte para indicação de tratamento cirúrgico na insuficiência mitral crônica assintomática. Em contrapartida, a Diretriz Europeia de Valvopatias recomenda valores de DsVE acima de $45 \mathrm{~mm}$ para intervenção. Para pacientes com disfunção ventricular grave (FE abaixo de 30\% e/ou DsVE acima de 55mm) e insuficiência mitral importante, os benefícios da cirurgia ainda são motivo de controvérsias.

O tratamento cirúrgico também é recomendado para indivíduos assintomáticos com insuficiência mitral importante e função ventricular normal quando houver HP, com PSAP acima de $50 \mathrm{mmHg}$ em repouso, ou fibrilação atrial de início recente. Em trabalho prospectivo, Le Tourneau e cols. verificaram uma sobrevida pós-operatória de 86,6\% para pacientes com insuficiência mitral importante e PSAP abaixo de $50 \mathrm{mmHg}$, contrastando com o índice de 58,6\% observado naqueles em que a PSAP pré-operatória foi maior que $50 \mathrm{mmHg}^{76}$. O desenvolvimento de FA também é considerado um preditor independente de mortalidade e insuficiência cardíaca ${ }^{77}$.A incidência de FA em pacientes com insuficiência mitral moderada a importante pode chegar a 5\% ao ano, determinando consequências prognósticas.

Nos últimos anos, tornou-se crescente o interesse pelo manejo dos pacientes assintomáticos com FE acima de $60 \%$, diâmetros ventriculares limítrofes (DsVE entre 40 e $45 \mathrm{~mm}$ ), sem outros indicadores de intervenção cirúrgica como HP crítica ou fibrilação atrial recente. Duas formas de abordagem foram avaliadas para esse grupo de pacientes: a cirurgia precoce e o seguimento clínico cauteloso com monitoramento periódico de sintomas. Rosenheke cols., por meiode estudo prospectivo randomizado, propuseram a estratégia de seguimento clínico cauteloso ("watchful waiting"), na qual 132 pacientes portadores de insuficiência mitral crônica degenerativa foram acompanhados por um período de oito anos, com avaliações médicas frequentes. O tratamento cirúrgico foi indicado quando constatada progressão para sintomas, DsVE acima de $45 \mathrm{~mm}$, FE abaixo de $60 \%$, PSAP em repouso superior a $50 \mathrm{mmHg}$ ou FA de início recente ${ }^{78}$.A sobrevida geral ao final dos oito anos do estudo foi próxima à esperada (91\%). O principal fator desencadeante da cirurgia foi o desenvolvimento de sintomas (cerca de dois terços dos pacientes operados). Embora com resultados consistentes, o estudo de Rosenhek não fez comparação direta com um grupo submetido à estratégia de tratamento cirúrgico precoce. Essa limitação não esteve presente num estudo prospectivo posterior, conduzido por Kang e cols. ${ }^{79}$.Nesse trabalho, as duas modalidades de tratamento foram comparadas em um grupo de 447 pacientes com insuficiência mitral crônica degenerativa importante, com FE acima de 60\%, DsVE abaixo de $45 \mathrm{~mm}$ e sem FA ou HP grave. O tratamento cirúrgico precoce foi realizado em 161 pacientes. Os demais pacientes foram submetidos ao "watchful waiting". Durante um tempo médio de seguimento de 5,4 anos, não foram registrados óbitos de causa cardiovascular no grupo operado precocemente. No grupo acompanhado clinicamente registraram-se 12 óbitos, além de 22 admissões hospitalares por insuficiência cardíaca descompensada. Essa aparente superioridade da intervenção cirúrgica precoce, no entanto, é passível de algumas críticas. Três óbitos ocorridos no grupo cirúrgico precoce não foram considerados de origem cardiovascular, embora tenham sido decorrentes de acidentes encefálicos com provável mecanismo cardioembólico subjacente. Além disso, dentre os óbitos registrados no grupo "watchful waiting", cinco foram devido a insuficiência cardíaca com recusa ao tratamento cirúrgico. Considerando tais ressalvas, a estratégia de seguimento clínico, com reavaliações periódicas a cada seis a 12 meses e monitoramento de parâmetros ecocardiográficos, parece a mais adequada para esse perfil de pacientes. Outros métodos diagnósticos, como ventriculografia radioisotópica e ressonância nuclear magnética, auxiliam na decisão terapêutica nos casos com função ventricular limítrofe. Ante a dificuldade na avaliação de sintomas, recomenda-se a utilização do teste ergoespirométrico para determinação objetiva do grau de limitação funcional. 


\section{Diretrizes}

\section{Tabela 14 - Recomendações para tratamento cirúrgico na insuficiência mitral primária}

\begin{tabular}{|c|c|c|}
\hline $\begin{array}{l}\text { Classe de } \\
\text { recomendação }\end{array}$ & Indicação & $\begin{array}{l}\text { Nível de } \\
\text { evidência }\end{array}$ \\
\hline Classe I & Pacientes com IM crônica importante, sintomáticos (CF II, III ou IV), com FE > 30\% e DsVE < 55mm. & B \\
\hline Classe I & Pacientes com IM crônica importante, assintomáticos, com FE entre $30 \%$ e $60 \%$ e DsVE $\geq 40 \mathrm{~mm}$. & B \\
\hline Classe I & $\begin{array}{l}\text { A plástica da valva mitral é preferível em relação à substituição valvar nos pacientes com IM crônica importante que necessitam } \\
\text { cirurgia, devendo ser realizada em centros com experiência no procedimento. }\end{array}$ & C \\
\hline Classe Ila & $\begin{array}{l}\text { Plástica da valva mitral em pacientes com IM crônica por prolapso, importante, assintomáticos, com FE } \geq 60 \% \text { e DsVE }<40 \mathrm{~mm} \text {, } \\
\text { desde que realizada em centros experientes, nos quais a taxa de sucesso estimada da plástica é maior que } 90 \% \text {. }\end{array}$ & B \\
\hline Classe Ila & Pacientes com IM crônica importante, assintomáticos, com função ventricular esquerda preservada e fibrilação atrial de início recente. & C \\
\hline Classe lla & $\begin{array}{l}\text { Pacientes com IM crônica importante, assintomáticos, com função ventricular esquerda preservada e com HP (PSAP > 50mmHg } \\
\text { em repouso ou }>60 \mathrm{mmHg} \text { com exercício). }\end{array}$ & C \\
\hline Classe lla & $\begin{array}{l}\text { Tratamento cirúrgico combinado da fibrilação atrial em pacientes com IM moderada a importante, sintomática (CF III ou IV), } \\
\text { quando indicado tratamento cirúrgico da IM. }\end{array}$ & C \\
\hline Classe IIb & $\begin{array}{l}\text { Plástica da valva mitral em pacientes com IM crônica reumática, importante, assintomáticos, com FE } \geq 60 \% \text { e DsVE }<40 \mathrm{~mm} \text {, } \\
\text { desde que realizada em centros experientes, nos quais a taxa de sucesso estimada da plástica é maior que } 90 \% \text {. }\end{array}$ & B \\
\hline Classe Illb & $\begin{array}{l}\text { Pacientes com IM crônica importante devido à disfunção ventricular grave (FE < 30\%) que apresentem sintomas persistentes (CF III } \\
\text { ou IV) a despeito de tratamento otimizado para insuficiência cardíaca, incluindo estimulação com marcapasso biventricular. }\end{array}$ & C \\
\hline Classe III & $\begin{array}{l}\text { Pacientes com IM crônica importante, assintomáticos, com FE } \geq 60 \% \text { e DsVE }<40 \mathrm{~mm} \text {, na ausência de HP ou fibrilação atrial de } \\
\text { início recente, nos quais existe dúvida sobre a possibilidade de realização de plástica mitral. }\end{array}$ & C \\
\hline
\end{tabular}

Abaixo, Fluxograma para tratamento cirúrgico da Insusficiênica mitral

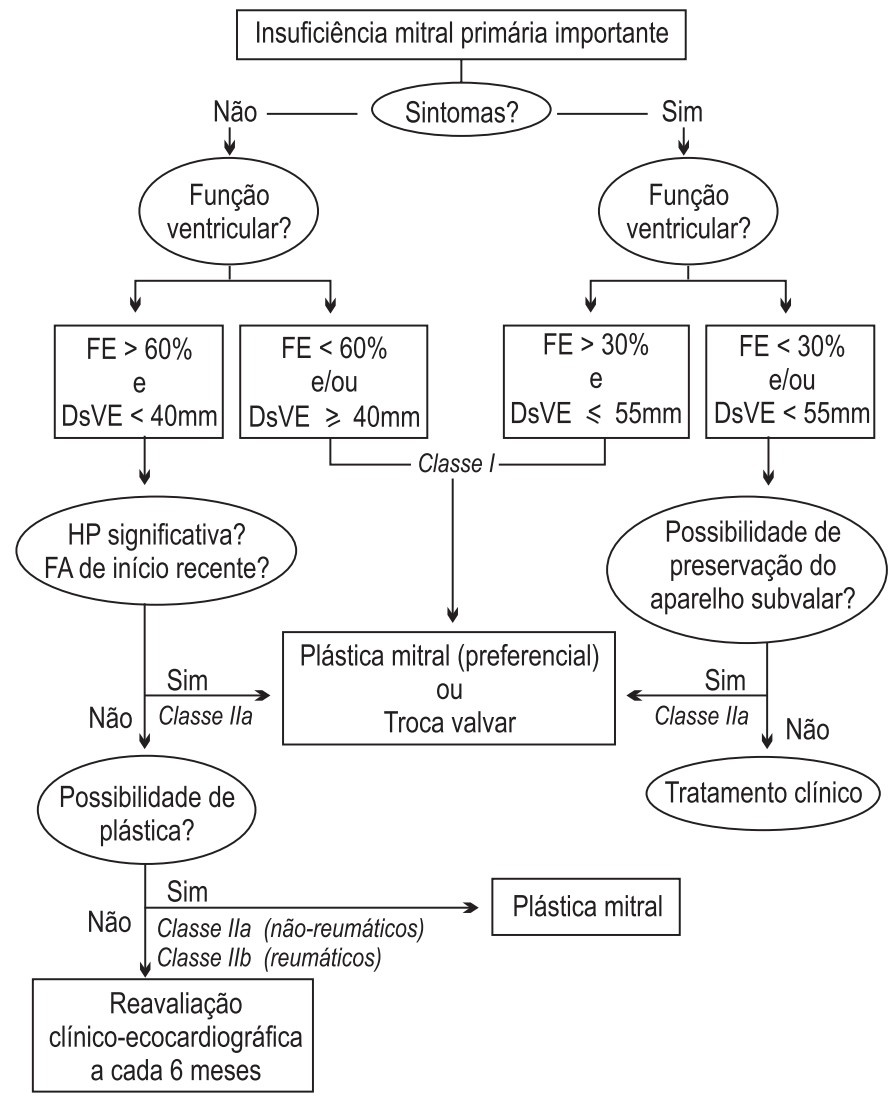

FE - Fração de ejeção; DsVE - Diâmetro sistólico do ventrículo esquerdo; HP - Hipertensão pulmonar; FA-Fibrilação atrial 


\subsubsection{Insuficiência mitral isquêmica}

A insuficiência mitral denominada isquêmica decorre de DAC com isquemia miocárdica. Pode manifestar-se agudamente pela ruptura do músculo papilar, causando grave instabilidade hemodinâmica e alta morbimortalidade. No entanto, a maioria dos casos relaciona-se à isquemia miocárdica crônica. Estima-se que 20\% a 30\% dos casos de infarto do miocárdico apresentem algum grau de insuficiência mitral associada ${ }^{80}$.

Historicamente, o tratamento cirúrgico da insuficiência mitral isquêmica era associado com alta morbimortalidade. No entanto, estudos atuais documentam melhores desfechos clínicos, com taxas de mortalidade inferiores a $5 \%{ }^{81,82}$. Nos casos de IM importante, a evidência científica atual demonstra que o tratamento combinado (revascularização miocárdica associada à cirurgia valvar) oferece os melhores resultados ${ }^{83}$. Quanto ao tipo de cirurgia valvar, a plástica possui melhores resultados do que a substituição valvar ${ }^{11,84}$.

\subsubsection{Procedimentos percutâneos na insuficiência} mitral

Recentemente, a possibilidade de correção menos invasiva da insuficiência mitral tem despertado o interesse da comunidade científica internacional. As abordagens percutâneas da valva mitral por anuloplastia ou implante de um clipe nos bordos dos folhetos estão em ativa investigação.

\subsubsection{Anuloplastia}

A anuloplastia pode ser executada através do seio coronariano, que cursa paralelamente com o ânulo mitral, implantando um dispositivo que tensiona ou reformata o seio, causando contração e deslocamento da parte posterior do ânulo mitral em direção ao septo. Vários dispositivos mostraram eficácia em experiências pré-clínicas e estão sendo testados em estudos clínicos. Alguns dos desafios dessa técnica incluem a grande variabilidade da relação do seio coronariano com o ânulo mitral, o curso da artéria coronária circunflexa e seus ramos sobre ou abaixo do seio coronariano, e o potencial de lesão do seio coronariano ${ }^{85}$. Atualmente existem três sistemas, descritos a seguir.

O Edwards Monarc é baseado em âncoras semelhantes a um stent (stent-like) proximal e distal conectadas por uma ponte de nitinol semelhante a uma mola (spring-like). A redução da distância pós-procedimento entre as âncoras proximal e distal promove um deslocamento anterior da parte posterior do ânulo, reduzindo assim a distância septal-lateral do ânulo mitral. Até o momento, a experiência é limitada e modificações no dispositivo foram solicitadas após experiência inicial em humanos ${ }^{86}$. O estudo Evolution I já encerrado teve a inclusão de 55 pacientes, e o Evolution II está em andamento, desenhado como um estudo prospectivo, nãorandomizado e multicêntrico.

O sistema Carillon também utiliza duas âncoras de nitinol desenhadas como dupla hélice, conectadas por uma ponte curvada, e a diferença entre esse e o Edwards Monarc é que pode ser completamente retirado se a tração realizada pela ponte causar compressão da artéria coronariana ou se as âncoras permanecerem instáveis. Após a conclusão do AMADEUS e TITAN, estudos de viabilidade e segurança na Europa, os sistemas receberam aprovação comercial ${ }^{87,88}$.

O Viacor é um dispositivo que inclui um cateter triplo lúmen com uma ponta de silicone maleável que é avançada até a porção proximal da veia interventricular anterior. A rigidez do cateter produz uma pressão significante, que é máxima na parte póstero-lateral do ânulo mitral, resultando na redução do diâmetro desse anel ${ }^{89}$, aumentando a coaptação dos folhetos. O estudo de viabilidade e segurança inicial foi o PTOLEMY-1, e no momento o PTOLEMY-2 está sendo realizado em alguns locais da Europa e Canadá.

\subsubsection{Clipe mitral}

O implante do clipe mitral, indicado para os casos de insuficiência mitral degenerativa ou funcional, segue o princípio cirúrgico descrito por Alfieri e cols. ${ }^{90,91}$, que sutura as extremidades livres dos folhetos criando um duplo orifício na valva mitral. O procedimento é guiado através da ETE, e se a insuficiência mitral não for controlada de maneira satisfatória, um segundo clipe pode ser utilizado, ou o clipe pode ser removido sem aparente dano do folheto.

O primeiro estudo de viabilidade e segurança foi o EVEREST I $^{92}$, e recentemente foram publicados os resultados do EVEREST II, em que foram randomizados 279 pacientes com IM moderada ou importante, na razão 2:1 para correção percutânea ou cirurgia de reparo ou troca valvar. O desfecho primário de eficácia foi sobrevida livre de cirurgia para correção da valva mitral e de IM moderada a importante após 12 meses. O desfecho primário de segurança foi o composto de eventos adversos maiores em 30 dias. Em 12 meses, as taxas de desfecho primário de eficácia foram de 55\% no grupo percutâneo e de $73 \%$ no grupo cirúrgico ( $p=0,007$ ). Os eventos adversos maiores ocorreram em 15\% dos pacientes do grupo percutâneo contra 48\% do grupo cirúrgico em 30 dias ( $p<0,001$ ). Em 12 meses, ambos os grupos tiveram melhora no tamanho ventricular, na classe funcional e na qualidade de vida, quando comparado com as características basais. Os autores concluíram que o procedimento percutâneo foi menos efetivo em reduzir a IM que a cirurgia, mas apresentou maior segurança e melhora similar nos resultados clínicos ${ }^{93}$.

Embora os procedimentos percutâneos da valva mitral tenham o objetivo de preencher a lacuna terapêutica dos pacientes com IM moderada ou importante, não candidatos a cirurgia de reparo ou troca valvar, os desafios para desenvolver dispositivos e técnicas efetivas e seguras são numerosos. Todas as tecnologias existentes têm potenciais benefícios e limitações, e em casos selecionados, combinações das técnicas podem ser necessárias para a obtenção do resultado ótimo. No Brasil, até o presente momento esses dispositivos não se encontram disponíveis para uso clínico.

\subsection{Insuficiência mitral aguda}

A IM crônica leva a aumento do átrio esquerdo e de sua complacência. Dessa forma, a pressão intra-atrial tenderá a ser normal, apesar de um volume regurgitante significativo. Na insuficiência mitral aguda existe um aumento do volume de 
sangue em um átrio esquerdo cuja complacência é inteiramente normal. Esse fato resulta em aumento significativo da pressão intra-atrial ${ }^{11}$.Dentre as causas mais comuns destacam-se o infarto agudo do miocárdio (45\%), a doença valvar degenerativa (26\%) e a endocardite infecciosa $(28 \%)^{94}$.

O quadro habitualmente se apresenta como emergência médica de início súbito, com rápida progressão para edema pulmonar agudo e/ou choque cardiogênico. A HP secundária pode determinar insuficiência cardíaca direita. Ao exame físico, sinais de síndrome de baixo débito estão presentes, com turgência jugular e presença de onda " $\mathrm{V}$ ". O sopro pode se apresentar em decrescendo (em vez de holossistólico), sendo mais grave e mais discreto do que o sopro da IM crônica. O ECG usualmente não exibe características específicas. Contudo, pode apresentar alterações indicativas da etiologia (onda P mitrale em casos crônicos agudizados e alterações isquêmicas no IAM). A radiografia de tórax frequentemente exibe dimensões cardíacas normais com sinais de congestão e edema pulmonar.

Dada a dramaticidade do quadro clínico, a intervenção cirúrgica frequentemente é necessária. O balão intra-aórtico pode ser um efetivo mecanismo de suporte, servindo como ponte para o tratamento cirúrgico definitivo.

\subsubsection{Insuficiência mitral isquêmica aguda}

Na IM importante devido ao IAM agudo instala-se choque cardiogênico, e a cirurgia de emergência se faz necessária, seja plástica ou substituição valvar, sendo importante o conhecimento prévio do mecanismo causador da IM para o sucesso do procedimento. O risco cirúrgico imediato nesses casos é elevado e geralmente o suporte circulatório com balão intra-aórtico deve ser instalado, quando possível, para auxiliar a melhora hemodinâmica ${ }^{95}$. A sobrevida dos pacientes com IM de etiologia isquêmica é relativamente menor comparada às demais causas, porque a doença está fundamentalmente centrada na disfunção do VE, o que também concorre para a maior recorrência da insuficiência valvar.

A prevalência de IM no IAM diagnosticada pela ausculta cardíaca varia de $17 \%$ a 55\% ${ }^{96}$. A Insuficiência Mitral Aguda (IMA) ocorre em $0,04 \%$ a $0,11 \%$ dos IAM e em $0,9 \%$ a $5 \%$

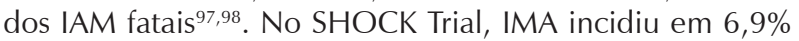
dos pacientes ${ }^{99}$. As principais causas de IM após IAM incluem isquemia, necrose ou ruptura de Músculo Papilar (MP) e dilatação global ou segmentar do VE ${ }^{98}$.

A ruptura do MP total ou parcial causa IM por prolapso dos folhetos da valva mitral ${ }^{100}$. A ruptura total do tronco do MP é a mais grave e letal das disfunções de MP após o IAM. A ruptura parcial pode envolver um ou mais pilares do MP ou a ponta de um pilar causando graus variáveis e quase sempre significantes de $\mathrm{IM}^{98}$. Dois terços dos casos de IMA por ruptura ou disfunção do MP envolvem o MP póstero-medial, cujo suprimento vascular em geral é dependente de uma única artéria coronariana (coronária direita ou circunflexa), enquanto o suprimento vascular do MP anterolateral é duplo (artéria descendente anterior e circunflexa) ${ }^{98,100,101}$. Nesses pacientes, o quadro clínico dependerá do grau de regurgitação mitral e do grau de comprometimento da função do VE ${ }^{101}$.
A IMA caracteriza-se clinicamente por deterioração hemodinâmica aguda e rápida, em geral entre o $2^{\circ}$ e o $7^{\circ} \underline{0}$ dias após IAM envolvendo a parede inferior ou ínfero-posterior do $\mathrm{VE}^{96,98}$. Edema pulmonar agudo está quase sempre presente e choque cardiogênico pode se desenvolver na dependência da gravidade da IM e do comprometimento das funções do VE e ventrículo direito ${ }^{101}$. No exame físico há sinais de congestão pulmonar e de baixo débito cardíaco e, na ausculta cardíaca, sopro de IM com intensidade e duração variáveis devido à equalização das pressões do átrio e ventrículo esquerdos. $\mathrm{O}$ sopro pode, até mesmo, estar ausente ou quase inaudível. Diferente da ruptura do septo interventricular, o sopro não é rude, nem produz frêmito ${ }^{102}$.

O ECG é quase que invariavelmente anormal e sinais de IAM inferior ou ínfero-posterior são comuns ${ }^{103-105}$. A radiografia de tórax quase sempre mostra sinais de congestão venocapilar pulmonar, com área cardíaca normal ou pouco aumentada e ausência de aumento do átrio esquerdo ${ }^{104,105}$. Atualmente, o ETT tem papel fundamental no diagnóstico da IMA, avaliando o grau da regurgitação, as alterações regionais de contração do VE e ainda pode demonstrar o PVM e até o MP roto ${ }^{97,101,102}$. Todavia, o ETE é o método de escolha para a investigação diagnóstica, documentando o grau da IM, as características do jato regurgitante, as anormalidades de contração da parede ventricular e o estado dos MP. Essas informações são cruciais para a decisão entre o reparo e a troca valvar mitral. Mesmo com instabilidade hemodinâmica, a maioria dos pacientes é submetida à cineangiocoronariografia para definir a anatomia coronariana.

O prognóstico da IMA é variável. Na era pré-cirúrgica a mortalidade por ruptura de MP atingia 83\% dos casos nas primeiras 24 horas, com pouco mais de $6 \%$ sobrevivendo mais do que dois meses ${ }^{96,98,99}$. O objetivo do tratamento farmacológico é estabilizar o paciente e prepará-lo para a cirurgia por meio de agentes redutores da pós-carga e inotrópicos, e podem ser utilizados ainda dispositivos de suporte mecânico, como balão intra-aórtico, oxigenação extracorpórea por membrana (ECMO, da sigla em inglês) e dispositivo de assistência ventricular ${ }^{106,107}$. Cirurgia de urgência oferece a melhor chance de sobrevivência na IMA grave pós-IAM; no entanto, em muitos pacientes o tempo de realização da cirurgia ainda é controverso ${ }^{108}$.

A mortalidade hospitalar da cirurgia varia de $31 \%$ a $69 \%$ e reflete provavelmente o processo de seleção mais do que a qualidade do cuidado ${ }^{106}$. As variáveis que aumentam a mortalidade incluem a idade avançada, a presença de choque cardiogênico, de comorbidades, de massa de miocárdio necrosada e a demora para realização da cirurgia ${ }^{108}$. A experiência mais recente tem sido melhor, por conta do diagnóstico e de cirurgia mais precoces, revascularização completa e aplicação de técnicas de preservação das cordas tendinosas, que contribui para preservação da função do VE. Tirone David relatou uma mortalidade hospitalar de 22\% em 18 pacientes usando a técnica de preservação das cordas ${ }^{109}$. No entanto, no SHOCK Trial, a mortalidade hospitalar foi de $39 \%$ nos pacientes com IM submetidos a cirurgia ${ }^{99}$. A cirurgia pode ser por reparo ou troca da valva mitral na dependência da experiência da equipe cirúrgica e do grau de comprometimento do aparelho valvar mitral. A sobrevivência em cinco anos dos pacientes operados na Mayo Clinic por ruptura de MP foi $65 \pm 7 \%{ }^{110}$. 


\section{Estenose aórtica}

\subsection{Introdução}

A Estenose Aórtica (EAo) é a obstrução da via de saída do VE pela calcificação das estruturas valvares, associada ou não à fusão das válvulas da valva aórtica. É a doença valvar aórtica adquirida mais frequente e está presente em 4,5\% da população acima de $75 \operatorname{anos}^{111}$. Com o envelhecimento populacional, deverá aumentar em incidência e importância nas próximas décadas. Suas principais causas são EAo congênita, calcificação de uma valva aórtica bicúspide, calcificação de uma valva aórtica tricúspide - EAo degenerativa -, e FR ${ }^{102}$. Esta última está invariavelmente associada à valvopatia mitral ${ }^{11,102}$, e apesar da diminuição de sua incidência nos países desenvolvidos, continua frequente no Brasil e demais países da América Latina, levando ao acometimento de pacientes mais jovens $\mathrm{s}^{102,112,113}$.

A definição da gravidade da EAo segue critérios ecocardiográficos (ver seção de Diagnóstico adiante). Com o tempo e a progressão do processo de calcificação valvar, a EAo leva à hipertrofia ventricular concêntrica, à elevação das pressões de enchimento, e finalmente à disfunção ventricular. Como a evolução dessa calcificação é lenta, os sintomas resultantes da EAo (dor torácica, síncope e dispneia) tipicamente surgem após a 6 ${ }^{\mathbf{a}}$ década de vida, sendo ainda mais tardios nos casos de EAo degenerativa ${ }^{102}$. Uma vez sintomáticos, os pacientes passam a apresentar uma piora significativa de seu prognóstico, com média de sobrevivência de dois atrês anos, com aumento significativo no risco de morte súbita11,102. Daí a importância da identificação precoce do surgimento de sintomas ou de disfunção ventricular (FE $<50 \%$ ), que apontarão o momento de indicação de intervenção visando à interrupção da evolução natural da doença.

Os pacientes com EAo importante assintomáticos têm sido tema de muito debate nos últimos anos. De acordo com o paradigma anterior, baseado em observações das décadas de 1960 e 1970, esses pacientes poderiam ser observados clinicamente, desde que não apresentassem disfunção ventricular sistólica, uma vez que sua curva de sobrevida seria semelhante à da população em geral. Entretanto, o conceito de "benignidade" da EAo importante sem sintomas tem sido refutado nos últimos anos, basicamente apoiado em duas premissas:

1. Nem sempre o paciente assintomático está realmente livre de sintomas, muitas vezes limitando progressivamente suas atividades, mascarando sintomas (especialmente idosos); são na realidade "pseudoassintomáticos", e, dessa forma, têm pior prognóstico.

2. O grupo de pacientes assintomáticos é heterogêneo, e alguns fatores de risco indicam pior prognóstico.

\subsubsection{Marcadores prognósticos na estenose aórtica}

Os pacientes com EAo, mesmo que apresentem a mesma área valvar, função ventricular preservada e ausência de sintomatologia, não são idênticos; ou seja, existem outras variáveis que podem aumentar ou diminuir o risco desses pacientes, tornando-os heterogêneos ${ }^{114}$. Nos últimos anos, os resultados de algumas coortes prospectivas ${ }^{26,29,115-120}$ têm agregado fatores de risco, ou fatores de pior prognóstico, na EAo. Os principais estudos seguem adiante.
Em 1997, Otto e cols. ${ }^{115}$ apresentaram um estudo em que 123 pacientes com EAo importante assintomáticos foram acompanhados prospectivamente por 2,5 $\pm 1,4$ anos. Nesse estudo, a probabilidade de sobrevida livre de sintomas foi de $93 \%$ no primeiro ano, $62 \%$ no terceiro ano, e $26 \%$ no quinto ano. Por meio de análise multivariada, a velocidade de jato transvalvar aórtico, o aumento da velocidade de jato transvalvar aórtico e a mudança do status funcional foram preditores independentes de óbito ou necessidade de cirurgia. A probabilidade do paciente permanecer vivo sem necessidade de cirurgia aos dois anos de seguimento foi de apenas $21 \%$ para os que apresentavam na inclusão do estudo velocidade de jato transvalvar aórtico maior que $4 \mathrm{~m} / \mathrm{s}$.

Em 2000, Rosenhek e cols. ${ }^{116}$ publicaram um estudo prospectivo em que 126 pacientes portadores de EAo importante assintomáticos foram seguidos por $22 \pm 18$ meses. Verificaram que o grau de calcificação valvar foi preditor independente de desenvolvimento de sintomas e/ou óbito. A probabilidade de sobrevida livre de sintomas para os pacientes com calcificação valvar aórtica moderada ou intensa foi de $60 \%$ no primeiro ano, $47 \%$ no segundo ano, e apenas $20 \%$ no quarto ano.

Em 2001, Amato e cols. ${ }^{26}$ apresentaram um estudo prospectivo que acompanhou 66 pacientes com EAo importante assintomáticos. Todos os pacientes foram submetidos a teste de esforço em esteira, com o objetivo de estratificação. Houve quatro casos de morte súbita durante o acompanhamento, e nesses o teste de esforço havia sido positivo e a área valvar aórtica era menor ou igual a $0,6 \mathrm{~cm}^{2}$.

Em 2004, Bergler-Klein e cols. ${ }^{29}$ estudaram o Brain Natriuretic Peptide (BNP) e o N-Terminal Prohormone BNP (NT-proBNP) como marcadores prognósticos em pacientes com EAo. O foco era a análise da sobrevida livre de sintomas em assintomáticos. O valor de BNP menor que 130 pg/mL e de NT-proBNP menor que $80 \mathrm{pmol} / \mathrm{L}(678 \mathrm{pg} / \mathrm{mL}$ ) foram preditores de sobrevida livre de sintomas por um período de seis anove meses.

Em 2005, Pellikka e cols. ${ }^{117}$ apresentou um estudo em que 622 pacientes assintomáticos com EAo importante foram acompanhados prospectivamente por cinco anos. Nesse estudo, a probabilidade de pacientes não operados permanecerem livres de sintomas foi de apenas 33\% em cinco anos, enquanto a probabilidade de sobrevida sem cirurgia foi de $25 \%$ em cinco anos. O risco de morte súbita não precedida por sintomas foi de cerca de $1 \%$ ao ano. Nesse trabalho, a partir de dois anos de seguimento, mesmo assintomáticos os pacientes passaram a ter prognóstico pior que o da população em geral. Idade avançada, insuficiência renal crônica e velocidade de jato transvalvar aórtico foram preditores de mortalidade.

Mais recentemente, Monin e cols. ${ }^{118}$ conduziram um estudo com 107 pacientes com EAo importante assintomáticos com objetivo de desenvolver um escore de risco que pudesse ser aplicado e fosse capaz de predizer a chance de eventos adversos ao longo do tempo. Os pacientes foram seguidos por 24 meses e foram computados como evento adverso óbito ou necessidade de cirurgia. Os preditores independentes utilizados para a construção do escore, posteriormente validado, foram sexo feminino, velocidade de jato transvalvar aórtico no pico da sístole, e o valor inicial do BNP. 


\section{Diretrizes}

\subsection{Diagnóstico}

No ECG podem ser vistos sinais de sobrecarga de VE nas lesões moderadas a importantes, apesar do aumento de voltagem não ser muito habitual na EAo. A presença de bloqueio de ramo ou bloqueio atrioventricular está associada a EAo importante. O teste ergométrico pode ser realizado com baixo risco em pacientes selecionados, com cautela. Atualmente, as indicações mais comumente aceitas são: no paciente completamente assintomático, quando se deseja avaliar os parâmetros para sua atividade; ou quando se pretende esclarecer a real ausência de sintomas em pacientes possivelmente "pseudoassintomáticos". Na radiografia de tórax, é frequente a chamada dilatação pósestenótica da aorta. Os sinais radiológicos de aumento do VE não são frequentes até que a EAo se torne importante, uma vez que a hipertrofia é tipicamente concêntrica.

\subsubsection{Ecocardiografia}

A ecocardiografia constitui a mais importante ferramenta complementar no diagnóstico na EAo. Fornece não apenas a anatomia da valva, mas também a quantificação dos gradientes e da área valvar aórtica (tabela 15). Permite ainda a avaliação da repercussão hemodinâmica da doença pela detecção da hipertrofia ventricular esquerda e a avaliação das funções sistólica e diastólica do VE.

A determinação dos gradientes aórticos pelo Doppler é muito precisa, desde que o feixe esteja devidamente alinhado com o fluxo aórtico. Gradientes aórticos são dependentes do fluxo transvalvar, e a área valvar, apesar de válida, é uma medida menos robusta, especialmente em razão da dificuldade em se medir a via de saída do VE em alguns pacientes. Portanto, a área valvar isoladamente não deve ser usada na tomada de decisão e outros parâmetros, como a classe funcional, gradiente pressórico transvalvar, taxa de fluxo transvalvar e a função ventricular devem ser considerados. Quando é difícil obter a área da valva, o índice da velocidade do fluxo da via de saída do VE pela velocidade da valva aórtica (dimensionless index) pode ser usado para estimar a gravidade da lesão (quando < 0,25 indica EAo importante). Ocasionalmente, a ETE pode ser indicada para analisar melhor a valva aórtica ou mesmo medir a área valvar. Mais recentemente, a aferição precisa dessa área faz-se possível também por meio da ecocardiografia tridimensional ${ }^{121}$.

Um gradiente médio acima de $40 \mathrm{mmHg}^{11}$ ou $50 \mathrm{mmHg}^{19}$ tem sido tradicionalmente aceito como indicando estenose aórtica importante.

Tabela 15 - Quantificação da estenose valvar aórtica

\begin{tabular}{lccc}
\hline & Discreta & Moderada & Importante \\
\hline $\begin{array}{l}\text { Velocidade do jato } \\
(\mathrm{m} / \mathrm{s})\end{array}$ & $<3,0$ & 3,0 a 4,0 & $>4,0$ \\
\hline $\begin{array}{l}\text { Gradiente médio } \\
(\mathrm{mmHg})\end{array}$ & $<25$ & 25 a 40 & $>40$ \\
\hline Área valvar $\left(\mathrm{cm}^{2}\right)$ & $>1,5$ & 0,8 a 1,5 & $<0,8\left(<0,6 \mathrm{~cm}^{2} / \mathrm{m}^{2}\right)$ \\
\hline
\end{tabular}

$\mathrm{O}$ aumento do gradiente em resposta ao exercício à ecocardiografia de esforço parece ter valor incremental na estratificação de risco, mas ainda não foi incorporado em diretrizes internacionais. Em um artigo recente, Marechaux e cols. ${ }^{122}$ mostraram que a ecocardiografia de esforço fornece informação prognóstica incremental, além da obtida na ecocardiografia de repouso ou no teste ergométrico. Um aumento no gradiente médio maior que $20 \mathrm{mmHg}$ com o exercício foi independentemente associado a um aumento de 3,8 vezes no risco de eventos. Pacientes que tiveram tanto um gradiente médio basal maior que $35 \mathrm{mmHg}$ e um aumento do gradiente induzido pelo exercício maior que $20 \mathrm{mmHg}$ apresentaram um aumento de 9,6 vezes no risco de eventos, em comparação com aumento de 2,5 vezes em pacientes com um gradiente basal maior que $35 \mathrm{mmHg}$ e um aumento no gradiente menor ou igual a $20 \mathrm{mmHg}$ com o exercício.

7.2.1.1. Estenose aórtica com baixo gradiente e função ventricular reduzida

Um uso mais bem estabelecido da ecocardiografia sob estresse com dobutamina é em pacientes com estenose aórtica, baixos gradientes e função ventricular reduzida. O teste pode não apenas estabelecer a gravidade da lesão valvar, mas também elucidar se há reserva contrátil, o que é um importante fator prognóstico. Baixa dose de dobutamina deve ser utilizada (até $20 \mathrm{mcg} / \mathrm{kg} / \mathrm{min}$ ) e se houver um aumento no volume de ejeção e no gradiente médio, enquanto a área da valva aórtica permanece inalterada, a estenose aórtica é significativa e pode ser responsável pela disfunção ventricular esquerda. Se o gradiente continua baixo, apesar de um volume de ejeção maior, e a área valvar aórtica aumenta, a estenose aórtica é considerada discreta. Se não há aumento no volume de ejeção, a gravidade da estenose aórtica não pode ser estabelecida.

7.2.1.2. Estenose aórtica "importante" na presença de baixo gradiente e fração de ejeção normal

Recentemente, uma nova entidade descrevendo pacientes com EAo importante e baixo gradiente na presença de fração de ejeção normal tem sido relatada. Alguns trabalhos sugerem que esses pacientes possam representar um subgrupo de EAo importante em estágio avançado, com volume de ejeção reduzido em razão da função ventricular comprometida, apesar da FE preservada. Esses pacientes teriam pior prognóstico, especialmente se a cirurgia não for indicada ${ }^{123,124}$. No entanto, um estudo recente envolvendo 1.525 pacientes do estudo SEAS descobriu que 435 (29\%) pacientes assintomáticos apresentavam EAo "importante" e baixos gradientes na presença de FE $\geq 55 \%$. A evolução desses pacientes foi semelhante à de pacientes com EAo moderada ${ }^{125}$. Esses autores concluíram que, desde que os pacientes sejam assintomáticos, eles devem ser manejados como pacientes com EAo moderada e acompanhados de perto com a utilização da ecocardiografia.

Como a fração de ejeção não é um índice puro de contratilidade ventricular, sendo influenciada por pré e pós-carga, novos índices não invasivos de análise da contratilidade têm surgido, como o strain e strain rate. Estudo em pacientes com EAo importante e FE normal, que apresentavam strain diminuído, mostraram que após a cirurgia o strain desses pacientes se normalizou, sugerindo que pacientes com EAo importante e função sistólica "normal" pelos métodos convencionais podem já apresentar disfunção incipiente do VE, quando técnicas mais 
avançadas de avaliação da função ventricular são empregadas ${ }^{126}$. Contudo, esses são estudos iniciais e, portanto, ainda insuficientes para serem incorporados como recomendação nesta Diretriz.

\subsubsection{Ecocardiografia transesofágica na estenose aórtica}

Por meio do ETT, por vezes não é possível obter com acurácia a medida direta da planimetria da valva aórtica estenótica. Essa aferição se faz possível com o ETE, com excelente correlação com a área valvar aferida pela equação de continuidade, uma vez que a disponibilidade de tecnologiamultiplanar da sonda transesofágica permite uma avaliação mais precisada área valvar. O coeficiente de correlação com a área valvar determinada pelocateterismo (fórmula de Gorlin) foi de 0,95, com sensibilidade de 96\% para detectarestenose importante(área valvar $<0,75 \mathrm{~cm}^{2}$ ). A etiologia da doença valvar também pode ser melhor determinada ao ETE. É possível, também, excluir de forma confiável a presença de doença subvalvar, como uma discreta membrana fibrosa subaórtica.

\subsubsection{Ecocardiografia 3D na valvopatia aórtica}

A observação ecocardiográfica tridimensional da valva aórtica pode ser realizada a partir da via de saída do VE ou tendo como referência a aorta ascendente. Essa rotação angular da valva aórtica possibilita a sua visualização integral. A medida tridimensional da área valvar aórtica pode ser determinada por método planimétrico (com o emprego da ETT ou ETE) ou também levando-se em consideração o volume sistólico ejetado através da valva e a integral da velocidade tempo do fluxo através da valva, conforme demonstrado ${ }^{127}$ :

$$
\text { Área valvar aórtica: } \frac{\text { Volume sistólico }\left(\mathrm{cm}^{3}\right)}{\text { VTI (valva aórtica) }(\mathrm{cm})}
$$

Essa nova possibilidade de determinação da área da valva aórtica apresenta melhor correlação com a aferição invasiva (método de Gorlin), quando comparada com métodos ecocardiográficos bidimensionais ${ }^{127}$.
A tabela 16 sintetiza as principais indicações de ecocardiografia na EAo.

\subsubsection{Cateterismo cardíaco na estenose aórtica}

Se os dados clínicos e ecocardiográficos são típicos de EAo importante isolada, a angiografia coronariana pode ser o único procedimento invasivo necessário antes da cirurgia. Uma avaliação completa com cateterismo direito e esquerdo pode ser necessária se existe discrepância entre os dados clínicos e ecocardiográficos (tabela 17).

O gradiente pressórico através de uma valva aórtica estenótica está relacionado à área do orifício valvar e ao fluxo transvalvar ${ }^{128}$. Na presença de um débito cardíaco baixo, gradientes pressóricos relativamente mais baixos podem ser obtidos em pacientes com EAo importante. Por sua vez, durante o exercício ou estados de fluxo elevado, gradientes pressóricos significativos podem ser medidos em valvas aórticas com estenoses mínimas. Por esses motivos, uma avaliação completa da EAo requer medida do fluxo transvalvar, determinação do gradiente pressórico transvalvar médio e cálculo do orifício valvar efetivo.

7.2.2.1. Cateterismo cardíaco na estenose aórtica com baixo fluxo / baixo gradiente

Pacientes com EAo importante e débito cardíaco baixo com frequência se apresentam com um gradiente pressórico médio menor que $30 \mathrm{mmHg}$. Esses pacientes podem ser difíceis de distinguir daqueles com baixo débito cardíaco e EAo discreta a moderada. Nos pacientes com EAo verdadeiramente importante, a lesão estenótica contribui para uma pós-carga elevada, FE reduzida e baixo volume sistólico. Nos pacientes com EAo discreta a moderada, a disfunção contrátil primária é responsável pela redução na FE e baixo volume sistólico. Em ambas as situações, o estado de baixo fluxo e gradiente pressórico baixo contribuem para um cálculo de área efetiva valvar que pode atingir o critério de EAo importante.

Tabela 16 - Indicações de ecocardiografia na estenose aórtica

\begin{tabular}{|c|c|c|}
\hline Classe de recomendação & Indicação & $\begin{array}{l}\text { Nível de } \\
\text { evidência }\end{array}$ \\
\hline Classe I & Diagnóstico e avaliação da gravidade da EAo e suas repercussões ventriculares. & B \\
\hline Classe I & Reavaliação de pacientes com mudança de sintomas e sinais. & B \\
\hline Classe I & $\begin{array}{l}\text { Reavaliação de pacientes assintomáticos a cada } 6 \text { meses na EAo importante, a cada um ano na EAo } \\
\text { moderada e a cada } 2 \text { a } 3 \text { anos na EAo discreta. }\end{array}$ & B \\
\hline Classe I & Após intervenção percutânea ou cirúrgica da valva aórtica, como nova avaliação de base. & C \\
\hline Classe I & Na avaliação das alterações hemodinâmicas e adaptação ventricular durante a gravidez. & C \\
\hline Classe I & ETE quando as imagens à ETT forem inadequadas para se excluir obstrução subaórtica fixa ou dinâmica. & B \\
\hline Classe lla & $\begin{array}{l}\text { Ecocardiografia sob estresse para avaliação da EAo na presença de disfunção do VE e gradiente médio } \\
\text { baixo em repouso para se definir a gravidade da EAo e a presença de reserva contrátil. }\end{array}$ & B \\
\hline Classe Illb & $\begin{array}{l}\text { Ecocardiografia de esforço para avaliação do comportamento dos gradientes e de sintomas induzidos pelo } \\
\text { exercício ou respostas anormais de pressão arterial em pacientes com EAo assintomáticos. }\end{array}$ & $\mathrm{C}$ \\
\hline Classe III & Ecocardiografia de esforço em pacientes com EAo sintomáticos. & B \\
\hline
\end{tabular}

EAo - Estenose aórtica; ETE - Ecocardiografia transesofágica; ETT - Ecocardiografia transtorácica; VE - Ventrículo esquerdo. 
Em pacientes selecionados com EAo de fluxo baixo/ gradiente baixo e disfunção ventricular, pode ser útil determinar o gradiente pressórico transvalvar e calcular a área valvar em estado basal e novamente durante exercício ou com estresse farmacológico em dose baixa (dobutamina), com o propósito de demonstrar se a estenose é importante ou moderada. Tais estudos podem ser realizados na ecocardiografia ou no laboratório de hemodinâmica ${ }^{129}$. Pacientes que não apresentam estenose importante exibem um aumento na área valvar e pouca alteração no gradiente durante o aumento no volume sistólico. Logo, se a dobutamina produz um aumento no volume sistólico e um aumento na área valvar maior do que $0,2 \mathrm{~cm}^{2}$ e discreta alteração no gradiente, é provável que a avaliação basal tenha superestimado o gradiente. Pacientes com falha em apresentar um aumento no volume sistólico com a dobutamina (menos do que $20 \%$ ), referida como "falta de reserva contrátil", parecem ter um pior prognóstico, seja com tratamento clínico ou cirúrgico. Testes com dobutamina em pacientes com EAo deve ser feitos apenas em centros com experiência em testes de estresse farmacológico e com a presença de cardiologista no procedimento.

\section{Tabela 17 - Indicacões de cateterismo cardíaco na estenose aórtica}

\begin{tabular}{|c|c|c|}
\hline $\begin{array}{l}\text { Classe de } \\
\text { recomendação }\end{array}$ & Indicação & $\begin{array}{c}\text { Nível de } \\
\text { evidência }\end{array}$ \\
\hline Classe I & $\begin{array}{l}\text { Cateterismo cardíaco para realização de } \\
\text { medidas hemodinâmicas para avaliação } \\
\text { da gravidade da EAo em pacientes } \\
\text { sintomáticos quando os testes não } \\
\text { invasivos são inconclusivos. }\end{array}$ & C \\
\hline Classe I & $\begin{array}{l}\text { Cineangiocoronariografia antes do } \\
\text { tratamento cirúrgico da valva aórtica em } \\
\text { pacientes com fatores de risco para DAC. }\end{array}$ & B \\
\hline Classe I & $\begin{array}{l}\text { Cineangiocoronariografia antes da } \\
\text { intervenção transcateter da valva } \\
\text { aórtica em pacientes com fatores de } \\
\text { risco para DAC. }\end{array}$ & C \\
\hline Classe Ila & $\begin{array}{l}\text { Cineangiocoronariografia em pacientes } \\
\text { com EAo em quem um autoenxerto } \\
\text { pulmonar (cirurgia de Ross) é planejado e } \\
\text { se a origem da artérias coronarianas não } \\
\text { foi identificada por técnica não invasiva. }\end{array}$ & C \\
\hline Classe lla & $\begin{array}{l}\text { Cateterismo cardíaco com infusão } \\
\text { de dobutamina para avaliação } \\
\text { hemodinâmica da EAo na presença de } \\
\text { disfunção do VE e gradiente baixo. }\end{array}$ & C \\
\hline Classe III & $\begin{array}{l}\text { Cateterismo cardíaco para realização } \\
\text { de medidas hemodinâmicas para } \\
\text { avaliação da gravidade da EAo antes } \\
\text { da cirurgia da valva aórtica quando os } \\
\text { testes não invasivos são adequados e } \\
\text { concordandes com os achados clínicos. }\end{array}$ & C \\
\hline Classe III & $\begin{array}{l}\text { Cateterismo cardiaco para realização de } \\
\text { medidas hemodinâmicas para avaliação } \\
\text { da função ventricular e da gravidade da } \\
\text { EAo em pacientes assintomáticos. }\end{array}$ & C \\
\hline
\end{tabular}

EAo - Estenose aórtica; DAC - Doença arterial coronariana; VE Ventrículo esquerdo

\subsubsection{Tomografia computadorizada}

Esse exame é a melhor maneira de reconhecer e quantificar a magnitude da calcificação da valva aórtica, com implicações prognósticas. A angiotomografia de coronárias não substitui a cineangiocoronariografia pré-operatória nessa valvopatia porque, com frequência, existem calcificações coronarianas de tal magnitude que impedem a quantificação do grau de estenose coronariana.

\subsubsection{Ressonância Magnética Cardiovascular (RMC)}

A presença e a quantidade de fibrose miocárdica focal em pacientes com valvopatia aórtica importante correlacionou-se diretamente com a quantidade de fibrose intersticial vista na biópsia endomiocárdica realizada durante a cirurgia de troca valvar. Por sua vez, a quantidade de fibrose, seja medida pela biópsia, seja pela ressonância, correlacionou-se diretamente com a recuperação funcional do VE e com a mortalidade desses pacientes após a troca valvar ${ }^{130}$. Esse dado foi corroborado por trabalho semelhante em que a classe funcional não melhorou após troca valvar nos pacientes com fibrose miocárdica pela $\mathrm{RMC}^{131}$.

A visualização da valva aórtica é obtida de forma precisa pela cinerressonância (SSFP, de Steady-State Free Precession) e pode fornecer não só a gravidade da estenose pela medida da área valvar, como informações sobre a etiologia da estenose ${ }^{132}$. A ressonância magnética pode avaliar a gravidade da EAo basicamente de duas formas:

1. a avaliação da velocidade de fluxo pelo orifício valvar, calculando gradiente Ao-VE (equação de Bernoulli modificada) ou a área valvar aórtica pela equação da continuidade ${ }^{133-137}$;

2. planimetria direta do orifício valvar aórtico ${ }^{132,138}$. Apresenta a vantagem de ser uma medida independente do fluxo, dos volumes ventriculares ou da função ventricular esquerda, fatores esses que têm levado a situações frequentes de discordância entre gradientes e áreas valvares baseados no fluxo aórtico, em casos de pacientes com estenose aórtica importante com gradiente normal e fração de ejeção preservada ${ }^{139}$. As recomendações para o uso da RMC na EAo estão apresentadas na tabela 18.

\section{Tabela 18 - Recomendações do uso da ressonância magnética} cardiovascular na EAo

\begin{tabular}{lcc}
\hline $\begin{array}{l}\text { Classe de } \\
\text { recomendação }\end{array}$ & Indicação & $\begin{array}{c}\text { Nível de } \\
\text { evidência }\end{array}$ \\
\hline Classe lla & $\begin{array}{l}\text { Avaliação de fração de ejeção ou volumes } \\
\text { ventriculares limítrofes ou duvidosos pela } \\
\text { ecocardiografia. }\end{array}$ & B \\
\hline Classe Ila & $\begin{array}{c}\text { Planimetria da área valvar aórtica } \\
\text { quando há incerteza na gravidade da } \\
\text { EAo ou quando outras modalidades de } \\
\text { imagem tiveram resultados conflitantes. }\end{array}$ & B \\
\hline Classe lla & Avaliação das dimensões da raiz aorta e & B aorta ascendente. \\
\hline EAo - Estenose ártica &
\end{tabular}

\subsection{Tratamento}

\subsubsection{Tratamento farmacológico}

O tratamento farmacológico na EAo é voltado ao alívio de sintomas em pacientes não candidatos a tratamento cirúrgico ou como ponte para o tratamento cirúrgico; ao tratamento 
de doenças associadas à estenose aórtica e à profilaxia de Endocardite Infecciosa (EI).

No paciente com sintomas decorrentes da EAo, o tratamento é eminentemente cirúrgico. O diurético de alça furosemida pode ser utilizado para alívio de sintomas. Em pacientes com edema agudo pulmonar e estenose aórtica importante, o uso cauteloso de nitroprussiato de sódio pode ser considerado ${ }^{140}$.

Não há evidências suficientes que embasem o uso de alguma medicação com o objetivo de retardar a evolução da EAo, como as estatinas. Por sua vez, condições associadas à EAo devem ser tratadas, entre elas a dislipidemia e a hipertensão arterial sistêmica. No tratamento da hipertensão arterial sistêmica, cuidado especial deve ser tomado na administração de vasodilatadores.

Em relação à profilaxia da El, os pacientes com EAo têm indicação de acordo com protocolo apresentado em seção específica. Nos pacientes com EAo de etiologia reumática, a prevenção secundária da FR deve ser instituída.

\subsubsection{Tratamento cirúrgico da estenose aórtica}

A Cirurgia Valvar Aórtica (CVAo) ainda é a única terapêutica efetiva a longo prazo no alívio da sobrecarga ventricular esquerda em pacientes com EAo importante. Entretanto, em decorrência do risco operatório e das complicações imediatas e tardias das próteses valvares, o momento ideal para a indicacão cirúrgica é muitas vezes controverso. O adequado conhecimento da história natural da doença juntamente com a avaliação clínica completa e de dados específicos de exames complementares possibilita traçar diretrizes racionais de tratamento ${ }^{141}$. Embora ensaios clínicos randomizados comparando cirurgia e tratamento clínico continuado não tenham sido realizados, estudos observacionais mostram que a cirurgia corretiva da estenose aórtica é quase sempre seguida de melhora sintomática e aumento importante na sobrevida.

A cirurgia de implante de prótese valvar cardíaca está associada a morbidade significativa. Entre as complicações encontram-se disfunção de prótese, vazamento paravalvular ("leak"), formação de trombos, êmbolos arteriais, endocardite infecciosa e os problemas associados à anticoagulação. As complicações graves dependem do tipo de prótese e de uma série de variáveis clínicas; entretanto, ocorrem com uma frequência de pelo menos 3\% ao ano. A taxa de mortalidade relacionada diretamente à valva ocorre em aproximadamente $1 \%$ ao ano.

Para a substituição isolada da valva aórtica, a taxa de mortalidade operatória é estimada em 3,2\%. Taxas de eventos adversos variam de 1,5\% para Acidente Vascular Encefálico (AVE) a 10,9\% para ventilação mecânica prolongada.

\subsubsection{Pacientes sintomáticos}

A cirurgia valvar aórtica está indicada em pacientes sintomáticos com EAo importante, sendo um procedimento que promove melhora dos sintomas e aumento da sobrevida ${ }^{142-147}$. O benefício do tratamento cirúrgico depende, entre outras variáveis, da função ventricular esquerda, sendo observada menor sobrevida tardia naqueles com FE reduzida ou com disfunção ventricular de longa duração.

Os pacientes com estenose aórtica de "baixo fluxo e baixo gradiente" representam um desafio clínico e terapêutico. Nos pacientes cuja estenose valvar seja responsável pela sobrecarga pressórica e disfunção ventricular, a cirurgia, mesmo que com riscos imediatos mais elevados e sobrevida tardia mais limitada, apresenta resultados superiores aos do tratamento Clínico ${ }^{148}$. Mesmo alguns pacientes sem reserva contrátil podem se beneficiar da CVAo, mas as decisões em pacientes de alto risco devem ser individualizadas, uma vez que não há dados indicando, nessa população, quais são os indivíduos que vão apresentar melhor evolução com a cirurgia.

Em pacientes com disfunção ventricular acentuada, é importante o uso de próteses com desempenho hemodinâmico apropriado, visto que gradientes transprotéticos residuais elevados aumentam muito o risco operatório nessa situação ${ }^{149}$.

O risco cirúrgico dos pacientes pode ser estimado de acordo com escores validados. Os dois escores mais utilizados são: European System for Cardiac Operative Risk Evaluation (EuroScore) e o Escore da Society of Thoracic Surgeons (STS) ${ }^{150-152}$. Um terceiro escore é o descrito por Ambler e cols. ${ }^{153}$ Este último tem a vantagem de ser específico para doença valvar, diferentemente dos anteriores. O EuroScore o STS podem ser consultados respectivamente nos sites euroscore.org e sts.org.

\subsubsection{Pacientes assintomáticos}

A decisão terapêutica para o paciente com EAo importante assintomático traz à tona o dilema: manter observação clínica ou indicar cirurgia "profilaticamente"?

A estratégia de operar profilaticamente todos os pacientes com EAo importante assintomáticos não é viável, pois estaríamos expondo 100\% dos pacientes com EAo importante assintomáticos a um risco de 3\% a $4 \%$ de mortalidade relacionado à cirurgia, somado a um risco de $1 \%$ ao ano relacionado à presença de prótese valvar, para o benefício de apenas aproximadamente $1 \%$ dessa população (risco anual de morte súbita) ${ }^{48,154-156}$.

Manter, entretanto, todos os pacientes desse grupo em observação clínica pode não ser seguro. Na realidade, estudos observacionais mais recentes relacionados à história natural da EAo importante em assintomáticos mostram que esse grupo não é tão "benigno" como se imaginava em décadas anteriores ${ }^{26,29,114-120}$.

Pacientes com EAo importante nos quais há dúvidas a respeito da real ausência de sintomas têm indicação de realizar teste de esforço no sentido de se assegurar que eles realmente permanecem assintomáticos e que o comportamento da pressão arterial seja normal durante o exame $^{157}$.O objetivo é identificar, dentre os pacientes com EAo importante assintomáticos, aqueles de maior risco, e que, portanto, se beneficiam da cirurgia, evitando a morte súbita e/ou o dano irreversível ao miocárdio. Nesse propósito, identificam-se fatores de alto risco ${ }^{11,19,29,158-160}$ :

- Teste de esforço com sintomas evidentes ou hipotensão ao esforço;

- Área valvar aórtica menor ou igual a $0,7 \mathrm{~cm}^{2}$ ou área valvar indexada menor ou igual a $0,4 \mathrm{~cm}^{2} / \mathrm{m}^{2}$;

- Diminuição da área valvar $>0,1 \mathrm{~cm}^{2} / \mathrm{ano}$;

- Velocidade de fluxo transvalvar $\geq 5 \mathrm{~m} / \mathrm{s}$; 
- Velocidade de jato transvalvar aórtico rapidamente progressiva, com taxa de aumento anual maior que $0,3 \mathrm{~m} / \mathrm{s}$ ao ano;

- Calcificação valvar aórtica moderada a intensa se associada com rápido aumento da velocidade de fluxo transvalvar aórtico;

- Hipertrofia ventricular acentuada (12 a $14 \mathrm{~mm}$ em mulheres e 14 a $16 \mathrm{~mm}$ em homens);

- Doença coronariana associada;

- Disfunção ventricular sistólica;

- $\quad$ Elevação do BNP.

\subsubsection{Aspectos relacionados à idade}

Apesar de a substituição valvar estar indicada e ser factível do ponto de vista técnico em virtualmente todos os pacientes sintomáticos com EAo importante, considerações especiais devem ser feitas levando-se em conta a idade dos pacientes. Muitos idosos com EAo importante não são encaminhados para a cirurgia supondo-se risco cirúrgico elevado com base somente na idade avançada. Os escores de avaliação mais frequentemente empregados tendem a superestimar os riscos operatórios e os resultados atuais em centros de referência mostram que a substituição valvar aórtica pode ser feita com mortalidade relativamente baixa ( $\sim 3-5 \%)$, mesmo em octagenários e nonagenários. Assim, a decisão da conduta terapêutica em idosos deve ser feita de forma individualizada, levando-se em conta não somente as expectativas e desejos do paciente, mas também as condições clínicas gerais e aspectos anatômicos que possam influenciar de forma significativa a morbimortalidade do procedimento ${ }^{161}$.

A avaliação clínica completa, incluindo o "índice de fragilidade" individual, presença de doenças malignas ou estados mórbidos significativos associados, é importante para evitar a cirurgia em situações nas quais o benefício estimado seja mínimo ou inexistente. Da mesma forma, aspectos anatômicos podem ser importantes na decisão quanto ao tipo de procedimento mais apropriado, considerando os riscos envolvidos. Assim, a presença de DAC triarterial concomitante pode determinar a necessidade de cirurgia convencional com toracotomia mediana para que a revascularização miocárdica seja possível, enquanto pacientes com doenças pulmonares crônicas podem ser mais convenientemente tratados com o uso de técnicas minimamente invasivas, que podem facilitar e acelerar o período de recuperação. Pacientes idosos, especialmente mulheres, com muita frequência apresentam a via de saída do VE e o anel aórtico com diâmetro pequeno e calcificado, o que pode levar à necessidade de cirurgias mais complexas, envolvendo técnicas de ampliação da raiz aórtica ou o uso de homoenxertos valvares e/ou tubos valvados para evitar a presença de gradientes residuais significativos em decorrência de "desproporção prótese / paciente"162,163. Portanto, o fator idade, isoladamente, não contraindica a cirurgia; entretanto, quando esse fator é somado a outros e o risco do paciente torna-se alto para o tratamento cirúrgico convencional, outras opções, como o implante percutâneo da valva aórtica, devem ser consideradas.

No outro espectro, o momento da indicação cirúrgica em pacientes jovens muitas vezes é indevidamente protelado pelo temor da necessidade de reoperações e/ou complicações tromboembólicas das próteses valvares biológicas e mecânicas convencionais. Apesar da controvérsia, dados mais recentes demonstram que o emprego do autoenxerto pulmonar (cirurgia de Ross), quando realizado de forma apropriada, apresenta baixa morbidade pós-operatória e está associado a sobrevida tardia de até 15 anos, quase comparável com a população normal pareada para sexo e idade. Pacientes jovens com diagnóstico de EAo com anel aórtico normal são os que apresentam os melhores resultados tardios envolvendo esse tipo de cirurgia ${ }^{164}$.

A tabela 19, abaixo, apresenta as indicações para o tratamento cirúrgico na EAo.

Tabela 19 - Indicações para o tratamento cirúrgico na estenose aórtica

\begin{tabular}{|c|c|c|}
\hline $\begin{array}{l}\text { Classe de } \\
\text { recomendação }\end{array}$ & Indicação & $\begin{array}{l}\text { Nível de } \\
\text { evidência }\end{array}$ \\
\hline Classe I & $\begin{array}{l}\text { Pacientes com EAo importante } \\
\text { sintomáticos. }\end{array}$ & B \\
\hline Classe I & $\begin{array}{l}\text { Pacientes com EAo importante que serão } \\
\text { submetidos a cirurgia de revascularização } \\
\text { miocárdica ou a cirurgia da aorta torácica } \\
\text { ou outra cirurgia valvar concomitante. }\end{array}$ & C \\
\hline Classe I & Pacientes com EAo importante e FE $<50 \%$. & $\mathrm{C}$ \\
\hline Classe lla & $\begin{array}{l}\text { Pacientes com EAo moderada que serão } \\
\text { submetidos a cirurgia de revascularização } \\
\text { miocárdica ou a cirurgia da aorta torácica } \\
\text { ou outra cirurgia valvar concomitante. }\end{array}$ & $\mathrm{B}$ \\
\hline Classe lla & $\begin{array}{l}\text { Pacientes com EAo importante, } \\
\text { assintomáticos, que apresentem resposta } \\
\text { anormal no teste de esforço (sintomas } \\
\text { desproporcionais ao esforço realizado ou } \\
\text { hipotensão). }\end{array}$ & C \\
\hline Classe lla & $\begin{array}{c}\text { Pacientes com EAo importante, } \\
\text { assintomáticos, com indicadores de } \\
\text { pior prognóstico (área valvar }<0,7 \mathrm{~cm}^{2} \text {, } \\
\text { gradiente médio transvalvar aórtico }> \\
60 \mathrm{mmHg} \text { e velocidade de jato transvalvar } \\
\text { aórtico }>5 \mathrm{~m} / \mathrm{s} \text { ), desde que o risco } \\
\text { cirúrgico do paciente seja baixo. }\end{array}$ & C \\
\hline Classe Ilb & $\begin{array}{l}\text { Pacientes com EAo importante, } \\
\text { assintomáticos, com alto risco de } \\
\text { progressão da doença (idade avançada, } \\
\text { calcificação valvar acentuada, DAC). }\end{array}$ & C \\
\hline Classe Ilb & $\begin{array}{l}\text { Pacientes com EAo discreta a moderada } \\
\text { que serão submetidos a cirurgia de } \\
\text { revascularização miocárdica e que } \\
\text { apresentem preditores de progressão rápida } \\
\text { da EAo, como calcificação valvar acentuada. }\end{array}$ & C \\
\hline Classe Ilb & $\begin{array}{l}\text { Pacientes com EAo com gradiente médio } \\
<40 \mathrm{mmHg} \text { e disfunção ventricular, mas } \\
\text { com reserva contrátil. }\end{array}$ & C \\
\hline Classe Ilb & $\begin{array}{l}\text { Pacientes com EAo importante, } \\
\text { assintomáticos, com arritmias ventriculares } \\
\text { complexas durante o teste de esforço. }\end{array}$ & C \\
\hline Classe Ilb & $\begin{array}{l}\text { Pacientes com EAo importante, } \\
\text { assintomáticos, com hipertrofia } \\
\text { ventricular importante (septo e parede } \\
\text { posterior }>15 \mathrm{~mm}) \text {. }\end{array}$ & C \\
\hline Classe III & $\begin{array}{l}\text { Pacientes assintomáticos com EAo que } \\
\text { não se encaixem nas indicações acima. }\end{array}$ & B \\
\hline
\end{tabular}

Eao - Estenose aórtica; FE - Fração de ejeção; DAC - Doença arterial coronariana. 


\section{Fluxograma - Indicações de tratamento cirúrgico da Eao}

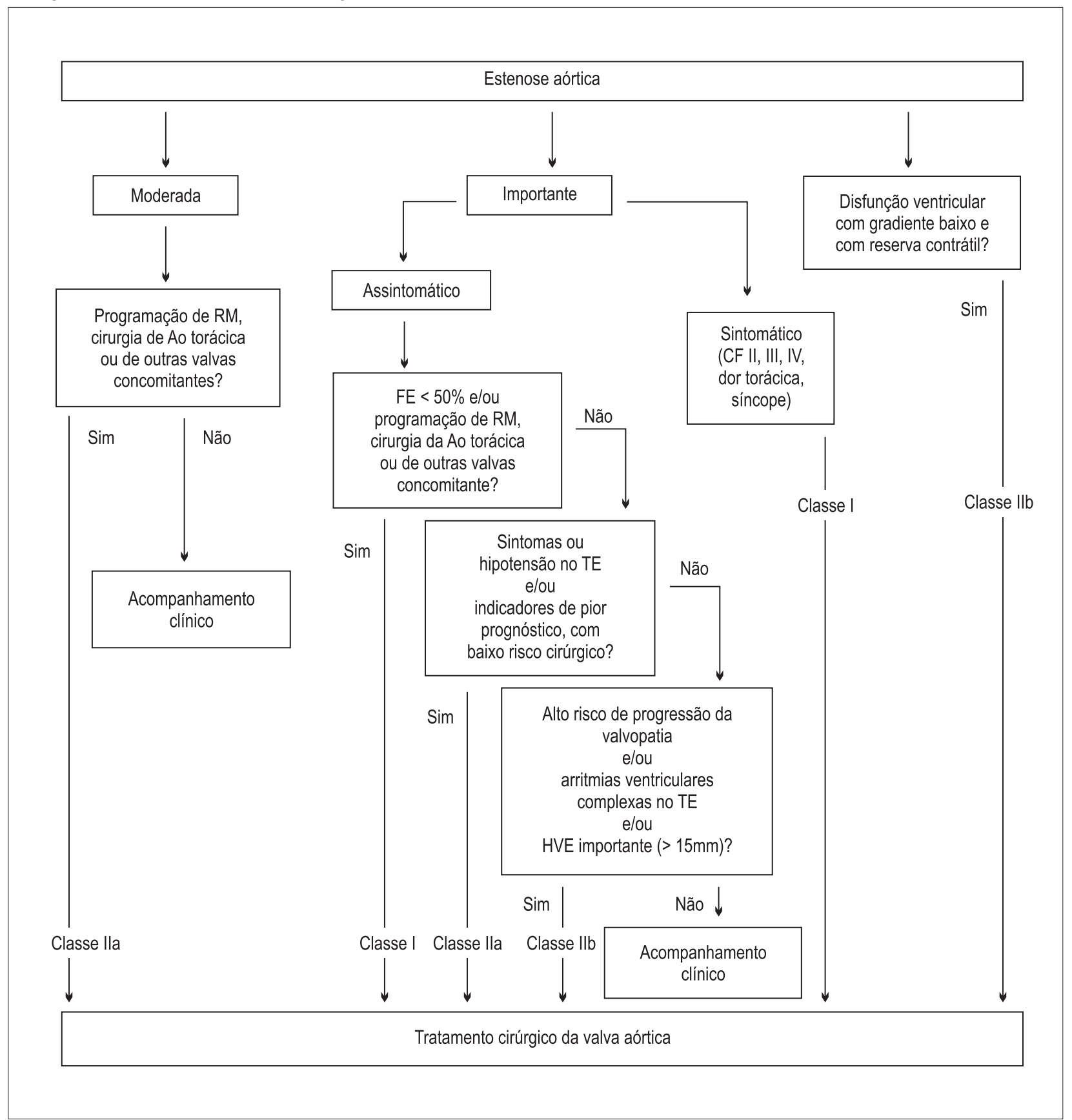

CF - classe funcional; FE - fração de ejeção do ventrículo esquerdo; RM - cirurgia de revascularização do miocárdio; Ao - aorta; TE - teste de esforço; HVE - hipertrofia de ventrículo esquerdo.

7.3.3. Tratamento percutâneo da estenose valvar aórtica: valvuloplastia por cateter-balão e implante de bioprótese por cateter

A substituição cirúrgica da valva aórtica é, há décadas, o tratamento de eleição para pacientes com estenose aórtica, determinando alívio dos sintomas e aumento da sobrevida. Entretanto, o risco cirúrgico aumenta expressivamente com o avançar da idade e com a associação de comorbidades, o que faz que mais de um terço dos octogenários com estenose aórtica sintomática sejam recusados para a cirurgia ${ }^{161}$. Nesses pacientes, a Valvuloplastia Aórtica por Cateter-Balão (VACB) determina melhora apenas temporária dos sintomas e do gradiente de pressão transvalvar, pela alta incidência de reestenose, sendo indicada, atualmente, apenas excepcionalmente, como medida paliativa ou como ponte para um tratamento definitivo ${ }^{165}$. Esses achados estimularam o desenvolvimento de dispositivos para 
a substituição da valva aórtica por cateter. Atualmente, a experiência acumulada com o emprego dessas biopróteses em pacientes com contraindicação à cirurgia ou com alto risco cirúrgico indica que a técnica é segura e eficaz ${ }^{166-171}$. Dessa forma, para os pacientes cujo risco operatório é muito alto (acima de 15\% de mortalidade), as abordagens percutânea ou transventricular (transapical) constituem opções terapêuticas aceitáveis ${ }^{172}$.

\subsubsection{Seleção dos pacientes para implante de bioprótese} por cateter

Em 2002, Cribier e cols. ${ }^{173}$ realizaram o primeiro implante em humanos utilizando o acesso percutâneo através dos vasos femorais. Atualmente, a indicação do implante percutâneo de biopróteses aórticas restringe-se aos pacientes que, pela idade avançada e/ou por comorbidades, têm contraindicação ou risco elevado para o tratamento cirúrgico convencional (tabela 20). A avaliação desses pacientes e a indicação do tratamento por cateter devem ser idealmente conduzidos por equipe médica multidisciplinar.

Tabela 20 - Recomendações para implante de bioprótese valvar aórtica por cateter

\begin{tabular}{lcc}
\hline $\begin{array}{l}\text { Classe de } \\
\text { recomendação }\end{array}$ & Indicação & $\begin{array}{c}\text { Nível de } \\
\text { evidência }\end{array}$ \\
\hline Classe I & $\begin{array}{c}\text { Pacientes portadores de EAo importante } \\
\text { com indicação de CVAo, porém com } \\
\text { contraindicações ao tratamento cirúrgico } \\
\text { convencional. }\end{array}$ & B \\
\hline Classe Ila & $\begin{array}{c}\text { Como alternativa ao tratamento cirúrgico } \\
\text { em pacientes portadores de EAo } \\
\text { importante com indicação de CVAo, } \\
\text { porém com alto risco cirúrgico. }\end{array}$ & B \\
\hline Classe III & $\begin{array}{c}\text { Como alternativa ao tratamento } \\
\text { cirúrgico em pacientes portadores de }\end{array}$ & C \\
& $\begin{array}{c}\text { EAo importante sem contraindicação à } \\
\text { cirurgia e sem risco cirúrgico elevado. }\end{array}$ & \\
\hline
\end{tabular}

Eao - Estenose aórtica; CVAo - Cirurgia da valva aórtica.

Uma cuidadosa avaliação clínica com conhecimento e adequação dos escores de risco é fundamental. Ademais, o estabelecimento de fluxos e normativas para escolha do acesso arterial, tipo de dispositivo, técnica de implante, suporte anestésico, cuidados periprocedimentos e seguimento dos pacientes a curto, médio e longo prazos é indispensável. O processo é formado por etapas que não podem ser negligenciadas e que são as determinantes do sucesso da técnica.

A avaliação por meio do uso restrito de escores de risco é limitada, uma vez que esses, por vezes, não traduzem a realidade do risco cirúrgico de um determinado paciente individual ao não incluírem diversos fatores que, conhecidamente, elevam de forma significativa o risco do tratamento cirúrgico. Como exemplo, pode-se citar a presença de aorta em porcelana ou irradiação torácica prévia, ausentes no cálculo do EuroScore. Dessa maneira, os escores de risco apenas apoiam a avaliação clínica, que persiste soberana.
Pode-se obter também uma avaliação semiquantitativa por meio dos escores de fragilidade, que levam em consideração critérios clínicos, laboratoriais e funcionais. O escore de fragilidade da Columbia utilizado no estudo randomizado PARTNER é um deles ${ }^{170,171}$.

$\mathrm{O}$ alto risco do tratamento cirúrgico isoladamente não é suficiente para a indicação do procedimento por cateter. É parte integrante e essencial da avaliação a análise de parâmetros morfológicos do complexo aórtico e da via de acesso, objetivando determinar a exequibilidade técnica da substituição valvar por cateter. Para isso, a ecocardiografia, a angiotomografia de múltiplos detectores, a aortografia e a arteriografia do território iliacofemoral podem ser úteis e fornecer as informações essenciais para o planejamento do procedimento. Para descartar DAC grave associada, a cineangiocoronariografia também é indicada.

A anatomia femoral deve ser favorável. Grande tortuosidade na aorta, e artérias ilíacas e femorais estreitas ou muito envolvidas por ateroesclerose dificultam o procedimento, aumentando incidência de complicações embólicas distais. Placas em excesso na aorta ascendente também aumentam a morbidade, podendo promover embolização cerebral.

A seleção de pacientes para o implante transcateter de prótese valvar aórtica deve obedecer aos seguintes critérios gerais de avaliação:

- Presença de EAo importante sintomática;

- Idade > 80 anos ou alta probabilidade de morbimortalidade cirúrgica;

- Presença de comorbidade que eleve de forma proibitiva o risco da cirurgia cardíaca tradicional, por exemplo: cirrose hepática; doença pulmonar grave [Volume Expiratório Forçado no Primeiro Segundo (VEF1) < 1L ou uso de oxigenioterapia domiciliar]; múltiplas cirurgias cardíacas prévias, especialmente com enxerto de artéria mamária; aorta em porcelana; HP acentuada ( $>60 \mathrm{mmHg}$ ); radioterapia torácica prévia; fragilidade orgânica acentuada.

- Presença de condição anatômica e morfológica favorável para o procedimento por cateter, incluindo a avaliação pormenorizada da via de acesso e trajeto vascular, bem como dos aspectos cardíacos de interesse para a exequibilidade do procedimento.

7.3.3.2. Implante de bioprótese por cateter: procedimento e dispositivos

O sistema CoreValve consiste de três folhetos de pericárdio suíno, montados e suturados em um stent de nitinol de $5 \mathrm{~cm}$ de comprimento, autoexpansível. O implante é realizado exclusivamente por acesso retrógrado, por punção ou dissecção das artérias femoral ou subclávia ou pelo acesso transaórtico.

A prótese Edwards-Sapien consiste de um stent de aço inoxidável, expansível por balão, no qual se inserem três folhetos de pericárdio bovino. O procedimento pode ser realizado por acesso anterógrado - por via transapical, através de pequena toracotomia - ou retrógrado. 
O preparo para o implante consiste na administração de aspirina (100mg) e clopidogrel (dose de ataque de $300 \mathrm{mg}$ seguida de $75 \mathrm{mg}$ por dia), com início na véspera do procedimento e manutenção, idealmente, por três aseis meses. Recomenda-se antibioticoprofilaxia. Em geral, a intervenção por cateter pode ser realizada com anestesia local e sedação leve, mas, dependendo da condição clínica do paciente, a anestesia geral pode ser indicada.

Em geral, utiliza-se a VACB como pré-dilatação e, em seguida, libera-se a endoprótese valvar. Durante a prédilatação por balão, utiliza-se marca-passo provisório para elevar a frequência cardíaca até 180 a 220bpm, evitando o deslocamento do balão no momento de sua insuflação. Após o implante da endoprótese, o marca-passo também é útil para a manutenção do ritmo cardíaco, no caso de ocorrerem bradiarritmias e bloqueio atrioventricular total, devendo ser mantido por, pelo menos, 24 a 48 horas após a substituição por cateter da valva aórtica. A realização da aortografia ao final da intervenção é útil para avaliar a presença de regurgitação perivalvar.

A abordagem transapical da valva aórtica é realizada através do ápice do VE e o seu conceito é minimamente invasivo $^{174}$. A via de acesso é obtida por uma minitoracotomia anterior no quinto espaço intercostal esquerdo, por onde, através da punção do ápice do VE, efetua-se valvotomia aórtica por cateter-balão. A seguir, um dispositivo (haste), com a prótese no seu interior, é introduzido pelo orifício na ponta do VE avançando até a aorta onde, sob visão fluoroscópica, é liberada no nível do ânulo aórtico. O auxílio da ETE transoperatória e da fluoroscopia é fundamental para o posicionamento e escolha do tamanho adequado da prótese ${ }^{175}$. A CEC com acesso femoral pode ou não ser empregada como suporte e deve permanecer preparada na sala operatória. O acesso transapical evita manuseio excessivo da aorta abdominal, ascendente e descendente, e por isso a incidência de complicações tromboembólicas é menor, em comparação ao acesso percutâneo. Em semelhança à abordagem percutânea, podem ocorrer acidente vascular cerebral, oclusão de óstios coronarianos, distúrbios da condução atrioventricular, lesões da valva mitral, lesões da parede ventricular esquerda e escapes periprotéticos.

\subsubsection{Resultados do implante de biopróteses aórticas} por cateter

Estudos clínicos recentes demonstraram a exequibilidade, a segurança e a eficácia desse tipo de intervenção, com resultados animadores, ainda que de curto e médio prazos $^{166-171}$, que podem ser resumidos da seguinte forma:

- Os estudos divulgados são unânimes em demonstrar o adequado funcionamento das biopróteses aórticas implantadas por cateteres. Após o implante, atingese área valvar de aproximadamente $1,5 \mathrm{~cm}^{2}$ e notase queda importante ou resolução completa do gradiente de pressão transvalvar aórtico. A melhora hemodinâmica precoce reflete-se rapidamente na melhora dos sintomas de insuficiência cardíaca. Em médio prazo, ocorre melhora na função e redução da hipertrofia do VE. Cinquenta por cento a $70 \%$ dos casos apresentam regurgitação perivalvar discreta ou moderada ao final da intervenção, que tende a diminuir no seguimento. Regurgitação perivalvar acentuada ocorre em torno de 5\% dos casos e pode ser manuseada com redilatações da prótese com balões ou até o implante de prótese adicional. Não há relato de degeneração estrutural da prótese no seguimento de até dois anos.

- Complicações vasculares no local de acesso ocorrem em $1,9 \%$ a $15 \%$ dos casos, e acidente vascular cerebral em $1,9 \%$ a $10 \%$ dos casos. A oclusão de artérias coronarianas pelas biopróteses é rara $(<1 \%)$. Os bloqueios atrioventriculares com necessidade de implante de marca-passo permanente são detectados em até $20 \%$ a $40 \%$ dos pacientes submetidos ao procedimento com o dispositivo CoreValve e em torno de 5\% com a bioprótese Edwards-Sapien.

- A mortalidade em 30 dias varia de 5\% a 18\%. Deve-se ressaltar, entretanto, que essas taxas de mortalidade são inferiores àquelas estimadas pelo EuroScore para o tratamento cirúrgico desses pacientes. Algumas publicações apresentam o seguimento clínico tardio de até dois anos, com sobrevida de $70 \%$ a $80 \%$ e melhora expressiva na condição clínica da maior parte dos pacientes. A maioria dos óbitos tardios ocorre em decorrência de comorbidades e não de problemas com a prótese.

- Recentemente, divulgaram-se os dados do estudo randomizado PARTNER ${ }^{170,171}$ utilizando a bioprótese Edwards-Sapien. A mortalidade após um ano de tratamento em pacientes inoperáveis foi reduzida de aproximadamente $50 \%$ com o tratamento clínico convencional para 30\% com o implante da bioprótese por cateter. Nos casos considerados de alto risco cirúrgico, o implante por cateter apresentou mortalidade após um ano equivalente àquela obtida com o tratamento cirúrgico, demonstrando que o implante por cateter é uma boa opção terapêutica para essa população. Diversos registros europeus com a bioprótese CoreValve confirmam esses achados.

- As vias de acesso femoral, subclávia, transaórtica ou transapical têm sido descritas. Na prática, observa-se que a via femoral é aquela com maior exequibilidade técnica e menor necessidade de envolvimento de múltiplos profissionais médicos, culminando por ser a mais comumente utilizada no dia-a-dia, o que faz dela, possivelmente, a via de escolha preferencial, quando tecnicamente factível.

- O impacto clínico do procedimento está estreitamente relacionado à experiência. Após a superação da curva de aprendizado, o índice de sucesso de aproximadamente $90 \%$ é sistematicamente relatado, com embolização da prótese durante o procedimento ocorrendo somente em raros casos.

A ocorrência de insuficiência aórtica significativa $(>2+/ 4+)$ tem sido relacionada a pior prognóstico. Em um registro com as próteses CoreValve e Edwards-Sapien ${ }^{176}$, 17\% dos pacientes 
apresentaram insuficiência aórtica significativa pós-implante. Esses indivíduos evoluíram mais frequentemente com baixo débito cardíaco (20\% versus 4,4\%), insuficiência respiratória (16,5\% versus $7,1 \%)$ e óbito (15,1\% versus $6,7 \%)$ em 30 dias. Os fatores implicados na ocorrência de regurgitação significativa parecem relacionar-se às características anatômicas próprias do complexo anuloaórtico (configuração circular ou elíptica, calcificação assimétrica), à desproporção entre o anel valvar e a prótese escolhida, e ao posicionamento incorreto da prótese.

Investimento em treinamento constitui um dos pontos fundamentais do processo. A criação de uma equipe multidisciplinar é mandatória, visto que a associação de clínicos, intervencionistas e cirurgiões auxiliará na adequada seleção dos pacientes e na execução dos procedimentos. Profissionais experientes na interpretação de ETT e ETE, angiografias e tomografias também deverão fazer parte do time, visto que uma adequada mensuração dos referenciais anatômicos é imperativa. Além disso, o centro deverá ser treinado e certificado, considerando que todos os cuidados pré-, trans- e pós-procedimentos são vitais para seu sucesso. Um programa que estabeleça e normatize uma curva de aprendizado progressiva com preceptores capacitados também é indispensável, já que os detalhes e cuidados são muitos e a técnica de implante e manejo de eventuais complicações deve ser muito refinada.

Apesar de atraente, a abordagem percutânea merece indicação cuidadosa e há necessidade de mais estudos em médio e longo prazos para a adequada validação do método.

7.3.3.4. Implante de bioprótese por cateter em pacientes com disfunção de prótese biológica

O implante valvar transcateter também tem sido uma alternativa à cirurgia convencional nos pacientes com disfunção de prótese biológica considerados inoperáveis. A experiência clínica global com o uso da técnica conhecida como "valva em valva" tem crescido e o método já foi incorporado como estratégia assistencial em situações de exceção, com base em evidências ainda oriundas de séries de casos, ${ }^{177-179}$ como um procedimento off-label. Os maiores potenciais de uso são para as posições aórtica e mitral, embora já existam relatos para as posições pulmonar e tricúspide. A indicação, a via de acesso e a seleção do dispositivo a ser utilizado devem passar pelo crivo e avaliação de equipe multidisciplinar (clínico, intervencionista e cirurgião), especialmente nas situações em que as evidências são ainda mais escassas, como em casos considerados de alto risco cirúgico, porém sem contraindicação à cirurgia. Recomenda-se que esse tipo de procedimento seja realizado somente em centros com experiência.

\subsubsection{Valvuloplastia Aórtica com Cateter-balão (VACB)}

A VACB é um procedimento no qual um ou mais balões são colocados através da valva aórtica e inflados com a finalidade de reduzir a gravidade da estenose aórtica ${ }^{180}$. Ocasiona a fratura do cálcio depositado nos folhetos valvares, com alargamento do ânulo aórtico e separação das comissuras ${ }^{181}$.
Apesar das altas taxas de possíveis complicações (cardiovasculares e neurológicas), os resultados imediatos normalmente produzem quedas moderadas dos gradientes transvalvares com melhora sintomática, mas com apenas um pequeno aumento da área valvar, o que determina altas taxas de reestenose e pobre resultado em médio e longo prazos ${ }^{182}$.

A VACB nunca se firmou como um substituto à CVAo, e até o advento do implante valvar aórtico percutâneo sua indicação vinha sendo muito restrita. Todavia, nessa circunstância, sua utilização adjunta é recomendada, devendo, por protocolo, preceder o implante valvar aórtico percutâneo ${ }^{183}$.

O procedimento ainda é considerado como "ponte" para cirurgia em pacientes hemodinamicamente instáveis sem condições cirúrgicas, ou, ocasionalmente, como medida paliativa em pacientes com contraindicação à cirurgia valvar. Tem, ainda, potencial para uso como ponte para o implante percutâneo valvar aórtico (tabela 21) ${ }^{184}$.

\section{Tabela 21 - Recomendações para valvuloplastia aórtica por cateter-balão}

\begin{tabular}{lcc}
\hline $\begin{array}{l}\text { Classe de } \\
\text { recomendação }\end{array}$ & Indicação & $\begin{array}{c}\text { Nível de } \\
\text { evidência }\end{array}$ \\
\hline Classe Ila & $\begin{array}{c}\text { Em pacientes hemodinamicamente } \\
\text { instáveis, com elevado risco cirúrgico } \\
\text { e impossibilidade momentânea de } \\
\text { realização de implante de bioprótese por } \\
\text { cateter, como ponte para o tratamento } \\
\text { cirúrgico ou para implante de bioprótese } \\
\text { aórtica por cateter. }\end{array}$ & C \\
\hline Classe IIb & $\begin{array}{c}\text { Como tratamento paliativo em pacientes } \\
\text { sintomáticos nos quais o tratamento } \\
\text { cirúrgico e o implante de bioprótese por } \\
\text { cateter estão contraindicados. }\end{array}$ & C \\
& Como alternativa ao tratamento cirúrgico & \\
& $\begin{array}{c}\text { ou ao implante por cateter de bioprótese } \\
\text { aórtica em pacientes adultos portadores } \\
\text { de estenose valvar aórtica. }\end{array}$ & B \\
\hline
\end{tabular}

7.3.4.1. Valvuloplastia aórtica em estenose aórtica congênita em recém-nascidos e crianças

A VACB progressivamente substituiu a valvotomia cirúrgica como a modalidade terapêutica paliativa inicial de eleição da EAo importante de origem congênita na absoluta maioria dos centros mundiais. A VACB está indicada nos pacientes com EAo congênita com gradiente picoapico no cateterismo maior que $50 \mathrm{mmHg}$ sob anestesia geral ou sedação. O procedimento também está indicado na vigência de gradientes menores em situações em há disfunção ventricular esquerda (como no recém-nascido com EAo crítica com fluxo sistêmico dependente do canal arterial) ou sinais de isquemia miocárdica (angina, alterações da onda T e/ou do segmento ST em repouso ou exercício) ou síncopes.A valvuloplastia é contraindicada quando há insuficiência aórtica moderada ou importante previamente à dilatação. Apesar de cerca de 50\% dos pacientes submetidos a valvuloplastia apresentarem surgimento ou piora da insuficiência aórtica, a insuficiência importante ocorre em menos que $5 \%$ dos casos. 
Os resultados de médio e longo prazos depois de um procedimento bem-sucedido são, de modo geral, bons. Entretanto, a maioria dos pacientes requer um novo procedimento (cirúrgico ou percutâneo) para tratamento de reestenose ou de insuficiência aórtica em períodos variados de tempo, denotando o caráter paliativo do procedimento ${ }^{185-189}$. Estima-se que a probabilidade de estar livre de reintervenções é de 86\%, 67\% e $46 \%$, com 1, 5 e 12 anos, respectivamente, após a valvuloplastia em pacientes maiores que seis meses de idade ${ }^{187}$.

\subsection{Insuficiência cardíaca aguda no paciente com Estenose Aórtica (EAo)}

O paciente com EAo com insuficiência cardíaca aguda ou agudizada ou choque cardiogênico representa um desafio terapêutico. Trata-se de uma condição cujo tratamento definitivo consiste na correção cirúrgica da obstrução à via de saída do VE, por meio da cirurgia da valva aórtica. Entretanto, em um paciente agudamente descompensado, muitas vezes portador de disfunção miocárdica significativa, e hemodinamicamente instável, esse procedimento acarreta um risco de mortalidade perioperatória que pode chegar a níveis tão altos quanto $30 \%$ a $50 \%{ }^{140}$.

Apesar das reservas acerca do uso de vasodilatadores em pacientes com EAo, estudos ${ }^{140,190}$ indicaram aumento do índice cardíaco com o uso de nitroprussiato nos pacientes com insuficiência cardíaca aguda associada a essa valvopatia, sendo esse aumento demonstrado nos indivíduos com menor área valvar, menor fração de ejeção e menor índice cardíaco inicial ${ }^{190}$. Esse efeito poderia ser explicado pela diminuição - induzida pelo agente - da resistência vascular periférica, sabidamente aumentada em pacientes com insuficiência cardíaca aguda (ou crônica agudizada), com consequente aumento do débito cardíaco, apesar da estenose valvar. O mesmo raciocínio explicaria a ausência de benefício do uso dessa medicação em pacientes com fração de ejeção preservada.

É possível a utilização de digitálicos nos pacientes com disfunção ventricular ${ }^{11}$.Em razão do potencial desencadeamento de arritmias ou isquemia miocárdica, o uso de dobutamina nessa população é desencorajado por alguns autores ${ }^{140}$.

Um estudo publicado em 2011 com o uso de balão intra-aórtico demonstrou efeito benéfico sobre parâmetros hemodinâmicos, com melhora significativa do índice cardíaco, da resistência vascular sistêmica e da pressão venosa central após 24 horas do uso do dispositivo em 25 pacientes com estenose aórtica em choque cardiogênico ${ }^{191}$

Outro tratamento estudado nesse contexto é a VACB como ponte para a cirurgia. Entretanto, conforme exposto no item anterior deste documento, seu pequeno benefício sobre a área valvar associado a altas taxas de complicações limita sua utilização mesmo nesses pacientes ${ }^{192}$. Com o progressivo desenvolvimento do implante de bioprótese por cateter, tem sido levantada a possibilidade da realização desse procedimento também nesses pacientes instáveis. Entretanto, são necessários estudos adicionais para sua recomendação nesse contexto.

Por fim, em 2006 foi publicado o relato do uso de um dispositivo de assistência ventricular como ponte para o tratamento cirúrgico em uma paciente com EAo em choque cardiogênico, com resultado satisfatório ${ }^{193}$.

As recomendações para o tratamento da insuficiência cardíaca aguda em portadores de EAo estão na tabela 22.

Tabela 22 - Recomendações para o tratamento da insuficiência cardíaca aguda em pacientes com estenose aórtica

\begin{tabular}{lcc}
\hline $\begin{array}{l}\text { Classe de } \\
\text { recomendação }\end{array}$ & Indicação & $\begin{array}{c}\text { Nível de } \\
\text { evidência }\end{array}$ \\
\hline Classe I & Cirurgia da valva aórtica. & $\mathrm{C}$ \\
\hline Classe Ilb & $\begin{array}{c}\text { Nitroprussiato visando à estabilização } \\
\text { clínica para posterior tratamento } \\
\text { cirúrgico. }\end{array}$ & $\mathrm{C}$ \\
\hline Classe Ilb & Balão intra-aórtico como ponte para o \\
tratamento cirúrgico. & $\mathrm{C}$ \\
\hline
\end{tabular}

\section{Insuficiência aórtica}

\subsection{Introdução}

A etiologia da lesão regurgitante valvar aórtica compreende um grande número de causas, destacando-se a dilatação idiopática da aorta, anormalidades congênitas (valva bicúspide), calcificação da valva, doença reumática, endocardite infecciosa, hipertensão arterial sistêmica, degeneração mixomatosa, dissecção da aorta ascendente e síndrome de Marfan. Outras causas menos frequentes incluem as lesões traumáticas, espondilite anquilosante, aortite sifilítica, artrite reumatoide, osteogênese imperfeita, síndrome de Ehlers-Danlos, síndrome de Reiter, estenose subaórtica e defeito do septo interventricular com prolapso da cúspide aórtica ${ }^{194,195}$.

A IAo geralmente se desenvolve de maneira lenta e insidiosa, com uma morbidade muito baixa durante uma longa fase assintomática. Alguns pacientes com IAo discreta permanecem assintomáticos por décadas e raramente necessitam de tratamento. Outros exibem progressão da lesão regurgitante com o desenvolvimento gradual da IAo importante, disfunção sistólica do VE e eventualmente insuficiência cardíaca.

\subsubsection{Fatores prognósticos}

Os principais fatores prognósticos na história natural da IAo são derivados de estudos prospectivos ${ }^{17,196-204} \mathrm{com}$ 593 pacientes inicialmente assintomáticos e com função ventricular preservada, que foram acompanhados por uma média de 6,6 anos. A taxa de mortalidade dessa população foi de $0,2 \%$ ao ano. O início dos sintomas normalmente precedeu o surgimento de disfunção ventricular; entretanto, alguns pacientes assintomáticos evoluíram para diminuição da função do VE.

O aparecimento de sintomas e a redução da função sistólica do VE são os principais fatores de pior prognóstico e embasam o tratamento cirúrgico da IAo. Adilatação progressiva do VE, sem sintomas associados e com manutenção da função ventricular, embora indique progressão da doença, 
não necessariamente tem caráterirreversível. Em estudo conduzido com 75 pacientes assintomáticos com IAo importante de etiologia reumática, a estratégia de indicar tratamento cirúrgico baseada no surgimento de sintomas mesmo em pacientes com Diâmetro Diastólico final do Ventrículo Esquerdo (DdVE) maior que $75 \mathrm{~mm}$ e DsVE maior que $55 \mathrm{~mm}$ com função de VE normal foi eficaz em promover a melhora da qualidade de vida e com regressão da dilatação, com taxa de sobrevida de 90,6\% em dez anos de acompanhamento ${ }^{17}$.

\subsection{Diagnóstico}

Na IAo crônica grave pode haver sobrecarga atrial esquerda e de VE por critérios de voltagem ou por alterações do segmento ST e onda T, além de distúrbio da condução intraventricular. Na radiografia de tórax, ocorre cardiomegalia por dilatação e hipertrofia do VE que é proporcional ao grau de sobrecarga de volume. Na forma aguda, podem ser observados sinais de congestão pulmonar, sem cardiomegalia.

\subsubsection{Ecocardiografia}

A abordagem ecocardiográfica do paciente com IAo deve incluir a determinação de etiologia e gravidade da lesão valvar, juntamente com a definição do efeito da insuficiência sobre o tamanho e a função ventricular. A avaliação abrangente da anatomia e função da valva aórtica é feita através de ecocardiografia 2D e 3D, Doppler pulsado, contínuo e de fluxo em cores $^{25}$. Utilizam-se medições qualitativas e quantitativas; o uso das medidas quantitativas é altamente recomendado e de suma importância, especialmente na caracterização de lesões na faixa intermediária ou grave.

Ecocardiografias bidimensional e em 3D fornecem informações importantes sobre a anatomia da valva, dimensões da raiz da aorta, e resposta do VE à sobrecarga de volume. IAo crônica e grave ocorrem na presença de significativas alterações estruturais da valva e/ou raiz da aorta, levando a aumento do VE.

A avaliação do tamanho e função do VE na IAo significativa é importante por fornecer informações para diferenciação de processo agudo ou crônico, além de ajudar a determinar o momento oportuno para a intervenção cirúrgica. A aferição dos volumes do VE pela ecocardiografia 3D e o cálculo subsequente da FE por essa técnica são incentivados, sempre que disponíveis. O Doppler em cores mostra o fluxo regurgitante através da valva aórtica durante a diástole. Esse fluxo tem três componentes: a região de convergência de fluxo na aorta ou PISA, a vena contracta através do orifício regurgitante, e a direção e largura do jato no trato de saída do VE. A obtenção do pico de velocidade da regurgitação e da integral do tempo de velocidade pelo Doppler contínuo permite o cálculo da área do orifício regurgitante aórtico (AOR) e volume regurgitante. A vena contracta parece ser um método mais fidedigno do que a largura do jato e da área na via de saída do VE na avaliação da gravidade da $\mathrm{IAO}^{205}$. Seu valor associado a melhor sensibilidade e especificidade de IAo importante é de $0,6 \mathrm{~cm}^{2}$. A avaliação do tamanho do jato na via de saída do VE pode ser feita de forma qualitativa ou quantitativa. Os critérios para se definir IAo importante são uma proporção $\geq 65 \%$ para a largura do jato, e $\geq 60 \%$ para área do jato. Tal como acontece com o método PISA, um volume regurgitante $\geq 60 \mathrm{~mL}$ e Área do Orifício de Refluxo - AOR $\geq 0,30 \mathrm{~cm}^{2}$ são consistentes com IAo importante ${ }^{25}$. ETE pode ser necessária em pacientes com janelas acústicas pobres, nos quais a ETT não pode fornecer delineamento adequado da anatomia ou registros de Doppler precisos.

Com base em dados da literatura e em um consenso dos membros da comissão da Sociedade Americana de Ecocardiografia, é proposto um esquema de sinais específicos (especificidade $\geq 90 \%$ ) para a classificação de gravidade da $1 \mathrm{AO}^{25}$. O primeiro passo é fazer uma triagem de avaliação da largura do jato. Se o jato é central e a largura $<25 \%$ da via de saída, a lesão é discreta. Se o exame de triagem sugere IAo além de discreta, o próximo passo é a medida da vena contracta. Se a vena contracta é $>0,6 \mathrm{~cm}$, o Doppler contínuo deve ser utilizado para documentar o reverso do fluxo holodiastólico na aorta descendente abdominal, confirmando assim a presença de uma lesão importante. Se os dados primários podem ser quantificados, é desejável que ecocardiografistas com experiência em métodos quantitativos façam a aferição do grau de IAo, incluindo o volume e a fração regurgitantes - que expressam a sobrecarga de volume do VE - e o orifício efetivo de regurgitação, que permitem a quantificação da gravidade da lesão.

O emprego da ecocardiografia 3D possibilita também a aferição da vena contracta tridimensional do jato de insuficiência aórtica e a análise detalhada da aorta ascendente, do arco aórtico e do segmento proximal da aorta descendente. De forma semelhante à investigação ecocardiográfica 3D da valva mitral, há ainda carência de estudos para a determinação do impacto dessa nova tecnologia para a modificação da decisão clínica.

$\mathrm{Na}$ tabela 23, encontram-se as recomendações de ecocardiografia na IAo.

Tabela 23 - Recomendações de ecocardiografia na insuficiência aórtica

\begin{tabular}{lcc}
\hline $\begin{array}{l}\text { Classe de } \\
\text { recomendação }\end{array}$ & Indicação & $\begin{array}{c}\text { Nível de } \\
\text { evidência }\end{array}$ \\
\hline Classe I & $\begin{array}{c}\text { Diagnóstico e avaliação da etiologia e } \\
\text { gravidade da IAo aguda ou crônica e } \\
\text { suas repercussões ventriculares. }\end{array}$ & $\mathrm{C}$ \\
\hline Classe I & Avaliação de dilatação da raiz da aorta. & $\mathrm{C}$ \\
\hline Classe I & $\begin{array}{l}\text { Reavaliação periódica anual do } \\
\text { tamanho e função do VE em pacientes } \\
\text { com IAo importante assintomáticos. }\end{array}$ & $\mathrm{C}$ \\
\hline Classe I & $\begin{array}{l}\text { Reavaliação de pacientes com } \\
\text { mudança de sintomas e sinais. }\end{array}$ & $\mathrm{C}$ \\
\hline Classe I & $\begin{array}{c}\text { Após intervenção cirúrgica da valva } \\
\text { aórtica, como nova avaliação de base. }\end{array}$ & $\mathrm{C}$ \\
\hline
\end{tabular}

lao - Insuficiência aórtica; VE - Ventrículo esquerdo.

\subsubsection{Cateterismo cardíaco na insuficiência aórtica}

O cateterismo cardíaco geralmente não é necessário em pacientes com IAo a menos que persistam dúvidas sobre o grau da lesão ou disfunção do VE apesar do exame 
físico e testes não invasivos, ou a menos que a CVAo esteja contemplada e seja necessário acessar a anatomia coronária (tabela 24). Em alguns pacientes que são submetidos a cateterismo esquerdo para cineangiocoronariografia, a aortografia e medidas hemodinâmicas podem fornecer dados suplementares úteis.

\section{Tabela 24 - Recomendações de cateterismo cardíaco na} insuficiência aórtica

\begin{tabular}{lcc}
\hline $\begin{array}{l}\text { Classe de } \\
\text { recomendação }\end{array}$ & Indicação & $\begin{array}{c}\text { Nível de } \\
\text { evidência }\end{array}$ \\
\hline & $\begin{array}{c}\text { Cateterismo cardíaco com aortografia } \\
\text { e medida das pressões no VE } \\
\text { para avaliação da gravidade da } \\
\text { regurgitação, função ventricular e } \\
\text { dilatação da raiz da aorta quando os } \\
\text { testes não invasivos são inconclusivos. }\end{array}$ & B \\
\hline Classe I & $\begin{array}{c}\text { Cineangiocoronariografia antes da } \\
\text { cirurgia de CVAo em pacientes com } \\
\text { fatores de risco para DAC. }\end{array}$ & C \\
\hline Cateterismo cardíaco com & \\
\hline aortografia e medida de pressões \\
no VE para avaliação da função \\
ventricular, dilatação da aorta \\
e gravidade da regurgitação \\
antes da CVAo quando os testes \\
não invasivos são adequados e \\
concordantes com os achados \\
clínicos e a cineangiocoronariografia \\
não é necessária.
\end{tabular}

VE - Ventrículo esquerdo; CVAo - Cirurgia da valva aórtica; DAC - Doença arterial coronariana.

\subsubsection{Tomografia computadorizada e ressonância} magnética cardiovascular

A tomografia computadorizada permite reconhecer e quantificar a magnitude da dilatação da raiz aórtica, examinando a aorta torácica em toda a sua extensão. A angiotomografia de coronárias pode substituir e cineangiocoronariografia préoperatória em pacientes com baixa a moderada probabilidade pré-teste de DAC.

A ressonância magnética pode ser considerada na avaliação da lao, e suas recomendações estão sumarizadas na tabela 25. Alterações estruturais da valva podem ser visualizadas com precisão pela cinerressonância, assim como a mensuração das dimensões e dos volumes ventriculares, e ainda as dimensões da aorta. Esses dados podem fornecer informação importante sobre o efeito hemodinâmico da IAo no VE e na aorta. A medida volumétrica dos fluxos aórticos e da fração regurgitante tem grande precisão e reprodutibilidade, permitindo o seguimento acurado da evolução da gravidade da IAo, e podendo auxiliar no momento da indicação cirúrgica.
Tabela 25 - Recomendações do uso da ressonância magnética cardiovascular na insuficiência aórtica ${ }^{11}$

\begin{tabular}{lcc}
\hline $\begin{array}{l}\text { Classe de } \\
\text { recomendação }\end{array}$ & Indicação & $\begin{array}{c}\text { Nível de } \\
\text { evidência }\end{array}$ \\
\hline Classe lla & $\begin{array}{c}\text { Avaliação de FE ou volumes } \\
\text { ventriculares limitrofes ou duvidosos } \\
\text { pela ecocardiografia. }\end{array}$ & B \\
\hline Classe lla & $\begin{array}{c}\text { Quando há incerteza na gravidade da } \\
\text { IAo ou quando outras modalidades de } \\
\text { imagem tiveram resultados conflitantes. }\end{array}$ & B \\
\hline Classe lla & $\begin{array}{c}\text { Avaliação das dimensões da raiz aorta } \\
\text { e aorta ascendente. }\end{array}$ & B \\
\hline FE - Fração de ejeção; lao - Insuficiência aórtica.
\end{tabular}

\subsection{Tratamento}

\subsubsection{Tratamento farmacológico}

\subsubsection{Vasodilatadores}

O racional para o uso de vasodilatadores em IAo crônica baseia-se na possibilidade de redução da pós carga do VE, com consequente aumento do volume sistólico e diminuição do volume regurgitante. Assim, em tese, poderia ser postergada a velocidade de progressão da IAo, refletida na dilatação ventricular, perda de função ventricular e início de sintomas.

Existem 11 estudos clínicos relevantes publicados desde 1986 que avaliaram o efeito dos vasodilatadores em pacientes assintomáticos com IAo crônica importante 200,204,206-214. No total, 539 pacientes foram estudados, acompanhados por períodos que variaram de seis meses a sete anos. Desses estudos, oito compararam vasodilatador a placebo e apenas dois estudos foram de longo seguimento, com desfecho clínico. Foram avaliados bloqueadores dos canais de cálcio diidropiridínicos, hidralazina e inibidores da enzima de conversão da angiotensina ${ }^{215}$. Não houve uniformidade no método de avaliação hemodinâmica entre os estudos nem concordância dos achados entre vasodilatadores de mesma classe e de classes distintas. Os desfechos hemodinâmicos foram, no geral, favoráveis ao uso dos vasodilatadores, com diminuição da fração regurgitante e dos volumes ventriculares e aumento da FE; entretanto, não houve consistência na tradução desses achados em benefício clínico.

Dois estudos de maior relevância testaram o benefício clínico do uso de vasodilatadores em IAo. O primeiro ${ }^{200}$ comparou nifedipina de ação prolongada e digoxina em um estudo clínico randomizado de seis anos. O grupo nifedipina teve redução na indicação de CVAo baseada em sintomas ou perda da função ventricular. Entretanto, o estudo incluiu poucos pacientes, não houve grupo placebo, e a taxa de eventos foi baixa. Um segundo estudo ${ }^{204}$, com maior rigor metodológico, comparou placebo, nifedipina de ação prolongada e enalapril em 95 pacientes consecutivos com IAo importante seguidos por sete anos. Quando comparadas a placebo, nenhuma das medicações reduziu a incidência de sintomas ou perda de função ventricular com necessidade de cirurgia. Nesse estudo, as medicações também não tiveram 
benefício hemodinâmico, como diminuição da progressão da dilatação ventricular.

Dessa forma, não há atualmente evidências definitivas que suportem a indicação de vasodilatadores cronicamente, de rotina, para pacientes assintomáticos com IAo crônica, a menos que esses pacientes sejam hipertensos. Para o tratamento da hipertensão arterial sistêmica associada a IAo os vasodilatadores são uma excelente opção.

As recomendações sobre o uso de vasodilatadores na IAo encontram-se na tabela 26.

\section{Tabela 26 - Recomendações sobre o uso de vadodilatadores em insuficiência aórtica}

\begin{tabular}{lcc}
\hline $\begin{array}{l}\text { Classe de } \\
\text { recomendação }\end{array}$ & Indicação & $\begin{array}{c}\text { Nível de } \\
\text { evidência }\end{array}$ \\
\hline Classe I & $\begin{array}{c}\text { De forma regular para pacientes com IAo } \\
\text { importante que apresentam sintomas } \\
\text { ou disfunção ventricular esquerda } \\
\text { quando existem contraindicaçães ao } \\
\text { tratamento cirúrgico. }\end{array}$ & B \\
\hline Classe I & $\begin{array}{c}\text { Para uso de curto prazo como } \\
\text { ponte para o tratamento cirúrgico } \\
\text { em pacientes com IAo importante } \\
\text { sintomáticos, com ou sem disfunção } \\
\text { ventricular esquerda, candidatos à } \\
\text { intervenção cirúrgica. }\end{array}$ & C \\
\hline Classe IIb & $\begin{array}{c}\text { Como terapêutica de longo prazo } \\
\text { em pacientes com IAo importante } \\
\text { assintomáticos que apresentem } \\
\text { dilatação do ventrículo esquerdo, com } \\
\text { função ventricular preservada. }\end{array}$ & \\
\hline Como terapêutica de longo prazo em \\
pacientes com IAo discreta a moderada \\
efunção sistólica normal do ventrículo \\
esquerdo, na ausência de hipertensão \\
arterial sistêmica.
\end{tabular}

lao - Insuficiência aórtica.

\subsubsection{Tratamento cirúrgico}

O tratamento cirúrgico da IAo, mesmo em pacientes com acentuada redução da função ventricular esquerda, leva a um aumento da FE e da sobrevida da maioria dos pacientes, sem progressão da insuficiência cardíaca. Constitui o procedimento de escolha para tratamento da IAo importante em pacientes sintomáticos ou com disfunção ventricular.

As decisões para o tratamento de IAo crônica são baseadas na avaliação dos sintomas, da ecocardiografia e eventualmente de prova de esforço e da ressonância nuclear magnética (tabela 27).

Após a CVAo ocorre a recuperação da função ventricular esquerda, demonstrada por diminuição do volume sistólico, recuperação da $\mathrm{FE}$, regressão da hipertrofia miocárdica, redução dos diâmetros ventriculares esquerdos e normalização da relação massa/volume, e essa recuperação pode levar até três anos para ocorrer.

Uma vez que a IAo crônica, mesmo importante, em geral é bem tolerada, a CVAo não é recomendada para pacientes assintomáticos com função ventricular normal e tolerância adequada ao exercício.

Nos pacientes assintomáticos, a CVAo está indicada em pacientes com deterioração da função ventricular esquerda (FE $\leq 50 \%$ ) ou dilatação ventricular esquerda (DdVE $\geq$ $75 \mathrm{~mm}$ ou DsVE $\geq 55 \mathrm{~mm}$ ), especialmente os de etiologia não reumática. Ainda nos assintomáticos, a CVAo também pode ser indicada quando, durante prova de esforço, mesmo esforço leve gera o aparecimento de sintomas de insuficiência cardíaca ou diminuição da tolerância ao exercício.

Os pacientes com IAo importante com disfunção de VE e sintomas de insuficiência cardíaca têm maior risco cirúrgico, porém a sobrevida pós-operatória em médio prazo é maior que a dos pacientes tratados clinicamente.

Pacientes com IAo moderada podem ter a valva aórtica substituída durante cirurgias da aorta ascendente ou cirurgia de revascularização do miocárdio. A CVAo não está indicada em IAo moderada na ausência dessas condições, ou em IAo discreta.

A mortalidade operatória em pacientes com IAo pura que se submetem à substituição da valva aórtica isolada é relativamente baixa $(0,75 \%$ a $2,1 \%)$ em centros experientes, mas aumenta se a FE for reduzida $(4,2 \%$ a $7,7 \%)$.O resultado em longo prazo é relativamente bom em pacientes com IAo isolada após a troca valvar. A sobrevida global estimada é de 90\% em cinco anos, e 86\% em 10 anos.

\subsection{Situações clínicas especiais}

\subsubsection{Ectasia anuloaórtica}

$\mathrm{Na}$ ectasia anuloaórtica devem ser ressecadas a raiz da aorta, a porção dilatada da aorta ascendente e a valva aórtica. A cirurgia de Bentall de Bono, procedimento de eleição nesses casos, implica a troca da raiz da aorta por um tubo valvado com prótese valvar aórtica (mecânica ou biológica) e reimplante das artérias coronárias. Apresenta excelente resultado em longo prazo.

Alguns grupos cirúrgicos têm bons resultados com a ressecção da aorta ascendente e valvuloplastia aórtica pela técnica de remodelamento (Yacoub) ou reimplante valvar (David), mas esses procedimentos ainda não têm seu uso disseminado 217 .

\subsubsection{Dissecção aguda da aorta}

Na dissecção aguda da aorta tipo A de Stanford, a IAo importante ocorre por perda de sustentação das comissuras coronarianas como consequência da dissecção.

Em 80\% dos casos, a IAo pode ser tratada por ressuspensão das comissuras coronarianas e troca da aorta ascendente por tubo de dácron, e ocasionalmente pode ser necessário trocar a valva aórtica e a raiz da aorta (cirurgia de Bentall de Bono) ou reimplantar a valva aórtica (operação de David) ${ }^{217,218}$. 


\section{Tabela 27 - Recomendações para tratamento cirúrgico na insuficiência aórtica ${ }^{11,19,216}$}

\begin{tabular}{|c|c|c|}
\hline $\begin{array}{l}\text { Classe de } \\
\text { recomendação }\end{array}$ & Indicação & $\begin{array}{l}\text { Nível de } \\
\text { evidência }\end{array}$ \\
\hline Classe I & Pacientes com IAo importante sintomáticos. & $\mathrm{B}$ \\
\hline Classe I & Pacientes com IAo importante, assintomáticos, com FE < 50\% em repouso. & $\mathrm{B}$ \\
\hline Classe I & $\begin{array}{l}\text { Pacientes com IAo importante que serão submetidos concomitantemente a cirurgia de revascularização miocárdica ou cirurgia da aorta } \\
\text { ou de outras valvas cardíacas. }\end{array}$ & $\mathrm{C}$ \\
\hline Classe I & Pacientes com IAo importante aguda ou agudizada de qualquer etilogia levando a insuficiência cardíaca aguda. & B \\
\hline Classe Ila & Pacientes com IAo de etiologia não reumática, importante, assintomáticos, com FE $\geq 50 \%$, mas com DdVE > 75mm ou DsVE > 55mm. & $\mathrm{B}$ \\
\hline Classe Ilb & Pacientes com IAo de etiologia reumática, importante, assintomáticos, com FE $\geq 50 \%$, mas com DdVE > 75mm ou DsVE > 55mm. & $\mathrm{B}$ \\
\hline Classe IIb & $\begin{array}{c}\text { Pacientes com IAo importante, assintomáticos, com FE } \geq 50 \% \text {, mas com DdVE } 70-75 \mathrm{~mm} \text { ou DsVE } 50-55 \mathrm{~mm} \text {, associado a evidência de } \\
\text { resposta anormal ao exercício. }\end{array}$ & C \\
\hline Classe Ilb & $\begin{array}{l}\text { Pacientes com IAo moderada que serão submetidos concomitantemente a cirurgia de revascularização miocárdica ou cirurgia da aorta } \\
\text { ou de outras valvas cardíacas. }\end{array}$ & C \\
\hline Classe III & Pacientes com IAo importante, assintomáticos, com FE $\geq 50 \%$ e com DdVE $<70 \mathrm{~mm}$ e DsVE $<50 \mathrm{~mm}$. & B \\
\hline
\end{tabular}

Fluxograma de indicação de tratamento cirúrgico em pacientes com insuficiência aórtica

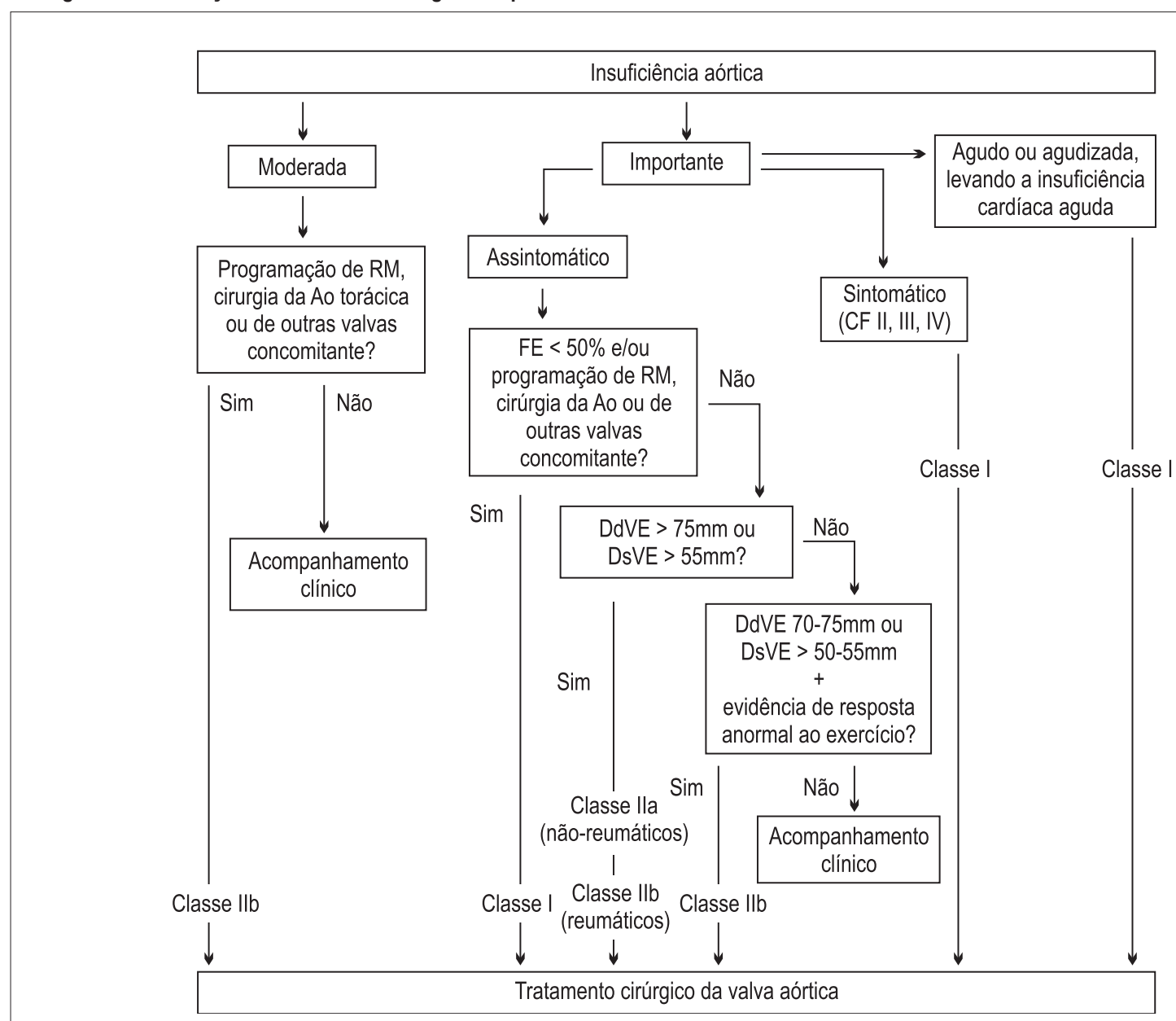

CF - classe funcional; FE - fração de ejeção do ventrículo esquerdo; RM - cirurgia de revascularização do miocárdio; Ao - aorta; DdVE - diâmentro diastólico final do ventrículo esquerdo; DsVE - diâmetro sistólico final do ventrículo esquerdo. 


\section{Diretrizes}

\subsection{Insuficiência aórtica aguda}

\subsubsection{Introdução}

A IAo aguda pode se apresentar como uma emergência médica, em que o tempo até o tratamento está intimamente ligado ao prognóstico. Em grande parte dos casos, o tratamento cirúrgico imediato é necessário.

As lesões agudas mais comuns estão ligadas a endocardite infecciosa, dissecção da aorta e trauma, e com menor frequência destacam-se a ruptura espontânea ou o prolapso das cúspides secundária à doença degenerativa, deiscência súbita parcial ou total do anel de prótese valvar aórtica, além de doenças inflamatórias do tecido conjuntivo envolvendo a valva aórtica ${ }^{195,219}$. A morte súbita advém pela elevação abrupta da pressão de enchimento em ventrículos não adaptados e redução do débito cardíaco. A despeito do mecanismo de Frank-Starling ser acionado, o VE não é capaz de aumentar agudamente o seu volume diastólico. A taquicardia compensatória muitas vezes não é suficiente e os sintomas de falência cardíaca esquerda são exuberantes. Muitas vezes o VE já apresenta sinais de hipertrofia, dificultando ainda mais a adaptação ao novo regime pressórico. Dessa forma, ocorre diminuição do volume sistólico, da pressão sistólica e da pressão de pulso 220,221 . A importante elevação da pressão diastólica final do $\mathrm{VE}$, juntamente com a taquicardia frequente nesses casos, causa um fechamento precoce da valva mitral que irá limitar o influxo de sangue para o ventrículo, resultando em uma diminuição do seu enchimento ${ }^{222}$.

\subsubsection{Tratamento}

\subsubsection{Tratamento farmacológico}

O tratamento da IAo aguda é o reparo ou a troca valvar. O tratamento farmacológico, nesse contexto, visa dar suporte temporário ao paciente até que a cirurgia seja realizada, não se devendo postergar a intervenção.

Enquanto são feitos os preparativos para a cirurgia, vasodilatadores como o nitroprussiato podem ser usados para diminuir a pós-carga e, com isso, melhorar o fluxo anterógrado. Em alguns casos, inotrópicos como a dobutamina ou a dopamina podem melhorar o débito cardíaco.

Nos casos de dissecção aguda de aorta, é importante o uso de betabloqueadores visando o adequado controle da frequência cardíaca.

Na insuficiência aórtica aguda, o balão intra-aórtico está contraindicado, uma vez que sua insuflação diastólica é prejudicial à hemodinâmica ventricular esquerda.

\subsubsection{Tratamento cirúrgico}

A cirurgia sobre a valva aórtica caracteriza-se fundamentalmente pela substituição valvar, estando a plástica reservada para situações especiais e mãos experientes, pois o risco de agravar a situação clínica do paciente não é desprezível ${ }^{223}$. Da mesma forma, a operação de Ross, um procedimento cirúrgico mais complexo, não é utilizada de rotina em todos os serviços e é sujeita a discussões, muitas vezes controversas ${ }^{224}$.
As valvas aórticas homólogas têm sido usadas desde o início da cirurgia cardíaca, porém a falência precoce do enxerto e as dificuldades na sua obtenção deram lugar a outros substitutos valvares. Mudanças na técnica de preservação do tecido com criopreservação ou mesmo a fresco têm sido apresentadas em experiências limitadas. Espera-se que em jovens e na endocardite possa oferecer vantagens adicionais.

\subsubsection{Endocardite infecciosa}

As opções cirúrgicas das endocardites envolvendo a valva aórtica são: homoenxerto, excisão do folheto comprometido pela endocardite, e colocação de prótese aórtica. Em alguns centros, particularmente em crianças, o uso do procedimento de Ross pode ser utilizado ${ }^{225}$.

Não há diferença na frequência de infecção após a colocação de uma prótese mecânica ou biológica quando essa troca valvar é feita por causa de uma endocardite infecciosa ${ }^{226}$.

\subsubsection{Dissecção aórtica}

A fisiopatologia da IAo aguda é variável e depende da sua patogênese. Quando existe uma anormalidade da valva aórtica na presença de uma dissecção aórtica ou um aneurisma da aorta, utiliza-se o procedimento modificado de Bentall de Bono, que consiste em colocar um enxerto valvado e reimplante de coronárias ${ }^{225}$.

\subsubsection{Trauma}

O trauma torácico por instrumento de corte resultando na IAo é o mais encontrado. Tal mecanismo resulta na perda da sustentação comissural, perfuração do folheto ou dissecção ${ }^{227}$.

\section{Doenças da valva tricúspide}

\subsection{Estenose tricúspide}

A Estenose Tricúspide (ET) é uma valvopatia rara, tendo como principal etiologia a doença reumática. Na maioria dos casos, a apresentação ocorre na forma de dupla lesão, com graus variados de insuficiência. Outra característica é a associação frequente com valvopatia mitral ${ }^{228,229} . \mathrm{Em}$ um estudo angiográfico com 525 pacientes com doença valvar reumática, a prevalência de ET foi de $9 \%$.Outras possíveis causas são atresia/estenose congênita da valva, tumores no átrio direito, síndrome carcinoide e endocardite infecciosa ${ }^{11}$.

Não há um sistema bem estabelecido para gradação de gravidade da ET. Geralmente, a ET é considerada importante quando a área valvar é menor que $1,0 \mathrm{~cm}^{2}$ e o gradiente pressórico médio é maior que $5 \mathrm{mmHg}^{84}$. Como as pressões de enchimento das câmaras cardíacas direitas são baixas, mesmo pequenos incrementos são capazes de elevar a pressão média do átrio direito e determinar congestão sistêmica.

O tratamento farmacológico é baseado no uso de betabloqueadores, com o intuito de aumentar o tempo de enchimento ventricular, e diuréticos, para alívio dos sintomas congestivos (tabela 28). 
A Valvuloplastia Tricúspide por Catéter-Balão (VTCB) é segura, eficaz e com baixas taxas de complicações. Mesmo não existindo estudos que comparem o desempenho da VTCB com a cirurgia convencional (plástica ou troca valvar), a intervenção percutânea é uma opção no manejo dos pacientes com ET. A principal contraindicação para a VTCB é a presença de trombo ou vegetação no átrio direito. Contrariamente à estenose mitral, graus moderados de insuficiência tricúspide não contraindicam a VTCB. O tratamento cirúrgico convencional pode ser uma alternativa para pacientes com anatomia valvar desfavorável à intervenção percutânea (tabela 29).

\section{Tabela 28 - Recomendações para o tratamento farmacológico da estenose tricúspide}

\begin{tabular}{lcc}
\hline $\begin{array}{l}\text { Classe de } \\
\text { recomendação }\end{array}$ & Indicação & $\begin{array}{c}\text { Nível de } \\
\text { evidência }\end{array}$ \\
\hline Classe I & $\begin{array}{c}\text { Betabloqueadores em pacientes com } \\
\text { ET moderada a importante, sintomática, } \\
\text { objetivando o controle da frequência } \\
\text { cardíaca no repouso e esforço, na } \\
\text { ausência de contraindicações. }\end{array}$ & C \\
\hline Classe I & $\begin{array}{c}\text { Bloqueadores dos canais de cálcio } \\
\text { não diidropiridínicos ou digoxina } \\
\text { em pacientes com ET importante e } \\
\text { sintomática, de forma associada aos } \\
\text { betabloqueadores, quando esses não } \\
\text { forem suficientes para se atingir controle } \\
\text { satisfatório da frequência cardiaca. }\end{array}$ & C \\
\hline Bloqueadores dos canais de cálcio \\
não diidropiridínicos ou digoxina \\
em pacientes com ET importante \\
sintomática quando houver \\
contraindicação aos betabloqueadores.
\end{tabular}

Tabela 29 - Recomendações para o tratamento intervencionista da estenose tricúspide

\begin{tabular}{lcc}
\hline $\begin{array}{l}\text { Classe de } \\
\text { recomendação }\end{array}$ & Indicação & $\begin{array}{c}\text { Nível de } \\
\text { evidência }\end{array}$ \\
\hline Classe I & $\begin{array}{c}\text { VTCB ou tratamento cirúrgico da } \\
\text { valva tricúspide em pacientes com ET } \\
\text { importante e sintomática, refratária ao } \\
\text { tratamento clínico. }\end{array}$ & C \\
\hline Classe I & $\begin{array}{c}\text { Tratamento cirúrgico da valva tricúspide } \\
\text { em pacientes com ET importante que } \\
\text { serão submetidos à cirurgia valvar em } \\
\text { câmaras esquerdas. }\end{array}$ & C \\
\hline Classe III & $\begin{array}{c}\text { VTCB em pacientes com ET importante } \\
\text { na vigência de insuficiência tricúspide } \\
\text { importante. }\end{array}$ & C \\
\hline
\end{tabular}

VTCB - Valvuloplastia tricúspide por cateter-balão; ET - Estenose tricúspide.

\subsection{Insuficiência tricúspide}

A incidência de insuficiência tricúspide (IT) moderada a importante no estudo Framingham foi de $0,8 \%$, com maior prevalência em mulheres (até 4,3 vezes maior que no sexo masculino). ${ }^{230}$ Nos países com prevalência significativa de doença reumática (Brasil, sudeste asiático e Africa), dados ecocardiográficos sugerem acometimento tricuspídeo em até $9 \%$ dos portadores de valvopatia sequelar reumática. ${ }^{231}$ Classicamente, as etiologias da IT são agrupadas em primárias ou secundárias (funcionais). Nos países desenvolvidos, as causas primárias correspondem a apenas 8 a 10\% dos diagnósticos de IT anatomicamente importante, destacando-se a doença reumática, a endocardite infecciosa, a degeneração mixomatosa e as doenças congênitas (anomalia de Ebstein) como principais etiologias. ${ }^{232,233}$ A maioria dos casos de IT são funcionais ou secundários e ocorrem pela dilatação progressiva do anel valvar tricuspídeo, gerando diferentes graus de insuficiência. ${ }^{234}$ Entre os principais responsáveis pela IT estão a sobrecarga ventricular direita decorrente de HP, a insuficiência cardíaca esquerda (especialmente quando relacionada à valvopatia mitral) e isquemia de câmaras direitas. Vale lembrar que portadores de marcapasso ou desfibriladores com eletrodos posicionados no ventrículo direito também podem apresentar IT secundária, mas em sua maioria sem significância clínica.

Farmacologicamente, recomenda-se o uso de diuréticos na presença de sinais e sintomas de congestão sistêmica (ascite, estase jugular, dispnéia e edema periférico). Na IT secundaria à disfunção ventricular esquerda, o tratamento envolve o uso de drogas como inibidores da enzima de conversão da angiotensina e beta-bloqueadores. Os casos de HP primária requerem uso de medicações específicas, como os inibidores de fosfodiesterase-5 e os antagonistas de endotelina, conforme indicação. ${ }^{234}$

As recomendações de tratamento comportamental e farmacológico na IT encontram-se na tabela 30.

A indicação de intervenção cirúrgica na IT (tabela 31) é influenciada pela existência de outras valvopatias concomitantes, especialmente as lesões mitrais. Os procedimentos disponíveis são a troca valvar e a plástica, e esta última deve ser o tratamento de escolha, quando possível. Para pacientes com IT isolada, a cirurgia é indicada nos casos de regurgitação importante associada a repercussão clínica evidente. Os pacientes com lesões moderadas recebem indicação cirúrgica em caso de dilatação ou disfunção ventricular direita progressivas associada ao aparecimento de sintomas. Um estudo retrospectivo com 60 pacientes com IT primária submetidos ao tratamento cirúrgico (plástica ou troca valvar) mostrou que $82 \%$ dos pacientes receberam plástica tricuspídea, com baixa mortalidade operatória (3\%) e significativa melhora dos sintomas $(88 \%)^{235}$. Os principais favorecidos pela intervenção foram os pacientes sintomáticos com lesões regurgitantes importantes.

$\mathrm{Na}$ IT associada à valvopatia mitral, a plástica é recomendada quando houver regurgitação tricuspídea importante. ${ }^{11} \mathrm{Em}$ grau moderado de insuficiência, a indicação deverá basear-se na presença de fatores de risco para progressão da lesão valvar, como idade, sexo feminino, etiologia reumática, presença de FA e HP. ${ }^{236}$ Alguns estudos demonstram progressão da IT mesmo após correção da valvopatia mitral. ${ }^{237}$ Nestes casos, a dilatação progressiva do anel valvar seria responsável pela evolução desfavorável, sendo recomendada a realização de anuloplastia tricuspídea quando o diâmetro anular for maior que 40mm ou 
$21 \mathrm{~mm} / \mathrm{m}^{2}$ (corrigido pela superfície corpórea) e houver dilatação de câmaras direitas. ${ }^{234} \mathrm{~A}$ técnica mais utilizada de anuloplastia foi descrita por DeVega e consiste na sutura contínua ao redor do anel valvar. ${ }^{238}$

Para pacientes com antecedente de cirurgia mitral, recomenda-se tratamento cirúrgico isolado da IT importante e sintomática apenas na ausência das seguintes condições: disfunção ventricular direita grave, HP grave (PSAP $>60 \mathrm{mmHg}$ ) e lesão mitral residual significativa, dada a alta mortalidade operatória reportada neste grupo (10 a 20\%). ${ }^{239}$

Quanto à $\mathrm{HP}$, a literatura sugere que valores sustentados de PSAP > 55mmHg podem determinar IT secundária. Quando houver IT associada a valores de PSAP $<40 \mathrm{mmHg}$ devemos buscar etiologias primárias. ${ }^{11,234}$

\section{Doenças da valva pulmonar}

\subsection{Estenose Pulmonar}

O procedimento de escolha para o tratamento da Estenose Pulmonar (EP) é a Valvuloplastia Pulmonar por Cateter-Balão (VPCB) em razão dos excelentes resultados em curto e longo prazos $^{11}$. Uma análise retrospectiva de 784 casos submetidos à VPCB registrou taxa de sucesso clínico de 98\%, com queda do gradiente sistólico na via de saída pulmonar de $71 \mathrm{mmHg}$ para $28 \mathrm{mmHg}$ (valores médios da população estudada ${ }^{240}$. A mortalidade relacionada ao procedimento foi inferior a $0,5 \%$. As taxas de reestenose também são baixas (menores que 5\%) e geralmente relacionadas a valvas displásicas ${ }^{241}$.

Basicamente, indica-se VPCB para pacientes com EP sintomática, considerada significativa quando o gradiente de pico sistólico entre o ventrículo direito e a artéria pulmonar for maior que 30mmHg. Para os assintomáticos, há indicação quando o gradiente de pico for maior que $40 \mathrm{mmHg}$. No entanto, centros de referência com bons resultados e baixa incidência de complicações podem recrutar pacientes assintomáticos com gradientes entre 30 e $40 \mathrm{mmHg}$ para VPCB. O implante de bioprótese em posição pulmonar é recomendado quando houver indicação de intervenção e impossibilidade técnica de realização da VPCB ${ }^{11,242}$.

\subsubsection{Valvuloplastia pulmonar em estenose pulmonar} congênita

Para a EP congênita, a VPCB também permanece como a modalidade de tratamento de escolha em pacientes de todas as idades, inclusive em recém nascidos e adultos ${ }^{243}$.

\section{Tabela 30 - Recomendações para o tratamento comportamental/farmacológico na insuficiência tricúspide}

\begin{tabular}{|c|c|c|}
\hline $\begin{array}{l}\text { Classe de } \\
\text { recomendação }\end{array}$ & Indicação & $\begin{array}{l}\text { Nível de } \\
\text { evidência }\end{array}$ \\
\hline Classe I & Diuréticos em todos os pacientes com IT importante e sinais de congestão sistêmica. & C \\
\hline Classe I & $\begin{array}{l}\text { Inibidores da enzima de conversão da angiotensina e betabloqueadores (carvedilol, metoprolol e bisoprolol) em todos os } \\
\text { pacientes com IT importante, sinais de insuficiência cardíaca e disfunção ventricular, na ausência de contraindicações. }\end{array}$ & C \\
\hline Classe lla & $\begin{array}{l}\text { Restrição hídrica (1000 a 1500mL/dia) e salina (4 a } 6 \mathrm{~g} \text { sal/dia) nos pacientes com IT importante e sinais de congestão que não } \\
\text { respondem à terapia isolada com diuréticos. }\end{array}$ & C \\
\hline Classe III & $\begin{array}{l}\text { Terapia comportamental/farmacológica como única opção terapêutica em pacientes com IT importante sintomática e candidatos } \\
\text { ao tratamento cirúrgico. }\end{array}$ & C \\
\hline
\end{tabular}

IT - Insuficiência tricúspide.

Tabela 31 - Recomendações para o tratamento cirúrgico da insuficiência tricúspide

\begin{tabular}{|c|c|c|}
\hline $\begin{array}{l}\text { Classe de } \\
\text { recomendação }\end{array}$ & Indicação & $\begin{array}{l}\text { Nível de } \\
\text { evidência }\end{array}$ \\
\hline Classe I & Plástica tricuspídea em pacientes com IT importante associada a valvopatia mitral com indicação cirúrgica. & $\mathrm{B}$ \\
\hline Classe I & Plástica tricuspídea em pacientes com IT primária importante e sintomática, refratária ao tratamento clínico. & C \\
\hline Classe lla & Troca da valva tricúspide em pacientes com IT primária importante, não candidatos à plástica valvar em razão da anatomia desfavorável. & C \\
\hline Classe Ila & $\begin{array}{l}\text { Intervenção cirúrgica isolada em pacientes com cirurgia valvar mitral prévia que apresentem IT importante e sintomática, desde } \\
\text { que não haja disfunção ventricular direita, HP grave (PSAP > 60mmHg) ou lesão mitral residual significativa. }\end{array}$ & C \\
\hline Classe lla & $\begin{array}{l}\text { Pacientes com indicação de cirurgia valvar mitral concomitante que apresentem IT moderada com dilatação do anel valvar, } \\
\text { disfunção ventricular direita e/ou HP. }\end{array}$ & C \\
\hline Classe III & $\begin{array}{c}\text { Pacientes com IT funcional como manifestação isolada, sem indicação para intervenção na valva mitral ou outras cirurgias } \\
\text { cardiacas concomitantes. }\end{array}$ & C \\
\hline Classe III & Pacientes com IT assintomáticos com PSAP $<60 \mathrm{mmHg}$ sem valvopatia mitral associada. & C \\
\hline Classe III & Pacientes com IT primária discreta. & C \\
\hline
\end{tabular}

IT:- Insuficiência tricúspide; HP - Hipertensão pulmonar; PSAP - Pressão sistólica da artéria pulmonar. 
A presença de gradiente de pico sistólico acima de 40$50 \mathrm{mmHg}$ no laboratório de cateterismo com o paciente sedado ou anestesiado constitui indicação para valvuloplastia pulmonar $^{244}$. A intervenção pode ser realizada na vigência de gradientes menores se houver disfunção ventricular direita ou sintomas (fadiga, intolerância ao exercício). A reestenose é infrequente, com alguns pacientes (especialmente neonatos) necessitando de novas dilatações ${ }^{245}$. A IP após a dilatação é comum, ocorrendo em $10 \%$ a $40 \%$ dos pacientes ${ }^{246}$.

\subsection{Insuficiência pulmonar}

A principal etiologia de Insuficiência Pulmonar (IP) em adultos é a HP, que pode ser primária ou secundária. A IP também pode resultar de dilatação do anel valvar, como na síndrome de Marfan e na dilatação idiopática do tronco pulmonar ${ }^{11,242}$. Outras causas descritas são endocardite infecciosa, sequela reumática, síndrome carcinoide, pósoperatório de tetralogia de Fallot e após Valvuloplastia Pulmonar por Cateter-Balão (VPCB).

Geralmente, há indicação de tratamento cirúrgico com substituição valvar nos pacientes com IP importante e sintomática (CF II a IV). A intervenção nos casos de IP importante assintomática ainda é motivo de controvérsias, com necessidade de maior sedimentação cientifica para sua recomendação ${ }^{11}$.

10.2.1. Implante percutâneo da valva pulmonar em pacientes com doenças cardíacas congênitas

A IP no pós-operatório tardio da correção cirúrgica da tetralogia de Fallot (e outras cardiopatias que necessitam de condutos do ventrículo direito à artéria pulmonar) pode resultar em dilatação e disfunção ventricular direita progressivas, intolerância ao exercício, arritmias e morte súbita. O restabelecimento da função da valva pulmonar em um momento apropriado pode reverter esse processo, restaurando a função ventricular e melhorando a sintomatologia 247,248 .

A troca cirúrgica da valva pulmonar necessita de CEC, o que pode agravar ainda mais a função do ventrículo direito já comprometida ${ }^{247,248}$. Há várias técnicas cirúrgicas para o tratamento da IP, incluindo o uso de homoenxertos de cadáveres, condutos valvados, enxertos de veia jugular bovina ou uma valva bioprotética implantada diretamente no trato de saída do ventrículo direito. Entretanto, todos esses condutos ou valvas implantados cirurgicamente apresentam disfunção variável com o passar do tempo, caracterizada por estenose acompanhada ou não de insuficiência.

Bonhoeffer e cols. ${ }^{249}$ foram os primeiros a relatar o implante percutâneo da valva pulmonar, posteriormente denominada de valva Melody ${ }^{\circledR}$ (Medtronic) ${ }^{249}$. Após esse relato inicial, centenas de pacientes foram tratados dessa forma na Europa com ótimos resultados ${ }^{250}$. A segurança e eficácia dessa valva está amplamente documentada na literatura ${ }^{251-258}$. Há ainda outro sistema de implante percutâneo da valva pulmonar, a valva Edwards-Cribier ${ }^{\circledR}$ (Edwards Lifesciences), que está em estudo clínico nos Estados Unidos ${ }^{259}$. Ambos os sistemas mencionados foram desenhados para tratamento da disfunção pulmonar dentro de condutos e valvas bioprotéticas. Eles não foram desenhados para tratar pacientes que tenham sido submetidos à reconstrução da via de saída do ventrículo direito com retalhos transanulares.

As indicações de uso desses sistemas incluem evidências objetivas de disfunção do conduto (estenose e/ou insuficiência significativa), acompanhadas ou não de aumento da pressão ventricular direita (próximas a níveis sistêmicos), dilatação ventricular direita significativa (geralmente determinada pela ressonância magnética) e graus variáveis de disfunção ventricular direita e IT. A presença de sintomas como fadiga e intolerância à atividade física só ocorre em fases mais tardias do processo e não são parâmetros isolados para indicação de intervenção.

No Brasil, nem a valva Melody ${ }^{\circledR}$ nem a Edwards-Cribier ${ }^{\circledR}$ estão aprovadas pela Anvisa para uso clínico. Espera-se que a aprovação seja obtida entre o final de 2011 e 2012.

\section{Próteses mecânicas e biológicas}

A substituição da valva mitral por próteses é realizada através de esternotomia mediana, toracotomia ânterolateral direita, minitoracotomias videoassistidas ou com auxilio da robótica e de CEC em hipotermia sistêmica moderada $\left(28^{\circ} \mathrm{C}\right.$ a $\left.30^{\circ} \mathrm{C}\right)$. A valva é mais frequentemente acessada diretamente pelo átrio esquerdo e outras vezes pelo átrio direito por via transseptal. Durante a cirurgia, a proteção miocárdica é necessária para proteger o coração do dano isquêmico, utilizando-se soluções cardioplégicas cristaloides ou sanguíneas oxigenadas hipotérmicas, que são administradas nos óstios coronarianos pela aorta ascendente.

Desde que se iniciou a aplicação clínica de próteses valvares na posição mitral por Starr e cols. ${ }^{260}$ em 1960, a técnica empregada contemplava a ressecção completa das cúspides, cordoalhas e extremidades dos músculos papilares, fixando-se no ânulo uma prótese de forma permanente. Essa fase inicial foi acompanhada de altas taxas de mortalidade por síndrome de baixo débito cardíaco no pós-operatório, vinculando-se a sua gênese à ressecção completa do aparelho valvar.

Dahlback e Schuler ${ }^{261}$, em 1961, explicitaram que tais fatos estavam ligados à descontinuidade anatômica entre as paredes do VE com o ânulo e o esqueleto fibroso do coração, provocados pela ressecção completa da valva, propondo o implante da prótese com manutenção da valva nativa intacta. Lillehei e cols. ${ }^{262}$, em 1964, tendo como base esse e outros estudos, sugeriram a preservação do complexo cordopapilar na troca valvar mitral, conseguindo expressiva redução na mortalidade imediata (de $37 \%$ para $14 \%$ ) com a manutenção dos músculos papilares e cordas tendíneas. David e cols. ${ }^{263}$ e Hetzer e cols. ${ }^{264}$. em 1983, demonstraram em estudos experimentais e clínicos que a preservação dos músculos papilares e respectivas cordas tendíneas na troca valvar mitral, na IM crônica, tem efeito benéfico na função do VE no pós-operatório, proporcionando melhores resultados.

Consolidado o conceito, surgiram várias técnicas de preservação da cúspide posterior ou de ambas as cúspides, na troca valvar mitral, adaptadas às diferentes etiologias e contemplando tanto o uso de próteses mecânicas como biológicas. 
Na última década, por meio de pesquisas explorando os índices de função ventricular em repouso e em exercício, e os volumes ventriculares associados à sobrevida em longo prazo, foi comprovada a importância definitiva da preservação do complexo cordopapilar na melhora sustentada desses parâmetros ${ }^{265,266}$. Os efeitos benéficos da preservação estão associados à estrutura anatômica da valva mitral. Os músculos papilares desempenham um importante papel na sístole do VE, aproximando as paredes ântero-lateral e póstero-medial, além de tracionar o ânulo em direção ao ápice. Esses movimentos ocasionam o encurtamento dos eixos longitudinal e transversal do VE durante a contração, promovendo alteração no formato do coração, com tendência a esfericidade na diástole e elipse na sístole ${ }^{267}$.

A troca valvar mitral com reimplante das estruturas subvalvares permite mais rápida recuperação da função ventricular e previne a progressiva dilatação do VE. Também contribui para reduzir tanto a morbimortalidade hospitalar quanto a mortalidade em longo prazo ${ }^{268}$.

As desvantagens das próteses estão diretamente relacionadas a seus riscos específicos, como a durabilidade das próteses biológicas e a necessidade de anticoagulação com as próteses mecânicas. Na escolha do substituto valvar - se prótese mecânica ou biológica -, deve-se, sempre que possível, seguir as recomendações das diretrizes adaptando-as às condições específicas de cada paciente. Uma vez esclarecido sobre as vantagens e desvantagens de cada prótese, o paciente deve participar de sua escolha.

Cada tipo e modelo de prótese apresenta vantagens e desvantagens reconhecidas pela avaliação de sua performanceem longo prazo - entre 10 e 20 anos. Esses substitutos valvares de última geração são avaliados por eventos que espelham os seus riscos específicos, como degeneração estrutural, trombose e Tromboembolismo (TE), hemorragias, regurgitação paravalvar e endocardite infecciosa.

Essas complicações remetem a reoperação, mortalidade relacionada à prótese, morte súbita inexplicável, óbitos de origem cardíaca e óbitos totais, bem como disfunção valvar permanente. Geralmente implica recorrência de sintomas como dispneia, fadiga e angina, podendo ainda ocorrer fístula paravalvar ou hemólise em razão da prótese.

\subsection{Próteses mecânicas mitrais}

Os substitutos valvares mecânicos apresentaram um grande desenvolvimento desde o seu primeiro modelo implantado por Hufnagel ${ }^{269}$ em 1951. A introdução do carbono pirolítico na confecção das próteses veio colaborar com os seus resultados, especialmente no que se refere à durabilidade estrutural e ao risco de TE.

Os maiores riscos com as próteses mecânicas compreendem trombose, TE e hemorragias pelo uso obrigatório e contínuo dos anticoagulantes orais. As próteses mecânicas de duplo folheto apresentam boas características hemodinâmicas, baixo perfil de trombogenicidade e excelente durabilidade, sendo atualmente as mais utilizadas em pacientes com idade inferior a 65 anos. As recomendações do seu emprego encontram-se na tabela 32.

Os trombos podem ocorrer tanto no nível do anel de tecido da prótese como no mecanismo oclusor, provocando redução orificial, com aumento do gradiente transprotético e/ou regurgitação pelo incompleto fechamento dos folhetos. Sua incidência é relatada em torno de $0,1 \%$ pacientes/ano, e o TE $1,3 \%$ a $3,19 \%$ pacientes/ano, nas séries atuais. Esses baixos índices devem-se ao controle mais adequado do INR de 2,5a 3,5 . As hemorragias de maior porte, que exigem transfusões, ocorrem em taxa de $0,6 \%$ pacientes/ano, enquanto a fístula paraprotética incide em torno de $0,7 \%$ pacientes/ano ${ }^{270}$.

$\mathrm{Na}$ avaliação ecocardiográfica no pós-operatório, as próteses mecânicas costumam mostrar áreas de fluxo menores tanto em repouso quanto em exercício, em razão da redução da área orificial pela endotelização do anel de tecido por células do hospedeiro. Apresentam baixo gradiente transprótese durante as atividades físicas dos pacientes, geralmente na faixa entre 1,2 e 2,0 $\mathrm{mmHg}$, podendo, nas próteses de menor tamanho ou com má função apresentar gradientes maiores.

Na ecocardiografia do pós-operatório é comum a visualização de leves jatos regurgitantes de alta velocidade, os quais fazem parte do mecanismo protetor de trombos nas áreas pivotantes dos folhetos, e não devem ser interpretados como disfunção da prótese. As próteses mecânicas de duplo folheto em uso atual e com mais de dez anos de seguimento e com boa performance clínica são: St Jude Medical (1977), CarboMedics (1985), Sorin Bicarbon (1990) e ATS Open Pivot (1992).

As recomendações de ecocardiografia em pacientes com próteses valvares estão na Tabela 33.

\subsection{Próteses biológicas ou biopróteses mitrais}

Os substitutos valvares biológicos se caracterizam pela baixa trombogenicidade, baixa turbulência em razão do seu fluxo central, boa hemodinâmica, facilidade de implante e ausência de ruído. As limitações das biopróteses estão relacionadas à sua durabilidade, especialmente ligada à ruptura e à calcificação, o que condiciona os pacientes a reoperações, com os seus custos e riscos associados.

Quando implantadas em valvopatas com idade igual ou superior a 65 anos, as próteses biológicas porcinas e de pericárdio bovino têm baixo risco de falha estrutural e, portanto, reduzem drasticamente a necessidade de nova operação. Nos pacientes com idade inferior a 60 anos, os efeitos da degeneração estrutural, como fibrose e calcificação, induzem a obstrução e/ou ruptura, comprometendo sua função entre sete e 15 anos, implicando sua substituição. Os fatores que aumentam a probabilidade de reoperação são a baixa idade no momento do implante e a duração do implante da prótese.

Em publicação recente, a Sociedade Americana de Cirurgia Torácica (STS) publicou os resultados de 58.370 cirurgias isoladas da valva mitral, das quais 25.671 foram substituição valvar por próteses ${ }^{271}$, mostrando uma dramática redução do uso de próteses mecânicas nessa última década (de 68\% em 2000 para 37\% em 2007), com um aumento significativo do uso de próteses biológicas. As razões apontadas incluem a maior durabilidade das próteses biológicas atuais e a drástica redução na mortalidade, entre 2,2\% e 4,7\%, nas reoperações para retroca valvar. Nesse período, a média de idade nos que receberam próteses 
manteve-se em 65 anos, tendo diminuído de 60 para 55 anos naqueles que receberam próteses mecânicas.

Atualmente existem fortes evidências de que o tratamento concomitante da FA persistente oferece a possibilidade de manter o paciente em ritmo sinusal. Esses pacientes mantêm o ritmo sinusal em torno de $75 \%$ a $90 \%$ após seis meses de pós-operatório, e os dados em longo prazo (superiores a oito anos) mostram a sustentabilidade desses resultados aliados a uma apreciável redução nos riscos de AVE. Ainda, a redução do átrio esquerdo com diâmetro maior que $55 \mathrm{~mm}$ e a exclusão da auriculeta impactam favoravelmente os resultados em longo prazo. Da mesma forma, a correção da IT moderada a importante previne a conhecida progressão da insuficiência cardíaca direita, responsável pela má evolução tardia de pacientes operados da valva mitral com sucesso. A revascularização do miocárdio nos pacientes com IM isquêmica impacta favoravelmente sua evolução imediata e tardia.
O paciente com prótese mitral deve ser instruído a aderir aos cuidados essenciais para o bom desempenho desse dispositivo, e a submeter-se, no mínimo, a um exame clínico anual para acompanhamento. A substituição valvar mitral induz significativa melhora dos sintomas, reduz os eventos cardíacos tardios desfavoráveis, melhora a qualidade de vida e aumenta as taxas de sobrevivência dos pacientes em longo prazo, constituindo-se num tratamento seguro e eficaz.

As recomendações para substituição da valva mitral por bioprótese estão na tabela 34 .

\subsection{Procedimentos da valva aórtica}

As próteses podem ser mecânicas ou biológicas. As próteses biológicas podem ser heterólogas (bovina ou porcina), homólogas ou correspondentes ao transplante autólogo

\section{Tabela 32 - Recomendações para substituição da valva mitral por prótese mecânica}

\begin{tabular}{lcc}
\hline $\begin{array}{l}\text { Classe de } \\
\text { recomendação }\end{array}$ & Pacientes com longa expectativa de vida. & $\begin{array}{c}\text { Nível de } \\
\text { evidência }\end{array}$ \\
\hline Classe Ila & Pacientes com idade inferior a 65 anos com fibrilação atrial de longa duração. & C \\
\hline Classe Ila & Pacientes que necessitam de tratamento com anticoagulante pela presença de outros fatores de risco para tromboembolismo. & B \\
\hline Classe Ila & Pacientes com insuficiência renal em hemodiálise ou com hipercalcemia. \\
\hline Classe Ila & Na substituição valvar devido a bioprótese com trombose. \\
\hline Classe Ilb & Pacientes que não podem ou não aceitam fazer uso de anticoagulantes. \\
\hline Classe III & $C$
\end{tabular}

Tabela 33 - Recomendações de ecocardiografia em próteses valvares

\begin{tabular}{lc}
\hline $\begin{array}{l}\text { Classe de } \\
\text { recomendação }\end{array}$ & Indicação \\
\hline Classe I & Pacientes com próteses valvares com alteração de sinais ou sintomas sugestiva de disfunção protética (estenose ou insuficiência). \\
\hline Classe lla & ETE em pacientes com ETT mostrando disfunção protética, para confirmar o diagnóstico e quantificar melhor a disfunção. \\
\hline Classe lla & Reavaliação periódica em pacientes portadores de próteses, com disfunção ventricular, sem modificação dos sinais ou sintomas clínicos. \\
\hline Classe llb & Reavaliação periódica em pacientes com próteses valvares sem sinais ou sintomas de disfunção protética. \\
\hline
\end{tabular}

ETT - Ecocardiografia transtorácica; ETE - Ecocardiografia transesofágica

Tabela 34 - Recomendações para substituição da valva mitral por bioprótese

\begin{tabular}{|c|c|c|}
\hline $\begin{array}{l}\text { Classe de } \\
\text { recomendação }\end{array}$ & Indicação & $\begin{array}{l}\text { Nível de } \\
\text { evidência }\end{array}$ \\
\hline Classe I & Pacientes que não podem ou não aceitam fazer uso de anticoagulantes. & C \\
\hline Classe Ila & Pacientes com idade igual ou maior que 65 anos. & C \\
\hline Classe Ila & $\begin{array}{l}\text { Pacientes com idade inferior a } 65 \text { anos em ritmo sinusal e que escolhem receber esta prótese por circunstâncias de estilo de } \\
\text { vida, após detalhada discussão a respeito dos riscos dos anticoagulantes versus a probabilidade de nova troca valvar futura. }\end{array}$ & C \\
\hline Classe Ila & Em mulheres em idade fértil. & C \\
\hline Classe Illb & Na substituição valvar devido a prótese mecânica com trombose. & C \\
\hline Classe III & Pacientes com insuficiência renal em hemodiálise ou com hipercalcemia. & C \\
\hline
\end{tabular}


da valva pulmonar para a posição da valva aórtica (cirurgia de Ross). As mais comumente utilizadas são as próteses mecânicas e biológicas heterólogas, cujo uso está bem estabelecido e padronizado.

A via de acesso mais frequente para a realização dos procedimentos é a esternotomia mediana, havendo como alternativas a esternotomia parcial e a minitoracotomia anterior direita para cirurgias minimamente invasivas videoassistidas. A cirurgia exige o uso de CEC com hipotermia moderada e de proteção miocárdica com a utilização de soluções cardioplégicas administradas diretamente nos óstios coronarianos.

O tamanho da prótese a ser implantada deve ser definido com rigor. A seleção de prótese de tamanho inadequado pode resultar em gradiente transvalvar residual alto, escapes periprotéticos, oclusão de óstios coronarianos e bloqueio atrioventricular. A superfície corpórea, a idade, a função ventricular e a atividade física do paciente são parâmetros orientadores do tamanho da prótese a ser utilizado.

Ânulos valvares pequenos dificultam o tratamento adequado. Conceitualmente, deve-se tentar implantar a maior prótese possível, sem dificuldade técnica ${ }^{272}$. Próteses biológicas com diâmetro menor que $21 \mathrm{~mm}$ devem ser evitadas em virtude do alto gradiente residual. Próteses mecânicas de diâmetro $19 \mathrm{~mm}$ podem ser aceitas em pacientes de baixo peso.

As manobras para a ampliação do anel aórtico são complexas e podem tanto aumentar o tempo operatório quanto gerar sangramento de difícil correção, mas algumas vezes são necessárias para o implante de uma prótese de tamanho adequado, evitando gradientes significativos pela desproporção (mismatch) prótese-paciente (MPP) no pós-operatório ${ }^{273}$.

\subsubsection{Próteses mecânicas aórticas}

As próteses mecânicas de duplo folheto de uso corrente são St. Jude Medical, CarboMedics, ATS Medical e a On-X, e diferem entre si por pequenos detalhes. Esses dispositivos fazem pouco ruído, são muito duráveis e de boa função hemodinâmica, mas têm como desvantagens a necessidade do uso contínuo de anticoagulantes para prevenção de $\mathrm{TE}$, com consequente risco de sangramentos, risco de El e ineficiência hemodinâmica nos menores tamanhos. Embora possuam excelente durabilidade, podem exigir reoperação em virtude de trombose ou formação de tecido exagerado (pannus) com disfunção da prótese, para o tratamento de El envolvendo a prótese, ou ainda diante da presença de fístula periprotética, hemólise, múltiplos episódios de hemorragia ou MPP sintomática.

Portadores de prótese mecânica em outra posição e pacientes com FA com indicação de anticoagulação merecem consideração para receber prótese mecânica, uma vez que já são anticoagulados.

Os anéis valvares pequenos devem ser considerados para o emprego de próteses mecânicas, especialmente naqueles pacientes em que a ampliação do anel é de alto risco ou está contraindicada. O melhor desempenho hemodinâmico é garantido pelo baixo perfil do anel rígido e é menor a possibilidade de MPP 274

\subsubsection{Próteses biológicas aórticas}

A evolução das biopróteses foi notória a partir do final da década de 1960. Inicialmente, vários tecidos biológicos foram testados e os resultados em longo prazo foram favoráveis às próteses confeccionadas com as válvulas da valva aórtica de porco e de pericárdio bovino. O processo de preparo comumente envolve o glutaraldeído, conforme proposto por Carpentier em 1967, e tratamentos específicos para retardar o processo de calcificação foram desenvolvidos, existindo atualmente biopróteses com expectativa de durabilidade superior a 20 anos.

A área efetiva valvar das biopróteses é um pouco menor que a das próteses mecânicas pela necessidade de suporte rígido robusto para a fixação do tecido biológico, especialmente nas porcinas. As mais empregadas são as heterólogas construídas com tecido de pericárdio bovino ou com a valva aórtica porcina, e montadas num suporte de metal (anel rígido) recoberto por tecido de dácron.

\subsubsection{Homoenxertos aórticos}

Atualmente, há disponibilidade para o emprego de homoenxertos de cadáver a fresco ou criopreservados, tanto para a reconstrução do trato pulmonar na operação de Ross como para a substituição da valva aórtica e aorta ascendente.

O implante do homoenxerto é mais trabalhoso e tecnicamente mais elaborado. Nesse procedimento, não só a valva aórtica é removida, mas também a aorta ascendente é abordada, uma vez que ela faz parte da estrutura de sustentação da valva aórtica do homoenxerto. Os óstios coronarianos devem ser reimplantados.

Por não apresentarem anéis rígidos de suporte, os homoenxertos apresentam excelente desempenho hemodinâmico e constituem uma excelente opção técnica para pacientes com anel aórtico pequeno. Além disso, pacientes atletas ou com atividade física intensa podem se beneficiar do uso de enxertos com melhores características hemodinâmicas.

Outra excelente indicação para o emprego de homoenxertos é a endocardite infecciosa. Já foi bem demonstrado que homoenxertos são bastante resistentes a infecção, e seu emprego nessa condição é bastante vantajoso, especialmente naqueles pacientes com abscessos e destruição importante da raiz aórtica. A incidência de complicações tromboembólicas com homoenxertos é ainda menor que a das biopróteses, o que torna seu uso bastante apropriado em pacientes com contraindicação ao uso de anticoagulantes.

O emprego de homoenxertos, contudo, também tem limitações e desvantagens. Sua disponibilidade é limitada e a logística de transporte e preparo do enxerto durante a cirurgia é mais complicada. Além disso, mesmo com o controle de qualidade aprimorado dos bancos de tecidos, os riscos de doenças transmissíveis não são nulos. Os maiores impedimentos para o uso mais abrangente dos homoenxertos devem-se à complexidade técnica tanto da cirurgia inicial como da reoperação em caso de falência estrutural do enxerto. A obtenção de resultados 
sistematicamente satisfatórios exige o treinamento específico da equipe cirúrgica.

As técnicas básicas para o implante de homoenxertos aórticos são a subcoronariana, a técnica de inclusão e a de substituição total da raiz aórtica, cada qual com suas vantagens e desvantagens. Entretanto, a substituição da raiz aórtica é a mais frequentemente empregada por permitir o implante anatômico, sem distorções do enxerto, garantindo a competência valvar.

A durabilidade dos homoenxertos também está relacionada à idade do paciente. O'Brein e cols. ${ }^{275}$ reportaram os resultados tardios em 1.022 pacientes com até 29 anos de evolução, e demonstraram que a durabilidade foi muito satisfatória para todas as faixas etárias acima de 20 anos de idade, especialmente nos mais idosos. A incidência de disfunção estrutural por falência tecidual primária foi inferior a 20\% aos 15 anos de evolução. Entretanto, em crianças e jovens, a taxa de reoperações foi elevada, e apenas $47 \%$ dos enxertos estavam normofuncionantes aos 10 anos de evolução.

\subsubsection{Próteses sem suporte (stentless)}

No final década de 1980, surgiram as biopróteses "stentless" - montadas sem o anel de sustentação - para a substituição da valva aórtica. Foram idealizadas para diminuir as desvantagens hemodinâmicas das biopróteses convencionais (stented), já que a ausência do anel diminuiria o gradiente transvalvar e, consequentemente, o estresse sobre o tecido, diminuindo os problemas da disfunção estrutural e reduzindo o volume de massa do VE, melhorando a função ventricular esquerda e a sobrevida tardia dos pacientes. Porém, a técnica de seu implante é mais complexa que a das próteses convencionais, sendo associada a maiores taxas de mortalidade e reoperações precoces por insuficiência protética ${ }^{276}$.

Os resultados em médio prazo com as próteses stentless são satisfatórios. Goldman e cols. ${ }^{277}$ publicaram a evolução de oito anos de 447 pacientes que tiveram as próteses Toronto Stentless implantadas na posição aórtica. Os autores observaram sobrevida atuarial de 93,6\%, e sobrevida livre de disfunção estrutural de 97,4\%, com baixas taxas de complicações, baixos gradientes transvalvares médios $(4,4 \mathrm{mmHg})$ e boa área valvar efetiva $\left(2,4 \mathrm{~cm}^{2}\right)$. Houve redução significativa do índice de massa ventricular e melhora da função do VE. No entanto, quase $20 \%$ dos pacientes apresentavam IAo moderada ou importante no pós-operatório tardio, tendo cinco desses pacientes sido reoperados $(0,3 \%$ pacientes-ano), o que foi atribuído pelos autores à dilatação da aorta. Segundo os autores, essas próteses estariam bem indicadas na substituição aórtica em pacientes com anel aórtico pequeno.

Essas vantagens e desvantagens são conhecidas em curto e médio prazos, mas não em longo prazo. Os dados atualmente disponíveis não mostram superioridade quando comparadas às próteses com suporte.

\subsubsection{Escolha da prótese}

A escolha de prótese biológica ou mecânica não foi associada a uma significativa diferença na sobrevida. O seguimento de 20 anos livre de óbito atribuível a isquemia ou AVE hemorrágico foi $97,9 \pm 1,2 \%$ em pacientes que receberam bioprótese e 83,9 \pm 4,9\% naqueles com prótese mecânica. Em relação à reoperação, o seguimento de 20 anos livre de reoperação foi de 11,4 $\pm 3,5 \%$ naqueles inicialmente implantados com uma prótese de tecido versus 73,0 \pm 4,9\% nos que receberam prótese aórtica mecânica (hazard ratio 3,9, bioprótese versus prótese mecânica, índice de confiança $95 \% 2,6-6,3 ; p<0,001)$.

As duas complicações mais comuns e clinicamente mais significativas da substituição da valva em longo prazo são eventos embólicos e hemorrágicos. Não houve diferenças significativas nos eventos embólicos quando comparados os dois tipos de próteses. Aos 15 anos, 71\% e 75\% de todos os pacientes estavam livres de eventos embólicos após a substituição valvar por bioprótese ou prótese mecânica, respectivamente. A liberdade atuarial de 15 anos de hemorragia foi de $92 \pm 2,6 \%$ e $85 \pm 2,0 \%$ para biopróteses e próteses mecânicas, respectivamente ${ }^{278}$.

As recomendações gerais na escolha da prótese aórtica, considerando também a preferência do paciente, estão na tabela 35 .

Tabela 35 - Recomendações para escolha da prótese na troca de valva aórtica

\begin{tabular}{|c|c|c|}
\hline $\begin{array}{l}\text { Classe de } \\
\text { recomendação }\end{array}$ & Indicação & $\begin{array}{l}\text { Nível de } \\
\text { evidência }\end{array}$ \\
\hline Classe I & $\begin{array}{l}\text { A prótese mecânica é recomendada } \\
\text { na substituição da valva aórtica nos } \\
\text { pacientes que já apresentam próteses } \\
\text { mecânicas em posição mitral ou } \\
\text { tricúspide. }\end{array}$ & C \\
\hline Classe I & $\begin{array}{l}\text { A bioprótese é recomendada na } \\
\text { substituição da valva aórtica nos pacientes } \\
\text { que apresentam contraindicação aos } \\
\text { anticoagulantes orais. }\end{array}$ & C \\
\hline Classe Ila & $\begin{array}{l}\text { O paciente com menos de } 65 \text { anos } \\
\text { pode optar pela a prótese mecânica, } \\
\text { desde que não haja contraindicação à } \\
\text { anticoagulação. O paciente pode optar } \\
\text { pela bioprótese caso opte por um estilo } \\
\text { de vida sem o uso de anticoagulantes. }\end{array}$ & $C$ \\
\hline Classe Ila & $\begin{array}{l}\text { A bioprótese é recomendada para } \\
\text { pacientes acima de } 65 \text { anos sem } \\
\text { fatores de risco para tromboembolismo. }\end{array}$ & $C$ \\
\hline Classe Ila & $\begin{array}{l}\text { O uso de homoenxertos podem } \\
\text { ser utilizados nos pacientes com } \\
\text { endocardite em prótese ou pacientes } \\
\text { com anel valvar pequeno. }\end{array}$ & C \\
\hline Classe Ila & $\begin{array}{l}\text { A bioprótese e o homoenxerto podem } \\
\text { ser considerados em mulheres em } \\
\text { idade fértil. }\end{array}$ & C \\
\hline Classe Ilb & $\begin{array}{l}\text { A prótese mecânica pode ser } \\
\text { recomendada para pacientes com } \\
\text { raiz da aorta pequena nos quais a } \\
\text { ampliação do anel valvar é de alto risco } \\
\text { ou contraindicada. }\end{array}$ & C \\
\hline
\end{tabular}




\subsection{Situações clínicas especiais}

\subsubsection{Desproporção (mismatch) prótese-paciente}

Mismatch Prótese-Paciente (MPP) é um termo introduzido por Rahimtoola ${ }^{279}$ em 1978 para descrever a condição na qual, in vivo, a Área do Orifício Efetivo (AOE) da prótese valvar é menor do que a da valva nativa. Essa perda de área do orifício efetivo pode ou não ser clinicamente significativa, dependendo do tamanho e tipo de prótese valvar implantada. Blais e cols. ${ }^{280}$ definiram MPP como "grave" quando a AOE da prótese valvar aórtica foi $<0,65 \mathrm{~cm}^{2} / \mathrm{m}^{2}$, como "moderada" com AOE entre 0,65 e $0,85 \mathrm{~cm}^{2} / \mathrm{m}^{2}$, e "normal" com AOE $>0,85 \mathrm{~cm}^{2} / \mathrm{m}^{2}$. Na realidade, os pacientes com anel aórtico pequeno geralmente são idosos, portadores de hipertrofia ventricular esquerda importante, disfunção diastólica expressiva e, frequentemente, DAC.

Felizmente, pacientes com anel aórtico anatomicamente pequeno (diâmetro transversal $<18 \mathrm{~mm}$ ao ecocardiograma) ou via de saída do VE estreita $(<15 \mathrm{~mm})$ são raros, mas representam um desafio para o cirurgião. O tratamento é a miectomia septal extensa e da reconstrução da raiz da aorta para acomodar uma prótese hemodinamicamente adequada. Deste modo, as próteses aórticas ${ }^{281-283}$ menores devem ser evitadas em pacientes com grande superfície corpórea e fisicamente ativos, bem como naqueles com função ventricular esquerda comprometida, a fim de reduzir o risco operatório e otimizar a recuperação funcional. Além disso, MPP pode ser considerada como um dos mecanismos para explicar a não melhora funcional no pós-operatório.

\subsubsection{Reoperação para substituir uma prótese valvar}

O importante comprometimento da função das diferentes próteses depende do tipo e modelo de cada uma, pode ser súbito ou progressivo, e implica novo procedimento cirúrgico, muitas vezes de emergência. O desfecho é dependente do diagnóstico preciso da disfunção, do estado clínico do paciente e suas comorbidades, e da experiência do cirurgião em reoperações.

Essas complicações podem ser decorrentes de disfunção estrutural, como calcificação ou ruptura de uma prótese biológica, ou nãoestrutural, como trombose de uma prótese mecânica com imobilização dos elementos móveis, deiscência, El e formação exagerada de tecido do hospedeiro (pannus). Outras vezes, a reoperação é indicada para solucionar TE recorrente, hemólise intravascular significativa ou repetidos sangramentos pelo uso da terapia anticoagulante.

Os pacientes com ânulo aórtico pequeno podem apresentar quadro clínico gerado pela desproporção prótese-paciente, mantendo gradientes elevados através de uma prótese de pequeno diâmetro e cujo fluxo é em parte dificultado, especialmente se uma prótese biológica pequena com suporte ("stented") foi implantada. Nesses casos, se o paciente não melhora clinicamente e não mostra regressão na hipertrofia e massa do VE, a função valvar deve ser reavaliada e, confirmada esta disfunção, o paciente deve ser reoperado.

Nas reoperações de pacientes em condição estável e sem El protética o risco cirúrgico é um pouco maior que o da primeira cirurgia. Nos países em desenvolvimento, os pacientes costumam apresentar-se em condições clínicas mais desfavoráveis, geralmente necessitando de cirurgias de urgência ou emergência, com maiores taxas de mortalidade. Os pacientes com El e disfunção protética importante requerem cuidadosa avaliação hemodinâmica, e a reoperação é indicada de acordo com os sintomas, a função ventricular, o conhecimento da história natural da prótese envolvida e as alterações hemodinâmicas presentes. A mortalidade nas cirurgias eletivas varia de 3,5\% a $6 \%$ na retroca aórtica, podendo duplicar-se nas cirurgias de urgência e alcançar taxas de até $30 \%$ ou mais em cirurgias de emergência (pacientes em choque cardiogênico ou cirurgia de salvamento). Outros fatores que aumentam o risco operatório são idade e classe funcional avançadas, fração de ejeção reduzida e insuficiência renal grave ${ }^{284}$.

\section{Anticoagulação em pacientes portadores de valvopatias}

As valvopatias, independentemente do ritmo cardíaco, mas especialmente na presença da FA, expõem a risco de eventos embólicos ${ }^{285}$. O TE sistêmico é apontado como uma das graves complicações da formação do trombo em câmara atrial.

O fenômeno tromboembólico pode modificar de forma expressiva a história natural da doença valvar. Portanto, a prevenção do TE é muito importante durante o acompanhamento do paciente com valvopatia ${ }^{286}$.

Estão disponíveis dois grupos de antitrombóticos:

- Anticoagulantes de administração oral: fenprocumona (Marcoumar ${ }^{\circledR}$ ), acenocumanol (Sintron $\left.{ }^{\circledR}\right)$, fenindiona (Dindevan $\AA)$, varfarina sódica cristalina (Coumadin $\AA$ ) e varfarina sódica (Marevan $\left.{ }^{\circledR}\right)$. Dos cinco compostos, o último é o mais utilizado na prática clínica.

- Anticoagulantes de uso parenteral: heparinas. Nesse grupo são conhecidas as Heparinas Não Fracionadas (HNF) (Liquemine ${ }^{\circledR}$ ) e as Heparinas de Baixo Peso Molecular (HBPM): dalteparina (Fragmin $\AA$ ), nadroparina (Fraxiparina ${ }^{\circledR}$ ) e enoxaparina (Clexane $®)$.

O tratamento com anticoagulante nas valvopatias, quando indicado, é por tempo prolongado, o que torna a escolha da via oral a melhor opção, ficando a indicação das heparinas (de aplicação intravenosa ou subcutânea) para situações especiais de tratamento.

\subsection{Anticoagulação oral}

\subsubsection{Varfarina}

Dos compostos utilizados por via oral com ação anticoagulante, a varfarina, tanto na composição sódica como na sódica cristalina, é a mais utilizada por suas propriedades favoráveis - boa biodisponibilidade e início e duração de ação previsíveis -, além de comprovada eficácia ${ }^{19}$.

Seu início de ação ocorre em uma hora, com pico de concentração de duas aoito horas. Entretanto, a ação eficaz somente é percebida ao final de cinco dias, em razão da meia-vida dos fatores de coagulação. As proteínas C e S (anticoagulantes) têm meia-vida efêmera de apenas quatro horas, mas os fatores X e II têm meia-vida estimada em 40 e 100 horas, respectivamente. Esse fato explicaria a ação paradoxal pró-coagulante da medicação que pode ocorrer no início do tratamento. 


\subsection{Anticoagulação injetáve}

Dos compostos anticoagulantes injetáveis, a heparina de baixo peso molecular tornou-se o agente de escolha, tanto pela eficácia quanto pela praticidade na aplicação.

O uso isolado ou combinado das duas formas de apresentação dos anticoagulantes se prende à vida média de cada um deles. Quando desejamos alcançar a proteção antitrombótica de forma rápida, a heparina é utilizada concomitantemente à anticoagulação oral ${ }^{287}$.

\subsubsection{Dose inicial e de manutenção do anticoagulante oral}

A dose inicial e de manutenção é aquela que impede a formação do trombo, mas não a do coágulo, e deve ser individualizada. Deve ser orientada pelos valores do INR.

Especula-se que pacientes idosos, debilitados, malnutridos, com insuficiência cardíaca, doença hepática, cirurgia de grande porte recente ou tomando medicações que aumentam a sensibilidade à varfarina são mais sensíveis à anticoagulação oral, em razão do menor metabolismo hepático ${ }^{288}$. Portanto, para pacientes com mais de 65 anos, inicia-se a varfarina com $2,5 \mathrm{mg} / \mathrm{dia}$, e para os demais, $5 \mathrm{mg} / \mathrm{dia}$. O controle laboratorial deve ser feito três a cinco dias após o início do tratamento. Após ajustes das doses, consideramos ter atingido a dose adequada quando conseguirmos, com intervalos de cinco dias, três amostras de sangue com valores dentro do desejado.

Ao longo do tratamento, em razão de inúmeros fatores externos (exemplo: flutuação da dose de vitamina $\mathrm{K}$ ingerida por causa de cardápios frequentemente modificados, polimedicação com ação agonista ou antagonista, edema da mucosa gástrica resultando em menor absorção do fármaco), muitas vezes pode tornar-se difícil a manutenção dos valores alvo de INR. Recomenda-se que, uma vez encontrada a dose adequada, os controles laboratoriais não excedam 30 dias ${ }^{289}$.

Discute-se qual o melhor momento para a administração do anticoagulante oral. Sugere-se que a tomada seja pela manhã e em jejum, evitando-se a influência do $\mathrm{pH}$ gástrico, modificado por alimentos ingeridos.

\subsection{Anticoagulação na doença valvar com valva nativa}

O risco de TE é maior na Doença Valvar Mitral Reumatismal (DVMR) quando comparada à lesão aórtica. Alguns autores admitem que pacientes com DVMR tenham uma chance cinco vezes maior de apresentar episódio de TE durante a evolução da doença. Entre aqueles com doença valvar aórtica, especialmente a estenose por calcificação em ritmo sinusal, o TE não é frequente. Com o aumento da longevidade, tem-se detectado com maior frequência a calcificação do aparelho valvar aórtico. Holley e cols. ${ }^{290}$ atribuem à degeneração aórtica a presença de microêmbolos, especialmente renais.

A presença de FA, que aumenta em 17,5 vezes a incidência de TE, é mais frequente nas disfunções mitrais, sendo maior na estenose (39\%) do que na insuficiência (23\%). Na disfunção aórtica, a FA está mais presente na insuficiência $(14,5 \%)$ do que na estenose (13\%).

Os pacientes com disfunção valvar mitral, estenose ou insuficiência, ainda em ritmo sinusal, sem clínica sugestiva de TE prévio, não necessitam de prevenção medicamentosa ${ }^{291}$.
Vários estudos não conseguiram demonstrar que as maiores dimensões do átrio esquerdo ( $\mathrm{AE} \geq 55 \mathrm{~mm}$ ) aumentam os riscos do TE. Portanto, $A E \geq 55 \mathrm{~mm}$, isoladamente, não é indicativo de tratamento preventivo antitrombótico. Entretanto, em pacientes idosos em ritmo pré-fibrilatório, ou na presença de contraste espontâneo, pode-se considerar a prevenção do TE ${ }^{292}$.

Nos pacientes com condição socioeconômica desfavorável e difícil acesso aos serviços de saúde, ocorre aumento das complicações associadas à anticoagulação oral. Nesses pacientes, pode-se utilizar aspirina na dose de 200 a 300mg/dia como alternativa, na profilaxia de $\mathrm{TE}^{286}$.

Na tabela 36 estão as recomendações para profilaxia de tromboembolismo na doença valvar com valva nativa.

Tabela 36 - Recomendação para profilaxia de tromboembolismo na doença valvar com valva nativa

\begin{tabular}{|c|c|c|}
\hline $\begin{array}{l}\text { Classe de } \\
\text { recomendação }\end{array}$ & Indicação & $\begin{array}{l}\text { Nível de } \\
\text { evidência }\end{array}$ \\
\hline Classe I & $\begin{array}{l}\text { Profilaxia antitrombótica com } \\
\text { anticoagulantes orais em pacientes } \\
\text { com doença valvar e ritmo de FA. }\end{array}$ & $B$ \\
\hline Classe I & $\begin{array}{c}\text { Profilaxia antitrombótica com } \\
\text { anticoagulantes orais em pacientes } \\
\text { com doença valvar e episódio prévio } \\
\text { de TE em ritmo sinusal. }\end{array}$ & B \\
\hline Classe I & $\begin{array}{c}\text { Anticoagulação na presença de trombo } \\
\text { em átrio esquerdo. }\end{array}$ & C \\
\hline Classe lla & $\begin{array}{l}\text { Anticoagulação em paciente com átrio } \\
\text { esquerdo } \geq 55 \mathrm{~mm} \text { na presença de } \\
\text { contraste espontâneo em ritmo sinusal. }\end{array}$ & C \\
\hline Classe Ila & $\begin{array}{l}\text { Profilaxia antitrombótica com aspirina } \\
\text { em pacientes com doença valvar e } \\
\text { ritmo de FA com contraindicação aos } \\
\text { anticoagulantes orais. }\end{array}$ & B \\
\hline Classe Ila & $\begin{array}{l}\text { Associação de aspirina em pacientes } \\
\text { com doença valvar em ritmo de FA } \\
\text { com episódio de TE na vigência de } \\
\text { anticoagulação oral com INR adequado. }\end{array}$ & C \\
\hline Classe III & $\begin{array}{c}\text { Profilaxia antitrombótica com } \\
\text { anticoagulantes orais em pacientes } \\
\text { com doença valvar em ritmo sinusal e } \\
\text { sem evidência de TE prévio, trombo } \\
\text { atrial ou contraste espontâneo. }\end{array}$ & C \\
\hline
\end{tabular}

12.4. Anticoagulação em portadores de prótese mecânica

É consenso geral que as próteses mecânicas expõem a riscos elevados de TE, independentemente do ritmo cardíaco, estimados anualmente em $12 \%$ para as próteses na posição aórtica e 22\% na posição mitral, na ausência de anticoagulação ${ }^{293}$. A incidência de trombogênese na posição aórtica é menor em razão da maior pressão do fluxo de sangue sobre a superfície valvar, reduzindo o depósito de fibrina. Dessa forma, a presença de prótese mecânica, independentemente de sua localização e do ritmo cardíaco, implica necessidade de prevenção antitrombótica (tabela 37). 


\section{Tabela 37 - Recomendação de anticoagulação em prótese mecânica}

\begin{tabular}{|c|c|c|}
\hline $\begin{array}{l}\text { Classe de } \\
\text { recomendação }\end{array}$ & Indicação & $\begin{array}{c}\text { Nível de } \\
\text { evidência }\end{array}$ \\
\hline Classe I & $\begin{array}{l}\text { Manter INR entre } \\
2,0 \text { e 3,0 em } \\
\text { pacientes com } \\
\text { prótese mecânica } \\
\text { aórtica em ritmo } \\
\text { sinusal. }\end{array}$ & B \\
\hline Classe I & $\begin{array}{l}\text { Manter INR entre 2,5 } \\
\text { e 3,5 em pacientes } \\
\text { com prótese } \\
\text { mecânica aórtica em } \\
\text { fibrilação atrial. }\end{array}$ & B \\
\hline Classe I & $\begin{array}{c}\text { Manter INR entre } \\
\text { 2,5 e 3,5 em } \\
\text { pacientes com } \\
\text { prótese mecânica } \\
\text { mitral independente } \\
\text { do ritmo cardíaco. }\end{array}$ & C \\
\hline
\end{tabular}

INR - International Normalized Ratio.

\subsection{Anticoagulação em portadores de prótese biológica}

As biopróteses são consideradas menos trombogênicas. Entretanto, alguns autores consideram os três primeiros meses após a implantação da prótese como os de maior risco para TE. A trombogenicidade estaria ligada aos pontos de sutura e tecidos perivalvares traumatizados ainda não endotelizados ${ }^{294}$. No entanto, a baixa incidência de TE nesse período não compensa a exposição dos pacientes aos riscos de sangramento pelo uso de anticoagulantes ${ }^{295}$. As recomendações para anticoagulação em portadores de prótese valvar biológica estão na tabela 38.

\section{Tabela 38 - Recomendação para anticoagulação em prótese biológica}

\begin{tabular}{|c|c|c|}
\hline $\begin{array}{l}\text { Classe de } \\
\text { recomendação }\end{array}$ & Indicação & $\begin{array}{c}\text { Nível de } \\
\text { evidência }\end{array}$ \\
\hline Classe I & $\begin{array}{l}\text { Profilaxia antitrombótica } \\
\text { com anticoagulante } \\
\text { oral em pacientes com } \\
\text { prótese biológica em } \\
\text { fibrilação atrial. }\end{array}$ & B \\
\hline Classe Ilb & $\begin{array}{l}\text { Profilaxia antitrombótica } \\
\text { com anticoagulante oral } \\
\text { durante os três primeiros } \\
\text { meses após implante } \\
\text { de prótese biológica } \\
\text { em pacientes em ritmo } \\
\text { sinusal. }\end{array}$ & B \\
\hline Classe III & $\begin{array}{l}\text { Profilaxia antitrombótica } \\
\text { com anticoagulante } \\
\text { oral a longo prazo } \\
\text { em pacientes com } \\
\text { prótese biológica } \\
\text { em ritmo sinusal, na } \\
\text { ausência de outras } \\
\text { condições que indiquem } \\
\text { anticoagulação. }\end{array}$ & C \\
\hline
\end{tabular}

\subsection{Superdosagem}

Vários estudos demonstram aumento significativo de eventos hemorrágicos à medida que o INR se torna superior a 5,0296. Diante de valores de INR fora dos resultados adequados, é dever, antes do ajuste posológico, procurar identificar possíveis causas da anticoagulação inadequada, como o mau cumprimento do esquema proposto e a ingestão de fármacos associados $^{297}$. As tabelas 40 e 41 mostram as interações medicamentosas e alimentares com a varfarina.

Para valores de INR acima do previsto, mas inferior ou igual a 5,0, na ausência de sangramento e sem causa aparente para a perda do controle, suspender a próxima tomada e reiniciar o tratamento com menor dose (menos 10 a 20\% da dose semanal). Geralmente, é suficiente a retirada de 1,25mg de varfarina em dias alternados. Repete-se o controle de INR em no máximo cinco dias (Grau de recomendação I, nível de evidência C).

Para valores de INR entre 5,0 e 9,0 sem sangramento e sem fator de potencial risco para hemorragia, como hipertensão arterial sistêmica, suspender as doses durante os próximos dois ou três dias, ou suprimir uma dose e administrar vitamina K oral nas doses de 1 a 2,5mg/dia. Se houver necessidade de reversão mais rápida (por exemplo, cirurgia) administra-se vitamina $\mathrm{K}$ oral na dose de $5 \mathrm{mg}$ e espera-se redução em 24 horas; em caso de não haver

redução, administra-se dose adicional de 1 a 2 mg de vitamina $\mathrm{K}$ oral. Retornar com doses menores (redução da dose semanal de 5 a 20\%) após conhecer o valor do INR no 4음 dia e controlar, a seguir, com intervalo não superior a sete dias (Grau de recomendação I, nível de evidência $\mathrm{C}$ ).

Com valores de INR $>9,0$, mesmo sem sangramento, sugerese internar o paciente em ambiente hospitalar com suspensão do anticoagulante por quatro dias em média. A administração de vitamina $\mathrm{K} 2,5$ a $5 \mathrm{mg}$ por via oral pode reduzir mais rápido o INR (24 a 48 horas) (Grau de recomendação I, nível de evidência B). Exames laboratoriais para INR devem ser diários. Se de 24 a 48 horas não houver redução significativa do INR, ou seja, valores próximos a 5,0, deve-se acrescentar nova dose de 1,0 a 2,5 mg via oral de vitamina K (Grau de recomendação lla, nível de evidência C) e somente reiniciar o tratamento com o anticoagulante, com doses menores do que as habituais (redução de 10 a 25\% da dose semanal), após constatar valores de INR próximos aos valores alvo - INR $\leq 4,0$.

Para pacientes com perdas evidentes de sangue (queda da hemoglobina $\geq 2 \mathrm{~g} / \mathrm{dL}$ ) e INR $\geq 9,0$ recomenda-se internação hospitalar, suspensão do medicamento e administração de vitamina K 10mg intravenosa (IV) associada a infusão de plasma fresco (2 a 3 unidades - 200 a 300mL), concentrado do complexo protrombínico ou fator VIla recombinante. Repetir dose de vitamina K 5 a 10mg IV a cada 12 horas se o INR persistir elevado (Grau de recomendação I, nível de evidência C).

Em pacientes com valores elevados de INR $(>9,0)$ e sangramento significativo, recomenda-se concentrado de hemácias e plasma fresco, vitamina K 10mg IV com repetição em 24 a 48 horas, se necessário, além do fator VIla recombinante. Só iniciar a varfarina com doses menores do que as habituais após INR $\leq$ 4,0. (Grau de recomendação I, nível de evidência C). ${ }^{298}$

Perdas de sangue durante a anticoagulação com INR entre 4,0 e 5,0 podem ocorrer pela presença de doença clínica com potencial de sangramento. Nessa situação, deve-se ter cautela na redução do anticoagulante, e agilidade na investigação do órgão sangrante. 
A tabela 39 sumariza o ajuste da dose de varfarina de acordo com o INR, na ausência de sangramento.

\section{Tabela 39 - Ajuste de dose de varfarina de acordo com INR, na} ausência de sangramento

\begin{tabular}{|c|c|}
\hline INR & Ajuste sugerido da dose da varfarina \\
\hline$<1,5$ & $\begin{array}{l}\text { Aumentar a dose semanal em } 10 \% \text { a } 20 \% \text {. Considerar uma } \\
\text { dose extra. Repetir o exame entre três e cinco dias. }\end{array}$ \\
\hline 1,5 a 2,0 & $\begin{array}{c}\text { Aumentar a dose semanal em } 5 \% \text { a } 10 \% \text {. Repetir o exame } \\
\text { entre três e cinco dias. }\end{array}$ \\
\hline 2,0 a 3,0 & Sem alterações. \\
\hline 3,0 a 3,5 & Diminuir dose semanal em $5 \%$ a $10 \%$. Repetir a critério médico. \\
\hline 3,5 a 5,0 & $\begin{array}{l}\text { Suspender uma dose. Diminuir dose semanal em } 10 \% \text { a } 20 \% \text {, } \\
\text { conforme INR-alvo. Repetir o exame com uma semana. }\end{array}$ \\
\hline 5,0 a 9,0 & $\begin{array}{l}\text { Suspender duas atrês doses. Diminuir dose semanal em } 10 \% \\
\text { a } 20 \% \text {. Repetir o exame com três a cinco dias. }\end{array}$ \\
\hline$>9,0$ & $\begin{array}{l}\text { Internação hospitalar. Suspender a medicação e administrar } \\
\text { vitamina K oral ou intravenosa. INR diário e reintroduzir } \\
\text { varfarina quando INR < } 4,0 \text { com diminuição da dose } 10 \% \text { a } \\
25 \% \text {. Em caso de sangramento, administrar plasma fresco } \\
\text { congelado, complexo protrombínico ou fator VIlla recombinante. }\end{array}$ \\
\hline
\end{tabular}

Tabela 40 - Interações medicamentosas com varfarina299

\begin{tabular}{cc}
\hline Agonistas & Antagonistas \\
\hline Amiodarona & Azatioprina \\
Diltiazem & Carbamazepina \\
Propranolol & Barbitúricos \\
Aspirina & Rifampicina \\
Fenofibrato & Ciclosporina \\
Sinvastatina & \\
Anti-inflamatórios não hormonais & \\
Omeprazol & \\
Ciprofloxacina & \\
Norfloxacina & \\
Fluconazol & \\
Itraconazol & \\
Isoniazida & \\
Cimetidina & \\
Fenitoína & \\
Metronidazol & \\
Ginko biloba & \\
Eritromicina & \\
\hline
\end{tabular}

Tabela 41 - Interações alimentares com varfarina ${ }^{299}$

\begin{tabular}{cc}
\hline Agonistas & Antagonistas \\
\hline Óleo de peixe & Hortaliças verdes (brócolis, couve, \\
Manga & couve-flor, alface) \\
Suco de toranja & Abacate \\
& Leite de soja e óleo de soja \\
& Chá verde \\
\hline
\end{tabular}

\subsection{Ponte de heparina}

O tratamento com anticoagulante oral em pacientes com doença em valva nativa e FA e entre aqueles com prótese mecânica com qualquer ritmo cardíaco se faz por tempo indefinido. Essa situação abre espaço para que o paciente possa apresentar, no acompanhamento, doenças que necessitem de tratamento cirúrgico.

Tomando como premissa que a anticoagulação não deve ser interrompida em pacientes com alto risco de TE, como nas próteses mecânicas em qualquer posição e ritmo, ou prótese biológica e FA, a escolha da conduta terapêutica anticoagulante deve ser norteada pelo conhecimento do risco de sangramento da cirurgia proposta.

Consideram-se cirurgias de baixo risco de sangramento as de até $0,2 \%$ de risco ou nas quais a hemostasia mecânica é eficiente, tais como a exodontia de um ou dois dentes, cirurgia oftalmológica para remoção de catarata e pequenas cirurgias de pele ${ }^{300}$. Nessas situações, não há necessidade de suspensão do anticoagulante oral, ficando o paciente liberado para o procedimento indicado desde que o valor do INR esteja 24 horas antes do procedimento no intervalo entre 2,0 e 2,5 (Grau de recomendação I, nível de evidência B).

Há situações em que a probabilidade de sangramento é pequena, mas com hemostasia difícil. Pertencem a esse grupo: colonoscopia com ressecção de pólipos intestinais $\geq 2 \mathrm{~cm}$ (as dimensões são conhecidas somente durante o procedimento), prostatectomia, vasectomia, colecistectomia por via laparoscópica, biópsia de órgãos internos - fígado, rim e próstata. Para esses pacientes, e para pacientes que serão submetidos a cirurgias que expõem a riscos de sangramento maior (laparoscopia exploradora, cirurgia ortopédica), recomenda-se o uso da ponte de heparina ${ }^{299,300}$, em razão da meia-vida menor desse fármaco (HNF: 4h, HBPM: 8h a 14h). A "ponte de heparina" fornece proteção de TE durante a interrupção do anticoagulante oral, que deve ser iniciada no quinto dia pré-operatório. Introduzir a HNF de aplicação IV ou a HBPM de aplicação subcutânea a partir do terceiro dia antes do procedimento (Grau de recomendação I, nível de evidência C).

A determinação do INR 24 horas antes do procedimento cirúrgico dará maior segurança para a liberação da cirurgia. Nos casos em que o INR estiver maior que 1,5, a vitamina $\mathrm{K}$ oral nas doses de 1 a $2 \mathrm{mg}$ é suficiente para otimizar a situação (Grau de recomendação Ila, nível de evidência C). Inicia-se a reintrodução da heparina em comum acordo com o cirurgião. Quando a hemostasia foi eficaz e o risco de TE é elevado, a heparina pode ser reintroduzida utilizando-se intervalo de 12 horas; caso contrário, o intervalo preconizado é de 48 a 72 horas (Grau de recomendação I, nível de evidência C).

As doses utilizadas devem ser as mesmas para tratamento de eventos embólicos e não doses menores como as indicadas para a profilaxia de trombose venosa profunda. A HNF (25.000UI / $5 \mathrm{~mL}$ ) é dissolvida em soro glicosado a $5 \%$ (245 mL) e infundida por bomba de infusão contínua. A dose pode se modificar em função do tempo de tromboplastina parcial ativada (TTPA), que deve permanecer em 1,5 a 2,5 vezes o normal (em torno de 50 a 70 segundos). A suspensão da HNF pode ser realizada quatro horas antes da cirurgia (Grau de recomendação I, nível de evidência C).

Dentre as heparinas de baixo peso molecular, a enoxaparina é prescrita na dose de $1 \mathrm{mg} / \mathrm{kg}$ a cada 12 horas, a dalteparina na dose de $100 \mathrm{UI} / \mathrm{kg}$ a cada 12 horas e a nadroparina na dose de $86 \mathrm{UI} / \mathrm{kg}$ a cada 12 horas. A HBPM é a medicação de escolha, e em casos selecionados, pode-se inciar a "ponte com heparina" ambulatorialmente (Grau de recomendação I, nível de evidência C). A última dose da HBPM deve ser realizada 24 horas antes 
do procedimento e corresponder a metade da dose diária total (Grau de recomendação I, nível de evidência C) ${ }^{300}$.

O controle laboratorial da HBPM pode ser obtido por meio da dosagem da atividade antiXa, que deve permanecer entre 0,7 e 1,0 U/mL. No entanto, deve ser realizado apenas em casos selecionados.

O retorno da anticoagulação oral deverá ocorrer em comum acordo com o cirurgião. O tempo médio de reintrodução depende do controle do sangramento. Estima-se entre 24he 48h o tempo médio para que o esquema de anticoagulação volte a ser prescrito.Inicia-se com a reintrodução da heparina em doses utilizadas antes da cirurgia e o anticoagulante oral em conjunto à heparina tão logo haja condição de deglutição. Esse esquema é mantido por pelo menos $72 \mathrm{~h}$. Se INR $\geq 1,8 \mathrm{em}$ portadores de risco médio ou baixo de TE, a heparina pode ser suspensa. Para pacientes com maior risco para TE, exige-se INR $\geq 2,2$ antes da suspensão da heparina.

\section{Hipertensão pulmonar}

\subsection{Definição}

A Hipertensão Pulmonar (HP) é uma condição hemodinâmica e fisiopatológica definida como pressão arterial pulmonar média (PAPm) $\geq 25 \mathrm{mmHg}$ em repouso, medida através de cateterismo cardíaco de câmaras direitas. A HP pode ser dividida em précapilar ou pós-capilar de acordo com alterações hemodinâmicas. A HP pré-capilar é definida por uma PAPm $\geq 25 \mathrm{mmHg}$ e Pressão Capilar Pulmonar (PCP) $\leq 15 \mathrm{mmHg}$. Como exemplo, podemos citar a hipertensão arterial pulmonar primária e doenças pulmonares. A HP pós-capilar é definida por uma PAPm $\geq$ $25 \mathrm{mmHg}$ e PCP $\geq 15 \mathrm{mmHg}$. Nesse grupo encontram-se as doenças valvares e as disfunções sistólica e diastólica do VE. A HP pós-capilar pode ser dividida em passiva, quando o gradiente de pressão transpulmonar (PAPm-PCP) for $\leq 12 \mathrm{mmHg}$, e reativa quando o gradiente for $\geq 12 \mathrm{mmHg}$ (tabela 42$)^{301}$.

\section{Tabela 42 - Definições hemodinâmicas da HP}

\begin{tabular}{|c|c|c|}
\hline Definição & Características & Grupos clínicos \\
\hline HP & $\mathrm{PAPm} \geq 25 \mathrm{mmHg}$ & Todos \\
\hline \multirow{2}{*}{$\begin{array}{l}\text { HP pré- } \\
\text { capilar }\end{array}$} & $\mathrm{PAPm} \geq 25 \mathrm{mmHg}$ & HP primária \\
\hline & $\mathrm{PCP} \leq 15 \mathrm{mmHg}$ & $\begin{array}{c}\text { HP secundária às doenças } \\
\text { pulmonares }\end{array}$ \\
\hline
\end{tabular}

$\begin{array}{llr}\begin{array}{l}\text { HP pós- } \\ \text { capilar }\end{array} & \text { PAPm } \geq 25 \mathrm{mmHg} & \text { HP secundária às doenças valvares } \\ & P C P \geq 15 \mathrm{mmHg} & \text { HP secundária à insuficiência cardiaca }\end{array}$

$\begin{array}{ll}\text { Passiva } & \text { PAPm }-\mathrm{PCP} \leq 12 \mathrm{mmHg} \\ \text { Reativa } & \text { PAPm }-\mathrm{PCP} \geq 12 \mathrm{mmHg}\end{array}$

HP - Hipertensão pulmonar; PAPm - Pressão de artéria pulmonar média; PCP Pressão capilar pulmonar; PAPm - PCP - Gradiente pressórico transpulmonar.

\subsection{Fisiopatologia}

No contexto da doença valvar, as alterações patológicas são caracterizadas pelo aumento e espessamento das veias pulmonares, dilatação dos capilares pulmonares, espessamento da membrana basal alveolar, edema intersticial, hemorragia alveolar e aumento da drenagem dos vasos linfáticos. As artérias pulmonares distais podem ser afetadas, apresentando hipertrofia da camada média, disfunção endotelial com proliferação intimal e alterações fibróticas que favorecem a vasoconstrição ${ }^{301,302}$.

Os mecanismos responsáveis pelo aumento da pressão arterial pulmonar são complexos e incluem: transmissão retrógrada do aumento de pressão do AE (HP pós-capilar passiva); aumento do tônus vasomotor das artérias pulmonares e/ou alterações estruturais fixas com remodelamento obstrutivo das arteríolas pulmonares (HP pós-capilar reativa). Na HP pós-capilar passiva, o gradiente pressórico transpulmonar e a resistência vascular pulmonar estão normais. Na HP reativa, o aumento da PAPm é maior que o aumento da PCP, com consequente aumento do gradiente pressórico transpulmonar e da resistência vascular pulmonar, sugerindo alterações intrínsecas pulmonares associadas ${ }^{303}$. Mais recentemente, postula-se que fatores genéticos influenciem na variabilidade da resposta do leito arterial pulmonar na presença de hipertensão venocapilar ${ }^{302}$. Os pacientes que evoluem com HP reativa apresentam genótipo permissivo para alterações estruturais mais importantes nas artérias pulmonares distais ${ }^{304}$.

\subsection{Diagnóstico}

\subsubsection{Ecocardiografia}

A abordagem diagnóstica através da ecocardiografia com Doppler inclui a aferição da PSAP, PAPm, pressão diastólica da artéria pulmonar, resistência vascular pulmonar e a avaliação do Ventrículo Direito (VD). As recomendações da ecocardiografia em pacientes com HP estão na tabela 43.

A abordagem quantitativa do tamanho e função do VD tem grande importância clínica em inúmeras doenças pulmonares e cardíacas. Numerosas publicações demonstraram o significado prognóstico da função do VD. ${ }^{305}$

Em condições normais, o VD é submetido a uma baixa resistência pulmonar $\mathrm{e}$, devido às suas paredes mais afiladas que o VE, é relativamente complacente. Condições agudas, como embolia pulmonar aguda, causam dilatação do VD antes do aumento da pressão pulmonar, que posteriormente pode levar a hipertrofia.

O VD deve ser examinado através de múltiplas janelas acústicas e algumas medidas são essenciais para análise e comparação.

\subsubsection{Dimensões do ventrículo direito}

As dimensões do VD são mais bem avaliadas no corte apical de quatro câmaras, com adequações da imagem. Diâmetros maiores que $42 \mathrm{~mm}$ no segmento basal e maiores que $35 \mathrm{~mm}$ no segmento médio indicam dilatação do VD. No corte paraesternal eixo curto, um diâmetro maior que $27 \mathrm{~mm}$ no final da diástole no nível do anel pulmonar indica dilatação. A espessura da 
parede do VD maior que $5 \mathrm{~mm}$ indica hipertrofia e pode sugerir sobrecarga de pressão, na ausência de outras anormalidades.

\subsubsection{Função sistólica do ventrículo direito}

A função sistólica do VD pode ser avaliada através de inúmeros parâmetros. O chamado índice de performance miocárdica representa uma medida global da função. Se obtido pelo Doppler pulsátil das valvas tricúspide e pulmonar o valor normal é maior que $40 \%$ e através do Doppler tecidual é maior que 55\%. Entretanto, não é confiável quando as pressões do átrio direito estão elevadas, com redução do tempo de relaxamento isovolumétrico ${ }^{306}$.

Os índices de deformação miocárdica (strain/strain rate) podem ser obtidos através do Doppler (unidimensional) ou pela técnica denominada speckle tracking em duas dimensões. Representam uma forma de abordagem da contratilidade miocárdica menos dependente de pré-carga e pós-carga e podem ser aplicadas em uma série de doenças. O strain bidimensional é ângulo independente e pode fornecer dados acerca da função miocárdica longitudinal global do VD $\mathrm{V}^{307}$.

Tabela 43 - Recomendações de ecocardiografia em pacientes com HP

\begin{tabular}{lcc}
\hline $\begin{array}{l}\text { Classe de } \\
\text { recomendação }\end{array}$ & Indicação & $\begin{array}{c}\text { Nível de } \\
\text { evidência }\end{array}$ \\
\hline Classe I & $\begin{array}{c}\text { Diagnóstico e avaliação anatômica em } \\
\text { pacientes com HP. }\end{array}$ & B \\
\hline Classe I & $\begin{array}{c}\text { Estimativa da pressão sistólica em } \\
\text { artéria pulmonar. }\end{array}$ & B \\
\hline Classe I & $\begin{array}{c}\text { Avaliação da função sistólica do } \\
\text { ventrículo direito. }\end{array}$ & B \\
\hline Classe Ila & $\begin{array}{c}\text { Estimativa das pressões média e } \\
\text { diastólica da artéria pulmonar. }\end{array}$ & B \\
\hline Classe III & Estimativa da resistência pulmonar. & B \\
\hline
\end{tabular}

\subsection{Hipertensão pulmonar nas valvopatias}

A presença de HP é um problema comum nas valvopatias e piora o prognóstico dos pacientes. Em pacientes com EM, HP importante, definida como PSAP $\geq 50 \mathrm{mmHg}$, é muito comum, podendo chegar à prevalência de $40 \%{ }^{308}$,e constitui o pior fator prognóstico desses pacientes, levando a sobrevida média de 2,9 anos nos que não são submetidos ao tratamento cirúrgico ${ }^{34}$.

A mortalidade cirúrgica precoce dos pacientes com EM sem HP varia de $2,4 \%$ a $3,6 \%$, enquanto nos pacientes com HP importante pode chegar a 10,5\% ${ }^{309,310}$. Quando a HP é considerada suprassistêmica, a mortalidade cirúrgica aproxima-se de $30 \%{ }^{309}$. A sobrevida em cinco e 10 anos após correção cirúrgica é de aproximadamente $80 \%$ e $65 \%$, respectivamente ${ }^{311}$. São preditores independentes de mortalidade cirúrgica: disfunção clínica de VD, hipertrofia de VD e pressão sistólica de VD ${ }^{309}$. A VMCB pode ser uma alternativa mais segura para o tratamento de pacientes com EM e HP muito importante ${ }^{312}$. Após a correção da EM (cirúrgica ou por $\mathrm{VMCB}$ ), ocorrem diminuição imediata dos níveis de HP por causa da diminuição da pressão do AE (HP passiva) e reversão da vasoconstrição pulmonar em alguns pacientes ${ }^{313}$. Entretanto, nos pacientes com alterações intrínsecas das arteríolas pulmonares (HP reativa), a redução da resistência vascular pulmonar pode ocorrer ao longo de meses e, na maioria dos casos, retorna a níveis pressóricos normais ${ }^{310,312}$. Por sua vez, nos pacientes com níveis de pressão pulmonar suprassistêmica, a ocorrência de HP residual pode chegar a $25 \%{ }^{312}$. Outra causa de HP residual é a presença de desproporção prótese-paciente ${ }^{314}$.

Nos pacientes com IM, a prevalência de HP importante é de aproximadamente 25\%. Os preditores de HP são: idade, diâmetro do AE, presença de FA e CF III ou IV. A presença de HP importante aumenta o risco de mortalidade geral em seis vezes e o risco de morte cardiovascular, em oito vezes nos pacientes mantidos em tratamento clínico. Os pacientes submetidos a cirurgia que apresentam HP apresentam o dobro de mortalidade ao término de cinco anos quando comparados àqueles com pressão pulmonar normal ${ }^{315}$.

A prevalência de HP na EAo importante pode chegar a $29 \%$ nos pacientes submetidos a tratamento cirúrgico ${ }^{316}$. A HP é fator de risco para morte súbita e está associada a pressões de enchimento ventricular elevadas (disfunção diastólica), IM, disfunção do VE e área valvar aórtica ${ }^{317,318}$. Um estudo observacional que incluiu 626 pacientes sugeriu que o uso de estatina e betabloqueador pode ter efeitos protetores $^{318}$.O impacto da HP na mortalidade cirúrgica de pacientes com EAo é controversa. Um pequeno estudo observacional sugeriu que HP é um preditor independente de mortalidade. Os pacientes com HP apresentaram um risco três vezes maior quando comparados àqueles com pressões pulmonares normais ${ }^{317}$. Por sua vez, um estudo retrospectivo que incluiu 119 pacientes com PSAP $\geq 60 \mathrm{mmHg}$ não mostrou piora nos resultados cirúrgicos ${ }^{319}$.

A prevalência de HP na IAo importante varia de 11\% a $16 \%{ }^{320}$ e está associada a presença de IM, disfunção de VE, maiores diâmetros ventriculares e $F^{321}$. Um estudo observacional com acompanhamento médio de 15 anos mostrou que nos pacientes com IAo a presença de HP esteve associada ao dobro de mortalidade, quando comparados àqueles com PSAP normal, manejados clinicamente ${ }^{322}$.A mortalidade cirúrgica dos pacientes com IAo e HP é de aproximadamente $10 \%$ em um ano, enquanto nos pacientes com IAo que permanecem em tratamento clínico a mortalidade é de $42 \%$ no mesmo período. Após ajustes para as comorbidades, a cirurgia de troca valvar permanece como preditor independente de melhora na sobrevida ${ }^{321}$.

\subsection{Cuidados no período pós-operatório}

Conforme descrito anteriormente, HP é uma importante causa de morbidade e mortalidade nos pacientes submetidos à cirurgia valvar, e pode persistir (HP residual) a despeito da redução adequada das pressões de enchimento das câmaras esquerdas. A principal consequência da HP é a presença de disfunção do VD, que dificulta sobremaneira o manejo pós-operatório. $\mathrm{O}$ arsenal terapêutico para o tratamento da HP nesse contexto inclui Óxido Nítrico Inalatório (NOi), Prostaciclina Inalatória (PGI2), vasodilatadores intravenosos (nitroprussiato de sódio e nitroglicerina) e inotrópicos

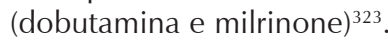


Dois pequenos estudos ${ }^{324,325}$ randomizados compararam as medicações inalatórias aos vasodilatadores intravenosos e mostraram que o NOi e a PGI2 foram igualmente eficazes em diminuir a resistência vascular pulmonar e aumentar o débito cardíaco, assim como diminuir o tempo de internação em unidade de terapia intensiva quando comparados aos vasodilatadores intravenosos. As medicações inalatórias são bem toleradas, pois são vasodilatadores seletivos da circulação pulmonar, aumentam o fluxo sanguíneo somente nas áreas ventiladas do pulmão (melhorando a relação ventilação/perfusão) e aumentam a pressão arterial de oxigênio. A taxa de descontinuação de uso do nitroprussiato de sódio e milrinone no pós-operatório é elevada em razão dos efeitos deletérios sobre a pressão arterial sistêmica.

Fernandes e cols. recentemente demonstraram que a utilização de NOi por um período de 48 horas reduziu de forma significativa a necessidade de agentes vasoativos e o tempo de internação em unidade de terapia intensiva, quando comparados ao oxigênio ${ }^{313}$.

O NOi é utilizado na posologia de 10 a 20ppm, por um período de até 48 horas. Deve-se ter cuidado com a metahemoglobinemia, e os níveis de Óxido Nitroso $\left(\mathrm{NO}_{2}\right)$ não devem ultrapassar 3 ppm. A PGI2 deve ser iniciada na dose de $25 \mathrm{ng} / \mathrm{kg} / \mathrm{min}$, podendo chegar até 100 a $200 \mathrm{ng} / \mathrm{kg} / \mathrm{min}$.

Até o momento, não há nenhum ensaio clínico avaliando a utilização das medicações para o tratamento de hipertensão arterial pulmonar nos pacientes com HP de etiologia valvar. Em casos selecionados de HP residual importante após correção cirúrgica, pode-se considerar a utilização de terapia oral nos pacientes que apresentam sintomatologia significativa compatível com HP. Entretanto, deve-se ter certeza de que a PCP está normalizada, com gradiente pressórico transpulmonar e resistência vascular pulmonar elevados. É importante ressaltar que os pacientes podem apresentar piora clínica após início da medicação por causa de retenção hídrica, aumento das pressões em câmaras esquerdas e edema pulmonar agudo ${ }^{326}$.

\section{Aterosclerose e doença valvar}

\subsection{Probabilidade de doença arterial coronariana em pacientes com valvopatias}

Muitos pacientes com valvopatias apresentam concomitantemente DAC. Esses pacientes, de uma forma geral, apresentam sintomas mais exuberantes, além de apresentarem pior prognóstico e um maior risco cirúrgico ${ }^{327}$. O adequado diagnóstico e tratamento de DAC em pacientes com valvopatia é desafiador e baseia-se em limitadas evidências na literatura, seguindo estudos randomizados existentes sobre o tratamento de DAC e séries de pacientes submetidos à cirurgia de troca valvar.

A prevalência de DAC em pacientes com valvopatia é determinada pelos mesmos fatores de risco da população geral: hipercolesterolemia, hipertensão arterial sistêmica, diabete melito, obesidade, tabagismo, dentre outros. Estratégias de prevenção e redução de risco devem seguir as orientações destinadas à população geral ${ }^{11}$. Da mesma forma, a prevalência de DAC é baixa (3\%) em pacientes que não apresentam angina ou fatores de risco para DAC ${ }^{328}$.

Angina é o principal sintoma na DAC, sendo secundária à limitação do fluxo coronariano imposta pela lesão obstrutiva. Em pacientes com valvopatia, porém, a manifestação de angina pode ter várias causas: hipertrofia do VE, aumento do estresse na parede ventricular, hipertrofia ventricular com isquemia subendocárdica ${ }^{329}$ e hipertrofia ventricular direita ${ }^{330}$. Dessa forma, angina é um indicador menos específico de DAC em pacientes valvopatas do que na população geral.

De uma maneira geral, a presença de angina é um marcador fraco de DAC em pacientes com EAo. Em jovens portadores de EAo congênita ou reumática, angina pode ser um sintoma comum na ausência de coronariopatia obstrutiva. Por sua vez, DAC é um achado frequente em idosos sintomáticos. Em pacientes acima de 70 anos de idade, angina é um forte determinante de DAC (sensibilidade de $78 \%$, especificidade $82 \%)^{331}$. Outro fator também associado à presença de DAC é a calcificação da valva aórtica $(90 \%)^{332}$.

DAC é menos prevalente em pacientes com IAo do que naqueles com EAo, em parte em razão da menor idade daqueles ${ }^{333}$. Ademais, a prevalência de DAC é menor em portadores de EM do que naqueles com doença valvar aórtica ${ }^{334}$. Porém, pelo impacto da DAC não tratada no perioperatório e na sobrevida no pós-operatório, é de fundamental importância o diagnóstico de coronariopatia no período pré-operatório de pacientes portadores de EAo, IAo e EM. Por essa razão, cineangiocoronariografia é recomendada de rotina em pacientes selecionados que serão submetidos a cirurgia valvar - homens acima de 40 anos, mulheres acima de 45 anos ou pacientes acima de 35 anos com fatores de risco para DAC.

A relação entre DAC e IM é única, uma vez que DAC é uma causa frequente dessa lesão valvar. Além disso, a etiologia isquêmica impõe um pior prognóstico quando comparada às outras causas de IM. Em pacientes que realizam cateterismo cardíaco para determinar a causa e gravidade da IM, DAC está presente em 33\% dos casos. Por sua vez, 20\% dos pacientes com síndrome coronariana aguda submetidos a cineangiocoronariografia apresentam IM associada ${ }^{335}$.

Pacientes com valvopatia de etiologia reumática representam um grupo com características peculiares, sendo pouco abordado nos estudos clínicos. A prevalência de DAC nesses pacientes é significativamente menor $(3,4 \%)$ do que naqueles com etiologia nãoreumática ${ }^{336,337}$. Esse fato ganha maior importância em populações com alta prevalência de doença reumática, como a brasileira. Pacientes reumáticos, em sua maioria, são do sexo feminino e têm idade mais baixa quando comparados aos nãoreumáticos. Além disso, dor torácica anginosa típica e fatores de risco para DAC como hipertensão arterial sistêmica, diabete melito e dislipidemia são mais encontrados em pacientes com etiologia nãoreumática ${ }^{338}$. Esses dados levam ao questionamento de qual seria a idade ideal para se realizar cineangiocoronariografia pré-operatória em pacientes valvopatas com indicação de tratamento cirúrgico. Todavia, 
não há, até o momento, indicação específica quanto à melhor estratégia diagnóstica e terapêutica de DAC em pacientes com valvopatia reumática no pré-operatório de cirurgia valvar.

\subsection{Diagnóstico de doença arterial coronariana}

O ECG em pacientes portadores de valvopatia pode mostrar alterações do segmento ST relacionadas à hipertrofia do VE, dilatação do VE ou bloqueio de ramo, o que diminui a acurácia do diagnóstico de DAC. Dessa forma, pode não ser útil no diagnóstico de coronariopatia obstrutiva, sendo necessária a realização de outros exames para esse fim.

Da mesma maneira, alterações regionais da parede ventricular em repouso ou com exercício não são marcadores específicos de DAC em pacientes portadores de doença valvar que apresentem dilatação e/ou hipertrofia de câmaras, assim como anormalidades de perfusão induzidas pelo esforço ou estresse farmacológico. Dados limitados são disponíveis sobre o uso das imagens de perfusão miocárdica com tálio-201 ou tecnécio-99m em pacientes com doença valvar importante ${ }^{339}$. Embora alguns estudos de perfusão miocárdica demonstrem sensibilidade de $87 \%$ e especificidade de $77 \%$, a presença de DAC não é diagnosticada em $13 \%$ dos pacientes com DAC ${ }^{340}$. Imagem não invasiva é útil quando a DAC é suspeitada em pacientes com estenose ou insuficiência valvar discreta e VE com cavidade e espessura de parede normais. Por essas razões, a cineangiocoronariografia é o exame mais apropriado e formalmente indicado na avaliação pré-operatória de pacientes selecionados que serão submetidos à correção cirúrgica de uma valvopatia.

O uso da angiotomografia de artérias coronarianas vem sendo recentemente estudado como uma alternativa à cineangiocoronariografia para a exclusão de DAC em pacientes que serão submetidos a procedimentos cardíacos nãocoronarianos, especialmente a cirurgias valvares, com resultados satisfatórios ${ }^{341,342}$.

Em pacientes que serão submetidos à cirurgia valvar de emergência por insuficiência aguda, dissecção de aorta ou endocardite infecciosa com instabilidade hemodinâmica, aortografia ou cineangiocoronariografia são raramente necessários, estando associados a aumento do risco e a atrasos desnecessários na realização do procedimento cirúrgico de emergência.

A tabela 44 mostra as recomendações para a investigação de DAC no paciente com valvopatia.

\subsection{Tratamento da doença arterial coronariana no momento da cirurgia valvar}

Mais de um terço dos pacientes com EAo submetidos à CVAo têm DAC concomitante. Mais de $50 \%$ desses pacientes acima de 70 anos têm DAC.

A realização concomitante de cirurgia valvar e revascularização cirúrgica do miocárdio reduz as taxas de IAM perioperatório, de mortalidade cirúrgica e de morbimortalidade tardias, quando comparado à realização de cirurgia valvar isolada em pacientes portadores de DAC significativa. Revascularização incompleta está associada a uma maior taxa de disfunção ventricular sistólica no pósoperatório e menor taxa de sobrevida, quando comparada aos pacientes submetidos a revascularização completa. As recomendações para o tratamento cirúrgico conjunto encontram-se na tabela 45 .

\section{Tabela 44 - Recomendações para o diagnóstico da doença arterial coronariana no paciente valvopata}

\begin{tabular}{|c|c|c|}
\hline Classe de recomendação & Indicação & Nível de evidência \\
\hline Classe I & $\begin{array}{l}\text { Cineangiocoronariografia antes da cirurgia valvar (incluindo EI) em pacientes com angina de peito, } \\
\text { evidências objetivas de isquemia miocárdica, redução da função do VE, história de DAC, ou fatores de risco } \\
\text { (incluindo idade). }\end{array}$ & C \\
\hline Classe I & $\begin{array}{l}\text { Cineangiocoronariografia antes da VMCB em pacientes com angina de peito, evidências objetivas de } \\
\text { isquemia miocárdica, redução da função do VE ou história de DAC. }\end{array}$ & $C$ \\
\hline Classe I & $\begin{array}{l}\text { Cineangiocoronariografia em pacientes com doença valvar discreta ou moderada, mas com angina } \\
\text { progressiva (CF II a IV da CCS), evidência objetiva de isquemia, redução da função do VE ou insuficiência } \\
\text { cardíaca manifesta. }\end{array}$ & C \\
\hline Classe I & $\begin{array}{l}\text { Cineangiocoronariografia antes da cirurgia valvar em homens com idade acima de } 40 \text { anos, em mulheres } \\
\text { com idade acima de } 45 \text { anos e pacientes com idade superior a } 35 \text { anos e fatores de risco para DAC. }\end{array}$ & $C$ \\
\hline Classe lla & $\begin{array}{l}\text { Cirurgia sem cineangiocoronariografia prévia em pacientes submetidos à cirurgia de emergência para } \\
\text { insuficiência valvar aguda, doença da aorta ascendente ou El. }\end{array}$ & C \\
\hline Classe Ilb & $\begin{array}{l}\text { Cineangiocoronariografia em pacientes submetidos a cateterismo para confirmar a gravidade de lesões } \\
\text { valvares antes da cirurgia sem evidência preexistente de DAC, múltiplos fatores de risco, ou idade } \\
\text { avançada. }\end{array}$ & C \\
\hline Classe III & $\begin{array}{l}\text { Cineangiocoronariografia em pacientes jovens que serão submetidos a cirurgia valvar eletiva quando não } \\
\text { há necessidade de avaliação hemodinâmica adicional, sem fatores de risco, sem história de DAC e sem } \\
\text { evidências de isquemia. }\end{array}$ & C \\
\hline Classe III & $\begin{array}{c}\text { Cineangiocoronariografia antes da cirurgia valvar na presença de instabilidade hemodinâmica } \\
\text { importante. }\end{array}$ & C \\
\hline
\end{tabular}

El - Endocardite infecciosa; VE - Ventrículo esuqerdo; VMCB - Valvuloplastia mitral por cateter-balão; DAC - Doença arterial coronariana; CF - Classe funcional; CCS - Sociedade Cardiovascular Canadense (da sigla em inglês). 


\section{Diretrizes}

Tabela 45 - Recomendações para o tratamento da doença arterial coronariana no momento da cirurgia valvar

\begin{tabular}{llc}
\hline $\begin{array}{l}\text { Classe de } \\
\text { recomendação }\end{array}$ & Indicação & $\begin{array}{c}\text { Nível de } \\
\text { evidência }\end{array}$ \\
\hline Classe I & $\begin{array}{l}\text { Cirurgia de revascularização } \\
\text { do miocárdio concomitante à } \\
\text { cirurgia valvar nos pacientes } \\
\text { que apresentem obstruções } \\
\text { coronarianas significativas } \\
\text { (redução luminal } \geq 70 \%) \text { em } \\
\text { artérias principais. }\end{array}$ & \\
\hline Classe III & $\begin{array}{c}\text { Cirurgia de revascularização } \\
\text { do miocárdio concomitante à } \\
\text { cirurgia valvar nos pacientes } \\
\text { que apresentem apenas } \\
\text { obstruções coronarianas } \\
\text { discretas (redução } \\
\text { luminal < } 50 \% \text { ). }\end{array}$ \\
\hline
\end{tabular}

\section{Profilaxia da febre reumática}

\subsection{Profilaxia primária da febre reumática}

Infecções (faringites e amigdalites) por estreptococos beta-hemolíticos do grupo A não diagnosticadas ou não tratadas adequadamente em indivíduos suscetíveis podem levar a um surto de febre reumática (FR). O mais importante para a diminuição da incidência da doença é realizar adequadamente a profilaxia primária, impedindo que os indivíduos suscetíveis venham a contrai-la. Assim, é necessário um esquema eficaz não só de tratamento mas de prevenção de infecções pelos estreptococos. ${ }^{343,344}$

A profilaxia primária, cujas recomendações encontramse na tabela 46, pressupõe a erradicação precoce da infecção da orofaringe por estreptococos beta-hemolíticos do grupo A, prevenindo assim o aparecimento da FR. É baseada no diagnóstico precoce dos portadores de infecções estreptocócicas de orofaringe e seu tratamento com antibióticos bactericidas ${ }^{343,345,346}$. O diagnóstico rápido é essencial. Os testes rápidos para o diagnóstico da estreptococcia podem ser realizados, embora devam ser evitados em saúde pública por adicionar custo e complexidade ao tratamento das faringoamigdalites ${ }^{345}$. A cultura de orofaringe, que em geral tem baixa positividade, não deve ser realizada a não ser em pesquisas sobre sorotipos de estreptococo incidentes em determinada comunidade. Devemos ressaltar que apenas 3\% dos infectados desenvolvem quadro clínico compatível com FR. Assim, não basta a estreptococcia, o paciente tem que ser suscetível à FR. Títulos elevados de ASLO não fazem diagnósico de FR, mas apenas demonstram estreptococcia anterior. Esses testes muitas vezes são de difícil obtenção e retardariam o tratamento correto da estreptococcia ${ }^{345-347}$, motivo pelo qual em saúde pública o procedimento mais adequado é tratar com antibióticos todas as infecções de garganta com a mínima possibilidade de serem bacterianas. Os regimes terapêuticos indicados estão na tabela 47 .

\subsection{Profilaxia secundária da febre reumática}

Para pacientes já com diagnóstico de FR, é indicada a profilaxia secundária para a prevenção de novos surtos da doença. É importante ressaltar que o diagnóstico correto da doença é fundamental e a melhor ferramenta para fazê-lo é a história clínica detalhada do paciente e um exame físico minucioso. Este cuidado é fundamental para evitar que, por exemplo, pacientes sem FR recebam profilaxia apenas por serem portadores de altos títulos de anti-estreptolisina $\mathrm{O}$ e que pacientes com valvopatia importante não recebam a adequada profilaxia, que pode melhorar o prognóstico do paciente a longo prazo. ${ }^{343,345,349}$

Os regimes medicamentosos indicados estão na Tabela 48. O agente de escolha é a benzilpenicilina $G$ benzatina, nas doses de $600.000 \mathrm{UI}$ para crianças com até $25 \mathrm{~kg}$ e 1.200.000UI acima desse peso. A frequência das doses de penicilina é motivo de controvérsia, mas vem ganhando mais definição graças a muitos estudos comparando diversos regimes de profilaxia. A profilaxia secundária deve ser realizada com aplicações de benzilpenicilina $G$ benzatina com intervalo máximo de três semanas. Considerandose que o maior risco de recorrência da FR ocorre nos dois primeiros anos após o surto reumático, durante esse período a penicilina deve ser administrada a cada 15 dias $^{346}$, havendo estudos em que não se observou recorrência de FR com aplicações com essa periodicidade ${ }^{345,346}$. Após dois anos, deverá ser administrada com intervalos de 21 dias. Aplicações mensais de penicilina benzatina não são suficientes para proteção adequada dos portadores de FR

Tabela 46 - Recomendações para profilaxia primária da febre reumática

\begin{tabular}{|c|c|c|}
\hline $\begin{array}{l}\text { Classe de } \\
\text { recomendação }\end{array}$ & Indicação & $\begin{array}{l}\text { Nível de } \\
\text { evidência }\end{array}$ \\
\hline Classe I & Benzilpenicilina G benzatina para pacientes com amigdalite estreptocócica. & A \\
\hline Classe I & Benzilpenicilina G benzatina para pacientes com suspeita de amigdalite estreptocócica, mesmo sem confirmação diagnóstica. & $\mathrm{B}$ \\
\hline Classe I & Antibioticoterapia por via oral para pacientes com amigdalite estreptocócica em pacientes alérgicos à penicilina. & C \\
\hline Classe lla & Antibioticoterapia por via oral para pacientes com amigdalite estreptocócica em pacientes não alérgicos à penicilina. & C \\
\hline Classe lla & Realização de testes rápidos para a detecção de estreptococos em orofaringe para decisão sobre tratamento com penicilina. & B \\
\hline Classe III & Realização de cultura de orofaringe em pacientes com suspeita de amigdalite para decisão sobre tratamento com penicilina. & C \\
\hline
\end{tabular}


Tabela 47 - Regimes terapêuticos indicados para a faringoamigdalite estreptocócica - profilaxia primária da febre reumática ${ }^{348}$

\begin{tabular}{|c|c|c|c|}
\hline Medicação & Dose & $\begin{array}{l}\text { Via de administraçãol } \\
\text { Duração }\end{array}$ & Comentários \\
\hline \multicolumn{4}{|l|}{ Penicilinas e derivados } \\
\hline Benzilpenicilina $\mathrm{G}$ benzatina & $\begin{array}{c}600.000 \mathrm{UI} \text { até } 25 \mathrm{Kg}, 1.200 .000 \mathrm{UI} \text { acima } \\
\text { de } 25 \mathrm{Kg}\end{array}$ & $\begin{array}{c}\mathrm{IM} \\
\text { Dose única }\end{array}$ & $\begin{array}{l}\text { Medicação de escolha: dose única, alta } \\
\text { eficácia e baixo custo }\end{array}$ \\
\hline Amoxicilina & $\begin{array}{l}50 \mathrm{mg} / \mathrm{kg} \text { para crianças e } 1,5 \mathrm{~g} \text { diárias para } \\
\text { adultos, divididos em } 2 \text { a } 3 \text { tomadas }\end{array}$ & $\begin{array}{l}\text { VO } \\
10 \text { dias }\end{array}$ & Baixa aderência ao tratamento completo \\
\hline Fenoximetilpenicilina & $\begin{array}{c}250 \mathrm{mg} 2 \text { a } 3 x \text { ao dia até } 25 \mathrm{Kg}, 500 \mathrm{mg} 3 \mathrm{x} \\
\text { ao dia }>25 \mathrm{Kg}\end{array}$ & $\begin{array}{l}\text { VO } \\
10 \text { dias }\end{array}$ & Baixa aderência ao tratamento completo \\
\hline \multicolumn{4}{|l|}{$\begin{array}{l}\text { Para pacientes alérgicos à } \\
\text { penicilina }\end{array}$} \\
\hline Clindamicina & $\begin{array}{c}20 \text { mg/kg para criança dividido 3x ao dia e } \\
300 \text { a } 600 \text { mg 3x ao dia para adultos }\end{array}$ & $\begin{array}{l}\text { VO } \\
10 \text { dias }\end{array}$ & Frequente intolerância gastrointestinal \\
\hline Azitromicina & $\begin{array}{l}12 \mathrm{mg} / \mathrm{kg} \text { em dose única diária. Para adultos, } \\
500 \mathrm{mg} 1 \mathrm{x} \text { ao dia }\end{array}$ & $\begin{array}{l}\text { VO } \\
5 \text { dias }\end{array}$ & $\begin{array}{l}\text { Única antibioticoterapia por via oral que pode } \\
\text { erradicar o estreptococo em menos de } 10 \text { dias }\end{array}$ \\
\hline Claritromicina & $\begin{array}{l}15 \mathrm{mg} / \mathrm{kg} 2 \mathrm{x} \text { ao dia ou, para adultos, } 250 \mathrm{mg} \\
2 \mathrm{x} \text { ao dia }\end{array}$ & $\begin{array}{c}\text { VO } \\
10 \text { dias }\end{array}$ & \\
\hline
\end{tabular}

IM - Via intramuscular; VO - Via oral.

em países com alta endemicidade da doença, como é o caso do Brasil e de outros da América Latina ${ }^{345,346,349-351 .}$ Para pacientes com alergia à penicilina está indicada a sulfadiazina, na dose de $1 \mathrm{~g} / \mathrm{dia}$, sendo necessário o controle de possíveis quadros leucopênicos. Em pacientes alérgicos, em geral é iniciada a profilaxia com sulfadiazina e providenciada a dessensibilização à penicilina, que quando concluída permite o retorno à profilaxia com penicilina $G$ benzatina ${ }^{343}$. Devemos ressaltar que não há estudos de profilaxia secundária de FR com o uso de eritromicina, motivo pelo qual só devemos usar esse regime em situações excepcionais. Há, ainda, o risco de resistência dos estreptococos à eritromicina ${ }^{352,353}$.

As recomendações de profilaxia secundária estão na tabela 49 .

Os critérios de suspensão da profilaxia ${ }^{345,354}$ (considerar o que gerar maior tempo) são: pacientes sem acometimento cardíaco, apenas com manifestação articular ou coreia

Tabela 48 - Regimes medicamentosos indicados para a profilaxia secundária da febre reumática ${ }^{348}$

\begin{tabular}{|c|c|c|c|}
\hline \multicolumn{2}{|c|}{ Medicação } & Dose e periodicidade & $\begin{array}{l}\text { Recorrência / } \\
\text { Notas }\end{array}$ \\
\hline \multicolumn{4}{|c|}{ Penicilinas e derivados } \\
\hline & Benzilpenicilina $\mathrm{G}$ benzatina & $\begin{array}{c}<25 \mathrm{Kg}-600.000 \mathrm{UI} \\
>25 \mathrm{Kg}-1.200 .000 \mathrm{Ui} \\
15 / 15 \text { dias nos dois primeiros anos do surto } \\
21 / 21 \text { dias nos anos subsequentes }\end{array}$ & $\begin{array}{l}\text { Recorrência de 0,3\% ao ano } \\
\text { Medicação de escolha }\end{array}$ \\
\hline & Fenximetilpenicilina & $250 \mathrm{mg}$ por boca $2 \mathrm{x}$ ao dia & $\begin{array}{c}\text { Recorrência de } 5 \% \text { ao ano - não deve } \\
\text { ser usada como alternativa à penicilina } \\
\text { G benzatina }\end{array}$ \\
\hline $\begin{array}{c}\text { Para pacientes alérgicos a } \\
\text { penicilina }\end{array}$ & Sulfadiazina & $\begin{array}{c}<25 \mathrm{Kg}-500 \mathrm{mg} \text { ao dia } \\
>25 \mathrm{Kg}-1 \mathrm{~g} \text { ao dia }\end{array}$ & $\begin{array}{l}\text { Recorrência de } 1,3 \% \text { ao ano } \\
\text { Pode ser usado até concluída } \\
\text { dessensibilização à penicilina }\end{array}$ \\
\hline
\end{tabular}

FR - Febre reumática. 
"pura" - suspender aos 18 anos ou cinco anos após o surto reumático; pacientes com cardite durante o surto agudo que não apresentam sequelas tardias ou apresentam sequelas muito discretas - suspender aos 25 anos ou dez anos após o último surto reumático, aqueles nos quais é retirada a profilaxia e os sintomas retornam deverão manter a profilaxia por mais cinco anos; pacientes que realizaram cirurgia cardíaca, mesmo com acometimento cardíacodiscreto residual, deverão realizar profilaxia prolongada, de preferência por toda a vida, e quando isso não for possível, pelo menos até os 40 anos. Devese lembrar que em pacientes que possuem exposição ocupacional ao estreptococo, como profissionais de saúde, trabalhadores em creches e escolas etc., deve-se manter a profilaxia secundária enquanto persistir a exposição ocupacional, independentemente da categoria em que o paciente esteja.

\section{Tabela 49 - Recomendações para profilaxia secundária da febre} reumática

\begin{tabular}{|c|c|c|}
\hline $\begin{array}{l}\text { Classe de } \\
\text { recomendação }\end{array}$ & Indicação & $\begin{array}{l}\text { Nível de } \\
\text { evidência }\end{array}$ \\
\hline Classe I & $\begin{array}{l}\text { Benzilpenicilina G benzatina de } 15 \text { em } \\
15 \text { dias nos dois primeiros anos após } \\
\text { o surto e de } 21 \text { em } 21 \text { dias nos anos } \\
\text { subsequentes. }\end{array}$ & B \\
\hline Classe I & $\begin{array}{c}\text { Benzilpenicilina G benzatina até os } \\
18 \text { anos, ou } 5 \text { anos após o último } \\
\text { surto, em pacientes com FR sem } \\
\text { cardite. }\end{array}$ & B \\
\hline Classe I & $\begin{array}{l}\text { Benzilpenicilina G benzatina até os } 25 \\
\text { anos, ou } 10 \text { anos após o último surto, } \\
\text { em pacientes com FR com cardite, mas } \\
\text { sem sequelas cardíacas ou apenas } \\
\text { com sequelas discretas, desde que não } \\
\text { sejam lesões valvares estenóticas. }\end{array}$ & B \\
\hline Classe I & $\begin{array}{c}\text { Benzilpenicilina G benzatina até os } 40 \\
\text { anos em pacientes com FR com cardite } \\
\text { e sequelas importantes ou cirurgia } \\
\text { cardiaca para correção de valvopatia } \\
\text { reumática. }\end{array}$ & $C$ \\
\hline Classe I & $\begin{array}{l}\text { Benzilpenicilina } \mathrm{G} \text { benzatina após os } \\
40 \text { anos em pacientes com exposição } \\
\text { ocupacional a estreptococos. }\end{array}$ & $C$ \\
\hline Classe I & $\begin{array}{l}\text { Sulfadiazina para antibioticoprofilaxia da } \\
\text { FR em pacientes alérgicos à penicilina. }\end{array}$ & $C$ \\
\hline Classe Ila & $\begin{array}{l}\text { Antibioticoprofilaxia via oral para } \\
\text { pacientes com FR não-alérgicos à } \\
\text { penicilina. }\end{array}$ & C \\
\hline Classe Ilb & $\begin{array}{l}\text { Eritromicina como antibioticoprofilaxia } \\
\text { para pacientes com FR alérgicos à } \\
\text { penicilina e às sulfas. }\end{array}$ & C \\
\hline Classe III & $\begin{array}{l}\text { Suspensão da antibioticoprofilaxia } \\
\text { para FR após a realização de cirurgia } \\
\text { cardíaca com implante de prótese(s) } \\
\text { valvar(es), mesmo com demais valvas } \\
\text { sem lesão aparente. }\end{array}$ & C \\
\hline
\end{tabular}

FR - Febre reumática.

\subsection{Perspectivas}

O maior desafio para o controle efetivo da FR é o desenvolvimento de uma vacina contra o estreprococo betahemolítico do grupo A. Essa vacina traz muitos obstáculos a serem superados, sendo o principal deles identificar um peptídeo que ao mesmo tempo confira proteção e não desencadeie a reação tardia que causa a FR.

\section{Profilaxia de endocardite infecciosa nas valvopatias}

A endocardite infecciosa (EI), complicação reconhecida das valvopatias, apresenta-se com características de gravidade, sendo frequentemente fatal. Desta forma, havendo a possibilidade de fazer profilaxia para tal entidade, de maneira factível, a mesma deveria ser aplicada. Com este intuito, foram utilizados vários esquemas antibióticos, porém com pouca evidência científica.

Os primeiros trabalhos experimentais demonstraram a fisiopatologia da El da seguinte maneira: eventual deposição de plaquetas e fibrina sobre lesões valvares, ou no sítio em que se abate o jato regurgitativo causado pela valvopatia, levando a formação de endocardite trombótica não bacteriana. Esta lesão inicial posteriormente seria infectada em episódio de bacteremia, sendo que a aderência da bactéria estimula um depósito ainda maior de fibrina e plaquetas, desencadeando a vegetação clássica da El.

Os estreptococos fazem parte da flora normal da orofaringe e trato gastrointestinal e causam pelo menos $50 \%$ das El adquiridas na comunidade. Demonstrou-se bacteremia pelos estreptococos do grupo viridans em até $61 \%$ dos pacientes, após extração dentária e cirurgia periodontal (36\% a 88\%). ${ }^{355-357}$ E estudos experimentais em animais mostraram que a profilaxia antibiótica era capaz de evitar El por estreptococos viridans e enterococos. ${ }^{358}$

Mais recentemente, com a sedimentação do conceito de medicina baseada em evidências, foram revistos alguns aspectos essenciais destas condutas. O principal fator considerado foi que a profilaxia antibiótica para a EI (PAEI) tem se mostrado ineficaz ou marginalmente eficaz.

Tem-se comprovado que, ao contrário do que se admitia no passado, os pacientes apresentam bacteremias espontâneas, de origem especialmente dentária e gengival, em situações do dia-a-dia. Assim, atividades prosaicas rotineiras, como escovação de dentes (0 a 50\%), uso de fio dental (20\% a 68\%), uso de palito de dentes e mesmo mastigação de refeição (7\% a 51\%), são associadas a bacteremia ${ }^{357,359-362}$. Desse modo, a carga de bacteremia espontânea, não determinada por intervenção odontológica, seria maior do que a determinada por tratamentos dentários (tabela 50). Um estudo teórico da bacteremia cumulativa, durante cerca de um ano, calculou que a bacteremia do dia-a-dia é seis vezes maior do que a bacteremia causada por uma extração dentária isolada ${ }^{363}$. Considerando que a indicação de profilaxia dentária recomenda duas visitas por ano ao dentista, percebe-se um impacto das atividades do dia-a-dia na geração de bacteremias muito maior do que a própria intervenção dentária. 
Trabalhos epidemiológicos recentes não mostram relação entre tratamento dentário duas semanas antes e episódios de El. ${ }^{363,364}$ Realmente, em estudos epidemiológicos amplos, apenas 2,7 a 5\% dos casos de EI foram precedidos por intervenção dentária. ${ }^{365-367}$

Além disso, mesmo quando há relação temporal entre a intervenção dentária e o episódio de EI, não é possível saber se a El foi causada pela intervenção, pela existência da doença odontológica tratada ou resultante das bacteremias causadas pelas atividades diárias. Assim sendo, é pouco provável que a PAEI tenha um efeito muito importante. ${ }^{363}$

Em relação à eficácia da $\mathrm{PAEI}$, os estudos têm sido controversos, com alguns trabalhos mostrando redução da bacteremia ${ }^{368,369}$ com seu uso antes do tratamento dentário, enquanto outros não mostraram este achado. ${ }^{370,371}$ Estudos recentes mostram que a amoxicilina reduz significativamente a incidência e duração da bacteremia, mas não a elimina. ${ }^{370,372}$ Além disso, não se comprovou que esta diminuição da bacteremia reduz a incidência de El.

A incidência de El após tratamento dentário varia de acordo com a valvopatia (por 100.000 pacientesano tratados): 5 pacientes na população geral; 4,6 nos pacientes com PVM sem sopro; 52 nos com PVM com sopro; 630 nos portadores de prótese valvar; 740 quando há antecedente de El prévia; e 2160 quando há implante de nova prótese valvar, em paciente com prótese infectada. ${ }^{373}$ Assim sendo, mesmo admitindo uma eficácia teórica de $100 \%$ da PAEI, teríamos uma efetividade muito pequena, com um número de pessoas tratadas muito elevado, para evitar um caso de El. Portanto, deve-se assumir que o risco de El depende de características do paciente, com a influência de diversas variáveis (por exemplo, a presença de próteses e outros materiais sintéticos). Para pacientes submetidos a intervenções dentárias, existe crescente evidência de que a PAEI, se é que realmente apresenta algum papel preventivo, previne apenas um número muito pequeno de casos.

Um fator que deve também ser considerado é a mudança epidemiológica dos germes causadores de El. A representação dos estreptococos viridans como causadores de El tem diminuído, e as infeções estafilocócicas (bactéria não abrangida nas recomendações de PAEI habituais), aumentado.

Há necessidade de estudos controlados para definir o real valor da $\mathrm{PAEI}$, sendo que não há trabalho prospectivo abordando o efeito da PAEI na diminuição da El após procedimento dentário. Deste modo, alguns grupos têm adotado posições ainda mais radicais, sendo que em uma diretriz britânica recente, o Instituto Nacional de Saúde e Excelência Clínica (NICE - sigla em inglês) propõe que não seja realizada PAEI em nenhuma ocasião. ${ }^{374}$

Em termos práticos, deve-se providenciar a PAEI antes de manipulações da boca e trato respiratório superior para os pacientes com valvopatia portadores de prótese valvar ou cirurgia conservadora valvar (com presença de material sintético) e naqueles com antecedente de
El. Uma situação especialmente rara também considerada como indicação de PAEI seriam os portadores de transplante cardíaco que desenvolvem valvopatias. Nesta diretriz brasileira e latino-americana, optou-se por também manter a PAEI, diferentemente do proposto pelas outras diretrizes citadas, para portadores de valvopatias com risco importante de El, incluindo valvopatia reumática, PVM com insuficiência, e valvopatia aórtica degenerativa ou de origem bicúspide (tabela 51).

\section{Profilaxia da endocardite infecciosa para procedimentos dentários}

Geralmente deve ser dada apenas uma dose de antibiótico, uma hora antes do procedimento. O regime usado deve impedir a bacteremia por estreptococos viridans sempre que for manipulado tecido da gengiva ou da região periapical do dente. O antibiótico de escolha, se não houver alergia, é a amoxicilina, por sua absorção adequada e pela suscetibilidade do agente infeccioso (tabela 52). No entanto, têm sido descritas resistências de várias cepas desse micro-organismo a esse antibiótico.

Para pacientes alérgicos a penicilina utiliza-se cefalexina, clindamicina, azitromicina ou claritromicina. ${ }^{375}$

\section{Profilaxia da endocardite infecciosa para procedimentos no trato respiratório}

Pacientes a serem submetidos a incisão ou biópsia da mucosa do trato respiratório, como cirurgias otorrinolaringológicas, devem receber esquema antibiótico semelhantes ao utilizados para afecções da boca ${ }^{375}$.

\section{Profilaxia da endocardite infecciosa}

\section{para procedimentos nos tratos}

\section{genitourinário e gastrointestinal (Tabela 53)}

Os enterococos fazem parte da flora normal do trato gastrointestinal. Podem causar El, inclusive grave, e era indicada de rotina, anteriormente, PAEI para intervenções nos tratos digestivo e genitourinário. No entanto, as evidências sobre esta conduta são ainda mais escassas, não havendo estudos publicados que demonstrem uma ligação de causa e efeito entre El e procedimentos nestas localizações, ${ }^{376}$ nem que a administração de PAEI evite El. Assim, considerando a falta de adequada evidência científica, as diretrizes americana e européia passaram a não mais indicar PAEI antes de intervenções nestas localizações. ${ }^{375}$ No entanto, considerando a gravidade de uma eventual ocorrência de El decorrente destas fontes, foi optado, no atual documento, por considerar a PAEI para pacientes com risco elevado para El grave e que serão submetidos a procedimentos genitourinários ou gastrointestinais associados a lesão de mucosa.

$\mathrm{Na}$ presença de infeções instaladas nos tratos genitourinário e gastrointestinal, o tratamento deve incluir antibióticos que ajam contra o enterococos, embora não se saiba se tal conduta previne El.

A tabela 54 mostra os pacientes e as situações associadas a risco elevado de EI grave. 


\section{Diretrizes}

\section{Tabela 50 - Probabilidade de bacteremia em procedimentos dentários}

\begin{tabular}{cc}
\hline Com alta probabilidade de bacteremia significativa & Sem alta probabilidade de bacteremia significativa \\
\hline Procedimentos que envolvem a manipulação de tecido gengival, região periodontal \\
ou perfuração da mucosa oral.
\end{tabular}

Tabela 51 - Profilaxia antibiótica da endocardite infecciosa em valvopatas ${ }^{377}$

\begin{tabular}{|c|c|c|}
\hline $\begin{array}{l}\text { Classe de } \\
\text { recomendação }\end{array}$ & Indicação & $\begin{array}{l}\text { Nível de } \\
\text { evidência }\end{array}$ \\
\hline Classe I & $\begin{array}{c}\text { Pacientes com risco elevado para El grave e que serão submetidos a procedimentos odontológicos de alta probabilidade de } \\
\text { bacteremia significativa. }\end{array}$ & C \\
\hline Classe Ila & $\begin{array}{c}\text { Pacientes com valvopatia ou cardiopatia congênita sem risco elevado de El grave e que serão submetidos a procedimentos } \\
\text { odontológicos de alta probabilidade de bacteremia significativa. }\end{array}$ & C \\
\hline Classe Ila & $\begin{array}{l}\text { Pacientes com risco elevado para El grave e que serão submetidos a procedimentos genitourinários ou gastrointestinais } \\
\text { associados a lesão de mucosa. }\end{array}$ & C \\
\hline Classe lla & $\begin{array}{l}\text { Pacientes com risco elevado para El grave e que serão submetidos a procedimentos esofágicos ou do trato respiratório } \\
\text { associado a lesão de mucosa. }\end{array}$ & C \\
\hline Classe Ilb & $\begin{array}{c}\text { Pacientes com valvopatia ou cardiopatia congênita sem risco elevado de El grave e que serão submetidos a procedimentos } \\
\text { odontológicos sem alta probabilidade de bacteremia significativa. }\end{array}$ & C \\
\hline Classe llb & $\begin{array}{l}\text { Pacientes com valvopatia ou cardiopatia congênita sem risco elevado de El grave e que serão submetidos a procedimentos } \\
\text { genitourinários ou gastrointestinais associados a lesão de mucosa. }\end{array}$ & C \\
\hline Classe Illb & $\begin{array}{l}\text { Pacientes com valvopatia ou cardiopatia congênita sem risco elevado de El grave e que serão submetidos a procedimentos } \\
\text { esofágicos ou do trato respiratório associado a lesão de mucosa. }\end{array}$ & $C$ \\
\hline Classe III & $\begin{array}{c}\text { Pacientes com CIA isolada, com CIV ou PCA corrigidas e sem fluxo residual, com PVM sem regurgitação, após cirurgia de } \\
\text { revascularização miocárdica ou após colocação de stents, com sopros cardiacos inocentes, portadores de marcapasso ou } \\
\text { CDI, com doença de Kawasaki ou FR sem disfunção valvar, que serão submetidos a procedimentos odontológicos, do trato } \\
\text { respiratório, genitourinário ou gastrointestinal. }\end{array}$ & C \\
\hline Classe III & Pacientes submetidos a procedimentos que não envolvam risco de bacteremia. & C \\
\hline
\end{tabular}

Tabela 52 - Esquemas de profilaxia para endocardite infecciosa antes de procedimentos dentários

\begin{tabular}{|c|c|c|c|}
\hline \multirow[t]{2}{*}{ Via de administração } & \multirow[t]{2}{*}{ Medicação } & \multicolumn{2}{|c|}{$\begin{array}{l}\text { Dose única } 30 \text { a } 60 \text { minutos } \\
\text { antes do procedimento }\end{array}$} \\
\hline & & Criança & Adulto \\
\hline Oral & Amoxicilina & $50 \mathrm{mg} / \mathrm{Kg}$ & $2 \mathrm{~g}$ \\
\hline \multirow{3}{*}{$\begin{array}{l}\text { Oral } \\
\text { (alergia à penicilina) }\end{array}$} & Clindamicina & $20 \mathrm{mg} / \mathrm{Kg}$ & $600 \mathrm{mg}$ \\
\hline & Cefalexina & $50 \mathrm{mg} / \mathrm{Kg}$ & $2 \mathrm{~g}$ \\
\hline & Azitromicina ou claritromicina & $15 \mathrm{mg} / \mathrm{Kg}$ & $500 \mathrm{mg}$ \\
\hline \multirow{2}{*}{$\begin{array}{l}\text { Parenteral } \\
\left(\mathrm{IV} \mathrm{ou} \mathrm{IM}^{*}\right)\end{array}$} & Ampicilina & $50 \mathrm{mg} / \mathrm{Kg}$ & $2 \mathrm{~g}$ \\
\hline & Cefazolina ou ceftriaxone & $50 \mathrm{mg} / \mathrm{Kg}$ & $1 \mathrm{~g}$ \\
\hline \multirow{2}{*}{$\begin{array}{l}\text { Parenteral } \\
(\text { IV ou IM*) } \\
\text { (alergia à penicilina) }\end{array}$} & Clindamicina & $20 \mathrm{mg} / \mathrm{Kg}$ & $600 \mathrm{mg}$ \\
\hline & Cefazolina ou ceftriaxone & $50 \mathrm{mg} / \mathrm{Kg}$ & $1 \mathrm{~g}$ \\
\hline
\end{tabular}

IV - Via intravenosa; IM* - Via intramuscular. 
Tabela 53 - Esquemas de profilaxia para endocardite infecciosa antes de procedimentos do trato gastrointestinal e trato genitourinário

\begin{tabular}{|c|c|c|c|}
\hline \multirow{2}{*}{$\begin{array}{c}\text { Via de } \\
\text { administração }\end{array}$} & \multirow{2}{*}{ Medicação } & \multicolumn{2}{|c|}{$\begin{array}{c}\text { Dose única } 30 \text { minutos antes do } \\
\text { procedimento }\end{array}$} \\
\hline & & Criança & Adulto \\
\hline \multirow{2}{*}{ Parenteral (IV) } & \multirow{2}{*}{$\begin{array}{l}\text { Ampicilina* + } \\
\text { Gentamicina }\end{array}$} & $50 \mathrm{mg} / \mathrm{Kg}$ & $2 g$ \\
\hline & & \multicolumn{2}{|c|}{$1,5 \mathrm{mg} / \mathrm{Kg}$} \\
\hline \multirow{2}{*}{$\begin{array}{l}\text { Parenteral } \\
\text { (IV) - alergia à } \\
\text { penicilina }\end{array}$} & \multirow{2}{*}{$\begin{array}{c}\text { Vancomicina + } \\
\text { Gentamicina }\end{array}$} & $20 \mathrm{mg} / \mathrm{Kg}$ & $1 \mathrm{~g}$ \\
\hline & & \multicolumn{2}{|c|}{$1,5 \mathrm{mg} / \mathrm{Kg}$} \\
\hline
\end{tabular}

* Obs: Fazer reforço com 1,0 6 horas após o procedimento.

IV - Intravenoso.

Tabela 54 - Pacientes/situações com risco de endocardite infecciosa grave

\begin{tabular}{l}
\hline Prótese cardíaca valvar \\
\hline Valvopatia corrigida com material protético \\
\hline Antecedente de endocardite infecciosa \\
\hline Valvopatia adquirida em paciente transplantado cardíaco \\
\hline Cardiopatia congênita cianogênica não corrigida \\
\hline Cardiopatia congênita cianogênica corrigida que evolui com lesão residual \\
\hline Cardiopatia congênita corrigida com material protético \\
\hline
\end{tabular}

\section{Acompanhamento no pós-operatório de cirurgia valvar}

O período pós-operatório de uma cirurgia cardíaca deve ser avaliado de forma individual e sofre influência direta das alterações fisiológicas ocasionadas pela anestesia, pelo trauma cirúrgico e pela $\mathrm{CEC}^{378}$. A CEC está relacionada a complicações, especialmente disfunção miocárdica transitória e resposta inflamatória sistêmica, que pode expressar-se clinicamente como febre, leucocitose, coagulopatia, hipoxemia, aumento da permeabilidade capilar pulmonar, disfunção renal e alteração cognitiva ${ }^{379}$. O resultado é a necessidade de vasopressores e outros agentes vasoativos nas primeiras horas após o procedimento cirúrgico.

Atelectasia é uma complicação pulmonar frequente, porém apresenta baixa morbidade na maioria dos pacientes. Derrame pleural geralmente tem resolução espontânea em até seis semanas. Quando tardio, pode representar síndrome pós-pericardiotomia, de resolução espontânea em poucos meses.

Arritmias e sangramentos devem ser monitorizados, assim como rigoroso controle dos eletrólitos. A FA aguda é a arritmia sustentada mais comum no pós-operatório. Arritmias ventriculares são menos frequentes, podendo necessitar de terapia antiarrítmica por períodos curtos.

Febre nos primeiros dias de pós-operatório pode ter caráter inflamatório ou ser secundária a infecção, sendo as mais prevalentes infecção do trato urinário, infecção respiratória, infecção de ferida operatória, infecção de corrente sanguínea e El.
O tempo de permanência no hospital varia conforme o procedimento e depende das características individuais de cada paciente. No preparo do paciente para a alta hospitalar é importante uma nova avaliação ecocardiográfica. Os pontos fundamentais do exame, nesse momento, são: análise da função ventricular; resultado final da intervenção sobre a valva (visando a comparações futuras) e análise do pericárdio.

Após a alta, o retorno às atividades deve ser individualizado, mas de forma geral podem ser observadas as seguintes orientações:

- Aguardar 8 a 12 semanas para dirigir (tempo suficiente para consolidação esternal, garantindo maior segurança ao paciente);

- Dormir em decúbito lateral: liberação a partir do momento em que o paciente não apresentar mais dor esternal nesta posição, em geral no primeiro mês pósoperatório.

- Atividades do lar: inicialmente restritas às atividades de baixa intensidade, até reavaliação ambulatorial subsequente.

- Atividade sexual: considerada de baixa intensidade, pode ser liberada, com a orientação do cuidado à ferida operatória, principalmente no primeiro mês de pós-operatório.

A retomada da atividade física regular, com intensidade moderada, deverá ser orientada de forma individual. Os principais aspectos que devem ser considerados nessa fase são a ausência de infecção relacionada à cirurgia, a estabilização dos parâmetros hematimétricos, boa cicatrização da ferida operatória e esternal e uma avaliação criteriosa do "status cardiovascular" do paciente. Os pacientes em condições de iniciar atividade física regular podem ser submetidos a um teste ergométrico ou ergoespirométrico para estratificação adicional e planejamento da carga de exercício recomendada. Não há dados suficientes a respeito do efeito do treinamento físico vigoroso e repetitivo após cirurgia valvar na função ventricular e na prótese valvar.

\section{Valvopatia e gravidez}

A doença cardíaca ainda permanece como a principal causa não obstétrica de mortalidade materna no ciclo gravídico puerperal, e a valvopatia reumática corresponde à metade das causas de cardiopatias que ocorrem na gravidez ${ }^{380,381}$. É fundamental o conhecimento das modificações hemodinâmicas fisiológicas da gestação ${ }^{381}$ para a estimativa do prognóstico e tomada de condutas em valvopatias na gravidez.

O aumento de 40\% no débito cardíaco que ocorre à custa do volume sistólico e da frequência cardíaca no segundo e terceiro trimestres da gestação é a causa principal de descompensação cardíaca em pacientes valvopatas. Além disso, o estado de hipercoagulabilidade da segunda metade da gestação e puerpério aumenta o risco de TE em pacientes com lesão mitral, FA e próteses valvares. A redução da resistência vascular periférica a partir do primeiro trimestre da gravidez influencia na evolução das lesões valvares obstrutivas e em pacientes com hipertensão arterial sistêmica. Em vista dessas alterações fisiológicas, justifica-se, portanto, que as lesões estenóticas mitral e aórtica apresentem pior evolução clínica quando comparadas às de insuficiência valvar. 


\section{Diretrizes}

O prognóstico materno da gravidez em portadoras de valvopatias $^{382,383}$ relaciona-se a variáveis clínicas, como a CF (III ou IV), antecedentes de insuficiência cardíaca e TE, eletrocardiográficas, como a sobrecarga de câmaras cardíacas e presença de FA, e ecocardiográficas, como a disfunção ventricular, medidas da área valvar mitral e aórtica e presença de HP.

\subsection{Prognóstico e complicações das valvopatias na gravidez}

\subsubsection{Estenose mitral}

A EM é a valvopatia reumática mais frequente e não raramente tem a primeira manifestação clínica durante a gestação. Os riscos da gravidez são maiores em pacientes em CF III, que apresentam sobrecarga do VD, FA e área valvar mitral $\leq 1,5 \mathrm{~cm}^{2}$. As complicações maternas habituais são congestão pulmonar e arritmia supraventricular paroxística, e em menor frequência o TE. A CF I ou II não deve ser usada como estimativa para a evolução em pacientes com EM, tendo sido documentado que $70 \%$ das portadoras de EM moderada a importante evoluíram para CF III ou IV na gravidez, independentemente de serem previamente assintomáticas ${ }^{384}$. As medidas de gradiente transvalvar mitral aumentam com a volemia materna e não devem servir como parâmetro de gravidade da lesão valvar.

\subsubsection{Insuficiência mitral}

A IM geralmente é consequente à doença reumática ou PVM, e mais raramente às doenças do colágeno. Pacientes com IM discreta a moderada com função ventricular preservada toleram bem a gravidez. As complicações mais frequentes são insuficiência cardíaca e arritmias cardíacas, e ocorrem em pacientes com diâmetros de AE muito aumentados e disfunção de $\mathrm{VE}^{383,385}$.

\subsubsection{Prolapso da valva mitral}

A evolução da gravidez depende do grau de IM e sua associação às arritmias cardíacas mal toleradas ${ }^{382,383}$.

\subsubsection{Estenose aórtica}

Nessa população, quando isolada, a EAo geralmentetem etiologia congênita. Os riscos da gravidez estão relacionados à presença de sintomas, ao grau de sobrecarga do VE, à área valvar aórtica $<1,0 \mathrm{~cm}^{2}$ e à presença de disfunção do VE. O gradiente transvalvar aórtico sofre um incremento funcional na segunda metade da gestação por causa do aumento da volemia materna. Pacientes assintomáticas com EAo discreta ou moderada sem disfunção ventricular toleram bem a gravidez ${ }^{386}$.

\subsubsection{Insuficiência aórtica}

A IAo, quando reumática, tem boa adaptação à gravidez. Entretanto, em casos associados à valva bicúspide ou doenças do tecido conectivo como a síndrome de Marfan, tem o risco adicional de dissecção da aorta ${ }^{387}$. Os riscos da gravidez estão relacionados à presença de sintomas e de disfunção do VE.

\subsubsection{Lesão tricúspide}

A valvopatia tricúspide geralmente acompanha a lesão mitral reumática ou é secundária à anomalia de Ebstein. Apesar de, nessas pacientes, a evolução clínica ser geralmente favorável, a presença de HP e disfunção de VD pode comprometer a evolução materna ${ }^{380,388}$.

\subsubsection{Prótese biológica}

A evolução materna depende da função da prótese no início da gestação, da presença de disfunção ventricular e do ritmo cardíaco. A gravidez não influencia a degeneração da bioprótese, mas a presença de calcificação favorece a evolução para insuficiência cardíaca e risco de morte súbita e leva a indicação de cirurgia de troca valvar independentemente da idade gestacional. Na presença de disfunção da prótese biológica que acarrete insuficiência valvar em pacientes assintomáticas, opta-se pelo seguimento clínico. De modo geral, o período de melhor prognóstico da gravidez é entre um e cinco anos após o implante da bioprótese $\mathrm{b}^{389,390}$.

\subsubsection{Prótese mecânica}

Os riscos da gravidez em portadoras de próteses mecânicas relacionam-se aos efeitos adversos da anticoagulação permanente na gestação, parto e puerpério. O uso da varfarina no primeiro trimestre associa-se a uma frequência de abortamento espontâneo e de embriopatia de $30 \%$ e $4,3 \%$, respectivamente, e no parto e puerpério aos riscos entre $2,4 \%$ e $8,1 \%$ de hemorragia materna. A ocorrência de trombose de prótese e de perdas fetais está relacionada à anticoagulação inadequada, seja com varfarina, seja com heparina ${ }^{391}$. Portanto, o sucesso da gravidez em portadoras de próteses mecânicas depende de rigorosa anticoagulação no ciclo gravídico-puerperal visando simultaneamente à eficácia antitrombótica materna e à proteção fetal ${ }^{389}$.

21.2. Manejo das complicações das valvopatias durante a gravidez $^{392,393}$

\subsubsection{Recomendações gerais}

Consultas periódicas e simultâneas com o obstetra e o cardiologista devem ser realizadas de acordo com a evolução materno-fetal. Deve-se providenciar internação hospitalar perante sinais de complicações obstétricas ou cardíacas.

Atividades físicas devem ser reduzidas. A ingestão de sal não deve ultrapassar 4 a $6 \mathrm{~g} /$ dia desde a segunda metade da gestação até o final do puerpério.

A profilaxia secundária de FR deve ser mantida, com os agentes e doses previamente apresentadas em seção específica. 


\subsubsection{Tratamento farmacológico}

A terapêutica farmacológica durante a gestação ${ }^{394-396}$ deve considerar que os medicamentos de ação cardiovascular atravessam a barreira placentária. A prioridade do tratamento é sempre o controle materno, contudo deve-se considerar que os efeitos teratogênicos dos fármacos ocorrem na embriogênese, que compreende as primeiras oito semanas após a concepção, e que efeitos no desenvolvimento e crescimento do feto podem ocorrer nas demais fases da gestação ${ }^{389-391}$. Nesse sentido, o Food and Drug Administration (FDA) classifica os fármacos nas seguintes categorias:

$A \rightarrow$ estudos controlados em mulheres não demonstram risco para o feto no primeiro trimestre, não havendo evidência de risco nos demais;

$\mathbf{B} \rightarrow$ estudos em animais não demonstraram risco fetal e não existem estudos controlados em mulheres no primeiro trimestre, não havendo evidência de risco nos demais;

$\mathrm{C} \rightarrow$ estudos em animais não revelaram risco fetal, mas não há estudos controlados em mulheres nem em animais, e o agente deve ser administrado quando o risco potencial justifica o benefício;

D $\rightarrow$ há evidência de risco fetal em humanos, mas os benefícios são aceitáveis, apesar dos riscos;

$\mathbf{X} \rightarrow$ estudos em animais e humanos demonstraram anormalidades fetais, sendo contraindicado.

\subsubsection{Tratamento da congestão pulmonar na estenose} mitral

O uso de fármacos visa ao controle da frequência cardíaca e consequente redução da pressão do AE e PCP. A terapêutica farmacológica ${ }^{384}$ deve ser a primeira opção, com o uso de:

- Betabloqueador: sem atividade simpaticomimética intrínseca, que inclui o propranolol e o metoprolol em doses de até $80 \mathrm{mg} /$ dia e $50 \mathrm{mg} /$ dia, respectivamente (FDA C). O atenolol tem efeito hemodinâmico semelhante na dose de 50 a $75 \mathrm{mg} /$ dia, porém está associado a maior grau de restrição de crescimento intrauterino (FDA D).

- Diurético: a furosemida é o mais utilizado, na dose de 40 a 60mg/dia, cuidando para evitar a hipovolemia materna, que resulta em redução do fluxo placentário.A espironolactona (FDA C) é contraindicada por sua ação antiandrogênica, podendo provocar feminilização de fetos masculinos.

- Digital: a digoxina, na dose de 0,25 a 0,50mg/ dia, associada ou não ao betabloqueador, é usada nos casos de disfunção do VD e no controle da frequência ventricular da FA (FDA B).

- Bloqueadores dos canais de cálcio: verapamil em doses não superiores a $240 \mathrm{mg} /$ dia é uma alternativa no controle da frequência cardíaca quando houver contraindicação aos betabloqueadores ou em associação ao digital para o controle da frequência ventricular nos casos de FA (FDA C).
Em casos refratários às medidas farmacológicas, está indicada a terapêutica intervencionista. Dentre elas, a primeira opção é a VMCB, que mostrou-se segura à mãe, com resultados superponíveis ao tratamento cirúrgico. Utiliza tempo de fluoroscopia aquém da dose de $5 \mathrm{Mrd}$, considerada prejudicial ao feto. A gravidez não modifica os critérios de indicação da VMCB, que deve ser precedida pelo ETE. O procedimento deve ser evitado no primeiro trimestre ${ }^{397}$.

\subsubsection{Tratamento da estenose aórtica grave}

Em pacientes com EAo grave, sintomáticas, que apresentam insuficiência cardíaca, baixo fluxo cerebral ou baixo fluxo coronariano, o tratamento consiste na cirurgia de correção da EAo, independentemente da idade gestacional. A VACB é uma alternativa nos casos que não apresentam condições clinicas para a cirurgia cardíaca ${ }^{386}$.

21.2.2.3. Tratamento da insuficiência cardíaca na valvopatia mitral e aórtica

O diurético e digital devem ser mantidos em associação aos vasodilatadores. A hidralazina (FDA C) não é teratogênica e não tem contraindicação. A sua associação aos nitratos é o tratamento de escolha para a insuficiência cardíaca durante a gestação ${ }^{382}$. Dose diária de 75 a 100mg de hidralazina e 30mg de nitratos não tem mostrado efeitos colaterais maternos em qualquer época da gestação. O nitroprussiato de sódio (FDA C) usado em casos de emergência tem a vantagem da ação rápida, contudo o uso prolongado (acima de quatro horas) nas doses habituais pode levar a intoxicação fetal pelos cianetos. É útil nos casos de pré-eclampsia e edema pulmonar agudo e na dissecção aguda de aorta.

Inibidores da enzima conversora da angiotensina (FDA X) são contraindicados na gestação, independentemente da idade gestacional. Provocam malformação dos sistemas cardiovascular, nervoso central, renal e ósseo. Podem levar a morte neonatal por hipoplasia pulmonar e insuficiência renal.

Bloqueadores dos receptores AT1 da angiotensina II (FDA X) também são contraindicados por provocarem máformações fetais, além de natimortos, neomortos ou ainda crianças sobreviventes, porém com lesão renal.

\subsubsection{Cirurgia cardíaca durante a gravidez}

A cirurgia é indicada nos casos de congestão pulmonar refratária ao tratamento clínico ou na impossibilidade do tratamento percutâneo por cateter-balão ${ }^{398}$. As causas mais frequentes são insuficiência cardíaca, El, trombose de prótese valvar e dissecção de aorta. Os riscos relacionados ao procedimento cirúrgico não são diferentes aos de mulheres não grávidas. Contudo, a morbidade e a mortalidade materna têm sido relatadas como maiores na gestação porque geralmente a cirurgia cardíaca é indicada em situações de emergência e de alta gravidade. A mortalidade materna varia de $8,6 \%$ a $13,3 \%$, sendo a insuficiência cardíaca refratária a principal indicação e a comissurotomia mitral o procedimento mais frequente. A mortalidade fetal varia de $18,6 \%$ a $33,3 \%{ }^{384}$, e o prognóstico fetal está relacionado 
à vitalidade fetal, ao tempo e à temperatura da CEC e à idade gestacional no momento da cirurgia. Visando um melhor resultado obstétrico e fetal, as recomendações para o procedimento cirúrgico incluem normotermia, alto fluxo na $\mathrm{CEC}^{385}$, fluxo pulsátil ${ }^{383,387,388,398}$, pressão arterial média $>60 \mathrm{mmHg}$, uterolítico profilático, monitorização fetal contínua com cardiotocografia e dopplerfluxometria, e manter hematócrito $>25 \%$.

Os cuidados obstétricos durante as intervenções (cirurgia cardíaca ou valvuloplastia) incluem o uso de fármacos com ação uterolítica, como os óvulos de progesterona. Dá-se preferência à progesterona natural, pois a indometacina pode provocar o fechamento do canal arterial quando utilizada após a $26^{\underline{a}}$ semana de gestação ${ }^{388}$.

\subsubsection{Tratamento das arritmias cardíacas}

Durante a gestação, é exigida a documentação eletrocardiográfica das arritmias para o seu tratamento ${ }^{395}$. O sistema Holter é útil para a correlação dos sintomas e a decisão terapêutica. A indicação dos antiarritmicos deve obedecer às diretrizes convencionais, com consideração às seguintes observações:

- Sotalol (FDA B): sem contraindicação até dose $160 \mathrm{mg} /$ dia.

- Amiodarona (FDA D): deve ser evitada em uso prolongado porque tem efeitos tóxicos pulmonares, tireoideos, neuromusculares, gastrointestinais e oculares na dose média diária materna de $325 \mathrm{mg} / \mathrm{dia}$.

- Adenosina (FDA C): sem contraindicação e eficaz no tratamento da reversão das taquiarritmias paroxísticas supraventriculares nas doses entre 6 e $12 \mathrm{mg}$ IV.

- Digitálicos (FDA C): sem contraindicação. Os níveis séricos devem ser ajustados pela maior depuração renal.

A cardioversão elétricanão tem contraindicação no tratamento das taquiarritmias instáveis. Pode ser realizada com segurança em qualquer idade gestacional, obedecendo às diretrizes convencionais. A anestesia para o procedimento pode ser realizada com propofol (FDA B) ou etomidato. É recomendada a presença de anestesista para o adequado suporte respiratório e a prevenção de hipóxia materna.

\subsection{Prevenção do tromboembolismo}

As situações clínicas de alto risco para TE exigem anticoagulação plena durante toda a gravidez. A escolha do anticoagulante depende da idade gestacional. As heparinas não atravessam a barreira placentária e a HBPM em doses plenas oferece níveis adequados de anticoagulação.

As recomendações atuais para a prevenção de TE em portadoras de próteses mecânicas incluem as seguintes etapas ${ }^{399}$ :

1. substituição da varfarina pela HBPM antes da quinta semana de gestação;

2. manutenção da HBPM até a $12^{a}$ semana de gestação (controle pelo fator anti-Xa na faixa de 0,6 a1,0U/mL);
3. reintrodução da varfarina em substituição à HBPM da $12^{\text {a }}$ semana até a $36^{\text {a }}$ semana de gestação, com controle convencional do INR;

4. suspensão da varfarina e introdução de HNF ou HBPM entre a $36^{\text {a }}$ semana de gestação até quatro ou 18 horas antes do parto, respectivamente;

5. reintrodução da HNF ou HBPM seis horas após o parto e da varfarina 48 horas após o parto. Quando for novamente atingido o INR-alvo, a heparina deverá ser suspensa.

O nível e controle da anticoagulação deve obedecer às recomendações convencionais usadas fora da gravidez.

\subsection{Profilaxia da endocardite infecciosa durante a gravidez e o parto}

A PAEI durante a gravidez deve seguir as recomendações convencionais, abordadas em seção específica ${ }^{400}$. O parto está associado a situações imprevisíveis que podem gerar bacteremia, dentre elas a ruptura prematura de membranas, remoção manual da placenta e trabalho de parto prolongado. Hemoculturas seriadas colhidas em parturientes saudáveis no período pré e pós-parto identificou bactérias que associam-se a El em 14\% a 19\% dos casos. Justifica-se, portanto, a indicação da $\mathrm{PAEI}$ para o parto de pacientes portadoras de valvopatias comampicilina $2 \mathrm{~g}$ IV associada a gentamicina 1,5 mg/kg IV uma hora antes do parto. Em pacientes alérgicas, a penicilina é substituída pela vancomicina na dose de $1 \mathrm{~g}$ IV.

\section{1,5. Assistência obstétrica}

Não há situação clinica que indique interrupção terapêutica da gestação em gestantes valvopatas. A indicação da via de parto ou do tipo de anestesia é obstétrica. A via vaginal apresenta menor risco de infecção puerperal ou hemorragia materna e menor alteração hemodinâmica decorrente da menor extensão da anestesia aplicada. No pós-parto, o uso de ocitocina deve ser mantido para o controle das perdas sanguíneas. A amamentação deve ser incentivada independentemente da terapêutica materna.

\subsection{Anticoncepção}

Para as portadoras de valvopatias, a gravidez é considerada de alto risco, apesar de não haver contraindicação. A anticoncepção reversível pode ser indicada de acordo com o planejamento familiar do casal. As recomendações baseiam-se na observação de pequenas séries da literatura, sendo os contraceptivos hormonais combinados (orais e injetáveis) e os compostos de progesterona (oral, injetável e implante cutâneo) os mais indicados. Em pacientes com risco elevado de TE ou em uso de anticoagulante tem sido dada preferência aos progestógenos isolados. O dispositivo intrauterino de cobre ou com progesterona tem sido contraindicado pelos riscos de El e sangramento uterino. O cardiologista não deve assumir a prescrição do anticoncepcional, e sim ser o consultor do ginecologista no sentido de estimar os riscos dos anticoncepcionais para cada $\mathrm{CasO}^{401}$. 


\section{Referências}

1. Programa das Nações Unidas para o Desenvolvimento. Ranking do Indice do Desenvolvimento Humano (IDH). [Acesso em 2011 maio 10]. Disponível em: http://www.pnud.org.br

2. United Nations World Population Prospects: The 2006 Revision. 2006. [Accessed in 2011 june 2011]. Available from:www.un.org

3. Instituto Brasileiro de Geografia e Estatística.(IBGE-2010). [Acesso em 2011 feb 10]. Disponível em: www.ibge.gov.br

4. Ministério da Saúde. Portal [Acesso em 2011 maio 10]. Disponível em: http:// portal.saude.gov.br

5. Ministério da Saúde - Informações de Saúde. [Acesso em 2011 jun 14]. Disponível em: http://portal.saude.gov.br

6. Meira ZM, Goulart EM, Colosimo EA, Mota CC. Long term follow up of rheumatic fever and predictors of severe rheumatic valvar disease in Brazilian children and adolescents. Heart. 2005;91(8):1019-22.

7. Huffman MD, Bonow RO. Clinical practice guidelines and scientific evidence. JAMA. 2009;302(2):144-5; author reply 6-7.

8. Flack JM, Kvasnicka JH, Gardin JM, Gidding SS, Manolio TA, Jacobs DR Jr. Anthropometric and physiologic correlates of mitral valve prolapse in a biethnic cohort of young adults: the CARDIA study. Am Heart J. 1999;138(3Pt1):486-92

9. Summers RM, Andrasko-Bourgeois J, Feuerstein IM, Hill SC, Jones EC, Busse MK, et al. Evaluation of the aortic root by MRI: insights from patients with homozygous familial hypercholesterolemia. Circulation. 1998;98(6):509-18.

10. Grinberg M, Sampaio, R.O. Doença valvar. Barueri (SP): Manole; 2006.

11. Bonow RO, Carabello BA, Chatterjee K, de Leon AC Jr, Faxon DP, Freed MD. 2008 Focused update incorporated into the ACC/AHA 2006 guidelines for the management of patients with valvular heart disease: a report of the American College of Cardiology/American Heart Association Task Force on Practice Guidelines (Writing Committee to Revise the 1998 Guidelines for the Management of Patients With Valvular Heart Disease): endorsed by the Society of Cardiovascular Anesthesiologists, Society for Cardiovascular Angiography and Interventions, and Society of Thoracic Surgeons. Circulation. 2008;118(15):e523-661.

12. Sibbald M, Panisko D, Cavalcanti RB. Role of clinical context in residents' physical examination diagnostic accuracy. Med Educ. 2011;45(4):415-21.

13. Monaco C. Manual de ausculta cardíaca. Rio de Janeiro (RJ): Revinter; 2000.

14. Grinberg M, Mathias W Jr. Narcissus and the echocardiographist. Arq Bras Cardiol. 2008;91(1):e9-11.

15. Iung B, Gohlke-Barwolf C, Tornos P, Tribouieloy C, Hale R, Butchart E, et al. Recommendations on the management of the asymptomatic patient with valvular heart disease. Eur Heart J. 2002;23(16):1253-66.

16. Swedberg K, Cleland J, Dargie H, Drexler H, Follath F, Komajda M, et al. Guidelines for the diagnosis and treatment of chronic heart failure: executive summary (update 2005): The Task Force for the Diagnosis and Treatment of Chronic Heart Failure of the European Society of Cardiology. Eur Heart J. 2005;26(11):1115-40.

17. Tarasoutchi F, Grinberg M, Spina GS, Sampaio RO, Cardoso LF, Rossi EG, et al. Ten-year clinical laboratory follow-up after application of a symptom-based therapeutic strategy to patients with severe chronic aortic regurgitation of predominant rheumatic etiology. J Am Coll Cardiol. 2003;41(8):1316-24.

18. Jessup M, Abraham WT, Casey DE, Feldman AM, Francis GS, Ganiats TG, et al. 2009 focused update: ACCF/AHA Guidelines for the Diagnosis and Management of Heart Failure in Adults: a report of the American College of Cardiology Foundation/American Heart Association Task Force on Practice Guidelines: developed in collaboration with the International Society for Heart and Lung Transplantation. Circulation. 2009;119(14):1977-2016.

19. Vahanian A, Baumgartner H, Bax J, Butchart E, Dion R, Filippatos G, et al. Guidelines on the management of valvular heart disease: The Task Force on the Management of Valvular Heart Disease of the European Society of Cardiology. Eur Heart J. 2007;28(2):230-68.

20. Accorsi TA, Machado FP, Grinberg M. Semiologia cardiovascular. In: Martins MA, Carrilho FJ, Alves VA, Castilho EA, Cerri GG, Wen CL, eds. Clínica médica. São Paulo (SP): Manole Ltda; 2009.XXXXXXXXX

21. Perloff JK. Physical examination of the heart and circulation. $4^{\text {th }}$ ed. New York: Peoples Medical Publishing House (PMPH-USA);2009.

22. Shaver JA, Salerni, R. Auscultation of the heart. In: The heart. New York (NY) McGraw-Hill; 1994.

23. Quinones MA, Otto CM, Stoddard M, Waggoner A, Zoghbi WA Recommendations for quantification of Doppler echocardiography: a report from the Doppler Quantification Task Force of the Nomenclature and Standards Committee of the American Society of Echocardiography. J Am Soc Echocardiogr. 2002;15(2):167-84.

24. Bermejo J, Odreman R, Feijoo J, Moreno MM, Gomez-Moreno P, GarciaFernandez MA. Clinical efficacy of Doppler-echocardiographic indices of aortic valve stenosis: a comparative test-based analysis of outcome. J Am Coll Cardiol. 2003;41(1):142-51

25. Zoghbi WA, Enriquez-Sarano M, Foster E, Grayburn PA, Kraft CD, Levine RA, et al. Recommendations for evaluation of the severity of native valvular regurgitation with two-dimensional and Doppler echocardiography. J Am Soc Echocardiogr. 2003;16(7):777-802

26. Amato MC, Moffa PJ, Werner KE, Ramires JA. Treatment decision in asymptomatic aortic valve stenosis: role of exercise testing. Heart. 2001;86(4):381-6.

27. Messika-Zeitoun D, Aubry MC, Detaint D, Bielak LF, Peyser PA, Sheedy PF, et al. Evaluation and clinical implications of aortic valve calcification measured by electron-beam computed tomography. Circulation. 2004;110(3):356-62.

28. Westenberg JJ, Doornbos J, Versteegh MI, Bax JJ, van der Geest RJ, de Roos A, et al. Accurate quantitation of regurgitant volume with MRI in patients selected for mitral valve repair. Eur J Cardiothorac Surg. 2005;27(3):462-6; discussion 467.

29. Bergler-Klein J, Klaar U, Heger M, Rosenhek R, Mundigler G, Gabriel H, et al. Natriuretic peptides predict symptom-free survival and postoperative outcome in severe aortic stenosis. Circulation. 2004;109(19):2302-8.

30. Rochitte CE, Pinto IM, Fernandes JL, Filho CF, Jatene A, Carvalho AC, et al. [I cardiovascular magnetic resonance and computed tomography guidelines of the Brazilian Society of Cardiologia - Executive summary]. Arq Bras Cardiol. 2006;87(3):e48-59.

31. Hamon M, Biondi-Zoccai GG, Malagutti P, Agostoni P, Morello R, Valgimigl $M$. Diagnostic performance of multislice spiral computed tomography of coronary arteries as compared with conventional invasive coronary angiography: a meta-analysis. J Am Coll Cardiol. 2006;48(9):1896-910.

32. Chandrashekhar Y, Westaby S, Narula J. Mitral stenosis. Lancet 2009;374(9697):1271-83.

33. Selzer A, Cohn KE. Natural history of mitral stenosis: a review. Circulation. 972;45(4):878-90.

34. Ward C, Hancock BW. Extreme pulmonary hypertension caused by mitral valve disease. Natural history and results of surgery. Br Heart J. 1975;37(1):74-8.

35. Wilkins GT, Weyman AE, Abascal VM, Block PC, Palacios IF. Percutaneous balloon dilatation of the mitral valve: an analysis of echocardiographic variables related to outcome and the mechanism of dilatation. Br Heart J 1988;60(4):299-308

36. Braunwald E, Moscovitz HI, Amram SS, Lasser RP, Sapin SO, Himmelstein A, et al. The hemodynamics of the left side of the heart as studied by simultaneous left atrial, left ventricular, and aortic pressures; particular reference to mitral stenosis. Circulation. 1955;12(1):69-81. 
37. Bruce CJ, Nishimura RA. Newer advances in the diagnosis and treatment of mitral stenosis. Curr Probl Cardiol. 1998;23(3):125-92.

38. Meister SG, Engel TR, Feitosa GS, Helfant RH, FrankI WS. Propranolol in mitral stenosis during sinus rhythm. Am Heart J. 1977;94(6):685-8.

39. Stoll BC, Ashcom TL, Johns JP, Johnson JE, Rubal BJ. Effects of atenolol on rest and exercise hemodynamics in patients with mitral stenosis. Am J Cardiol. 1995;75(7):482-4.

40. Chiang CW, Lo SK, Ko YS, Cheng NJ, Lin PJ, Chang CH. Predictors of systemic embolism in patients with mitral stenosis: a prospective study. Ann Intern Med. 1998;128(11):885-9.

41. Salem DN, O'Gara PT, Madias C, Pauker SG. Valvular and structural heart disease: American College of Chest Physicians Evidence-Based Clinical Practice Guidelines (8th Edition). Chest. 2008;133(6 Suppl):593S-629S.

42. Fawzy ME. Percutaneous mitral balloon valvotomy. Catheter Cardiovasc Interv. 2007;69(2):313-21.

43. Hernandez R, Bañuelos C, Alfonso F, Goicolea J, Fernández-Ortiz A, Escaned J, et al. Long-term clinical and echocardiographic follow-up after percutaneous mitral valvuloplasty with the Inoue balloon. Circulation. 1999;99(12):1580-6.

44. Orrange SE, Kawanishi DT, Lopez BM, Curry SM, Rahimtoola SH. Actuarial outcome after catheter balloon commissurotomy in patients with mitral stenosis. Circulation. 1997;95(2):382-9.

45. Iung B, Garbarz E, Michaud P, Helou S, Farah B, Berdah P, et al. Late results of percutaneous mitral commissurotomy in a series of 1024 patients: analysis of late clinical deterioration: frequency, anatomic findings, and predictive factors. Circulation. 1999;99(25):3272-8.

46. Dean LS, Mickel M, Bonan R, Holmes DR Jr, O'Neill WW, Palacios IF, et al. Four-year follow-up of patients undergoing percutaneous balloon mitral commissurotomy. A report from the National Heart, Lung, and Blood Institute Balloon Valvuloplasty Registry. J Am Coll Cardiol. 1996;28(6):1452-7.

47. Cardoso LF, Ayres CV, Bento AM, Tarasoutchi F, Vieira ML, Grinberg M. Immediate and late results of percutaneous mitral valve repair in patients with mitral stenosis. Arq Bras Cardiol. 2010;94(3):383-90, 406-13.

48. Hammermeister K, Sethi GK, Henderson WG, Grover FL, Oprian C, Rahimtoola SH. Outcomes 15 years after valve replacement with a mechanical versus a bioprosthetic valve: final report of the Veterans Affairs randomized trial. J Am Coll Cardiol. 2000;36(4):1152-8.

49. Devereux RB, Brown WT, Kramer-Fox R, Sachs I. Inheritance of mitral valve prolapse: effect of age and sex on gene expression. Ann Intern Med. 1982;97(6):826-32.

50. Shell WE, Walton JA, Clifford ME, Willis PW $3^{\text {rd }}$. The familial occurrence of the syndrome of mid-late systolic click and late systolic murmur. Circulation. 1969;39(3):327-37.

51. Rosenberg CA, Derman GH, Grabb WC, Buda AJ. Hypomastia and mitral-valve prolapse. Evidence of a linked embryologic and mesenchymal dysplasia. N Engl J Med. 1983;309(20):1230-2.

52. Mills P, Rose J, Hollingsworth J, Amara I, Craige E. Long-term prognosis of mitral-valve prolapse. N Engl J Med. 1977;297(1):13-8.

53. Avierinos JF, Gersh BJ, Melton LJ $3^{\text {rd }}$, Bailey KR, Shub C, Nishimura RA, et al. Natural history of asymptomatic mitral valve prolapse in the community. Circulation. 2002;106(11):1355-61

54. Krivokapich J, Child JS, Dadourian BJ, Perloff JK. Reassessment of echocardiographic criteria for diagnosis of mitral valve prolapse. Am J Cardiol. 1988;61(1):131-5.

55. Allen $\mathrm{H}$, Harris A, Leatham A. Significance and prognosis of an isolated late systolic murmur: a 9- to 22-year follow-up. Br Heart J. 1974;36(6):525-32.

56. Marks AR, Choong CY, Sanfilippo AJ, Ferre M, Weyman AE. Identification of high-risk and low-risk subgroups of patients with mitral-valve prolapse. N Engl J Med. 1989;320(16):1031-6.
57. Shah PM. Echocardiographic diagnosis of mitral valve prolapse. J Am Soc Echocardiogr. 1994;7(3 Pt 1):286-93.

58. Fontana ME, Sparks EA, Boudoulas H, Wooley CF. Mitral valve prolapse and the mitral valve prolapse syndrome. Curr Probl Cardiol. 1991;16(5):309-75.

59. Faletra F, La Marchesina U, Bragato R, De Chiara F. Three dimensional transthoracic echocardiography images of tricuspid stenosis. Heart. 2005;91(4):499.

60. Croft CH, Lipscomb K, Mathis K, Firth BG, Nicod P, Tilton G, et al. Limitations of qualitative angiographic grading in aortic or mitral regurgitation. Am J Cardiol. 1984;53(11):1593-8.

61. Fuchs RM, Heuser RR, Yin FC, Brinker JA. Limitations of pulmonary wedge V waves in diagnosing mitral regurgitation. Am J Cardiol. 1982;49(4):849-54.

62. Kay EB, Cross FS. Surgical treatment of mitral insufficiency. Surgery 1955;37(5):697-706.

63. Lillehei CW, Gott VL, Dewall RA, Varco RL. Surgical correction of pure mitral insufficiency by annuloplasty under direct vision. Surgery. 1955;37(5):697706.

64. Kay EB, Nogueira C, Head LR, Coenen JP, Zimmerman HA. Surgical treatment of mitral insufficiency. J Thorac Surg. 1958;36(5):677-90.

65. Moss RR, Humphries KH, Gao M, Thompson CR, Abel JG, Fradet G, et al. Outcome of mitral valve repair or replacement: a comparison by propensity score analysis. Circulation. 2003;108(Suppl 1):I190-7

66. Flameng W, Herijgers $\mathrm{P}$, Bogaerts $\mathrm{K}$. Recurrence of mitral valve regurgitation after mitral valve repair in degenerative valve disease. Circulation. 2003;107(12):1609-13.

67. Ling LH, Enriquez-Sarano M, Seward JB, Orszulak TA, Schaff HV, Bailey KR, et al. Early surgery in patients with mitral regurgitation due to flail leaflets: a long-term outcome study. Circulation. 1997;96(6):1819-25.

68. Thourani VH, Weintraub WS, Guyton RA, Jones EL, Williams WH, Elkabbani $\mathrm{S}$, et al. Outcomes and long-term survival for patients undergoing mitral valve repair versus replacement: effect of age and concomitant coronary artery bypass grafting. Circulation. 2003;108(3):298-304.

69. Enriquez-Sarano M, Schaff HV, Orszulak TA, Tajik AJ, Bailey KR, Frye RL. Valve repair improves the outcome of surgery for mitral regurgitation: a multivariate analysis. Circulation. 1995;91(4):1022-8.

70. Duran CG, Pomar JL, Revuelta JM, Gallo I, Poveda J, Ochoteco A, et al. Conservative operation for mitral insufficiency: critical analysis supported by postoperative hemodynamic studies of 72 patients. J Thorac Cardiovasc Surg. 1980;79(3):326-37.

71. Enriquez-Sarano M, Freeman WK, Tribouilloy CM, Orszulak TA, Khandheria BK, Seward JB, et al. Functional anatomy of mitral regurgitation: accuracy and outcome implications of transesophageal echocardiography. J Am Coll Cardiol. 1999;34(3):1129-36.

72. David TE, Ivanov J, Armstrong S, Christie D, Rakowski H. A comparison of outcomes of mitral valve repair for degenerative disease with posterior, anterior, and bileaflet prolapse. J Thorac Cardiovasc Surg. 2005;130(5):1242-9.

73. Gillinov AM, Cosgrove DM, Blackstone EH, Diaz R, Arnold JH, Lytle BW, et al. Durability of mitral valve repair for degenerative disease. J Thorac Cardiovasc Surg. 1998;116(5):734-43

74. Suri RM, Schaff HV, Dearani JA, Sundt TM 3rd, Daly RC, Mullany CI, et al. Survival advantage and improved durability of mitral repair for leaflet prolapse subsets in the current era. Ann Thorac Surg. 2006;82(3):819-26.

75. Enriquez-Sarano M, Tajik AJ, Schaff HV, Orszulak TA, Bailey KR, Frye RL. Echocardiographic prediction of survival after surgical correction of organic mitral regurgitation. Circulation. 1994(2);90:830-7.

76. Le Tourneau T, Richardson M, Juthier F, Modine T, Fayad G, Polge AS, et al. Echocardiography predictors and prognostic value of pulmonary artery systolic pressure in chronic organic mitral regurgitation. Heart. 2010;96(16):1311-7. 
77. Grigioni F, Avierinos JF, Ling LH, Scott CG, Bailey KR, Tajik AJ, et al. Atrial fibrillation complicating the course of degenerative mitral regurgitation: determinants and long-term outcome. J Am Coll Cardiol. 2002;40(1):84-92.

78. Rosenhek R, Rader F, Klaar U, Gabriel H, Krejc M, Kalbeck D, et al. Outcome of watchful waiting in asymptomatic severe mitral regurgitation. Circulation. 2006;113 (18):2238-44

79. Kang DH, Kim JH, Rim JH, Kim MJ, Yun SC, Song JM, et al. Comparison of early surgery versus conventional treatment in asymptomatic severe mitral regurgitation. Circulation. 2009;119(6):797-804

80. Grigioni F, Enriquez-Sarano M, Zehr KJ, Bailey KR, Tajik AJ. Ischemic mitral regurgitation: long-term outcome and prognostic implications with quantitative Doppler assessment. Circulation. 2001;103(13):1759-64.

81. Grossi EA, Goldberg JD, LaPietra A, Ye X, Zakow P, et al. Ischemic mitral valve reconstruction and replacement: comparison of long-term survival and complications. J Thorac Cardiovasc Surg. 2001;122(6):1107-24

82. Gillinov AM, Wierup PN, Blackstone EH, Bishay ES, Cosgrove DM, White J, et al. Is repair preferable to replacement for ischemic mitral regurgitation? Thorac Cardiovasc Surg. 2001;122(6):1125-41.

83. Kim YH, Czer LS, Soukiasian HJ, De Robertis M, Magliato KE, Blanche C, et al. Ischemic mitral regurgitation: revascularization alone versus revascularization and mitral valve repair. Ann Thorac Surg. 2005;79(6):1895-901.

84. Grayburn PA. Vasodilator therapy for chronic aortic and mitral regurgitation. Am J Med Sci. 2000;320(3):202-8.

85. Feldman T. Percutaneous therapies for valvular heart disease. In: Baim DS. (ed). Grossman's cardiac catheterization, angiography, and intervention. $7^{\text {th }}$ ed. Philadelphia: Lippincott Williams \& Wilkins; 2006.p.543.

86. Webb JG, Harnek J, Munt BI, Kimblad PO, Chandavimol M, Thompson $\mathrm{CR}$, et al. Percutaneous transvenous mitral annuloplasty: initial human experience with device implantation in the coronary sinus. Circulation. 2006;113(6):851-5

87. Schofer J, Siminiak T, Haude M, Herrman JP, Vainer J, Wu JC, et al. Percutaneous mitral annuloplasty for functional mitral regurgitation: results of the CARILLON Mitral Annuloplasty Device European Union Study. Circulation. 2009;120(4):326-33.

88. Siminiak T, Hoppe UC, Schofer J, Haude M, Herrman JP, Vainer J, et al. Effectiveness and safety of percutaneous coronary sinus-based mitral valve repair in patients with dilated cardiomyopathy (from the AMADEUS trial). Am J Cardiol. 2009:104(4):565-70.

89. Daimon M, Shiota T, Gillinov AM, Hayase M, Ruel M, Cohn WE, et al. Percutaneous mitral valve repair for chronic ischemic mitral regurgitation: a real-time three-dimensional echocardiographic study in an ovine model. Circulation. 2005:111(17):2183-9.

90. Alfieri O, Maisano F, De Bonis M, Stefano PL, Torracca L, Oppizzi M, et al. The double-orifice technique in mitral valve repair: a simple solution for complex problems. J Thorac Cardiovasc Surg. 2001;122(4):674-81.

91. Maisano F, Torracca L, Oppizzi M, Stefano PL, D’Addario G, La Canna G, et al. The edge-to-edge technique: a simplified method to correct mitral insufficiency. Eur J Cardiothorac Surg. 1998;13(3):240-5; discussion 245-6.

92. Feldman T, Kar S, Rinaldi M, Fail P, Hermiller J, Smalling R, et al. Percutaneous mitral repair with the MitraClip system: safety and midterm durability in the initial EVEREST (Endovascular Valve Edge-to-Edge REpair Study) cohort. J Am Coll Cardiol. 2009; 54(8):686-94.

93. Feldman T, Foster E, Glower DD, Kar S, Rinaldi MJ, Fail PS, et al. Percutaneous repair or surgery for mitral regurgitation. N Engl J Med. 2011:364(15):1395-406

94. Lorusso R, Gelsomino S, De Cicco G, Beghi C, Russo C, De Bonis M, et al. Mitral valve surgery in emergency for severe acute regurgitation: analysis of postoperative results from a multicentre study. Eur J Cardiothorac Surg. 2008:33(4):573-82
95. Tavakoli R, Weber A, Vogt P, Brunner HP, Pretre R, Turina M. Surgical management of acute mitral valve regurgitation due to post-infarction papillary muscle rupture. J Heart Valve Dis. 2002;11(1):20-5; discussion 26.

96. Heikkila J. Mitral incompetence complicating acute myocardial infarction Br Heart J. 1967;29(2):162-9.

97. Loperfido F, Biasucci LM, Pennestri F, Laurenzi F, Gimigliano F, Vigna C, et al. Pulsed Doppler echocardiographic analysis of mitral regurgitation after myocardial infarction. Am J Cardiol. 1986;58(9):692-7.

98. Edwards WD. Pathology of myocardial infarction and repercussion. In: Gersh BJ, Rahimtoola SH. (eds.). Acute myocardial infarction. $2^{\text {nd }}$ ed. New York: Chapman \& Hall; 1997.p.16-50.

99. Thompson CR, Buller CE, Sleeper LA, Antonelli TA, Webb JG, Jaber WA, et al. Cardiogenic shock due to acute severe mitral regurgitation complicating acute myocardial infarction: a report from the SHOCK Trial Registry. SHould we use emergently revascularize Occluded Coronaries in cardiogenic shock? J Am Coll Cardiol. 2000;36(3 Suppl A):1104-9.

100. Agricola E, Oppizzi M, Pisani M, Meris A, Maisano F, Margonato A. Ischemic mitral regurgitation: mechanisms and echocardiographic classification. Eur J Echocardiogr. 2008;9(2):207-21.

101. Nishimura RA, Gersh BJ, Schaff HV. The case for an aggressive surgical approach to papillary muscle rupture following myocardial infarction: "From paradise lost to paradise regained". Heart. 2000;83(6):611-3.

102. Otto CM, Bonow RO. Valvular heart disease. In: Libby P, Bonow RO, Mann DL, Zipes DP. (eds.). Braunwald's heart disease: a textbook of cardiovascular medicine. $8^{\text {th }}$ ed. Philadelphia: Saunders/ Elsevier; 2008.p.1625-712.

103. Wei JY, Hutchins GM, Bulkley BH. Papillary muscle rupture in fatal acute myocardial infarction: a potentially treatable form of cardiogenic shock. Ann Intern Med. 1979;90(2):149-52.

104. Loisance DY, Deleuze P, Hillion ML, Cachera JP. Are there indications for reconstructive surgery in severe mitral regurgitation after acute myocardial infarction? Eur J Cardiothorac Surg. 1990;4(7):394-7.

105. Clements SD Jr, Story WE, Hurst JW, Craver JM, Jones EL. Ruptured papillary muscle, a complication of myocardial infarction: clinical presentation, diagnosis, and treatment. Clin Cardiol. 1985;8(2):93-103.

106. Vanzetto G, Akret C, Bach V, Barone G, Durand M, Chavanon O, et al [Percutaneous extracorporeal life support in acute severe hemodynamic collapses: single centre experience in 100 consecutive patients]. Can J Cardiol. 2009;25(6):e179-86.

107. Dang NC, Topkara VK, Leacche M, John R, Byrne JG, Naka Y. Left ventricular assist device implantation after acute anterior wall myocardial infarction and cardiogenic shock: a two-center study. J Thorac Cardiovasc Surg. 2005:130(3):693-8

108. Seto WY, Gorman RC, Gorman JH III, Acker MA. Ischemic mitra regurgitation. In: Cohn LH. (ed). Cardiac surgery in the adult. New York: McGraw-Hill; 2005.p.785-802.

109. David TE. Techniques and results of mitral valve repair for ischemic mitral regurgitation. J Card Surg. 1994;9(2 Suppl):274-7.

110. Russo A, Suri RM, Grigioni F, Roger VL, Oh JK, Mahoney DW, et al. Clinical outcome after surgical correction of mitral regurgitation due to papillary muscle rupture. Circulation. 2008;118(15):1528-34.

111. Freeman RV, Otto CM. Spectrum of calcific aortic valve disease: pathogenesis, disease progression, and treatment strategies. Circulation. 2005; 111(24):3316-26.

112. Fontes RD, Salerno HD, Hijo AV, Najjar A, Scala LC, Farah MC, et al. Remodelação cirúrgica da valva aórtica. Rev Bras Cir Cardiovasc. 2001:16(3):212-7.

113. Schwartz JB, Zipes DP. Cardiovascular disease in the elderly. In: Libby P, Bonow RO, Mann DL, Zipes DP. (eds.). Braunwald's heart disease: a textbook of cardiovascular medicine. $8^{\text {th }}$ ed. Philadelphia, PA: Saunders/ Elsevier; 2008.p.1923-53. 
114. Katz M, Tarasoutchi F, Grinberg M. [Severe aortic stenosis in asymptomatic patients: the dilemma of clinical versus surgical treatment]. Arq Bras Cardiol. 2010;95(4):541-6.

115. Otto CM, Burwash IG, Legget ME, Munt BI, Fujioka M, Healy NL, et al. Prospective study of asymptomatic valvular aortic stenosis. Clinical, echocardiographic, and exercise predictors of outcome. Circulation. 1997;95(9):2262-70.

116. Rosenhek R, Binder T, Porenta G, Lang I, Christ G, Schemper M, et al. Predictors of outcome in severe, asymptomatic aortic stenosis. N Engl J Med. 2000;343(9):611-7.

117. Pellikka PA, Sarano ME, Nishimura RA, Malouf JF, Bailey KR, Scott CG, et al. Outcome of 622 adults with asymptomatic, hemodynamically significant aortic stenosis during prolonged follow-up. Circulation. $2005 ; 111(24): 3290-5$.

118. Monin JL, Lancellotti P, Monchi M, Lim P, Weiss E, Pierard L, et al. Risk score for predicting outcome in patients with asymptomatic aortic stenosis. Circulation. 2009;120(1):69-75.

119. Pellikka PA, Nishimura RA, Bailey KR, Tajik AJ. The natural history of adults with asymptomatic, hemodynamically significant aortic stenosis. J Am Coll Cardiol. 1990;15(5):1012-7.

120. Amato MC, Moffa PJ. [Prognosis of asymptomatic aortic valve stenosis evaluated with exercise test]. Arq Bras Cardiol. 1998;70(4):251-5.

121. Gutiérrez-Chico JL, Zamorano JL, Prieto-Moriche E, Hernández-Antolín RA, Bravo-Amaro M, Pérez de Isla $L$, et al. Real-time three-dimensional echocardiography in aortic stenosis: a novel, simple, and reliable method to improve accuracy in area calculation. Eur Heart J. 2008;29(10):1296-306.

122. Maréchaux S, Hachicha Z, Bellouin A, Dumesnil JG, Meimoun P, Pasquet A, et al. Usefulness of exercise-stress echocardiography for risk stratification of true asymptomatic patients with aortic valve stenosis. Eur Heart J. 2010;31(11):1390-7

123. Hachicha Z, Dumesnil JG, Bogaty P, Pibarot P. Paradoxical low-flow, low-gradient severe aortic stenosis despite preserved ejection fraction is associated with higher afterload and reduced survival. Circulation. 2007; 115(22):2856-64.

124. Barasch E, Fan D, Chukwu EO, Han J, Passick M, Petillo F, et al. Severe isolated aortic stenosis with normal left ventricular systolic function and low transvalvular gradients: pathophysiologic and prognostic insights. J Heart Valve Dis. $2008 ; 17(1): 81-8$

125. Jander N, Minners J, Holme I, Gerdts E, Boman K, Brudi P, et al. Outcome of patients with low-gradient "severe" aortic stenosis and preserved ejection fraction. Circulation. 2011;123(8):887-95.

126. Delgado V, Tops LF, van Bommel RJ, van der Kley F, Marsan NA, Klautz RJ, et al. Strain analysis in patients with severe aortic stenosis and preserved left ventricular ejection fraction undergoing surgical valve replacement. Eur Heart J. 2009;30(24):3037-47.

127. Oe H, Hozumi T, Arai K, Matsumura Y, Negishi K, Sugioka K, et al. Comparison of accurate measurement of left ventricular mass in patients with hypertrophied hearts by real-time three-dimensional echocardiography versus magnetic resonance imaging. Am J Cardiol. 2005; 95(10):1263-7.

128. Gorlin R, Gorlin SG. Hydraulic formula for calculation of the area of the stenotic mitral valve, other cardiac valves, and central circulatory shunts. I. Am Heart J. 1951;41(1):1-29.

129. deFilippi CR, Willett DL, Brickner ME, Appleton CP, Yancy CW, Eichhorn EJ, et al. Usefulness of dobutamine echocardiography in distinguishing severe from nonsevere valvular aortic stenosis in patients with depressed left ventricular function and low transvalvular gradients. Am J Cardiol. 1995;75(2):191-4.

130. Azevedo CF, Nigri M, Higuchi ML, Pomerantzeff PM, Spina GS, Sampaio $\mathrm{RO}$, et al. Prognostic significance of myocardial fibrosis quantification by histopathology and magnetic resonance imaging in patients with severe aortic valve disease. J Am Coll Cardiol. 2010;56(4):278-87.
131. Weidemann F, Herrmann S, StörkS, Niemann M, Frantz S, Lange V, etal. Impact of myocardial fibrosis in patients with symptomatic severe aortic stenosis. Circulation. 2009;120(7):577-84.

132. Kupfahl C, Honold M, Meinhardt G, Vogelsberg H, Wagner A, Mahrholdt $\mathrm{H}$, et al. Evaluation of aortic stenosis by cardiovascular magnetic resonance imaging: comparison with established routine clinical techniques. Heart. 2004;90(8):893-901.

133. Yap SC, van Geuns RJ, Meijboom FJ, Kirschbaum SW, McGhie JS, Simoons $\mathrm{ML}$, et al. A simplified continuity equation approach to the quantification of stenotic bicuspid aortic valves using velocity-encoded cardiovascular magnetic resonance. J Cardiovasc Magn Reson. 2007;9(6):899-906.

134. Tanaka K, Makaryus AN, Wolff SD. Correlation of aortic valve area obtained by the velocity-encoded phase contrast continuity method to direct planimetry using cardiovascular magnetic resonance. J Cardiovasc Magn Reson. 2007;9(5):799-805.

135. Pouleur AC, le Polain de WarouxJB, PasquetA, VancraeynestD, Vanoverschelde $J \mathrm{~L}$, Gerber BL. Planimetric and continuity equation assessment of aortic valve area: head to head comparison between cardiac magnetic resonance and echocardiography. J Magn Reson Imaging. 2007;26(6):1436-43.

136. Waters EA, Caruthers SD, Wickline SA. Correlation analysis of stenotic aortic valve flow patterns using phase contrast MRI. Ann Biomed Eng. 2005;33(7):878-87.

137. Caruthers SD, Lin SJ, Brown P, Watkins MP, Williams TA, Lehr KA, et al. Practical value of cardiac magnetic resonance imaging for clinical quantification of aortic valve stenosis: comparison with echocardiography. Circulation. 2003;108(18):2236-43.

138. O'Brien KR, Gabriel RS, Greiser A, Cowan BR, Young AA, Kerr AJ. Aortic valve stenotic area calculation from phase contrast cardiovascular magnetic resonance: the importance of short echo time. J Cardiovasc Magn Reson. $2009 ; 11: 49$

139. Minners J, Allgeier M, Gohlke-Baerwolf C, Kienzle RP, Neumann FJ, Jander $\mathrm{N}$. Inconsistent grading of aortic valve stenosis by current guidelines: haemodynamic studies in patients with apparently normal left ventricular function. Heart. 2010;96(18):1463-8.

140. Khot UN, Novaro GM, Popović ZB, Mills RM, Thomas JD, Tuzcu EM, et al. Nitroprusside in critically ill patients with left ventricular dysfunction and aortic stenosis. N Engl J Med. 2003;348(18):1756-63.

141. Freed BH, Sugeng L, Furlong K, Mor-Avi V, Raman J, Jeevanandam V, et al. Reasons for nonadherence to guidelines for aortic valve replacement in patients with severe aortic stenosis and potential solutions. Am J Cardiol. 2010;105(9):1339-42.

142. Schwarz F, Baumann P,MantheyJ, Hoffmann M, Schuler G, Mehmel HC, etal. The effect of aortic valve replacement on survival. Circulation. 1982;66(5):1105-10.

143. Smith N, McAnulty JH, Rahimtoola SH. Severe aortic stenosis with impaired left ventricular function and clinical heart failure: results of valve replacement. Circulation. 1978;58(2):255-64.

144. Lund O. Preoperative risk evaluation and stratification of long-term survival after valve replacement for aortic stenosis. Reasons for earlier operative intervention. Circulation. 1990;82(1):124-39.

145. Kouchoukos NT, Davila-Roman VG, Spray TL, Murphy SF, Perrillo JB. Replacement of the aortic root with a pulmonary autograft in children and young adults with aortic-valve disease. N Engl J Med. 1994;330(1):1-6.

146. Connolly HM, OhJK, OrszulakTA, Osborn SL, Roger VL, Hodge DO, etal. Aortic valve replacement for aortic stenosis with severe left ventricular dysfunction. Prognostic indicators. Circulation. 1997;95(10):2395-400.

147. Kvidal P, Bergstrom R, Horte LG, Stahle E. Observed and relative survival after aortic valve replacement. J Am Coll Cardiol. 2000;35(3):747-56.

148. Brown JM, O'Brien SM, Wu C, Sikora JA, Griffith BP, Gammie JS. Isolated aortic valve replacement in North America comprising 108,687 patients in 10 years: changes in risks, valve types, and outcomes in the Society of Thoracic Surgeons National Database. J Thorac Cardiovasc Surg. 2009;137(1):82-90. 
149. Thourani VH, Ailawadi G, Szeto WY, Dewey TM, Guyton RA, Mack MJ, et al. Outcomes of surgical aortic valve replacement in high-risk patients: a multiinstitutional study. Ann Thorac Surg. 2011;91(1):49-55; discussion 55-6.

150. Nashef SA, Roques F, Michel P, Gauducheau E, Lemeshow S, Salamon R. European system for cardiac operative risk evaluation (EuroSCORE). Eur J Cardiothorac Surg. 1999;16(1):9-13.

151. Nashef SA, Roques F, Hammill BG, Peterson ED, Michel P, Grover FL, et al. Validation of European System for Cardiac Operative Risk Evaluation (EuroSCORE) in North American cardiac surgery. Eur J Cardiothorac Surg. 2002;22(1):101-5.

152. Shroyer AL, Coombs LP, Peterson ED, Eiken MC, DeLong ER, Chen A, et al. The Society of Thoracic Surgeons: 30-day operative mortality and morbidity risk models. Ann Thorac Surg. 2003;75(6):1856-64; discussion 1864-5.

153. Ambler G, Omar RZ, Royston P, Kinsman R, Keogh BE, Taylor KM. Generic, simple risk stratification model for heart valve surgery. Circulation. 2005;112(2):224-31.

154. Carabello BA. Evaluation and management of patients with aortic stenosis. Circulation. 2002;105(15):1746-50.

155. Carabello BA. Timing of valve replacement in aortic stenosis. Moving closer to perfection. Circulation. 1997;95(9):2241-3.

156. Carabello BA. Clinical practice: aortic stenosis. N Engl J Med. 2002;346(9):677-82.

157. Das $\mathrm{P}$, Rimington $\mathrm{H}$, Chambers J. Exercise testing to stratify risk in aortic stenosis. Eur Heart J. 2005;26(13):1309-13.

158. Rahimtoola SH. Perspective on valvular heart disease: an update. J Am Coll Cardiol. 1989; 14(1):1-23.

159. Rahimtoola SH. Valvular heart disease: a perspective on the asymptomatic patient with severe valvular aortic stenosis. Eur Heart J. 2008;29(14):1783-90.

160. Dal-Bianco JP, Khandheria BK, Mookadam F, Gentile F, Sengupta PP. Management of asymptomatic severe aortic stenosis. J Am Coll Cardiol. 2008;52(16):1279-92.

161. Iung B, Cachier A, Baron G, Messika-Zeitoun D, Delahaye F, Tornos P, et al. Decision-making in elderly patients with severe aortic stenosis: why are so many denied surgery? Eur Heart J. 2005;26(24):2714-20.

162. Likosky DS, Sorensen MJ, Dacey LJ, Barribeau YR, Leavitt BJ, DiScipio AW, et al. Long-term survival of the very elderly undergoing aortic valve surgery. Circulation. 2009;120(11 Suppl):S127-33.

163. Brinkman WT, Hoffman W, Dewey TM, Culica D, Prince SL, Herbert MA, et al. Aortic valve replacement surgery: comparison of outcomes in matched sternotomy and PORT ACCESS groups. Ann Thorac Surg. 2010;90(1):131-5.

164. David TE, Woo A, Armstrong S, Maganti M. When is the Ross operation a good option to treat aortic valve disease? J Thorac Cardiovasc Surg. 2010;139(1):68-73; discussion 73-5.

165. Kuntz RE, Tosteson AN, Berman AD, Goldman L, Gordon PC, Leonard BM, et al. Predictors of event-free survival after balloon aortic valvuloplasty. $\mathrm{N}$ Engl J Med. 1991;325(1):17-23.

166. Piazza N, Grube E, Gerckens U, den Heijer P, Linke A, Luha O, et al. Procedural and 30-day outcomes following transcatheter aortic valve implantation using the third generation $(18 \mathrm{Fr}$ ) corevalve revalving system: results from the multicentre, expanded evaluation registry 1 -year following CE mark approval. Eurolntervention. 2008;4(2):242-9.

167. Webb JG, Pasupati S, Humphries K, Thompson C, Altwegg L, Moss R, et al. Percutaneous transarterial aortic valve replacement in selected high-risk patients with aortic stenosis. Circulation. 2007;116(7):755-63.

168. Tamburino C, Capodanno D, Ramondo A, Petronio AS, Ettori F, Santoro G, et al. Incidence and predictors of early and late mortality after transcatheter aortic valve implantation in 663 patients with severe aortic stenosis. Circulation. 2011:123(3):299-308
169. Zahn R, Gerckens U, Grube E, Linke A, Sievert H, Eggebrecht H, et al. Transcatheter aortic valve implantation: first results from a multi-centre real-world registry. Eur Heart J. 2011;32(2):198-204

170. Smith CR, Leon MB, Mack MI, Miller DC, Moses JW, Svensson LG, et al Transcatheter versus surgical aortic-valve replacement in high-risk patients. N Engl J Med. 2011;364(23):2187-98.

171. Leon MB, Smith CR, Mack M, Miller DC, Moses JW, Svensson LG, et al. Transcatheter aortic-valve implantation for aortic stenosis in patients who cannot undergo surgery. N Engl J Med. 2010;363(17):1597-607.

172. Vassiliades TA Jr, Block PC, Cohn LH, Adams DH, Borer JS, Feldman T, et al. The clinical development of percutaneous heart valve technology: a position statement of the Society of Thoracic Surgeons (STS), the American Association for Thoracic Surgery (AATS), and the Society for Cardiovascular Angiography and Interventions (SCAI) Endorsed by the American College of Cardiology Foundation (ACCF) and the American Heart Association (AHA). J Am Coll Cardiol. 2005;45(9):1554-60.

173. Cribier A, Eltchaninoff H, Bash A, Borenstein N, Tron C, Bauer F, et al Percutaneous transcatheter implantation of an aortic valve prosthesis for calcific aortic stenosis: first human case description. Circulation. 2002;106(24):3006-8.

174. Walther T, Simon P, Dewey T, Wimmer-Greinecker G, Falk V, Kasimir MT et al. Transapical minimally invasive aortic valve implantation: multicenter experience. Circulation. 2007;116(11 Suppl):1240-5.

175. Tchetche D, Dumonteil N, Sauguet A, Descoutures F, Luz A, Garcia O, et al. Thirty-day outcome and vascular complications after transarterial aortic valve implantation using both Edwards Sapien and Medtronic CoreValve bioprostheses in a mixed population. Eurolntervention. 2010;5(6):659-65.

176. Abdel-Wahab M, Zahn R, Horack M, Gerckens U, Schuler G, Sievert H, et al. Aortic regurgitation after transcatheter aortic valve implantation: incidence and early outcome. Results from the German transcatheter aortic valve interventions registry. Heart. 2011;97:899-906.

177. Cheung AW, Gurvitch R, Ye J, Wood D, Lichtenstein SV, Thompson C, et al. Transcatheter transapical mitral valve-in-valve implantations for a failed bioprosthesis: a case series. J Thorac Cardiovasc Surg. 2011;141(3):711-5.

178. Gotzmann M, Mugge A, Bojara W. Transcatheter aortic valve implantation for treatment of patients with degenerated aortic bioprostheses--valve-in-valve technique. Catheter Cardiovasc Interv. 2010;76(7):1000-6.

179. Webb JG, Wood DA, Ye J, Gurvitch R, Masson JB, Rodés-Cabau J, et al. Transcatheter valve-in-valve implantation for failed bioprosthetic heart valves. Circulation. 2010;121(16):1848-57.

180. Cribier A, Savin T, Saoudi N, Rocha P, Berland J, Letac B. Percutaneous transluminal valvuloplasty of acquired aortic stenosis in elderly patients: an alternative to valve replacement? Lancet. 1986;1(8472):63-7.

181. Isner JM, Samuels DA, Slovenkai GA, Halaburka KR, Hougen TJ, Desnoyers MR, et al. Mechanism of aortic balloon valvuloplasty: fracture of valvular calcific deposits. Ann Intern Med. 1988;108(3):377-80.

182. Block PC, Palacios IF. Clinical and hemodynamic follow-up after percutaneous aortic valvuloplasty in the elderly. Am J Cardiol. 1988;62(10 Pt 1):760-3.

183. Webb J, Cribier A. Percutaneous transarterial aortic valve implantation: what do we know? Eur Heart J. 2011;32(2):140-7.

184. Kapadia SR, Goel SS, Yuksel U, Agarwal S, Pettersson G, Svensson LG, et al. Lessons learned from balloon aortic valvuloplasty experience from the pre-transcatheter aortic valve implantation era. J Interv Cardiol. 2010;23(5):499-508.

185. O'Connor BK, Beekman RH, Rocchini AP, Rosenthal A. Intermediate-term effectiveness of balloon valvuloplasty for congenital aortic stenosis: a prospective follow-up study. Circulation. 1991;84(2):732-8.

186. Galal O, Rao PS, Al-Fadley F, Wilson AD. Follow-up results of balloon aortic valvuloplasty in children with special reference to causes of late aortic insufficiency. Am Heart J. 1997:133(4):418-27. 
187. Pedra CA, Sidhu R, McCrindle BW, Nykanen DG, Justo RN, Freedom RM, et al. Outcomes after balloon dilation of congenital aortic stenosis in children and adolescents. Cardiol Young. 2004;14(3):315-21.

188. Reich O, Tax P, Marek J, Razek V, Gilik J, Chaloupecky V, et al. Long term results of percutaneous balloon valvoplasty of congenital aortic stenosis: independent predictors of outcome. Heart. 2004;50(1):70-6.

189. Fratz S, Gildein HP, Balling G, Sebening W, Genz T, Eicken A, et al. Aortic valvuloplasty in pediatric patients substantially postpones the need for aortic valve surgery: a single-center experience of 188 patients after up to 17.5 years of follow-up. Circulation. 2008;117(9):1201-6.

190.I kram H, Low CJ, Crozier IG, Shirlaw T. Hemodynamic effects of nitroprusside on valvular aortic stenosis. Am J Cardiol. 1992;69(4):361-6.

191. Aksoy O, Yousefzai R, Singh D, Agarwal S, O’Brien B, Griffin BP, et al. Cardiogenic shock in the setting of severe aortic stenosis: role of intra-aortic balloon pump support. Heart. 2011;97(10):838-43.

192. Buchwald AB, Meyer T, Scholz K, Schorn B, Unterberg C. Efficacy of balloon valvuloplasty in patients with critical aortic stenosis and cardiogenic shock-the role of shock duration. Clin Cardiol. 2001;24(3):214-8.

193. Frank CM, Palanichamy N, Kar B, Wilson JM, Gregoric ID, Loyalka P, et al. Use of a percutaneous ventricular assist device for treatment of cardiogenic shock due to critical aortic stenosis. Tex Heart Inst J. 2006;33(4):487-9.

194. Alpert JS. Acute aortic insufficiency. In: Alpert JS, Dalen JE, Rahimtoola SH. (eds.). Valvular heart disease. $3^{\text {rd }}$ ed. Philadelphia: Lippincott Williams \& Wilkins; 2000.p.269-89.

195. Gaudino M, Anselmi A, Glieca F, Tsiopoulos V, Pragliola C, Morelli M, et al. Contemporary results for isolated aortic valve surgery. Thorac Cardiovasc Surg. 2011;59(4):229-32.

196. Bonow RO, Rosing DR, McIntosh CL, Jones M, Maron BJ, Lan KK, et al. The natural history of asymptomatic patients with aortic regurgitation and normal left ventricular function. Circulation. 1983;68(3):509-17.

197. Scognamiglio R, Fasoli G, Dalla Volta S. Progression of myocardial dysfunction in asymptomatic patients with severe aortic insufficiency. Clin Cardiol. 1986;9(4):151-6

198. Siemienczuk D, Greenberg B, Morris C, Massie B, Wilson RA, Topic N, et al. Chronic aortic insufficiency: factors associated with progression to aortic valve replacement. Ann Intern Med. 1989;110(8):587-92.

199. Bonow RO, Lakatos E, Maron BJ, Epstein SE. Serial long-term assessment of the natural history of asymptomatic patients with chronic aortic regurgitation and normal left ventricular systolic function. Circulation. 1991;84(4):1625-35.

200. Scognamiglio R, Rahimtoola SH, Fasoli G, Nistri S, Dalla Volta S. Nifedipine in asymptomatic patients with severe aortic regurgitation and normal left ventricular function. N Engl J Med. 1994;331(11):689-94.

201. Tornos MP, Olona M, Permanyer-Miralda G, Herrejon MP, Camprecios $M$, Evangelista $A$, et al. Clinical outcome of severe asymptomatic chronic aortic regurgitation: a long-term prospective follow-up study. Am Heart J. 1995;130(2):333-9.

202. Ishii K, Hirota Y, Suwa M, Kita Y, Onaka H, Kawamura K. Natural history and left ventricular response in chronic aortic regurgitation. Am J Cardiol. 1996;78(3):357-61.

203. Borer JS, Hochreiter C, Herrold EM, Supino P, Aschermann M, Wencker D, et al. Prediction of indications for valve replacement among asymptomatic or minimally symptomatic patients with chronic aortic regurgitation and normal left ventricular performance. Circulation. 1998;97(6):525-34.

204. Evangelista A, Tornos P, Sambola A, Permanyer-Miralda G, Soler-Soler J. Long-term vasodilator therapy in patients with severe aortic regurgitation. N Engl J Med. 2005;353(13):1342-9.

205. Tribouilloy CM, Enriquez-Sarano M, Bailey KR, Seward JB, Tajik AJ. Assessment of severity of aortic regurgitation using the width of the vena contracta: A clinical color Doppler imaging study. Circulation. 2000;102(5):558-64
206. Greenberg BH, DeMots H, Murphy E, Rahimtoola SH. Mechanism for improved cardiac performance with arteriolar dilators in aortic insufficiency. Circulation. 1981;63:(2)263-8.

207. Sondergaard L, Aldershvile J, Hildebrandt P, Kelbaek H, Ståhlberg F, Thomsen C. Vasodilatation with felodipine in chronic asymptomatic aortic regurgitation. Am Heart J. 2000;139(4):667-74.

208. Banaszewski M, Rydlewska-Sadowska W, Rubkiewicz S. Captopril or nifedipine? Comparison of rest and exercise acute effects and long-term therapy in chronic isolated asymptomatic moderate to severe aortic regurgitation. J Heart Valve Dis. 1998;7(5):488-99.

209. Lin M, Chiang HT, Lin SL, Chang MS, Chiang BN, Kuo HW, et al. Vasodilator therapy in chronic asymptomatic aortic regurgitation: enalapril versus hydralazine therapy. J Am Coll Cardiol. 1994;24(4):1046-53.

210. Wisenbaugh T, Sinovich V, Dullabh A, Sareli P. Six month pilot study of captopril for mildly symptomatic, severe isolated mitral and isolated aortic regurgitation. J Heart Valve Dis. 1994;3(2):197-204.

211. Schon HR, Schroter G, Barthel P, Schomig A. Quinapril therapy in patients with chronic mitral regurgitation. J Heart Valve Dis. 1994;3(3):303-12.

212. Wilson R, Perlmutter N, Jacobson N, Siemienczuk D, Szlachcic J, Bristow JD, et al. Effects of long-term vasodilator therapy on electrocardiographic abnormalities in chronic aortic regurgitation. Am J Cardiol. 1991;68(9):935-9.

213. Scognamiglio R, Fasoli G, Ponchia A, Dalla-Volta S. Long-term nifedipine unloading therapy in asymptomatic patients with chronic severe aortic regurgitation. J Am Coll Cardiol. 1990;16(2):424-9.

214. Kleaveland JP, Reichek N, McCarthy DM, Chandler T, Priest C, Muhammed A, et al. Effects of six-month afterload reduction therapy with hydralazine in chronic aortic regurgitation. Am J Cardiol. 1986;57(13):1109-16.

215. Accorsi TA, Tarasoutchi F. Uso de vasodilatadores na insuficiência aórtica crônica importante oligo ou assintomática: ainda uma questão em aberto. Rev Soc Cardiol Estado de São Paulo. 2008;18(4):372-80.

216. Pomerantzeff PM, Barbosa GV, de Sousa Filho BS, Brandão CM, Ribeiro EJ, Costa FD, et al. [Guidelines for surgery in heart valve diseases]. Arq Bras Cardiol. 2004;82(Suppl 5):22-33.

217. David TE. The aortic valve-sparing operation. J Thorac Cardiovasc Surg. $2011 ; 141(3): 613-5$

218. Lai DT, Miller DC, Mitchell RS, Oyer PE, Moore KA, Robbins RC, et al. Acute type A aortic dissection complicated by aortic regurgitation: composite valve graft versus separate valve graft versus conservative valve repair. J Thorac Cardiovasc Surg. 2003;126(6):1978-86.

219. Pitsis AA, Anagnostopoulos CE. Acute heart failure: is there a role for surgery? Heart Fail Rev. 2007;12(2):173-8.

220. Reimold SC, Maier SE, Fleischmann KE, Khatri M, Piwnica-Worms D, Kikinis R, et al. Dynamic nature of the aortic regurgitant orifice area during diastole in patients with chronic aortic regurgitation. Circulation. 1994;89(5):2085-92.

221. Mann T, McLaurin L, Grossman W, Craige E. Assessing the hemodynamic severity of acute aortic regurgitation due to infective endocarditis. N Engl J Med. 1975;293(3):108-13

222. Eusebio J, Louie EK, Edwards LC 3rd, Loeb HS, Scanlon PJ. Alterations in transmitral flow dynamics in patients with early mitral valve closure and aortic regurgitation. Am Heart J. 1994;128(5):941-7.

223. da Costa FD, da Costa MB, da Costa IA, Poffo R, Sardeto EA, Matte E. Clinical experience with heart valve homografts in Brazil. Artif Organs. 2001;25(11):895-900

224. Elkins RC. The Ross operation: a 12-year experience. Ann Thorac Surg. 1999;68(3 Suppl):S14-8.

225. Stout KK, Verrier ED. Acute valvular regurgitation. Circulation. 2009;119(25):3232-41. 
226. Moon MR, Miller DC, Moore KA, Oyer PE, Mitchell RS, Robbins RC, et al. Treatment of endocarditis with valve replacement: the question of tissue versus mechanical prosthesis. Ann Thorac Surg. 2001;71(4):1164-71.

227. Symbas PJ, Horsley WS, Symbas PN. Rupture of the ascending aorta caused by blunt trauma. Ann Thorac Surg. 1998;66(1):113-7.

228. Hauck AJ, Freeman DP, Ackermann DM, Danielson GK, Edwards WD. Surgical pathology of the tricuspid valve: a study of 363 cases spanning 25 years. Mayo Clin Proc. 1988;63(9):851-63.

229. Daniels SJ, Mintz GS, Kotler MN. Rheumatic tricuspid valve disease: two-dimensional echocardiographic, hemodynamic, and angiographic correlations. Am J Cardiol. 1983;51(3):492-6.

230. Singh JP, Evans JC, Levy D, Larson MG, Freed LA, Fuller DL, et al. Prevalence and clinical determinants of mitral, tricuspid, and aortic regurgitation (the Framingham Heart Study). Am J Cardiol. 1999;83(6):897-902 .

231. Goswami KC, Rao MB, Dev V, Shrivastava S. Juvenile tricuspid stenosis and rheumatic tricuspid valve disease: an echocardiographic study. Int J Cardiol. 1999;72(1):83-6.

232. Nath J, Foster E, Heidenreich PA. Impact of tricuspid regurgitation on longterm survival. J Am Coll Cardiol. 2004;43(3):405-9.

233. Mutlak D, Lessick J, Reisner SA, Aronson D, Dabbah S, Agmon Y. Echocardiography-based spectrum of severe tricuspid regurgitation: the frequency of apparently idiopathic tricuspid regurgitation. J Am Soc Echocardiogr. 2007;20(4):405-8.

234. Irwin RB, Luckie M, Khattar RS. Tricuspid regurgitation: contemporary management of a neglected valvular lesion. Postgrad Med J. 2010;86(1021):648-55.

235. Messika-Zeitoun D, Thomson H, Bellamy M, ScottC, Tribouilloy C, Dearani $\mathrm{J}$, et al. Medical and surgical outcome of tricuspid regurgitation caused by flail leaflets. J Thorac Cardiovasc Surg. 2004;128(2):296-302.

236. Messika-Zeitoun D, Thomson H, Bellamy M, Scott C, Tribouilloy C, Dearani J, et al. Factors associated with development of late significant tricuspid regurgitation after successful left-sided valve surgery. Heart. 2009;128(2):296-302.

237. Antunes MJ, Barlow JB. Management of tricuspid valve regurgitation. Heart. 2007; 93(2):271-6.

238. De Vega NG. [Selective, adjustable and permanent annuloplasty. An original technic for the treatment of tricuspid insufficiency]. Rev Esp Cardiol. 1972;25(6):555-6

239. Kwon DA, Park JS, Chang HJ, Kim YJ, Sohn DW, Kim KB, et al. Prediction of outcome in patients undergoing surgery for severe tricuspid regurgitation following mitral valve surgery and role of tricuspid annular systolic velocity. Am J Cardiol. 2006;98(5):659-61.

240. Stanger P, Cassidy SC, Girod DA, Kan JS, Lababidi Z, Shapiro SR. Balloon pulmonary valvuloplasty: results of the Valvuloplasty and Angioplasty of Congenital Anomalies Registry. Am J Cardiol. 1990;65(11):775-83.

241. Roos-Hesselink JW, Meijboom FJ, Spitaels SE, vanDomburg RT, vanRijen EH, Utens EM, et al. Long-term outcome after surgery for pulmonary stenosis (a longitudinal study of 22-33 years). Eur Heart J. 2006;27(4):482-8.

242. Goldenberg DC, Alonso N, Sannomiya E. Sindrome de Marfan. São Paulo:Atheneu;2010.

243. Kan JS, White RI Jr, Mitchell SE, Gardner TJ. Percutaneous balloon valvuloplasty: a new method for treating congenital pulmonary-valve stenosis. N Engl J Med. 1982;307(9):540-2.

244. Silvilairat S, Cabalka AK, Cetta F, Hagler DJ, O'Leary PW. Echocardiographic assessment of isolated pulmonary valve stenosis: which outpatient Doppler gradient has the most clinical validity? J Am Soc Echocardiogr. 2005; 18(11):1137-42

245. McCrindle BW. Independent predictors of long-term results after balloon pulmonary valvuloplasty. Valvuloplasty and Angioplasty of Congenital Anomalies (VACA) Registry Investigators. Circulation. 1994;89(4):1751-9.
246. Masura J, Burch M, Deanfield JE, Sullivan ID. Five-year follow-up after balloon pulmonary valvuloplasty. J Am Coll Cardiol. 1993;21(1):132-6.

247. Therrien J, Siu SC, McLaughlin PR, Liu PP, Williams WG, Webb GD. Pulmonary valve replacement in adults late after repair of tetralogy of fallot: are we operating too late? J Am Coll Cardiol. 2000;36(5):1670-5.

248. d'Udekem Y, Rubay J, Ovaert C. Failure of right ventricular recovery of fallot patients after pulmonary valve replacement: delay of reoperation or surgical technique? J Am Coll Cardiol. 2001;37(7):2008-9.

249. Bonhoeffer P, Boudjemline Y, Saliba Z, Hausse AO, Aggoun Y, Bonnet D, et al Transcatheter implantation of a bovine valve in pulmonary position: a lamb study. Circulation. 2000;102(7):813-6.

250. Lurz P, Coats L, Khambadkone S, Nordmeyer J, Boudjemline Y, Schievano S, et al. Percutaneous pulmonary valve implantation: impact of evolving technology and learning curve on clinical outcome. Circulation. 2008;117(15):1964-72.

251. Zahn EM, Hellenbrand WE, Lock JE, McElhinney DB. Implantation of the melody transcatheter pulmonary valve in patients with a dysfunctional right ventricular outflow tract conduit early results from the u.s. Clinical trial. J Am Coll Cardiol. 2009;54(18):1722-9.

252. Khambadkone S, Coats L, Taylor A, Boudjemline Y, Derrick G, Tsang V, et al. Percutaneous pulmonary valve implantation in humans: results in 59 consecutive patients. Circulation. 2005;112(8):1189-97.

253. Coats L, Khambadkone S, Derrick G, Hughes M, Jones R, Mist B, et al Physiological consequences of percutaneous pulmonary valve implantation: the different behaviour of volume- and pressure-overloaded ventricles. Eur Heart J. 2007;28(15):1886-93.

254. Lurz P, Nordmeyer J, Coats L, Taylor AM, Bonhoeffer P, Schulze-Neick I. Immediate clinical and haemodynamic benefits of restoration of pulmonary valvar competence in patients with pulmonary hypertension. Heart. 2009;95(8):646-50.

255. Romeih S, Kroft LJ, Bokenkamp R, Schalij MJ, Grotenhuis H, HazekampMG, et al. Delayed improvement of right ventricular diastolic function and regression of right ventricular mass after percutaneous pulmonary valve implantation in patients with congenital heart disease. Am Heart J. 2009;158(1):40-6.

256. Momenah TS, El Oakley R, Al Najashi K, Khoshhal S, Al Qethamy H, Bonhoeffer P. Extended application of percutaneous pulmonary valve implantation. J Am Coll Cardiol. 2009;53(20):1859-63.

257. Vezmar M, Chaturvedi R, Lee KJ, Almeida C, Manlhiot C,McCrindle BW, etal. Percutaneous pulmonary valve implantation in the young 2-year follow-up. JACC Cardiovasc Interv. 2010;3(4):439-48.

258. Asoh K, Walsh M, Hickey E, Nagiub M, Chaturvedi R, Lee KJ, et al. Percutaneous pulmonary valve implantation within bioprosthetic valves. Eur Heart J. 2010;31(11):1404-9.

259. Garay F, Webb J, Hijazi ZM. Percutaneous replacement of pulmonary valve using the Edwards-Cribier percutaneous heart valve: first report in a human patient. Catheter Cardiovasc Interv. 2006;67(5):659-62.

260. Starr A, Edwards ML. Mitral replacement: clinical experience with a ball-valve prosthesis. Ann Surg. 1961;154:726-40.

261. Dahlbaeck O, Schueller H. Open correction of mitral insufficiency: a modification of the Starr-Edwards technique. Acta Chir Scand. 1963;126:300-4.

262. Lillehei CW, Levy MJ, Bonnabeau RC Jr. Mitral valve replacement with preservation of papillary muscles and chordae tendineae. J Thorac Cardiovasc Surg. 1964;47:532-43.

263. David TE, Burns RJ, Bacchus CM, Druck MN. Mitral valve replacement for mitral regurgitation with and without preservation of chordae tendineae. J Thorac Cardiovasc Surg. 1984; 88(5 Pt 1):718-25.

264. Hetzer R, Bougioukas G, Franz M, Borst HG. Mitral valve replacement with preservation of papillary muscles and chordae tendineae - revival of a seemingly forgotten concept. I. Preliminary clinical report. Thorac Cardiovasc Surg. 1983;31(5):291-6 
265. Barbosa GV. Análise comparativa do tamanho e função do ventrículo esquerdo na troca valvar mitral com preservação de cordas na dupla lesão mitral reumática isolada [Tese]. Porto Alegre (RS): Faculdade de Medicina. Universidade Federal do Rio Grande do Sul;2009.

266. Okita Y, MikiS, Ueda Y, Tahata T, Sakai T, Matsuyama K. Mitral valve replacement with maintenance of mitral annulopapillary muscle continuity in patients with mitral stenosis. J Thorac Cardiovasc Surg. 1994;108(1):42-51.

267. Yun KL, Sintek CF, Miller DC, Pfeffer TA, Kochamba GS, Khonsari S, et al. Randomized trial comparing partial versus complete chordal-sparing mitral valve replacement: effects on left ventricular volume and function. J Thorac Cardiovasc Surg. 2002;123(4):707-14.

268. Athanasiou T, Chow A, Rao C, Aziz O, Siannis F, Ali A, et al. Preservation of the mitral valve apparatus: evidence synthesis and critical reappraisal of surgical techniques. Eur J Cardiothorac Surg. 2008;33(3):391-401.

269. Hufnagel CA, Harvey WP, Rabil PJ, Mc DT. Surgical correction of aortic insufficiency. Surgery. 1954;35(5):673-83.

270. The Society of Thoracic Surgeons. Home. (Accessed in 2010 May 17). Available from: http://sts.org

271. Gammie JS, Sheng S, Griffith BP, Peterson ED, Rankin JS, O'Brien SM, etal. Trends in mitral valve surgery in the United States: results from the Society of Thoracic Surgeons Adult Cardiac Surgery Database. Ann Thorac Surg. 2009;87(5):14317; discussion 1437-9.

272. Garatti A, Mori F, Innocente F, Canziani A, Gagliardotto P, Mossuto E, et al. Aortic valve replacement with $17-\mathrm{mm}$ mechanical prostheses: is patient-prosthesis mismatch a relevant phenomenon? Ann Thorac Surg. 2011;91(1):71-7.

273. Kulik A, Al-Saigh M, Chan V, Masters RG, Bédard P, Lam BK, et al. Enlargement of the small aortic root during aortic valve replacement: is there a benefit? Ann Thorac Surg. 2008;85(1):94-100.

274. Okamura H, Yamaguchi A, Tanaka M, Naito K, Kimura N, Kimura C, et al. The 17-mm St. Jude Medical Regent valve is a valid option for patients with a small aortic annulus. Ann Thorac Surg. 2009;87(1):90-4.

275. O'Brien MF, Harrocks S, Stafford EG, Gardner MA, Pohlner PG, Tesar PJ, etal. The homograft aortic valve: a 29-year, $99.3 \%$ follow up of 1,022 valve replacements. J Heart Valve Dis. 2001;10(3):334-44; discussion 335.

276. Vrandecic MP, Gontijo BF, Fantini FA, Gutierrez C, Paula e Silva JA, Oliveira OC, et al. The new stentless aortic valve: clinical results of the first 100 patients. Cardiovasc Surg. 1994;2(3):407-14

277. Goldman BS, David TE, Wood JR, Pepper JR, Goldman SM, Verrier ED, et al. Clinical outcomes after aortic valve replacement with the Toronto stentless porcine valve. Ann Thorac Surg. 2001; 71(5 Suppl):S302-5.

278. Rahimtoola SH. The year in valvular heart disease. J Am Coll Cardiol. 2010;55(16):1729-42

279. Rahimtoola SH. The problem of valve prosthesis-patient mismatch. Circulation. 1978;58(1):20-4.

280. Blais C, Dumesnil JG, Baillot R, Simard S, Doyle D, Pibarot P. Impact of valve prosthesis-patient mismatch on short-term mortality after aortic valve replacement. Circulation. 2003;108(8):983-8.

281. Blackstone EH, Cosgrove DM, Jamieson WR, Birkmeyer NJ, LemmerJHJr, Miller DC, et al. Prosthesis size and long-term survival after aortic valve replacement. J Thorac Cardiovasc Surg. 2003;126(3):783-96.

282. Hanayama N, Christakis GT, Mallidi HR, Joyner CD, Fremes SE, Morgan CD, et al. Patient prosthesis mismatch is rare after aortic valve replacement: valve size may be irrelevant. Ann Thorac Surg. 2002;73(6):1822-9; discussion 1829.

283. Rao V, Jamieson WR, Ivanov J, Armstrong S, David TE. Prosthesis-patient mismatch affects survival after aortic valve replacement. Circulation. 2000;102(19 Suppl 3):III5-9.

284. de Almeida Brandão CM, Pomerantzeff PM, Souza LR, Tarasoutchi F, Grinberg $M$, Ramires JA, et al. Multivariate analysis of risk factors for hospital mortality in valvular reoperations for prosthetic valve dysfunction. Eur J Cardiothorac Surg. 2002;22(6):922-6.
285. Lip GY, Nieuwlaat R, Pisters R, Lane DA, Crijns HJ. Refining clinical risk stratification for predicting stroke and thromboembolism in atrial fibrillation using a novel risk factor-based approach: the euro heart survey on atrial fibrillation. Chest. 2010;137(2):263-72.

286. Lavitola P de L, Sampaio RO, Oliveira WA, Bôer BN, Tarasoutchi F, Spina GS, et al. Warfarin or aspirin in embolism prevention in patients with mitral valvulopathy and atrial fibrillation. Arq Bras Cardiol. 2010;95(6):749-55.

287. Higashi MK, Veenstra DL, Kondo LM, Wittkowsky AK, Srinouanprachanh SL, Farin FM, et al. Association between CYP2C9 genetic variants and anticoagulation-related outcomes during warfarin therapy. JAMA. 2002;287(13):1690-8

288. Palareti G, Legnani C. Warfarin withdrawal: pharmacokineticpharmacodynamic considerations. Clin Pharmacokinet. 1996;30(4):300-13.

289. Holley KE, Bahn RC, McGoon DC, Mankin HT. Spontaneous calcific embolization associated with calcific aortic stenosis. Circulation. 1963;27:197202.

290. Pumphrey CW, Fuster V, Chesebro JH. Systemic thromboembolism in valvular heart disease and prosthetic heart valves. Mod Concepts Cardiovasc Dis. 1982;51(12):131-6.

291. Landefeld CS, Beyth RJ. Anticoagulant-related bleeding: clinical epidemiology, prediction, and prevention. Am J Med. 1993;95(3):315-28

292. Arom KV, Emery RW, Nicoloff DM, Petersen RJ. Anticoagulant related complications in elderly patients with St. Jude mechanical valve prostheses. J Heart Valve Dis. 1996;5(5):505-10.

293. Cappelleri JC, Fiore LD, Brophy MT, Deykin D, Lau J. Efficacy and safety of combined anticoagulant and antiplatelet therapy versus anticoagulant monotherapy after mechanical heart-valve replacement: a metaanalysis. Am HeartJ. 1995;130(3 Pt 1):547-52.

294. Turpie AG, Gunstensen J, Hirsh J, Nelson H, Gent M. Randomised comparison of two intensities of oral anticoagulant therapy after tissue heart valve replacement. Lancet. 1988;1(8597):1242-5.

295. Hughes M, Lip GY. Risk factors for anticoagulation-related bleeding complications in patients with atrial fibrillation: a systematic review. QJM. 2007:100(10):599-607.

296. van Diermen DE, Aartman IH, Baart JA, Hoogstraten J, van der Waal I. Dental management of patients using antithrombotic drugs: critical appraisal of existing guidelines. Oral Surg Oral Med Oral Pathol Oral Radiol Endod. 2009;107(5):616-24.

297. Steger V, Bail DH, Graf D, Walker T, Rittig K, Ziemer G. A practical approach for bridging anticoagulation after mechanical heart valve replacement. J Heart Valve Dis. 2008;17(3):335-42

298. Bui HT, Krisnaswami A, Le CU, Chan J, Shenoy BN. Comparison of safety of subcutaneous enoxaparin as outpatient anticoagulation bridging therapy in patients with a mechanical heart valve versus patients with nonvalvular atrial fibrillation. Am J Cardiol. 2009;104(10):1429-33.

299. Ansell J, Hirsh J, Hylek E, Jacobson A, Crowther M, Palareti G. Pharmacology and management of the vitamin K antagonists: American College of Chest Physicians Evidence-Based Clinical Practice Guidelines (8th Edition). Chest. 2008;133(6 Suppl):160S-198S

300. Douketis JD, Berger PB, Dunn AS, Jaffer AK, Spyropoulos AC, Becker RC, etal. The perioperative management of antithrombotic therapy: American College of Chest Physicians Evidence-Based Clinical Practice Guidelines (8th Edition). Chest. 2008;133(6 Suppl):299S-339S

301. Galiè N, Hoeper MM, Humbert M, Torbicki A, Vachiery JL, Barbera JA, et al. Guidelines for the diagnosis and treatment of pulmonary hypertension: the Task Force for the Diagnosis and Treatment of Pulmonary Hypertension of the European Society of Cardiology (ESC) and the European Respiratory Society (ERS), endorsed by the International Society of Heart and Lung Transplantation (ISHLT). Eur Heart]. 2009;30(20):2493-537.

302. Rich S, Rabinovitch M. Diagnosis and treatment of secondary (non-category 1) pulmonary hypertension. Circulation. 2008;118(21):2190-9. 
303. Hoeper MM, Barbera JA, Channick RN, Hassoun PM, Lang IM, Manes $\mathrm{A}$, et al. Diagnosis, assessment, and treatment of non-pulmonary arterial hypertension pulmonary hypertension. J Am Coll Cardiol. 2009;54(1 Suppl):S85-96.

304. Du L, Sullivan CC, Chu D, Cho AJ, Kido M, Wolf PL, et al. Signaling molecules in nonfamilial pulmonary hypertension. N Engl J Med. 2003;348(6):500-9.

305. Anavekar NS, Skali H, Bourgoun M, Ghali JK, Kober L, Maggioni AP, et al. Usefulness of right ventricular fractional area change to predict death, heart failure, and stroke following myocardial infarction (from the VALIANT ECHO Study). Am J Cardiol. 2008;101(5):607-12.

306. Tei C, Dujardin KS, Hodge DO, Bailey KR, McGoon MD, Tajik AJ, et al. Doppler echocardiographic index for assessment of global right ventricular function. J Am Soc Echocardiogr. 1996;9(6):838-47.

307. La Gerche A, Jurcut R, Voigt JU. Right ventricular function by strain echocardiography. Curr Opin Cardiol. 2010;25(5):430-6.

308. Fawzy ME, Hassan W, Stefadouros M, Moursi M, El Shaer F, Chaudhary MA. Prevalence and fate of severe pulmonary hypertension in 559 consecutive patients with severe rheumatic mitral stenosis undergoing mitral balloon valvotomy. J Heart Valve Dis. 2004;13(6):942-7; discussion 947-8.

309. Mubeen M, Singh AK, Agarwal SK, Pillai J, Kapoor S, Srivastava AK. Mitral valve replacement in severe pulmonary arterial hypertension. Asian Cardiovasc Thorac Ann. 2008;16(1):37-42.

310. Cesnjevar RA, Feyrer R, Walther F, Mahmoud FO, Lindemann Y, von der Emde J. High-risk mitral valve replacement in severe pulmonary hypertension--30 years experience. Eur J Cardiothorac Surg. 1998;13(4):344-51; discussion $351-2$.

311. Vincens JJ, Temizer D, Post JR, Edmunds LH Jr, Herrmann HC. Long-term outcome of cardiac surgery in patients with mitral stenosis and severe pulmonary hypertension. Circulation. 1995;92(9 Suppl):II137-42

312. Umesan CV, Kapoor A, Sinha N, Kumar AS, Goel PK. Effect of Inoue balloon mitral valvotomy on severe pulmonary arterial hypertension in 315 patients with rheumatic mitral stenosis: immediate and long-term results. J Heart Valve Dis. 2000;9(5):609-15.

313. Fernandes JL, Sampaio RO, Brandão CM, Accorsi TA, Cardoso LF, Spina GS, et al. Comparison of inhaled nitric oxide versus oxygen on hemodynamics in patients with mitral stenosis and severe pulmonary hypertension after mitral valve surgery. Am J Cardiol. 2011;107(7):1040-5

314. Li M, Dumesnil JG, Mathieu P, Pibarot P. Impact of valve prosthesis-patient mismatch on pulmonary arterial pressure after mitral valve replacement. J Am Coll Cardiol. 2005;07(7):1040-5.

315. Barbieri A, Bursi F, Grigioni F, Tribouilloy C, Avierinos JF, Michelena HI, et al. Prognostic and therapeutic implications of pulmonary hypertension complicating degenerative mitral regurgitation due to flail leaflet: a multicenter long-term international study. Eur Heart J. 2011;32(6):751-9.

316. Silver K, Aurigemma G, Krendel S, Barry N, Ockene I, Alpert J. Pulmonary artery hypertension in severe aortic stenosis: incidence and mechanism. Am Heart J. 1993;125(1):146-50.

317. MaloufJF, Enriquez-Sarano M, Pellikka PA, Oh JK, Bailey KR, Chandrasekaran $\mathrm{K}$, et al. Severe pulmonary hypertension in patients with severe aortic valve stenosis: clinical profile and prognostic implications. J Am Coll Cardiol. 2002;40(4):789-95

318. Kapoor N, Varadarajan P, Pai RG. Echocardiographic predictors of pulmonary hypertension in patients with severe aortic stenosis. Eur J Echocardiogr. 2008;9(1):31-3.

319. Pai RG, Varadarajan P, Kapoor N, Bansal RC. Aortic valve replacement improves survival in severe aortic stenosis associated with severe pulmonary hypertension. Ann Thorac Surg. 2007;84(1):80-5.

320.Basu B, Cherian G, Krishnaswami S, Sukumar IP, John S. Severe pulmonary hypertension in advanced aortic valve disease. Br Heart J. 1978;40(11):1310-3.
321. Khandhar S, Varadarajan P, Turk R, Sampat U, Patel R, Kamath A, et al. Surviva benefit of aortic valve replacement in patients with severe aortic regurgitation and pulmonary hypertension. Ann Thorac Surg. 2009;88(3):752-6.

322. Parker MW, Mittleman MA, Waksmonski CA, Sanders G, Riley MF, Douglas PS, et al. Pulmonary hypertension and long-term mortality in aortic and mitral regurgitation. Am J Med. 2010;123(11):1043-8.

323. Denault A, Deschamps A, Tardif JC, Lambert J, Perrault L. Pulmonary hypertension in cardiac surgery. Curr Cardiol Rev. 2010;6(1):1-14.

324. Fattouch K, Sbraga F, Bianco G, Speziale G, Gucciardo M, Sampognaro R, et al. Inhaled prostacyclin, nitric oxide, and nitroprusside in pulmonary hypertension after mitral valve replacement. J Card Surg. 2005;6(1):1-14

325. Fattouch K, Sbraga F, Sampognaro R, Bianco G, Gucciardo M, Lavalle C, et al . Treatment of pulmonary hypertension in patients undergoing cardiac surgery with cardiopulmonary bypass: a randomized, prospective, double-blind study. J Cardiovasc Med (Hagerstown). 2006;7(2):119-23.

326. McLaughlin VV, Archer SL, Badesch DB, Barst RJ, Farber HW, Lindner JR, et al. ACCF/AHA 2009 expert consensus document on pulmonary hypertension: a report of the American College of Cardiology Foundation Task Force on Expert Consensus Documents and the American Heart Association developed in collaboration with the American College of Chest Physicians, American Thoracic Society, Inc., and the Pulmonary Hypertension Association. Circulation. 2009;119(16):2250-94.

327. Lytle BW. Impact of coronary artery disease on valvular heart surgery. Cardiol Clin. 1991;9(2):301-14

328. Ramsdale DR, Bennett DH, Bray CL, Ward C, Beton DC, Faragher EB. Angina, coronary risk factors and coronary artery disease in patients with valvular disease: a prospective study. Eur HeartJ. 1984;5(9):716-26.

329. Bertrand ME, LaBlanche JM, Tilmant PY, Thieuleux FP, Delforge MR, Carre AG. Coronary sinus blood flow at rest and during isometric exercise in patients with aortic valve disease. Mechanism of angina pectoris in presence of normal coronary arteries. Am J Cardiol. 1981;47(2):199-205.

330. Ross RS. Right ventricular hypertension as a cause of precordial pain. Am Heart J. 1961 jan;61:134-5.

331. Dangas G, Khan S, Curry BH, Kini AS, Sharma SK. Angina pectoris in severe aortic stenosis. Cardiology. 1999;92(1):1-3.

332. Adler Y, Vaturi M, Herz I, lakobishvili Z, Toaf J, Fink N, et al. Nonobstructive aortic valve calcification: a window to significant coronary artery disease. Atherosclerosis. 2002:161(1):193-7.

333. Morrison GW, Thomas RD, Grimmer SF, Silverton PN, Smith DR. Incidence of coronary artery disease in patients with valvular heart disease. Br Heart J. 1980;44(6):630-7.

334. Mattina Cl, Green SI, Tortolani AJ, Padmanabhan VT, Ong LY, Hall MH, et al. Frequency of angiographically significant coronary arterial narrowing in mitral stenosis. Am J Cardiol. 1986;57(10):802-5

335. Enriquez-Sarano M, Klodas E, Garratt KN, Bailey KR, Tajik AJ, Holmes DR Jr. Secular trends in coronary atherosclerosis--analysis in patients with valvular regurgitation. N Engl J Med. 1996;335(5):316-22.

336. Kruczan DD, Silva NA, Pereira B de B, Romao VA, Correa Filho WB, Morales $\mathrm{FE}$. Coronary artery disease in patients with rheumatic and non-rheumatic valvular heart disease treated at a public hospital in Rio de Janeiro. Arq Bras Cardiol. 2008;90(3):197-203.

337. Sampaio RO, Jonke VM, Falcão JL, Falcão S, Spina GS, Tarasoutchi F, et al. Prevalence of coronary artery disease and preoperative assessment in patients with valvopathy. Arq Bras Cardiol. 2008;91(3):183-6, 200-4.

338. Ramsdale DR, Faragher EB, Bennett DH, Bray CL, Ward C, Beton DC. Preoperative prediction of significant coronary artery disease in patients with valvular heart disease. Br Med J (Clin Res Ed). 1982;284(6311):223-6.

339. Kupari M, Virtanen KS, Turto H, Viitasalo M, Mänttäri M, Lindroos M, et al. Exclusion of coronary artery disease by exercise thallium-201 tomography in patients with aortic valve stenosis. Am J Cardiol. 1992;70(6):635-40. 
340. Van Tosh A. The value of myocardial perfusion imaging for diagnosing coronary artery disease in patients with aortic valve stenosis. Adv Cardiol. 2002;39:61-9.

341. Shrivastava V, Vundavalli S, Mitchell L, Dunning J. Is cardiac computed tomography a reliable alternative to percutaneous coronary angiography for patients awaiting valve surgery? Interact Cardiovasc Thorac Surg. 2007;6(1):105-9.

342. Bettencourt N, Rocha J, Carvalho M, Leite D, Toschke AM, Melica B, et al. Multislice computed tomography in the exclusion of coronary artery disease in patients with presurgical valve disease. Circ Cardiovasc Imaging. 2009;2(4):306-13.

343. Snitcowsky R. Rheumatic fever prevention in industrializing countries: problems and approaches. Pediatrics. 1996;97(6 Pt 2):996-8.

344. Bass JW. Antibiotic management of group A streptococcal pharyngotonsillitis. Pediatr Infect Dis J. 1991;10(10 Suppl):S43-9.

345. Manyemba J, Mayosi BM. Intramuscular penicillin is more effective than oral penicillin in secondary prevention of rheumatic fever--a systematic review. $S$ Afr Med J. 2003;93(3):212-8.

346. Kassem AS, Madkour AA, Massoud BZ, Zaher SR. Benzathine penicillin G for rheumatic fever prophylaxis: 2 -weekly versus 4 -weekly regimens. Indian J Pediatr. 1992;59(6):741-8.

347. Markowitz M, Gerber MA, Kaplan EL. Treatment of streptococcal pharyngotonsillitis: reports of penicillin's demise are premature. J Pediatr. 1993;123(5):679-85.

348. Gerber MA, Baltimore RS, Eaton CB, Gewitz M, Rowley AH, Shulman ST, et al. Prevention of rheumatic fever and diagnosis and treatment of acute Streptococcal pharyngitis: a scientific statement from the American Heart Association Rheumatic Fever, Endocarditis, and Kawasaki Disease Committee of the Council on Cardiovascular Disease in the Young, the Interdisciplinary Council on Functional Genomics and Translational Biology, and the Interdisciplinary Council on Quality of Care and Outcomes Research: endorsed by the American Academy of Pediatrics. Circulation. 2009;119(11):1541-51.

349. Dajani A, Taubert K, Ferrieri P, Peter G, Shulman S. Treatment of acute streptococcal pharyngitis and prevention of rheumatic fever: a statement for health professionals. Committee on Rheumatic Fever, Endocarditis, and Kawasaki Disease of the Council on Cardiovascular Disease in the Young, the American Heart Association. Pediatrics. 1995;96(4 Pt 1):758-64.

350. Lue HC, Wu MH, Wang JK, Wu FF, Wu YN. Three- versus four-week administration of benzathine penicillin G: effects on incidence of streptococcal infections and recurrences of rheumatic fever. Pediatrics. 1996;97(6 Pt 2):984-8.

351. Oran B, Tastekin A, Karaaslan S, Bas L, Ayçiçek A, Ceri A, et al. Prophylactic efficiency of 3-weekly benzathine penicillin $G$ in rheumatic fever. Indian J Pediatr. 2000;67(3):163-7.

352. Coonan KM, Kaplan EL. In vitro susceptibility of recent North American group A streptococcal isolates to eleven oral antibiotics. Pediatr Infect Dis J. 1994;13(7):630-5

353. Seppälä H, Nissinen A, Järvinen H, Huovinen S, Henriksson T, Herva E, et al. Resistance to erythromycin in group A streptococci. N Engl J Med. 1992;326:292-7.

354. Ministério da Saúde.Serviço de informações hospitalares (SIH/SUS). [Acesso em 2011 jan 2011]. Disponível em: http://www.datasus.gov.br

355. Fowler VG, Scheld WM, Bayer AS. Endocarditis and intravascular infections. In: Mandell GL, BennettJE, Dolin R, eds. Principles and practices of infectious diseases. Philadelphia, PA: Elsevier/Churchill Livingstone; 2005.p.975-1021.

356. Okell CC, Elliott SD. Bacteraemia and oral sepsis with special reference to the aetiology of subacute endocarditis. Lancet. 1935;2:869-72.

357. Roberts GJ, Gardner P, Longhurst P, BlackAE, Lucas VS. Intensity of bacteraemia associated with conservative dental procedures in children. Br Dent J. 2000;188(2):95-8.
358. Glauser MP, Bernard JP, Moreillon P, Francioli P. Successful single-dose amoxicillin prophylaxis against experimental streptococcal endocarditis: evidence for two mechanisms of protection. J Infect Dis. 1983;147(3):568-75.

359. Seymour RA, Lowry R, Whitworth JM, Martin MV. Infective endocarditis, dentistry and antibiotic prophylaxis; time for a rethink? Br Dent J. 2000;189(11):610-6.

360. Lucas V, Roberts GJ. Odontogenic bacteremia following tooth cleaning procedures in children. Pediatr Dent. 2000;22(2):96-100.

361. Al-Karaawi ZM, Lucas VS, Gelbier M, Roberts GJ. Dental procedures in children with severe congenital heart disease: a theoretical analysis of prophylaxis and non-prophylaxis procedures. Heart. 2001;85(1):66-8.

362. Roberts GJ, Lucas VS, Omar J. Bacterial endocarditis and orthodontics. J R Coll Surg Edinb. 2000;45(3):141-5.

363. Roberts GJ. Dentists are innocent! "Everyday" bacteremia is the real culprit: a review and assessment of the evidence that dental surgical procedures are a principal cause of bacterial endocarditis in children. Pediatr Cardiol. 1999;20(5):317-25.

364. Drangsholt MT. A new causal model of dental diseases associated with endocarditis. Ann Periodontol. 1998;3(1):184-96

365. Duval X, Alla F, Hoen B, Danielou F, Larrieu S, Delahaye F, et al. Estimated risk of endocarditis in adults with predisposing cardiac conditions undergoing dental procedures with or without antibiotic prophylaxis. Clin Infect Dis. 2006;42(12):e102-7.

366. van der Meer JT, Thompson J, Valkenburg HA, Michel MF. Epidemiology of bacterial endocarditis in The Netherlands. II. Antecedent procedures and use of prophylaxis. Arch Intern Med. 1992;152(9):1869-73.

367. Strom BL, Abrutyn E, Berlin JA, Kinman JL, Feldman RS, Stolley PD, etal. Dental and cardiac risk factors for infective endocarditis. A population-based, casecontrol study. Ann Intern Med. 1998;129(10):761-9.

368. Hockett RN, Loesche WJ, Sodeman TM. Bacteraemia in asymptomatic human subjects. Arch Oral Biol. 1977;22(2):91-8.

369. Shanson DC, Akash S, Harris M, Tadayon M. Erythromycin stearate, $1.5 \mathrm{~g}$, for the oral prophylaxis of streptococcal bacteraemia in patients undergoing dental extraction: efficacy and tolerance. J Antimicrob Chemother. 1985;15(1):83-90

370. Lockhart PB, Brennan MT, Kent ML, Norton HJ, Weinrib DA. Impact of amoxicillin prophylaxis on the incidence, nature, and duration of bacteremia in children after intubation and dental procedures. Circulation. 2004;109(23):2878-84.

371. Hall G, Hedstrom SA, Heimdahl A, Nord CE. Prophylactic administration of penicillins for endocarditis does not reduce the incidence of postextraction bacteremia. Clin Infect Dis. 1993:17(2):188-94.

372. Roberts GJ, Radford P, Holt R. Prophylaxis of dental bacteraemia with oral amoxycillin in children. Br Dent J. 1987;162(5):179-82.

373. Steckelberg JM, Wilson WR. Risk factors for infective endocarditis. Infect Dis Clin North Am. 1993; 7(1):9-19.

374. National Institute for Health and Clinical Excellence. Prophylaxis against infective endocarditis. [Accessed in 2011 June 18]. Available from: http:// www.nice.org.uk/CG064.)

375. Wilson W, Taubert KA, Gewitz M, Lockhart PB, Baddour LM, Levison M, et al. Prevention of infective endocarditis: guidelines from the American Heart Association: a guideline from the American Heart Association Rheumatic Fever, Endocarditis, and Kawasaki Disease Committee, Council on Cardiovascular Disease in the Young, and the Council on Clinical Cardiology, Council on Cardiovascular Surgery and Anesthesia, and the Quality of Care and Outcomes Research Interdisciplinary Working Group. Circulation. 2007;116(15):1736-54.

376. Strom BL, Abrutyn E, Berlin JA, Kinman JL, Feldman RS, Stolley PD, et al. Risk factors for infective endocarditis: oral hygiene and nondental exposures. Circulation. 2000;102(23):2842-8. 
377.Castro I, Gualandro DM, Yu PC, Calderaro D, Caramelli B, Feitosa AC, et al. II Guidelines for perioperative evaluation of the Brazilian Society of Cardiology. Arq Bras Cardiol. 2011;96(3 Suppl 1):1-68.

378.Libby P, Bonow RO, Mann D, Zipes DP. Braunwald's heart disease: a textbook of cardiovascular medicine. $8^{\text {th }}$ ed. Philadelphia:Saunders;2008.

379. Laffey JG, Boylan JF, Cheng DC. The systemic inflammatory response to cardiac surgery: implications for the anesthesiologist. Anesthesiology. 2002;97(1):215-52.

380.Avila WS, Rossi EG, Ramires JA, Grinberg M, Bortolotto MR, Zugaib M, et al. Pregnancy in patients with heart disease: experience with 1,000 cases. Clin Cardiol. 2003;26(3):135-42.

381. Ueland K, Metcalfe J. Circulatory changes in pregnancy. Clin Obstet Gynecol. 1975;18(3):41-50.

382.Siu SC, Sermer M, Harrison DA, Grigoriadis E, Liu G, Sorensen S, et al. Risk and predictors for pregnancy-related complications in women with heart disease. Circulation. 1997;96(9):2789-94.

383.Siu SC, Sermer M, Colman JM, Alvarez AN, Mercier LA, Morton BC, et al. Prospective multicenter study of pregnancy outcomes in women with heart disease. Circulation. 2001;104(5):515-21.

384.Avila WS, Grinberg M, Decourt LV, Bellotti G, Pileggi F. [Clinical course of women with mitral valve stenosis during pregnancy and puerperium]. Arq Bras Cardiol. 1992;58(5):359-64.

385. Hameed A, Karaalp IS, Tummala PP, Wani OR, Canetti M, Akhter MW, et al. The effect of valvular heart disease on maternal and fetal outcome of pregnancy. J Am Coll Cardiol. 2001;37(3):893-9.

386. Avila WS, Grinberg M, Bezi BE, Rossi EG, Da Luz P, Bellotti G. Influence of pregnancy on the natural history of aortic stenosis. In: Imai Y, Momma K. Proceedings of the second world congress of pediatric cardiology and cardiac surgery. Armonk (NY):Futura Pub.Co;1998.p.265-7.

387. Anderson RA, Fineron PW. Aortic dissection in pregnancy: importance 390. Avila WS, Rossi EG, Grinberg M, Ramires JA. Influence of pregnancy after bioprosthetic valve replacement in young women: a prospective five-year study. J Heart Valve Dis. 2002;11(6):864-9.

388. Elkayam U, Bitar F. Valvular heart disease and pregnancy part I: native valves. J Am Coll Cardiol. 2005;46(2):223-30.
389. Elkayam U, Bitar F. Valvular heart disease and pregnancy: part II: prosthetic valves. J Am Coll Cardiol. 2005;46(3):403-10.

390. Avila WS, Rossi EG, Grinberg M, Ramires JA. Influence of pregnancy after bioprosthetic valve replacement in young women: a prospective five-year study. J Heart Valve Dis. 2002;11(6):864-9.

391. Chan WS, Anand S, Ginsberg JS. Anticoagulation of pregnant women with mechanical heart valves: a systematic review of the literature. Arch Intern Med. 2000;160(2):191-6.

392. Expert consensus document on management of cardiovascular diseases during pregnancy. Eur Heart J. 2003;24(8):761-81

393. Andrade J, Franchi Jr A, Batlouni MA Drogas cardiovasculares no ciclo gravídico-puerperal. In: Andrade JA, Avila WS. Doença cardiovascular gravidez e planejamento familiar. São Paulo: Atheneu;2003.p.413-24.

394. Qasqas SA, McPherson C, Frishman WH, Elkayam U. Cardiovascular pharmacotherapeutic considerations during pregnancy and lactation. Cardiol Rev. 2004;12(5):240-61.

395. Roden DM. Risks and benefits of antiarrhythmic therapy. N Engl J Med. 1994;331(12):785-91.

396. Reimold SC, Rutherford JD. Clinical practice. Valvular heart disease in pregnancy. N Engl J Med. 2003;349(1):52-9.

397. de Souza JA, Martinez EE Jr, Ambrose JA, Alves CM, Born D, Buffolo E, et al. Percutaneous balloon mitral valvuloplasty in comparison with open mitral valve commissurotomy for mitral stenosis during pregnancy. J Am Coll Cardiol. 2001;37(3):900-3.

398. Avila WS, Gouveia AM, Pomerantzeff P, Bortolotto MR, Grinberg M, Stolf $\mathrm{N}$, et al. Maternal-fetal outcome and prognosis of cardiac surgery during pregnancy. Arq Bras Cardiol. 2009;93(1):9-14.

399. Avila WS, Grinberg M. [Anticoagulation, pregnancy and cardiopathy. A triad, three dominions and five moments]. Arq Bras Cardiol. 2005;84(1):44-8.

400. Embil JM, Chan KL. The American Heart Association 2007 endocarditis prophylaxis guidelines: a compromise between science and common sense. Can J Cardiol. 2008;24(9):673-5.

401. Melo N, Pinotti JA, Ramires, RC. Anticoncepção na cardiopata. In: Andrade J, Avila WS, eds. Doença cardiovascular, gravidez e planejamento familiar. São Paulo: Atheneu;2003.p.485-93. 




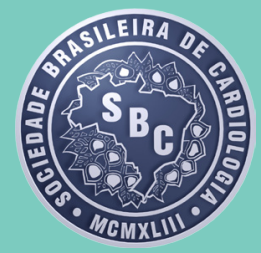

Sociedade Brasileira de Cardiologia www.cardiol.br 